\author{
UNIVERSIDADE DE SÃO PAULO \\ ESCOLA DE ENGENHARIA DE SÃO CARLOS \\ DEPARTAMENTO DE HIDRÁULICA E SANEAMENTO
}

GUILHERME LUCAS DE LAURENTIS

MODELO DE TRANSFERÊNCIA DE RISCOS HIDROLÓGICOS COMO ESTRATÉGIA DE ADAPTAÇÃO ÀS MUDANÇAS GLOBAIS SEGUNDO CENÁRIOS DE VULNERABILIDADE DOS RECURSOS HÍDRICOS

VERSÃO CORRIGIDA

SÃO CARLOS 


\title{
MODELO DE TRANSFERÊNCIA DE RISCOS HIDROLÓGICOS COMO ESTRATÉGIA DE ADAPTAÇÃO ÀS MUDANÇAS GLOBAIS SEGUNDO CENÁRIOS DE VULNERABILIDADE DOS RECURSOS HÍDRICOS
}

\begin{abstract}
Dissertação apresentada à Escola de Engenharia de São Carlos, da Universidade de São Paulo, como parte dos requisitos para obtenção do título de Mestre em Ciências, Programa de Engenharia Hidráulica e Saneamento.
\end{abstract}

Área de concentração: Hidráulica e Saneamento

Orientador: Prof. Dr. Eduardo Mario Mendiondo

VERSÃO CORRIGIDA

SÃO CARLOS 
AUTORIZO A REPRODUÇÃO E DIVULGAÇÃO TOTAL OU PARCIAL DESTE TRABALHO, POR QUALQUER MEIO CONVENCIONAL OU ELETRÔNICO, PARA FINS DE ESTUDO E PESQUISA, DESDE QUE CITADA A FONTE.

Ficha catalográfica preparada pela Seção de Tratamento da Informação do Serviço de Biblioteca - EESC/USP

Laurentis, Guilherme Lucas de
Modelo de transferência de riscos hidrológicos como
estratégia de adaptaça às mudanças globais segundo
cenários de vulnerabilidade dos recursos hídricos /
Guilherme Lucas de Laurentis ; orientador Eduardo Mario
Mendiondo. -- São Carlos, 2012.
Dissertação - Mestrado (Programa de Pós-Graduação e
Área de Concentração em Engenharia Hidráulica e
Saneamento)-- Escola de Engenharia de São Carlos da
Universidade de São Paulo, 2012.
1. Adaptação. 2. Mudanças globais. 3. Seguros. 4.
Transferência de risco. I. Título.




\section{FOLHA DE JULGAMENTO}

\section{Candidato: Engenheiro GUILHERME LUCAS DE LAURENTIS.}

Título da dissertação: "Modelo de transferência de riscos hidrológicos como estratégia de adaptação às mudanças globais segundo cenários de vulnerabilidade dos recursos hídricos".

Data da defesa: 14/09/2012

\section{Comissão Julgadora:}

Resultado:

Prof. Dr. Eduardo Mario Mendiondo (Orientador)

(Escola de Engenharia de São Carlos/EESC)

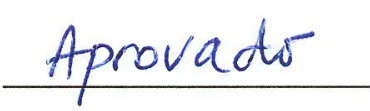

Prof. Dr. Walter Collischonn

APROVAOO

(Universidade Federal do Rio Grande do Sul/UFRGS)

†/Prof. Dr. Alberto Garrido Colmenero

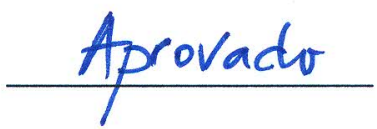

Coordenador do Programa de Pós-Graduação em Engenharia Hidráulica e Saneamento:

Prof. Titular Edson Cezar Wendland

Presidente da Comissão de Pós-Graduação:

Prof. Titular Denis Vinicius Coury 
Dedico aos meus pais e irmã, Emygdio, Vera e Valéria

GENTE da melhor espécie,

sem os quais eu realmente não sou nada.

Também à Fabi, amiga e companheira em todos os momentos. A pessoa mais LINDA que eu poderia ter encontrado. 


\section{AGRADECIMENTOS}

A realização deste trabalho não teria sido alcançada se não fosse pela participação direta ou indireta de algumas pessoas, às quais sou profundamente grato.

Aos meus pais, pelo suporte e amor incondicional que sempre me deram.

À minha irmã, por sempre estar por perto, mesmo que um pouco longe.

À Fabi, a mulher da minha vida.

Ao Victor, pequeno já não tão pequeno, agora também meu afilhado. A quem tenho os melhores sentimentos que se pode ter por alguém.

Ao Prof. Antônio Carlos Demanboro, da PUC-Campinas. Por me fornecer a base do que sou hoje e por sempre acreditar no meu trabalho.

Ao Prof. Eduardo Mario Mendiondo, pelas oportunidades concedidas e pela orientação desta pesquisa.

Ao Prof. Alberto Garrido, do Centro de Estudos e Investigação para a Gestão de Riscos Agrários e Ambientais (CEIGRAM), da Universidade Politécnica de Madri (UPM), pela revisão e contribuições a este trabalho.

Ao Prof. Walter Collischonn, do Instituto de Pesquisas Hidráulicas (IPH-UFRGS), pela paciência e disponibilidade em discutir aspectos da modelagem hidrológica. Também pelo aceite em participar da banca avaliadora e revisar este trabalho.

Ao Diogo Buarque, também do IPH, que também colaborou (e muito) com minhas dúvidas sobre o modelo. Aos outros amigos do IPH, Adalberto Meller, Adrien Paris, Paulo Rógenes e Rafael Cavalcanti, pela amizade e ajuda durante o período que estive em Porto Alegre.

Ao Prof. Javier Tomasela e a Daniel Andrés Rodriguez, do Centro de Previsão de Tempo e Estudos Climáticos (CPTEC/INPE), que contribuíram na parte de coleta e tratamento dos dados climáticos. Também ao colega Lázaro Siqueira Júnior, que forneceu imenso suporte durante a coleta dos dados. 
À Rochane Caram, do Centro Nacional de Monitoramento e Alerta de Desastres Naturais (CEMADEN), pelos dados fornecidos da bacia hidrográfica do Rio Piracicaba e pela pronta resposta a meus contatos.

À CAPES, CNPQ, FAPESP e FIPAI, pelo auxílio financeiro e pelas oportunidades de crescimento fornecidas.

À ação VIAGUA (Vulnerabilidad, Impactos y Adaptación al Cambio Climático sobre los Recursos Hídricos em Iberoamerica) pelo apoio institucional concedido.

Aos funcionários e docentes do Departamento de Hidráulica e Saneamento e da Escola de Engenharia de São Carlos (EESC-USP), por tudo que fizeram por mim.

Ao colegas do Núcleo Integrado de Bacias Hidrográficas (NIBH), Anton, Aline, Danie, Dulce, Ivie, Jairo, Pedro, Richard e Stephan. Sejam ex-integrantes ou não, foi (e é) um prazer dividir experiências com vocês.

Aos demais amigos do Departamento de Hidráulica e Saneamento, os quais não citarei nomes para não cometer injustiças. Mas foi muito bom tê-los como companhia esses anos.

Por fim, mas não menos importante, aos amigos de Mogi Mirim e Campinas, que compreenderam a minha ausência em diversas ocasiões e, mesmo um pouco distantes, ainda são importantes para mim. 
"A riqueza de um homem é proporcional ao número de coisas que ele pode se permitir ficar sem" Henry D. Thoreau (1817-1862) 


\section{RESUMO}

LAURENTIS, G. L. Modelo de transferência de riscos hidrológicos como estratégia de adaptação às mudanças globais segundo cenários de vulnerabilidade dos recursos hídricos. 2012. 181 p. Dissertação (Mestrado em Ciências) - Escola de Engenharia de São Carlos, Universidade de São Paulo, São Carlos, 2012.

Esta pesquisa é parte do projeto FAPESP-IAV "Assessment of Impacts and Vulnerability to Climate Change in Brazil and Strategies for Adaptation Options". Avaliou-se a acoplagem entre o modelo climático regional Eta-CPTEC, o modelo hidrológico de grandes bacias MGBIPH e o modelo de transferências de riscos hidrológicos MTRH-SHS como estratégia de adaptação à escassez hídrica em regimes fluviométricos sob mudanças de longo prazo. A metodologia foi aplicada em postos de monitoramento fluviométrico cujas áreas de drenagem variaram entre 386,6 e 10.929,9 km², pertencentes à bacia hidrográfica do Rio Piracicaba, com área total de $12.589 \mathrm{~km}^{2}$. Buscou-se avaliar a aptidão do MGB-IPH em representar as vazões mínimas médias anuais de sete dias consecutivos, $Q_{7 \text { mín. }}$ A calibração e a validação do MGB-IPH corresponderam ao período 1971-1990. Com o MGB-IPH calibrado e validado, foram acoplados dados climáticos diários de saída do Eta-CPTEC, referentes ao período 2013-2099. Foram obtidas séries de $Q_{7 \text { mín }}$ anuais que representaram a vulnerabilidade de escassez hídrica referentes a quatro cenários de mudanças globais para o período 2013-2099. Um quinto cenário, sem mudanças, foi proposto como a manutenção de características de $\mathrm{Q}_{7 \mathrm{~min}}$ anuais observados. Foram gerados cenários para cinco sub-bacias, com áreas de 927,1 a 10.929,9 km². Procedeu-se à análise de riscos, associando os prejuízos econômicos dos impactos decorrentes das vazões mínimas anuais nos cinco cenários propostos. Para o MTRH-SHS selecionaram-se a série de mínimos anuais, $\mathrm{Q}_{7 \text { mín }}$-ano, em cada cenário, associado a um prejuízo distribuído pela área da bacia. Para o ressarcimento dos prejuízos, otimizou-se o prêmio a ser pago pela aplicação do MTRH-SHS sob diferentes limites de cobertura do fundo de seguros, curvas de danos regionais e para tempos de retorno de 10 até 100 anos. Os resultados demonstraram diferentes impactos das mudanças globais conforme cada cenário. A variação climática resultou em impacto de $+24,8 \%$ na $Q_{7 \text { mín }}$ média futura. Por sua vez, a expansão da urbanização dos municípios da bacia representou impacto de $+0,2 \%$ na variação da $Q_{7 \text { min }}$. A operação do Sistema Cantareira, que atua nas cabeceiras, potencialmente interfere em $-14,6 \%$ da disponibilidade hídrica da bacia. As combinações de mudanças dos cenários resultaram em prejuízos e prêmios de acordo com a cobertura selecionada. Os prejuízos foram de 9,5 a $1.437 \mathrm{R} \$ \mathrm{~km}^{-2}$ e os prêmios otimizados para ressarcir esses prejuízos situaram-se entre 9,9 e $1.479 \mathrm{R} \$ . \mathrm{km}^{-2}$. Concluiu-se sobre a viabilidade da estratégia de acoplagem entre os modelos como alternativa de adaptação para o planejamento estratégico na recuperação de bacias hidrográficas vulneráveis a eventos extremos de escassez hídrica.

Palavras-chave: adaptação; mudanças globais; seguros, transferência de risco. 


\begin{abstract}
LAURENTIS, G. L. Hydrologic risks transfer models as a strategy for adaptation to global change under scenarios of vulnerability of the water resources. 2012. $181 \mathrm{p}$. Dissertation (Master in Sciences) - Engineering School of São Carlos, University of de São Paulo, São Carlos, 2012.
\end{abstract}

This research is part of the project FAPESP-IAV "Assessment of Impacts and Vulnerability to Climate Change in Brazil and Strategies for Adaptation Options". It was evaluated the coupling among the regional climate model Eta-CPTEC, the hydrological model for large basins MGB-IPH and the hydrologic risks transfer model MTRH-SHS as an adaptation strategy to cope with water scarcity in flow regimes under long-term changes. The methodology was applied to fluviometric monitoring stations whose drainage areas varied between 386.6 and $10,929.9 \mathrm{~km}^{2}$, belonging to the Piracicaba River basin with total area of $12.589 \mathrm{~km}^{2}$. The focus was on improving the performance of the MGB-IPH in representing the average of the annual seven day minimum flows, $Q_{7 \text { min. }}$. The calibration and validation of the MGB-IPH corresponded to the period 1971-1990. With the MGB-IPH calibrated and validated, the EtaCPTEC output daily climate data were coupled, related to the 2013-2099 period. It was obtained sets of annual $Q_{7 \min }$ that represented the vulnerability to water scarcity related to four scenarios of global change for the 2013-1099 period. A fifth scenario, without changes, was proposed as the maintenance of the characteristics of annual $Q_{7 \text { min }}$ observed. Scenarios were generated for five sub-basins with areas ranging from 927.1 to $10,929.9 \mathrm{~km}^{2}$. The risk analysis was done, relating the impacts of economic losses due to the occurrence of the annual minimum flows over the five proposed scenarios. To the MTRH-SHS a set of annual minima $\left(Q_{7 m i n}-y e a r\right)$ was selected in each scenario, associated to the losses distributed along the watershed area. For the losses compensation, the premium to be paid was optimized through the implementation of the insurance fund, under different coverage limits and regional damage curves, for return periods from 10 to 100 years. The results showed different impacts of global changes in each scenario. The climate change resulted in an impact of $+24.8 \%$ on the $Q_{7 \text { min }}$ future average. In turn, the expansion of urbanization of the watershed municipalities represented an impact of $+0.2 \%$ on the variation of the $Q_{7 m i n}$. The operation of the Cantareira System, which operates in the headwaters, potentially interferes with $-14.6 \%$ on the water availability in the basin. The combinations of the scenarios of changes resulted in losses and premiums depending on the coverage selected. The damages ranged from 9.5 to $1.437 \mathrm{R} \$ . \mathrm{km}^{-2}$ while the optimized premiums to compensate these losses varied between 9.9 and $1479 \mathrm{R} \$ . \mathrm{km}^{-2}$. It was concluded that is feasible this strategy of model coupling as an adaptation alternative to strategic planning in the recovery of watersheds vulnerable to extreme water shortage.

Keywords: adaptation; global changes; insurance; risk transfer. 


\section{LISTA DE FIGURAS}

Figura 1. Diagrama da acoplagem de modelos no âmbito deste trabalho (Fonte: Elaborado pelo autor).

Figura 2. Fluxograma do desenvolvimento da pesquisa com relação aos objetivos propostos, procedimentos metodológicos e resultados alcançados (Fonte: Elaborado pelo autor)

Figura 3. Localização da bacia hidrográfica do Rio Piracicaba (Fonte: Elaborado pelo autor). . 9

Figura 4. Topografia da bacia hidrográfica do Rio Piracicaba (Fonte: Elaborado a partir de JARVIS et al., 2008).

Figura 5. Rede de drenagem da bacia hidrográfica do Rio Piracicaba obtida a partir do MDE (Fonte: Elaborado pelo autor).

Figura 6. Porcentagem de ocorrência dos principais tipos de solos na bacia do Rio Piracicaba, segundo seu comportamento hidrológico (Fonte: Elaborado pelo autor). 18

Figura 7. Pedologia da bacia hidrográfica do Rio Piracicaba (Fonte: Elaborado pelo autor a partir do Projeto RADAM-BRASIL e OLIVEIRA et al., 1999).

Figura 8. Uso da terra na bacia hidrográfica do Rio Piracicaba para o ano de 1985 (Fonte: Projeto PiraCena/USP). 20

Figura 9. Uso da terra na bacia hidrográfica do Rio Piracicaba para o ano de 2010 (Fonte: Elaborado pelo autor). 20

Figura 10. Evolução das áreas ocupadas por cada uso da terra na bacia hidrográfica do Rio Piracicaba, período 1985-2010 (Fonte: Elaborado pelo autor). 21

Figura 11. Localização geográfica dos postos com informações climatológicas na bacia hidrográfica do Rio Piracicaba (Fonte: HidroWeb/ANA).

Figura 12. Localização geográfica dos postos pluviométricos selecionados na bacia hidrográfica do Rio Piracicaba (Fonte: HidroWeb/ANA). 23

Figura 13. Localização geográfica dos postos fluviométricos na bacia (Fonte: HidroWeb/ANA). 24

Figura 14. Reservatórios na bacia hidrográfica do Rio Piracicaba integrantes do Sistema Cantareira (Fonte: Elaborado pelo autor). 
Figura 15. Sub-bacias para modelagem hidrológica, definidas a partir da localização de postos fluviométricos de interesse (Fonte: Elaborado pelo autor). 26

Figura 16. Minibacias resultantes da discretização da bacia hidrográfica do Rio Piracicaba com base no limiar de área de drenagem mínima (Fonte: Elaborado pelo autor). 27

Figura 17. Fluxograma de operações de processamento de dados (em branco) e operações de SIG convencionais (em cinza) durante a execução do modelo (Fonte: Adaptado de COLLISCHONN et al., 2007). 31

Figura 18. Unidades de Resposta Hidrológica para o ano de 1985 (Fonte: Elaborado pelo autor). 33

Figura 19. Unidades de Resposta Hidrológica para o ano de 2010 (Fonte: Elaborado pelo autor). 33

Figura 20. Hidrograma de vazões diárias observadas (linha contínua preta) e simuladas (linha pontilhada vermelha) na estação Pires $\left(953,7 \mathrm{~km}^{2}\right)$, durante a calibração, no período de 1971 a 1980 (Fonte: Elaborado pelo autor).

Figura 21. Hidrograma de vazões diárias observadas (linha contínua preta) e simuladas (linha pontilhada vermelha) na estação Buenópolis $\left(1.927,1 \mathrm{~km}^{2}\right)$, durante a calibração, no período de 1971 a 1980 (Fonte: Elaborado pelo autor).

Figura 22. Hidrograma de vazões diárias observadas (linha contínua preta) e simuladas (linha pontilhada vermelha) na estação Jaguariúna $\left(2.182,1 \mathrm{~km}^{2}\right)$, durante a calibração, no período de 1971 a 1980 (Fonte: Elaborado pelo autor).

Figura 23. Hidrograma de vazões diárias observadas (linha contínua preta) e simuladas (linha pontilhada vermelha) na estação Monte Alegre do Sul $\left(386,6 \mathrm{~km}^{2}\right)$, durante a calibração, no período de 1971 a 1980 (Fonte: Elaborado pelo autor).

Figura 24. Hidrograma de vazões diárias observadas (linha contínua preta) e simuladas (linha pontilhada vermelha) na estação Fazenda Barra $(927,1$ km²), durante a calibração, no período de 1971 a 1980 (Fonte: Elaborado pelo autor).

Figura 25. Hidrograma de vazões diárias observadas (linha contínua preta) e simuladas (linha pontilhada vermelha) na estação Usina Ester $\left(3.397,5 \mathrm{~km}^{2}\right)$, durante a calibração, no período de 1971 a 1980 (Fonte: Elaborado pelo autor).

Figura 26. Hidrograma de vazões diárias observadas (linha contínua preta) e simuladas (linha pontilhada vermelha) na estação Bairro da Ponte $\left(1.921,4 \mathrm{~km}^{2}\right)$, durante a calibração, no período de 1971 a 1980 (Fonte: Elaborado pelo autor). 
Figura 27. Hidrograma de vazões diárias observadas (linha contínua preta) e simuladas (linha pontilhada vermelha) na estação Desembargador Furtado $\left(2.487,7 \mathrm{~km}^{2}\right)$, durante a calibração, no período de 1971 a 1980 (Fonte: Elaborado pelo autor). 43

Figura 28. Hidrograma de vazões diárias observadas (linha contínua preta) e simuladas (linha pontilhada vermelha) na estação Recreio $\left(1.577,5 \mathrm{~km}^{2}\right)$, durante a calibração, no período de 1971 a 1980 (Fonte: Elaborado pelo autor). 44

Figura 29. Hidrograma de vazões diárias observadas (linha contínua preta) e simuladas (linha pontilhada vermelha) na estação Artemis $\left(10.929,9 \mathrm{~km}^{2}\right)$, durante a calibração, no período de 1971 a 1980 (Fonte: Elaborado pelo autor). 44

Figura 30. Comparação dos valores de vazões específicas diárias médias (observadas e simuladas) e de $90 \%$ de permanência (observadas e simuladas), com relação à área de drenagem (Fonte: Elaborado pelo autor). 46

Figura 31. Diagramas de dispersão entre os dados de vazões diárias simuladas (eixo das ordenadas) e observadas (eixo das abscissas) para cada posto fluviométrico (Fonte: Elaborado pelo autor). 47

Figura 32. Curvas de permanência dos postos fluviométricos durante a calibração, comparando os dados observados (linha cinza contínua) e simulados (linha vermelha tracejada) (Fonte: Elaborado pelo autor) 49

Figura 33. Hidrograma de vazões diárias observadas (linha contínua preta) e simuladas (linha pontilhada vermelha) na estação Pires $\left(953,7 \mathrm{~km}^{2}\right)$, durante a validação, no período de 1981 a 1990 (Fonte: Elaborado pelo autor). 50

Figura 34. Hidrograma de vazões diárias observadas (linha contínua preta) e simuladas (linha pontilhada vermelha) na estação Buenópolis $\left(1.927,1 \mathrm{~km}^{2}\right)$, durante a validação, no período de 1981 a 1990 (Fonte: Elaborado pelo autor). 50

Figura 35. Hidrograma de vazões diárias observadas (linha contínua preta) e simuladas (linha pontilhada vermelha) na estação Jaguariúna $\left(2.182,1 \mathrm{~km}^{2}\right)$, durante a validação, no período de 1981 a 1990 (Fonte: Elaborado pelo autor). 51

Figura 36. Hidrograma de vazões diárias observadas (linha contínua preta) e simuladas (linha pontilhada vermelha) na estação Monte Alegre do Sul $\left(386,6 \mathrm{~km}^{2}\right)$, durante a validação, no período de 1981 a 1990 (Fonte: Elaborado pelo autor). 51 
Figura 37. Hidrograma de vazões diárias observadas (linha contínua preta) e simuladas (linha pontilhada vermelha) na estação Fazenda Barra $\left(927,1 \mathrm{~km}^{2}\right)$, durante a validação, no período de 1981 a 1990 (Fonte: Elaborado pelo autor). 51

Figura 38. Hidrograma de vazões diárias observadas (linha contínua preta) e simuladas (linha pontilhada vermelha) na estação Usina Ester (3.397,5 km²), durante a validação, no período de 1981 a 1990 (Fonte: Elaborado pelo autor). 52

Figura 39. Hidrograma de vazões diárias observadas (linha contínua preta) e simuladas (linha pontilhada vermelha) na estação Bairro da Ponte $\left(1.921,4 \mathrm{~km}^{2}\right)$, durante a validação, no período de 1981 a 1990 (Fonte: Elaborado pelo autor). 52

Figura 40. Hidrograma de vazões diárias observadas (linha contínua preta) e simuladas (linha pontilhada vermelha) na estação Desembargador Furtado $\left(2.487,7 \mathrm{~km}^{2}\right)$, durante a validação, no período de 1981 a 1990 (Fonte: Elaborado pelo autor). 52

Figura 41. Hidrograma de vazões diárias observadas (linha contínua preta) e simuladas (linha pontilhada vermelha) na estação Recreio $\left(1.577,5 \mathrm{~km}^{2}\right)$, durante a validação, no período de 1981 a 1990 (Fonte: Elaborado pelo autor). 53

Figura 42. Hidrograma de vazões diárias observadas (linha contínua preta) e simuladas (linha pontilhada vermelha) na estação Artemis $\left(10.292,9 \mathrm{~km}^{2}\right)$, durante a validação, no período de 1981 a 1990 (Fonte: Elaborado pelo autor). 53

Figura 43. Comparação dos valores de vazões específicas diárias médias (observadas e simuladas) e de $90 \%$ de permanência (observadas e simuladas), com relação à área de drenagem (Fonte: Elaborado pelo autor) 55

Figura 44. Diagramas de dispersão entre dados de vazões diárias simuladas (eixo das ordenadas) e observadas (eixo das abscissas) para cada posto fluviométrico (Fonte: Elaborado pelo autor) 56

Figura 45. Curvas de permanência dos postos fluviométricos durante a validação, referentes a dados observados (linha contínua) e simulados (linha tracejada) (Fonte: Elaborado pelo autor). 58

Figura 46. Exemplo de dados de precipitação gerado pelo modelo Eta-CPTEC, no formato de pontos de grade (Fonte: Elaborado pelo autor).

Figura 47. Postos climatológicos gerados a partir da grade do modelo CPTEC-ETA (Fonte: Elaborado pelo autor). 
Figura 48. Temperatura média (a), precipitação (b), pressão atmosférica (c), velocidade do vento (d), insolação (e) e umidade relativa (f) para o mês de Janeiro de 2041 (Fonte: projeções do modelo Eta-CPTEC).

Figura 49. Evolução da mancha urbana na bacia do Rio Piracicaba (Fonte: Elaborado pelo autor)

Figura 50. Localização dos postos fluviométricos considerados na modelagem, a jusante dos reservatórios do Sistema Cantareira (Fonte: Elaborado pelo autor). 74

Figura 51. Vazões médias diárias decorrentes da operação do Sistema Cantareira, posto Guapirocaba (Fonte: Elaborado pelo autor). 75

Figura 52. Vazões médias diárias decorrentes da operação do Sistema Cantareira, posto Atibaia (Fonte: Elaborado pelo autor).

Figura 53. Postos fluviométricos selecionados para a representação das vazões mínimas, conforme arranjo espacial das sub-bacias utilizadas na gestão (Fonte: Elaborado pelo autor).

Figura 54. Comparação entre as médias mensais de precipitação observada (linha azul), simulada pelo modelo Eta-CPTEC sem correção (linha vermelha) e simulada corrigida (linha verde), para o período de 1961 a 1990 (Fonte: Elaborado pelo autor) 79

Figura 55. Vazões médias anuais $\left(Q_{\text {méd }}\right)$ e o desvio padrão dos dados observados (azul), simulados com dados de precipitação observados (vermelho) e simulados com dados do modelo climático Eta-CPTEC antes (verde) e após a correção (roxo) (Fonte: Elaborado pelo autor).

Figura 56. Vazões mínimas médias de sete dias consecutivos $\left(Q_{7 \mathrm{~min}}\right)$ e o desvio padrão dos dados observados (azul), simulados com dados de precipitação observados (vermelho) e simulados com dados do modelo climático Eta-CPTEC antes (verde) e após a correção (roxo) (Fonte: Elaborado pelo autor).

Figura 57. Projeções da precipitação futura do modelo Eta-CPTEC, sem correção, para os períodos 2011-2040 (linha vermelha), 2041-2070 (linha verde), 2071-2099 (linha roxa) comparadas ao período 1961-1990 (linha azul) (Fonte: Elaborado pelo autor) 83

Figura 58. Variação (\%) da precipitação simulada, sem correção, comparada ao período observado (1961-1990) (Fonte: Elaborado pelo autor). 
Figura 59. Projeções da precipitação futura do modelo Eta-CPTEC, corrigida, para os períodos 2011-2040 (linha vermelha), 2041-2070 (linha verde), 2071-2099 (linha roxa) comparadas ao período 1961-1990 (linha azul) (Fonte: Elaborado pelo autor)..... 85

Figura 60. Variação (\%) da precipitação simulada, sem correção, comparada ao período observado (1961-1990) (Fonte: Elaborado pelo autor).

Figura 61. Vazões mínimas médias anuais observadas (barra azul), simuladas (barra vermelha) e média observada (linha verde) na estação Fazenda Barra, período 1971-1990 (Fonte: Elaborado pelo autor).

Figura 62. Vazões mínimas médias anuais observadas (barra azul), simuladas (barra vermelha) e média observada (linha verde) na estação Usina Ester, período 19711990 (Fonte: Elaborado pelo autor)

Figura 63. Vazões mínimas médias anuais observadas (barra azul), simuladas (barra vermelha) e média observada (linha verde) na estação Desembargador Furtado, período 1971-1990 (Fonte: Elaborado pelo autor) 88

Figura 64. Vazões mínimas médias anuais observadas (barra azul), simuladas (barra vermelha) e média observada (linha verde) na estação Recreio, período 1971-1990 (Fonte: Elaborado pelo autor). 88

Figura 65. Vazões mínimas médias anuais observadas (barra azul), simuladas (barra vermelha) e média observada (linha verde) na estação Artemis, período 19711990 (Fonte: Elaborado pelo autor)

Figura 66. Dispersão dos valores das $Q_{7 \min }$ para o período 1971-1990, por posto fluviométrico, conforme a área do posto fluviométrico (Fonte: Elaborado pelo autor).

Figura 67. Série de vazões mínimas anuais $\left(Q_{7 \min }\right)$ no posto Fazenda Barra $\left(927,1 \mathrm{~km}^{2}\right)$, no período de 2013 a 2099, para os cenários de mudança.

Figura 68. Séries de vazões mínimas anuais $\left(Q_{7 \text { min }}\right)$ no posto Usina Ester $\left(3.397,5 \mathrm{~km}^{2}\right)$, no período de 2013 a 2099, para os cenários de mudança.

Figura 69. Séries de vazões mínimas anuais $\left(Q_{7 \min }\right)$ no posto Desembargador Furtado $\left(2.487,7 \mathrm{~km}^{2}\right)$, no período de 2013 a 2099, para os cenários de mudança. 92

Figura 70. Séries de vazões mínimas anuais $\left(Q_{7 \min }\right)$ no posto Recreio $\left(1.577,5 \mathrm{~km}^{2}\right)$, no período de 2013 a 2099, para os cenários de mudança. 
Figura 71. Séries de vazões mínimas anuais $\left(Q_{7 \mathrm{~min}}\right)$ no posto Artemis $\left(10.929,9 \mathrm{~km}^{2}\right)$, no período de 2013 a 2099, para os cenários de mudança.

Figura 72. Fluxograma de atividades em cada etapa da estratégia de adaptação definida (Fonte: Elaborado pelo autor). 103

Figura 73. Representação das séries de vazões diárias simuladas para os cenários de mudanças, em cada sub-bacia, no período 2013-2099 (Fonte: Elaborado pelo autor). 105

Figura 74. Representação das séries de $Q_{7 \text { min }}$ anuais simuladas para os cenários de mudanças, em cada sub-bacia, no período 2013-2099 (Fonte: Elaborado pelo autor). 106

Figura 75. Critérios considerados para a priorização do atendimento das demandas entre os usuários identificados (Fonte: Elaborado pelo autor).

Figura 76. Fluxograma de representação da geração das séries sintéticas equiprováveis (SEQs) de $Q_{7 m i n}$ anual (Fonte: Elaborado pelo autor).

Figura 77. Exemplo de 30 séries equiprováveis (SEQs) geradas, segundo o cenário Cli, para a sub-bacia hidrográfica do rio Jaguari (Fonte: Elaborado pelo autor). 115

Figura 78. Exemplo da aplicação do AQUA-Risco na sub-bacia do rio Corumbataí, conforme cenário SMud, para obtenção dos valores dos prejuízos decorrentes da série de $Q_{7 m i n}$ anuais (Fonte: Elaborado pelo autor).

Figura 79. Curvas de dano para os cenários propostos, em função do período de retorno, para a sub-bacia do rio Camanducaia (Fonte: Elaborado pelo autor)

Figura 80. Curvas de dano para os cenários propostos, em função do período de retorno, para a sub-bacia do rio Jaguari (Fonte: Elaborado pelo autor).

Figura 81. Curvas de dano para os cenários propostos, em função do período de retorno, para a sub-bacia do rio Atibaia (Fonte: Elaborado pelo autor).

Figura 82. Curvas de dano para os cenários propostos, em função do período de retorno, para a sub-bacia do rio Corumbataí (Fonte: Elaborado pelo autor).

Figura 83. Curvas de dano para os cenários propostos, em função do período de retorno, para a sub-bacia do rio Piracicaba (Fonte: Elaborado pelo autor).

Figura 84. Exemplo de otimização do prêmio em uma série equiprovável limitada pelas restrições da operação do fundo de seguros (Fonte: Elaborado pelo autor). 
Figura 85. Simulação do MTRH-SHS através da otimização das séries equiprováveis (Fonte: Elaborado pelo autor).

Figura 86. Exemplo de prêmio ótimo médio obtido resultado da otimização das séries em cada cenário de mudanças (Fonte: Elaborado pelo autor). 128

Figura 87. Coeficiente de Solvência (CS) determinado para as sub-bacias do Rio Piracicaba, nos cinco cenários de mudanças globais propostos (Fonte: Elaborado pelo autor).132

Figura 88. Coeficiente de Eficiência (CE) determinado para as sub-bacias do Rio Piracicaba, nos cinco cenários de mudanças globais propostos (Fonte: Elaborado pelo autor).134

Figura 89. Índice de Sinistralidade (IS) determinado para as sub-bacias do Rio Piracicaba, nos cinco cenários de mudanças globais propostos (Fonte: Elaborado pelo autor)... 136 


\section{LISTA DE TABELAS}

Tabela 1. Agrupamento dos tipos de solos na bacia hidrográfica do Rio Piracicaba segundo características físicas e hidrológicas.

Tabela 2. Grupos de solos segundo características físicas e hidrológicas. 18

Tabela 3. Distribuição das classes de uso da terra na bacia hidrográfica do Rio Piracicaba, períodos 1985 e 2010. 19

Tabela 4. Características dos postos fluviométricos selecionados.

Tabela 5. Unidades de Resposta Hidrológica (URHs) resultantes das combinações entre os tipos de solo e os usos da terra na bacia.

Tabela 6. Valores recomendados para os parâmetros calibráveis do MGB-IPH.

Tabela 7. Valores mínimos e máximos permitidos para que o algoritmo variasse cada um dos parâmetros a serem calibrados.

Tabela 8. Resultados das FO para o período de calibração (1971-1980) do MGB-IPH na bacia hidrográfica do Rio Piracicaba.

Tabela 9. Resultados das FO para o período de calibração (1971-1980) e validação (19811990) do MGB-IPH na bacia hidrográfica do Rio Piracicaba.

Tabela 10. Unidades das variáveis de saída do modelo Eta-CPTEC e o formato ao qual devem ser convertidas para entrada no MGB-IPH.

Tabela 11. Cenários de mudanças elaborados com base nos atores de mudança identificados. 71

Tabela 12. Vazões médias nos postos fluviométricos para o período 1971-1990. 80

Tabela 13. Vazões mínimas, representadas pela $Q_{7 m i ́ n}$ nos postos fluviométricos, para o período 1971-1990. 81

Tabela 14. Valores de $Q_{7 \min }$ simulados e observados e de $r^{2}$, para o período 1971-1990, por posto fluviométrico.

Tabela 15. Valores de $Q_{7 \min }$ simulados e observados e do percentual de erro, para o período 1971-1990, por posto fluviométrico. 90

Tabela 16. Vazões mínimas $\left(Q_{7 \min }\right)$ médias anuais em cada cenário considerado, no período 2013-2099. 95 
Tabela 17. Valores de captação corrigidos, por sub-bacia hidrográfica, para cada usuário dos recursos hídricos. 108

Tabela 18. Valores de lançamento de efluentes corrigidos, por sub-bacia hidrográfica, para cada usuário dos recursos hídricos. 108

Tabela 19. Valores da carga remanescente nos efluentes após o tratamento, por sub-bacia hidrográfica, lançados nos corpos d'água. 109

Tabela 20. Valores de prejuízo e do prêmio ótimo nos cenários, em $\mathrm{R} \$ \mathrm{~km}^{-2}$, na sub-bacia do Rio Camanducaia, para TR 10, 25, 50 e 100 anos. 128

Tabela 21. Valores de prejuízo e do prêmio ótimo, em $\mathrm{R} \$ \mathrm{~km}^{-2}$, na sub-bacia do Rio Jaguari, para TR 10, 25, 50 e 100 anos.

Tabela 22. Valores de prejuízo e do prêmio ótimo, em $\mathrm{R} \$ \mathrm{~km}^{-2}$, na sub-bacia do Rio Atibaia, para TR 10, 25, 50 e 100 anos 129

Tabela 23. Valores de prejuízo e do prêmio ótimo nos cenários, em $\mathrm{R} \$ \mathrm{~km}^{-2}$, na sub-bacia do Rio Corumbataí, para TR 10, 25, 50 e 100 anos. 129

Tabela 24. Valores de prejuízo e do prêmio ótimo, em $\mathrm{R} \$ \mathrm{~km}^{-2}$, na sub-bacia do Rio Piracicaba, para TR 10, 25, 50 e 100 anos. 130

Tabela 25. Valores do Coeficiente de Solvência (CS) para cada sub-bacia nos cenários de mudanças considerados.

Tabela 26. Valores do Coeficiente de Eficiência $(C E)$ para cada sub-bacia nos cenários de mudanças considerados. 133

Tabela 27. Valores do Índice de Sinistralidade (IS) para cada sub-bacia nos cenários de mudanças considerados. 135

Tabela 28. Dados das estações meteorológicas utilizadas como entrada no modelo MGB-IPH. 159

Tabela 29. Estações pluviométricas utilizadas como fonte da precipitação observada considerada no modelo MGB-IPH. 160

Tabela 30. Valores de albedo definidos para cada bloco de uso da terra. 164

Tabela 31. Valores do índice de área foliar (IAF) definidos para cada bloco de uso da terra. 164

Tabela 32. Valores de altura da vegetação definidos para cada bloco de uso da terra. 165

Tabela 33. Valores de resistência superficial definidos para cada bloco de uso da terra..... 165

Tabela 34. Parâmetros calibráveis ajustados para a sub-bacia № 01 (Posto Pires). 165 
Tabela 35. Parâmetros calibráveis ajustados para a sub-bacia № 02 (Posto Buenópolis).... 166

Tabela 36. Parâmetros calibráveis ajustados para a sub-bacia no 03 (Posto Jaguariúna)..... 166

Tabela 37. Parâmetros calibráveis ajustados para a sub-bacia no 04 (Posto Monte Alegre do Sul) 166

Tabela 38. Parâmetros calibráveis ajustados para a sub-bacia № 05 (Posto Fazenda Barra).

Tabela 39. Parâmetros calibráveis ajustados para a sub-bacia no 06 (Posto Usina Ester).... 167

Tabela 40. Parâmetros calibráveis ajustados para a sub-bacia no 07 (Posto Bairro da Ponte).

Tabela 41. Parâmetros calibráveis ajustados para a sub-bacia no 08 (Posto Desembargador Furtado). 168

Tabela 42. Parâmetros calibráveis ajustados para a sub-bacia no 09 (Posto Recreio). 168

Tabela 43. Parâmetros calibráveis ajustados para a sub-bacia no 10 (Posto Artemis). 168

Tabela 44. Valores calculados para a determinação da disponibilidade de água $\left(Q_{r}\right)$ em cada sub-bacia estudada. 176 


\section{LISTA DE ABREVIATURAS E SIGLAS}

ANA Agência Nacional de Águas

CENA Centro de Energia Nuclear na Agricultura

Comitê PCJ Comitê das bacias hidrográficas dos Rios Piracicaba, Capivari e Jundiaí

COP-13 13a Conferência das Partes das Nações Unidas sobre Mudança Climática

COP-16 16a Conferência das Partes das Nações Unidas sobre Mudança Climática

COP-17 17ạ Conferência das Partes das Nações Unidas sobre Mudança Climática

CPTEC Centro de Previsão de Tempo e Estudos Climáticos

CRH Conselho Estadual de Recursos Hídricos

DAEE Departamento de Águas e Energia Elétrica

DGI Divisão de Geração de Imagens

Eta-CPTEC Modelo regional Eta do Centro de Previsão de Tempo e Estudos Climáticos

FAPESP Fundação de Amparo à Pesquisa do Estado de São Paulo

FEHIDRO Fundo Estadual de Recursos Hídricos

HadCM3 Hadley Centre Coupled Model, versão 3

IAC Instituto Agronômico de Campinas

IBAMA Instituto Brasileiro de Meio Ambiente e dos Recursos Naturais Renováveis

INMET Instituto Nacional de Meteorologia

INPE Instituto Nacional de Pesquisas Espaciais

IPCC AR4 Quarto Relatório de Avaliação do Painel Intergovernamental de Mudanças Climáticas

IPH Instituto de Pesquisas Hidráulicas

LARSIM Large Area Runoff Simulation Model

MCG Modelo de Circulação Global

MCR Modelo Climático Regional

MDE Modelo Digital de Elevação 
MGB-IPH Modelo de Grandes Bacias do Instituto de Pesquisas Hidráulicas

MOCOM-UA Multiple-Objective Complex Evolution Algorithm, Universidade do Arizona

MTRH-SHS Modelo de Transferência de Riscos Hidrológicos do Departamento de Hidráulica e Saneamento, Escola de Engenharia de São Carlos/Universidade de São Paulo

RMC Região Metropolitana de Campinas

RMSP Região Metropolitana de São Paulo

SIG Sistema de Informação Geográfica

SISCOM Sistema Compartilhado de Informações de Licenciamento Ambiental

SMA Secretaria Estadual de Meio Ambiente

SRTM Shuttle Radar Topography Mission

UFRGS Universidade Federal do Rio Grande do Sul

UGRHI-5 Unidade de Gerenciamento de Recursos Hídricos no 5 - Bacia Hidrográfica dos Rios Piracicaba, Capivari e Jundiaí

UPGRH-PJ1 Unidade de Planejamento e Gestão de Recursos Hídricos no 1 - Bacia Hidrográfica dos Rios Piracicaba e Jaguari

URH Unidade de Resposta Hidrológica

USP Universidade de São Paulo

VIC

Variable Infiltration Capacity Macroscale Hydrologic Model 


\section{LISTA DE SÍMBOLOS}

$\boldsymbol{a}, \boldsymbol{b}$ Parâmetros de ajuste da função de transferência de correção da precipitação

Ac Área total cultivada na bacia

b Parâmetro de forma da relação entre armazenamento e saturação

CAP Parâmetro que controla o fluxo do reservatório subterrâneo para a camada superficial do solo

CB Parâmetro de retardo do reservatório subterrâneo

CDN Curva de dano

CE Coeficiente de Eficiência

$\boldsymbol{C}_{e f} \quad$ Concentração de poluentes no efluente

$c_{\text {gde }} \quad$ Consumo per capita de água para animais de grande porte

Cl Parâmetro de calibração da propagação sub-superficial nas células

CIDis Cenário que considera mudanças no clima e na disponibilidade hídrica

Cli Cenário que considera apenas mudanças climáticas

CIUsDi Cenário que considera mudanças no clima, no uso da terra e na disponibilidade hídrica

ClUso Cenário que considera mudanças no clima e no uso da terra

$\boldsymbol{c}_{\text {méd }} \quad$ Consumo per capita de água para animais de médio porte

$\boldsymbol{C}_{\text {nat }} \quad$ Concentração natural encontrada do corpo receptor

$\boldsymbol{c}_{\text {peq }} \quad$ Consumo per capita de água para animais de pequeno porte

$\boldsymbol{C}_{\text {perm }} \quad$ Concentração remanescente permitida por lei ou regulamentação

CS Parâmetro de calibração da propagação superficial nas células

CS Coeficiente de solvência

D $\quad$ Prejuízo

d Percentual de dano ao rebanho

DEM $M_{\text {agr }} \quad$ Demanda hídrica para atividades agrícolas 
DEM gde Demanda hídrica de animais de grande porte

DEM méd Demanda hídrica de animais de médio porte

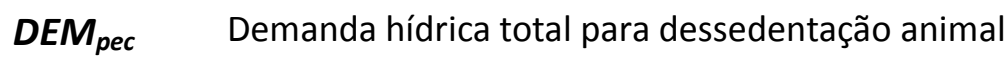

$D_{\text {peq }}$ Demanda hídrica de animais de pequeno porte

DEM $_{\text {rural }}$ Demanda para fins rurais na bacia

$D_{\text {total }}$ Demanda hídrica total para dessedentação animal

DF $\quad$ Fator diário

$D_{x, y}{ }^{a g} \quad$ Prejuízo a atividades agrícolas

$D_{x, y}{ }^{a n} \quad$ Prejuízo a atividades de pecuária

$\boldsymbol{D}_{x, y}{ }^{\boldsymbol{b}} \quad$ Prejuízo total na bacia $\mathrm{x}$ no ano y

$\boldsymbol{D}_{x, y}{ }^{d} \quad$ Prejuízo ambiental para diluição da poluição

$\boldsymbol{D}_{x, y}{ }^{i} \quad$ Prejuízo de atividades industriais

$\boldsymbol{D}_{x, y}{ }^{u} \quad$ Prejuízo ao abastecimento público urbano

$E[Z] \quad$ Valor esperado

$\boldsymbol{e}_{\boldsymbol{a}} \quad$ Pressão atual de vapor

$\boldsymbol{e}_{\boldsymbol{s}} \quad$ Pressão de saturação de vapor

$\boldsymbol{F}^{-1}{ }_{M-P} \quad$ Função inversa da função de distribuição de probabilidades acumulada dos dados de precipitação simulados pelo modelo climático para o período futuro

$\boldsymbol{F}^{-1}$ o-p $\quad$ Função inversa da função de distribuição de probabilidades acumulada dos dados observados para o período da linha de base

FDA Função de distribuição de probabilidade acumulada

FDP $\quad$ Função de distribuição de probabilidade

$\boldsymbol{F}_{\boldsymbol{M} \text { - }} \quad$ Função de distribuição de probabilidades acumulada dos dados de precipitação simulados para o futuro

FO Função-objetivo

HIM Máxima duração da insolação

Hn Ângulo horário do nascer do sol 


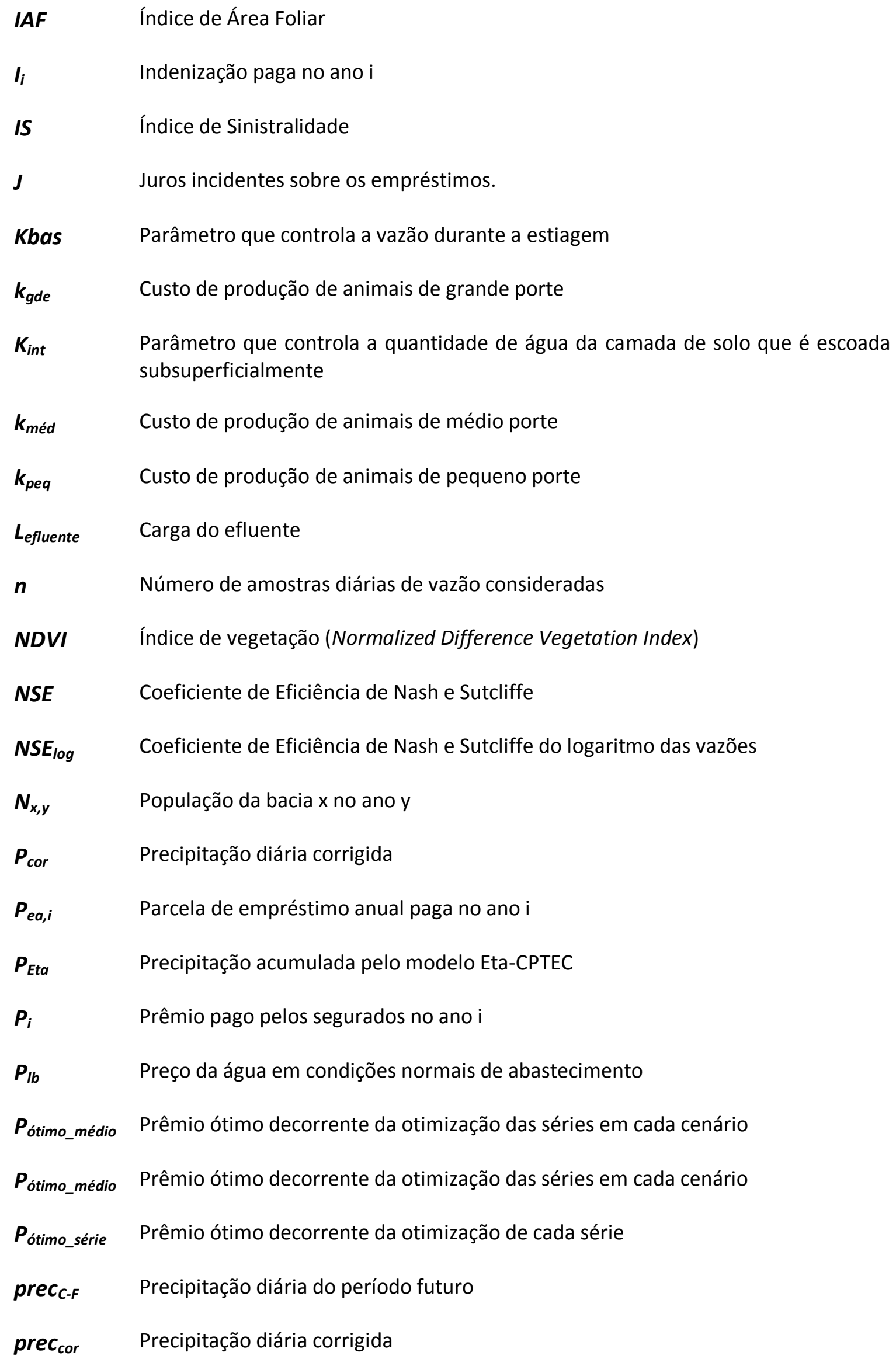




\begin{tabular}{|c|c|}
\hline $\operatorname{prec}_{M-F}$ & Precipitação simulada pelo modelo climático para o período futuro \\
\hline prec sim $_{\text {sim }}$ & Precipitação simulada pelo modelo Eta-CPTEC, a ser corrigida \\
\hline Prej $_{\text {médio }}$ & Prejuízo médio das séries simuladas para determinada faixa de cobertura \\
\hline Pres $_{\text {cor }}$ & Pressão atmosférica média diária corrigida \\
\hline Pres $_{\text {Eta }}$ & Pressão atmosférica média calculada pelo modelo Eta-CPTEC \\
\hline $\boldsymbol{P} \boldsymbol{R}_{\text {esp }}$ & Produção agrícola específica na bacia \\
\hline$Q_{7,10}$ & Vazão mínima média de sete dias consecutivos e dez anos de recorrência \\
\hline$Q_{7 m i n}$ & Vazão anual mínima média de sete dias consecutivos \\
\hline Q90 obs & Vazão observada de permanência de $90 \%$ \\
\hline Q90 sim & Vazão simulada de permanência de $90 \%$ \\
\hline QB & Vazão de referência específica \\
\hline$Q_{\text {captada }}$ & Vazão captada \\
\hline$Q_{\text {dil }}$ & Vazão necessária para diluição do efluente \\
\hline$Q_{e f}$ & Vazão de efluente lançada \\
\hline Qefluente & Vazão efluente \\
\hline$Q_{\text {lanc }}$ & Volume de esgoto que não será diluído \\
\hline$Q_{1 b}$ & Vazão média consumida em condições normais de abastecimento \\
\hline$Q_{\text {méd }}$ & Vazão média anual \\
\hline$Q_{o b s}$ & Vazão observada \\
\hline Qobs_médio & Média aritmética dos valores de vazões observadas \\
\hline$Q_{r}$ & Disponibilidade de água \\
\hline$Q_{\text {sim }}$ & Vazão simulada pelo modelo \\
\hline$r^{2}$ & Coeficiente de determinação \\
\hline RAD & Radiação solar que chega à superfície \\
\hline$r_{a g}$ & Risco de escassez hídrica para atividades agrícolas \\
\hline$r_{a n}$ & Risco de escassez hídrica para atividades de pecuári \\
\hline
\end{tabular}




\begin{tabular}{|c|c|}
\hline$R B_{\text {gde }}$ & Rebanho de grande porte na bacia \\
\hline$R B_{\text {méd }}$ & Rebanho de médio porte na bacia \\
\hline$R B M G P_{x}$ & Rebanho de grande porte no município $x$ \\
\hline$R B M M P_{x}$ & Rebanho de médio porte no município $x$ \\
\hline$R B M P P_{x}$ & Rebanho de pequeno porte no município $x$ \\
\hline$R B_{\text {peq }}$ & Rebanho de pequeno porte na bacia \\
\hline$r_{d}$ & Risco de escassez hídrica para diluição da poluição \\
\hline$R D I A$ & Dia juliano \\
\hline$r_{i}$ & Risco de escassez hídrica para atividades industriais \\
\hline RMA & Requerimento mínimo diário de água \\
\hline$r_{u}$ & Risco de escassez hídrica para o abastecimento urbano \\
\hline$r_{x, y}$ & Resiliência do setor \\
\hline$S A_{i}$ & Saldo armazenado no ano i \\
\hline SAmáx & Saldo armazenado máximo \\
\hline SAmín & Saldo armazenado mínimo \\
\hline SEQ & Série equiprovável \\
\hline SMud & Cenário sem mudanças \\
\hline SOL & Insolação diária \\
\hline STO & Radiação solar no topo da atmosfera, em mm.dia ${ }^{-1}$ \\
\hline STO & Radiação solar no topo da atmosfera, em MJ.m $\mathrm{m}^{-2} \cdot \mathrm{dia}^{-1}$ \\
\hline$T$ & Tempo \\
\hline$T_{C}$ & Temperatura média diária corrigida, em ${ }^{\circ} \mathrm{C}$ \\
\hline$T f$ & Função de transferência \\
\hline$T_{K}$ & Temperatura média diária calculada pelo modelo Eta-CPTEC, em Kelvin \\
\hline$T_{o}$ & Temperatura do ponto de orvalho \\
\hline$T R$ & Tempo de retorno associado ao evento considerado \\
\hline
\end{tabular}




\begin{tabular}{|c|c|}
\hline$T x$ & Taxa de juros incidente sobre o capital armazenado \\
\hline$u_{10}$ & Velocidade do vento a dez metros de altura \\
\hline$u_{2}$ & Velocidade do vento a dois metros de altura \\
\hline UR & Umidade relativa \\
\hline$V_{t}$ & Custo de tratamento de esgoto \\
\hline VT & Valor total arrecadado com a produção na bacia \\
\hline$V_{x, y}$ & Valor diário de prejuízo \\
\hline Wc & Parâmetro que limita o escoamento sub-superficial e o subterrâneo \\
\hline$W m$ & Capacidade de armazenamento do solo \\
\hline$W_{x, y}$ & Perda diária de bem-estar per capita \\
\hline$X L$ & $\begin{array}{l}\text { Parâmetro que controla a forma da curva de redução da drenagem sub-superficial } \\
\text { do solo }\end{array}$ \\
\hline$z_{0}$ & Rugosidade da superfície \\
\hline$z_{x, y}$ & Severidade da escassez \\
\hline$\alpha$ & Parâmetro de escala da distribuição de Gumbel \\
\hline$\alpha_{x, y}$ & Proporção entre abastecimento superficial e subterrâneo \\
\hline B & Parâmetro de posição da distribuição de Gumbel \\
\hline$\Delta$ & Declinação solar \\
\hline$\Delta Q 90$ & Erro do modelo no cálculo da vazão de $90 \%$ de permanência \\
\hline$\Delta V$ & Erro do modelo no cálculo do volume total \\
\hline$\eta$ & Elasticidade do preço para demanda de água \\
\hline$\lambda$ & Calor latente de vaporização da água \\
\hline$\lambda_{x, y}$ & Dano proporcional diário \\
\hline$\rho$ & Massa específica da água \\
\hline$\sigma_{z}^{2}$ & Variância da amostra \\
\hline$\Phi$ & Latitude \\
\hline
\end{tabular}




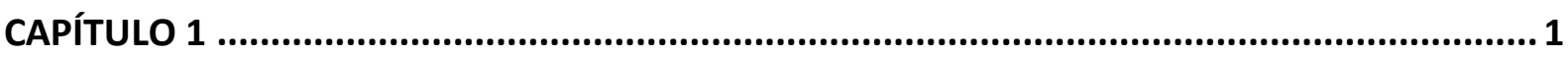

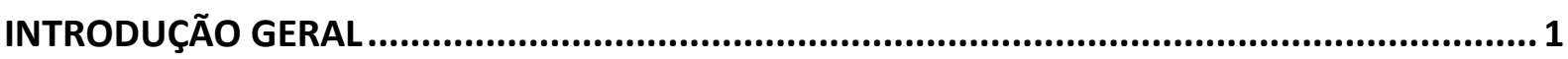

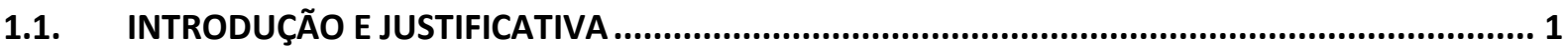

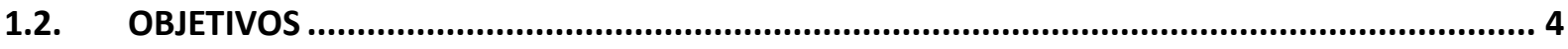

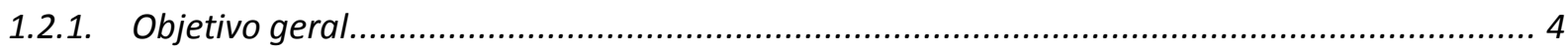

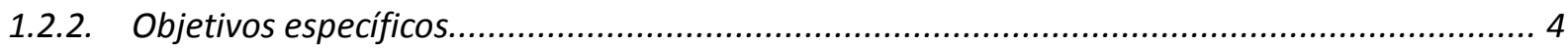

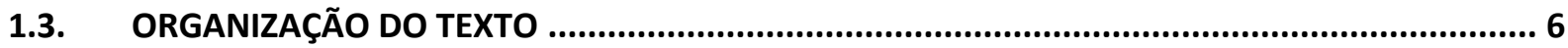

CAPÍTULO 2

CARACTERIZAÇÃO E PROCESSAMENTO DE DADOS DA BACIA HIDROGRÁFICA DO RIO

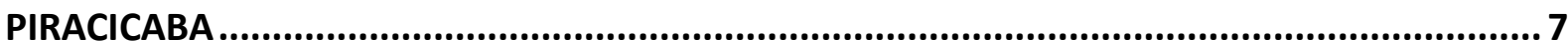

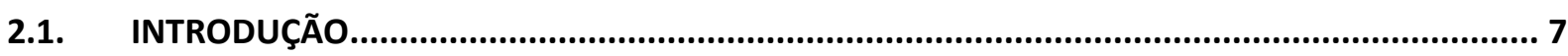

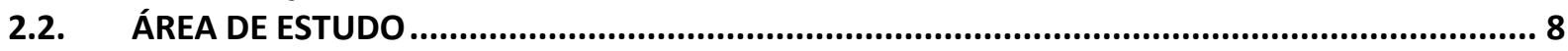

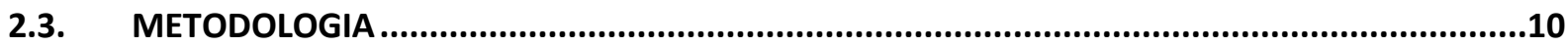

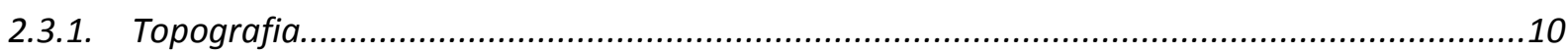

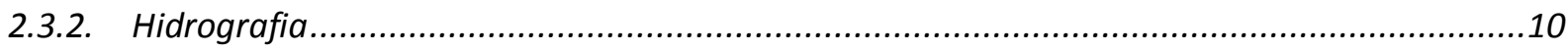

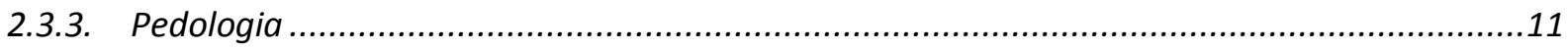

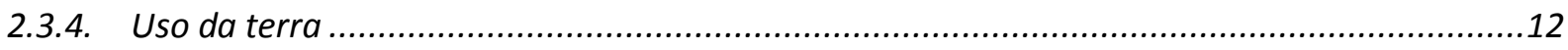

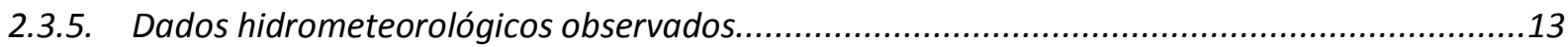

2.3.5.1. Clima

2.3.5.2. Pluviometria

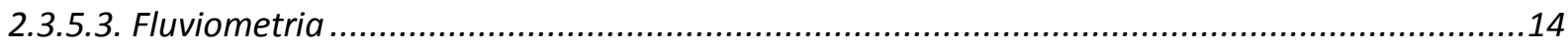

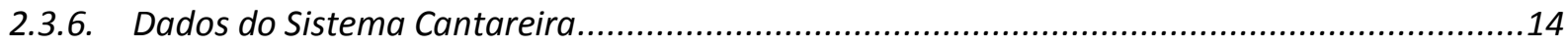

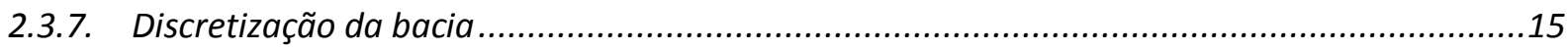

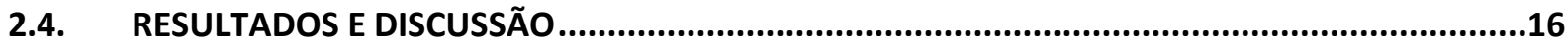

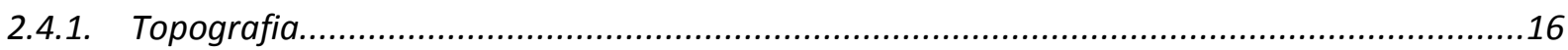

2.4.2. Hidrografia

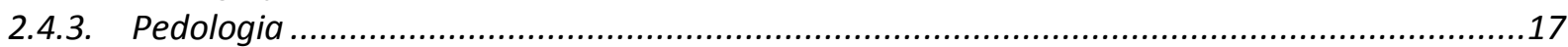

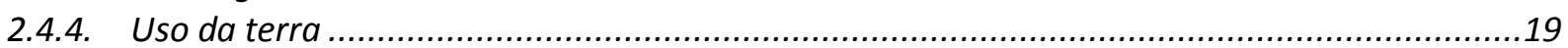

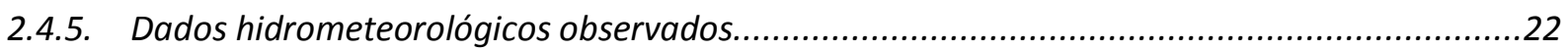

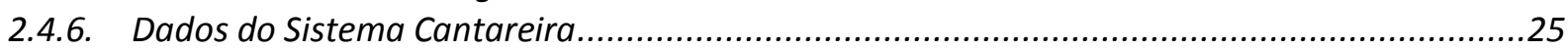

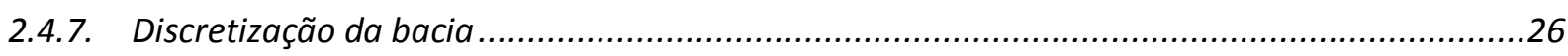

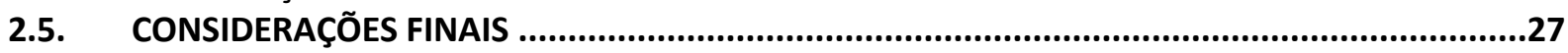

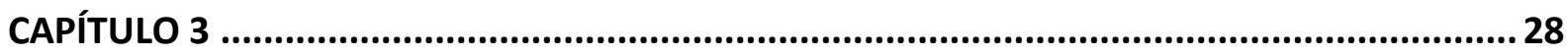

CALIBRAÇÃO E VALIDAÇÃO DO MODELO HIDROLÓGICO MGB-IPH NA BACIA

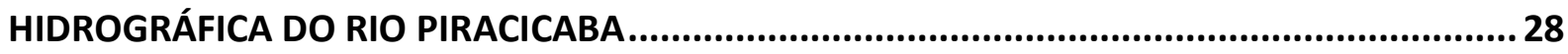

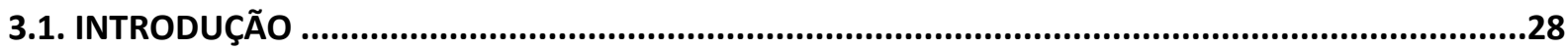

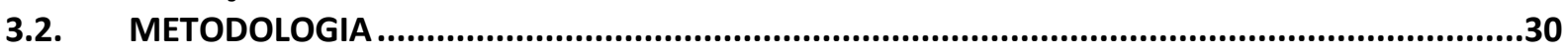

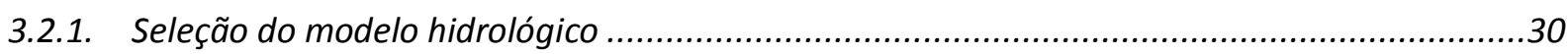

3.2.2. Definição das Unidades de Resposta Hidrológica (URHs)....................................................32

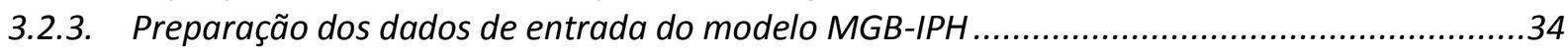

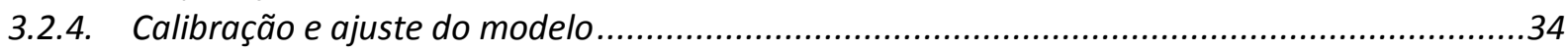




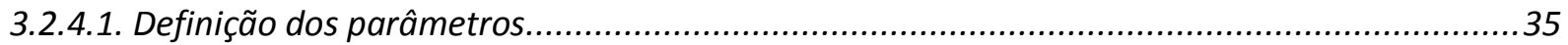

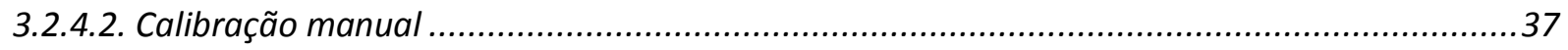

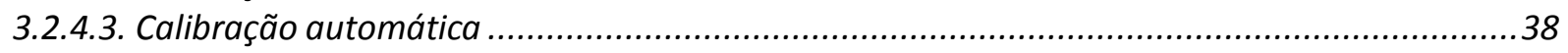

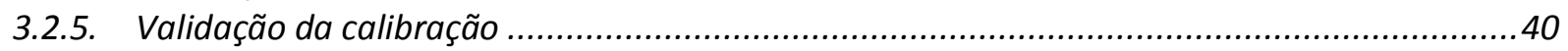

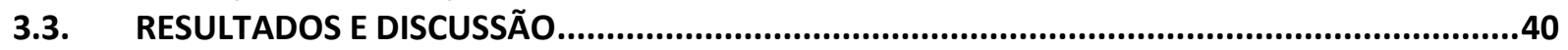

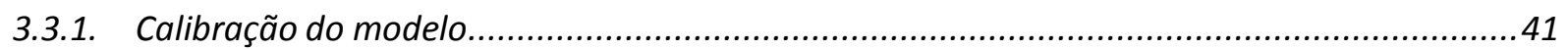

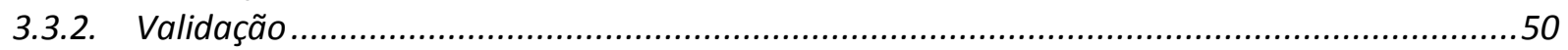

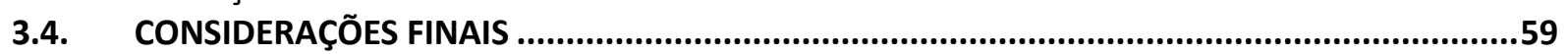

CAPÍTULO 4 .60

PROJEÇÕES DE VAZÕES MÍNIMAS NA BACIA DO RIO PIRACICABA COM BASE EM CENÁRIOS DE MUDANÇAS GLOBAIS PARA O PERÍODO 2013-2099................................................60

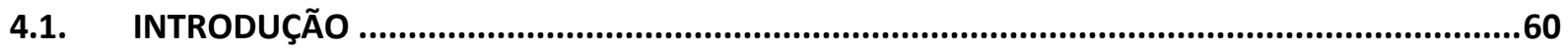

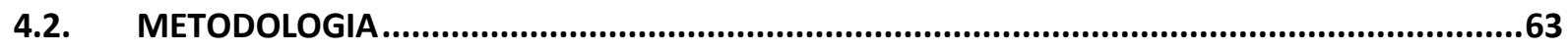

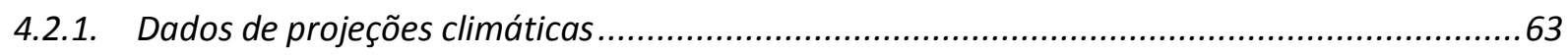

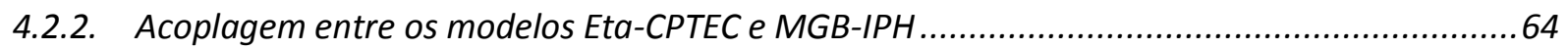

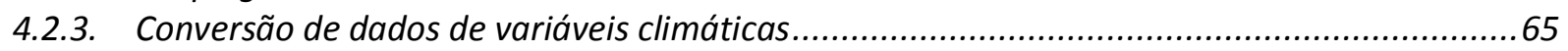

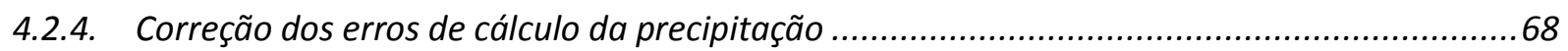

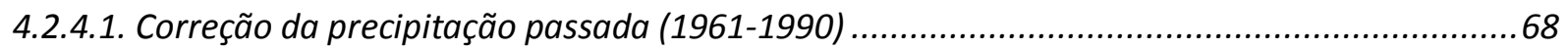

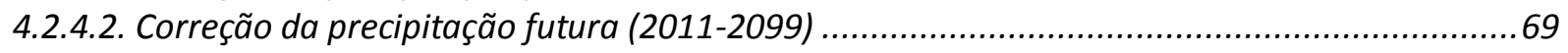

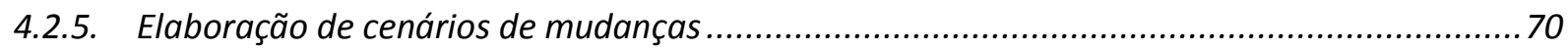

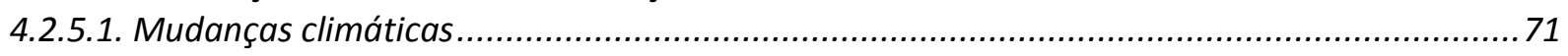

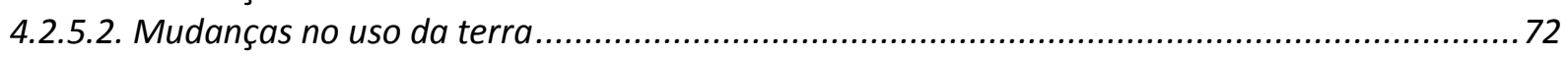

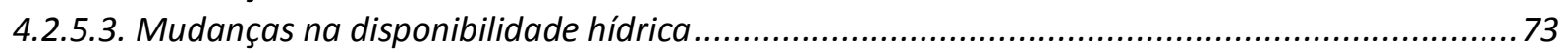

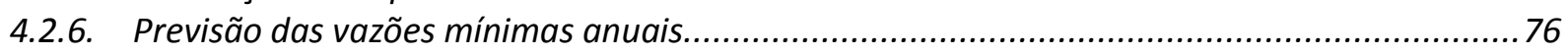

4.2.6.1. Verificação do ajuste do modelo para representar vazões mínimas ..................................... 77

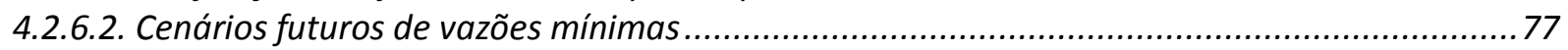

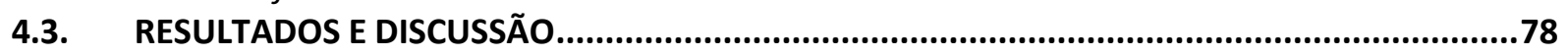

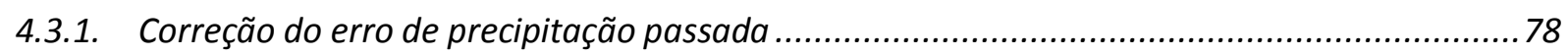

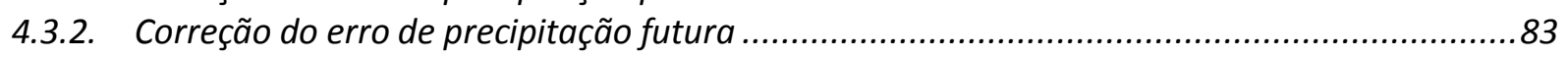

4.3.3. Simulação das vazões mínimas anuais por posto fluviométrico ...........................................86

4.3.3.1. Verificação do modelo para simular vazões mínimas no período $1971-1990$..........................86

4.3.3.2. Projeção das vazões mínimas anuais nos cenários ........................................................91

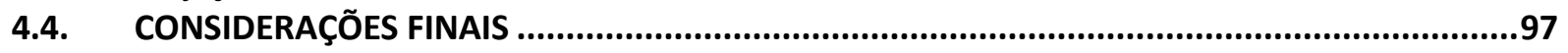

CAPÍTULO 5

SIMULAÇÃO DO MODELO DE TRANSFERÊNCIA DE RISCOS HIDROLÓGICOS COMO ESTRATÉGIA DE ADAPTAÇÃO A EVENTOS DE ESCASSEZ HÍDRICA..................................98

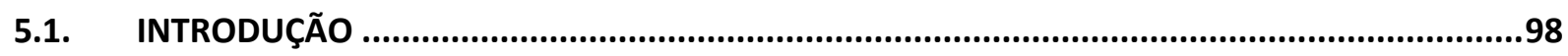

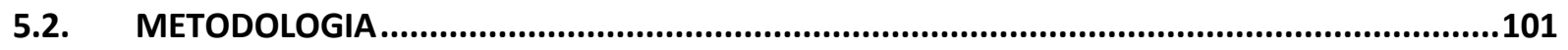

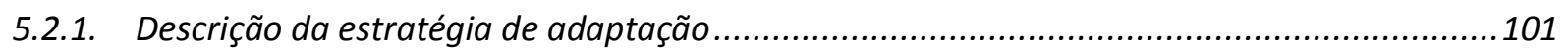

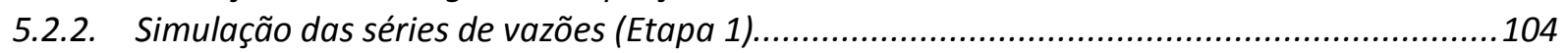

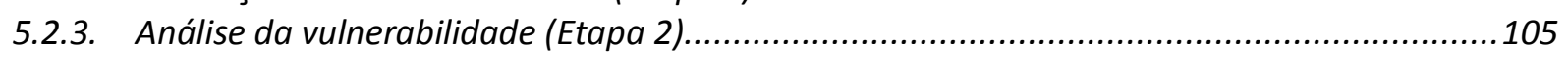

5.2.4. Aplicação do modelo de avaliação dos riscos - AQUA-Risco (Etapa 3)................................106

5.2.4.1. Determinação das vazões e probabilidades de ocorrência..................................................107

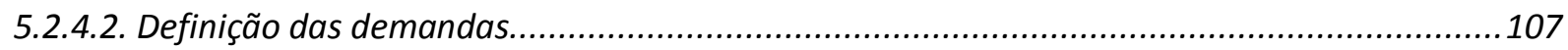

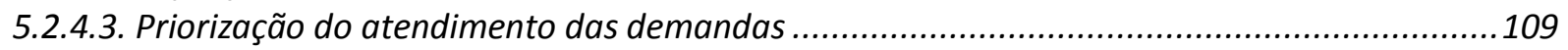

5.2.4.4. Quantificação dos prejuízos por setor usuário..................................................................110 
5.2.4.5. Cálculo do prejuízo total e composição das curvas de dano.........................................112

5.2.5. Simulação do MTRH-SHS (Etapa 4) ..................................................................112

5.2.5.1. Geração de séries sintéticas de vazões mínimas........................................................113

5.2.5.2. Acoplagem do AQUA-Risco ao MTRH-SHS...............................................................116

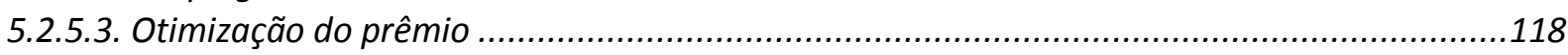

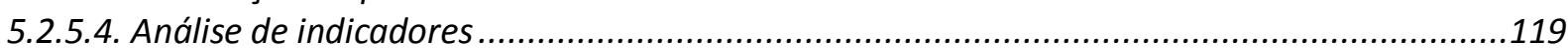

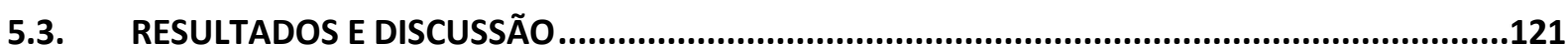

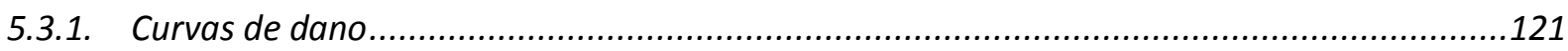

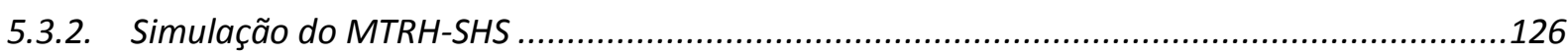

5.3.3. Avaliação dos indicadores de operação do fundo de seguros .......................................131

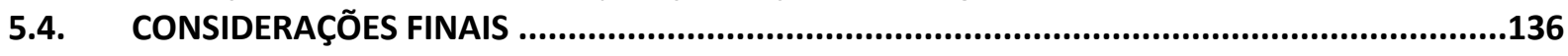

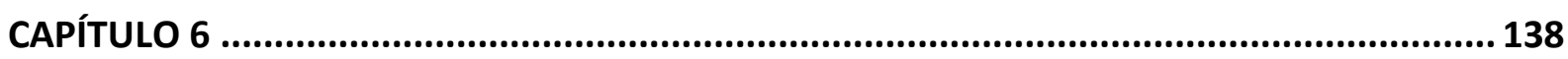

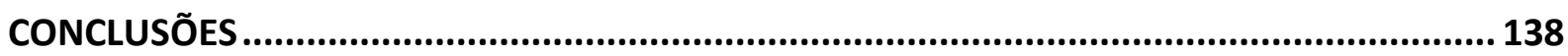

CAPÍTULO 7 ........................................................................................................ 144

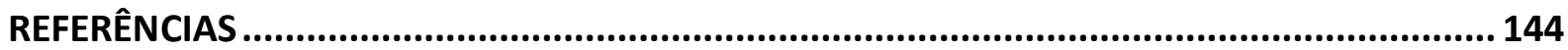

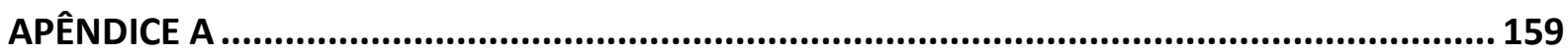

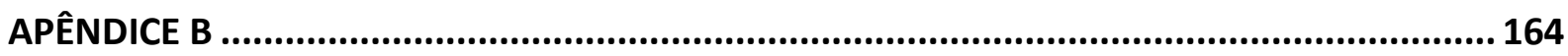

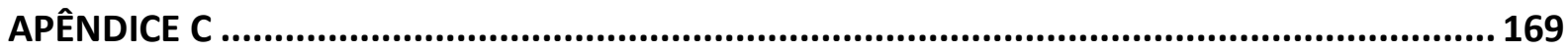

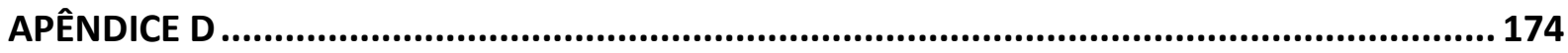





\section{INTRODUÇÃO GERAL}

\subsection{INTRODUÇÃO E JUSTIFICATIVA}

O balanço hídrico em bacias hidrográficas tem sofrido alterações significativas e diversos impactos, principalmente devido ao crescimento populacional, aumento da demanda, intervenções antrópicas e progressivas transformações na paisagem. Além disso, tem-se o aumento da vulnerabilidade a desastres naturais e eventos extremos, como resultado da degradação ambiental e das mudanças no comportamento de variáveis climáticas. Tais desastres causam prejuízos econômicos, sociais e ambientais, uma vez que afetam principalmente comunidades vulneráveis em países em desenvolvimento.

Para o planejamento e gerenciamento das alterações na dinâmica das bacias hidrográficas, bem como dos vetores das mudanças, faz-se necessário o desenvolvimento de estratégias de gerenciamento do risco dessas áreas. Deve-se buscar a redução ou a transferência dos danos decorrentes de eventos extremos, tais como enchentes, estiagens prolongadas, chuvas intensas e temperaturas extremas, na busca por estratégias de adaptação a condições adversas.

Surge, assim, a demanda por pesquisas em estratégias de adaptação às mudanças globais, com abordagem multidisciplinar, que sejam aceitas tanto por pesquisadores quanto por tomadores de decisão e investidores. O foco é a busca pelo equilíbrio do sistema, bem como a viabilização de medidas compensatórias que favoreçam a resiliência - econômica e ambiental - do local impactado, através da gestão dos riscos envolvidos.

Entre as principais ações internacionais neste sentido, citam-se a formação do Quadro para Ação de Hyogo, um tratado internacional firmado por 168 países em 2005, que visa garantir que estratégias de redução dos riscos de desastres sejam tratadas e implantadas no âmbito nacional pelos países signatários. Além disso, em 2007, o Plano de 
Ação de Bali, produto da 13a Conferência das Partes da Convenção-Quadro das Nações Unidas sobre Mudança do Clima - COP-13, evidencia a demanda por pesquisas que relacionem desastres climáticos a estratégias de redução e gestão dos riscos.

Somado a isto, o Programa de Trabalho de Nairobi, resultado da reunião das Partes realizada em Bonn, 2008, tem como uma de suas sugestões a inclusão de estratégias de redução dos riscos de desastres nas políticas e nos programas de governo dos paísesmembros. Entre as alternativas, destacam-se os mecanismos de transferência dos riscos, como os seguros ambientais, que objetivam a proteção e a redução do impacto das perdas em ecossistemas naturais e urbanos.

Tais mecanismos são reforçados em documento firmado em Cancun, 2010, durante a COP-16, intitulado Acordos de Cancun. Esse documento discorre, entre outros temas, sobre a necessidade de cooperação internacional, na busca por medidas de redução e transferência dos riscos como estratégias de adaptação. Além disso, estabelece que a resiliência de sistemas socioeconômicos e ecológicos deve ser tratada como prioridade em condições climáticas desfavoráveis.

Outras reuniões recentes, como a COP-17 em Durban, 2011, e a recém-finalizada Rio+20, realizada no Rio de Janeiro em junho deste ano, demonstram a preocupação e a organização de uma estrutura que viabilize a adoção de estratégias de adaptação às mudanças globais e a eventos extremos.

Apesar da importância que esta temática tem alcançado, e dos avanços das negociações internacionais supracitadas, ainda são incipientes os estudos que permitam o direcionamento dos esforços necessários para a implantação e um programa eficaz voltado à adaptação. São escassas até o momento medidas e políticas efetivas, sejam em escala regional, nacional ou global, que atuem simultaneamente na avaliação, gestão, redução e transferência dos riscos.

Neste trabalho, como estratégia de adaptação aos desastres decorrentes de eventos extremos de escassez hídrica, bem como de mitigação das catástrofes decorrentes das alterações climáticas, sugere-se a utilização de modelos de seguros. Foi utilizado o Modelo de Transferência de Riscos Hidrológicos (MTRH-SHS), com base em simulações de condições hidrológicas amparadas na elaboração de cenários de longo prazo.

Os cenários produzidos levam em conta, além de condições climáticas e ambientais, aspectos econômicos e a dinâmica de uso das terras nas bacias avaliadas. Além disso, o 
MRTH permite a inclusão de variáveis como vulnerabilidade e resiliência na avaliação e na gestão de bacias hidrográficas, relacionadas ao conceito de seguros ambientais.

A hipótese a ser testada é a de que o uso de tal estratégia seria uma medida viável de adaptação aos eventos extremos de escassez hídrica, através da transferência - ou compensação - dos riscos, na escala de bacias hidrográficas. Para que isto ocorra, sugeriu-se a acoplagem do MTRH-SHS ao modelo hidrológico de grandes bacias MGB-IPH, que por sua vez é acoplado ao modelo climático regional Eta-CPTEC, conforme Figura 1.

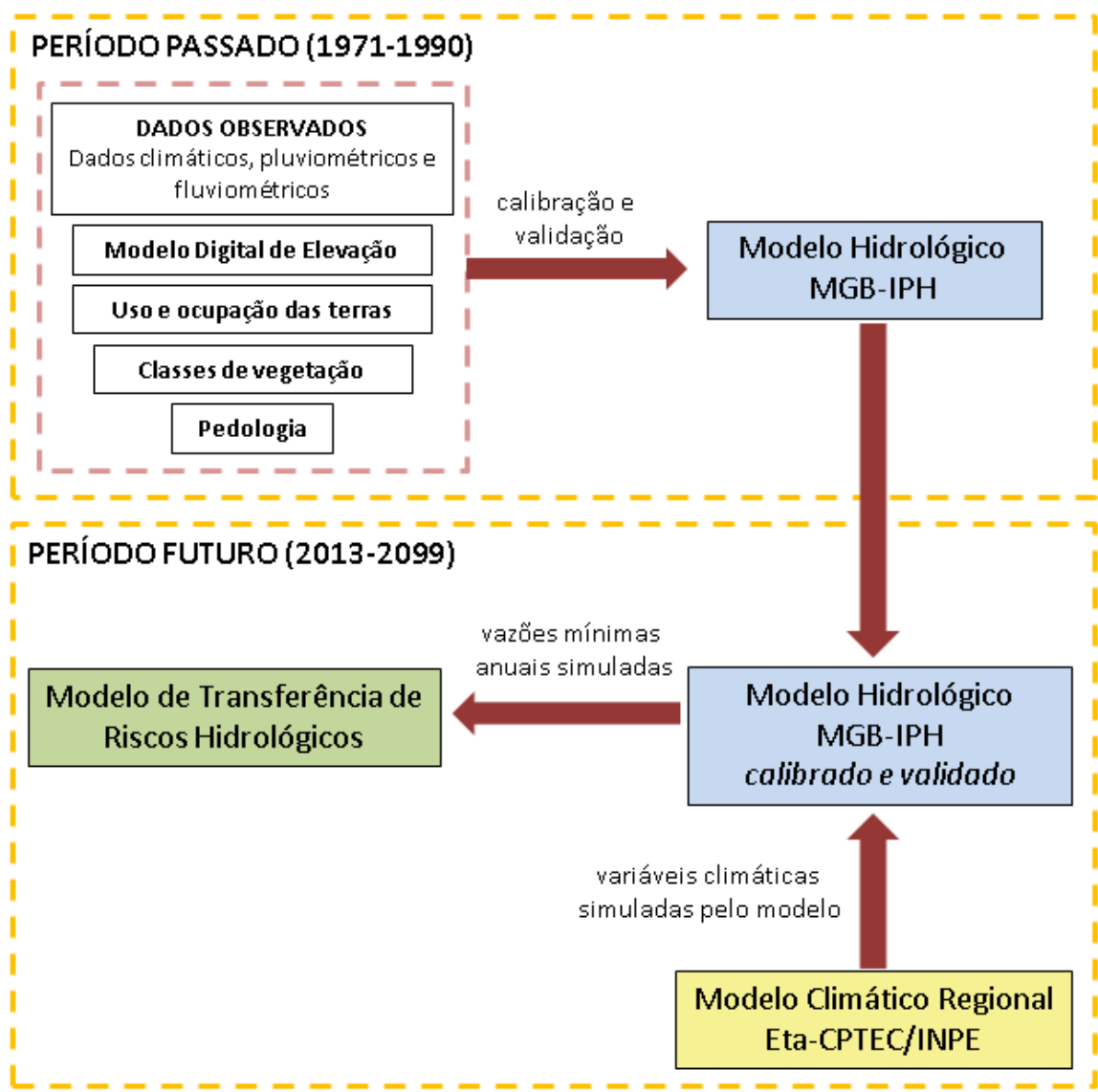

Figura 1. Diagrama da acoplagem de modelos no âmbito deste trabalho (Fonte: Elaborado pelo autor).

A área escolhida para aplicação do modelo compreende a região formada pelas bacias dos rios Piracicaba, Capivari e Jundiaí, localizadas no trecho leste-nordeste do estado de São Paulo, bem como em trecho mineiro adjacente.

Este estudo está amparado em Projeto Temático FAPESP-IAV “Assessment of Impacts and Vulnerability to Climate Change in Brazil and Strategies for Adaptation Options", $\mathrm{n}$ 2008/58161-1, inserido na componente que trata de estratégias de adaptação. Espera-se, 
com isso, contribuir metodologicamente para o desenvolvimento e replicação desta estratégia em outras bacias hidrográficas.

\subsection{OBJETIVOS}

Os objetivos, de caráter geral e específico, nos quais foi baseado este trabalho, são listados abaixo. Na sequência, tem-se quadro representativo da síntese metodológica que levou à obtenção dos principais resultados desta pesquisa (Figura 2).

\subsubsection{Objetivo geral}

Acoplar modelos de circulação regional a modelos hidrológicos distribuídos do tipo chuva-vazão e ao Modelo de Transferência de Riscos Hidrológicos, ou Modelo de Seguros Hidrológicos, como estratégia de adaptação à escassez hídrica em bacias hidrográficas brasileiras.

\subsubsection{Objetivos específicos}

i. Calibrar e validar o modelo hidrológico distribuído espacialmente MGB-IPH na bacia hidrográfica do Rio Piracicaba e em sub-bacias afluentes, no período 1971-1990;

ii. Realizar projeções de vazões mínimas anuais, segundo modelagem hidrológica, com base em cenários de mudanças no clima e no uso das terras na bacia, para o período 2013-2099;

iii. Simular e avaliar o desempenho de indicadores econômicos na operação de fundos de seguros em sub-bacias da bacia do Rio Piracicaba, de maneira concentrada, como estratégia de adaptação frente à ocorrência de sinistros relativos às vazões mínimas simuladas no período 2013-2099; 


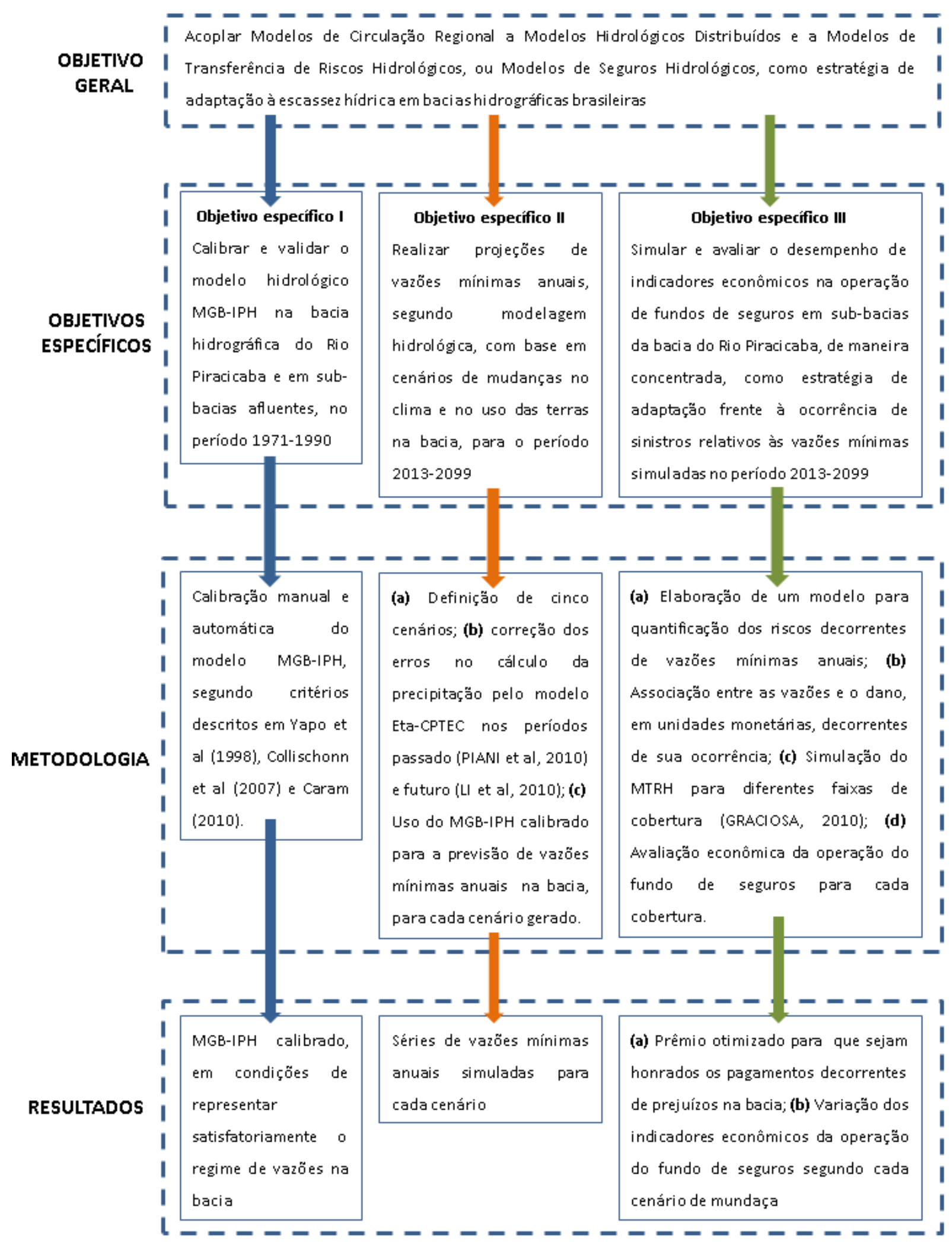

Figura 2. Fluxograma do desenvolvimento da pesquisa com relação aos objetivos propostos, procedimentos metodológicos e resultados alcançados (Fonte: Elaborado pelo autor). 


\subsection{ORGANIZAÇÃO DO TEXTO}

O presente trabalho é organizado em sete capítulos, independentes, porém interrelacionados. Cada um dos capítulos possui revisão da literatura e do estado da arte do tema tratado em cada seção, além dos respectivos objetivos, metodologia, resultados e considerações finais. Cada um dos objetivos propostos no item anterior é tratado em um capítulo específico.

No Capítulo 2, tem-se a descrição e caracterização da bacia hidrográfica do Rio Piracicaba, bem como a coleta e o processamento dos dados que serão utilizados em etapas seguintes do método.

O Capítulo 3 demonstra os critérios e procedimentos adotados para calibração e validação do modelo hidrológico utilizado, conforme dados monitorados na bacia de estudo (objetivo i).

A metodologia utilizada para projeção de vazões mínimas extremas (objetivo ii), utilizando o modelo calibrado em capítulo anterior, considerando um cenário de projeções climáticas, para o período 2013-2099, é descrita no Capítulo 4.

A análise dos riscos e a simulação do Modelo de Transferência de Riscos Hidrológicos (objetivo iii), bem como a explicação de sua estrutura, são demonstradas no Capítulo 5. Neste capítulo também foi possível avaliar a viabilidade de acoplagem entre os modelos utilizados, para a finalidade proposta na hipótese desta pesquisa.

Já no Capítulo 6, têm-se as principais conclusões obtidas com o desenvolvimento deste trabalho, a partir dos objetivos propostos. Por fim, no Capítulo 7, são listadas todas as referências bibliográficas nas quais foram buscadas definições, métodos e critérios de discussão aqui utilizados. 
CAPÍTULO 2

\section{CARACTERIZAÇÃO E PROCESSAMENTO DE DADOS DA BACIA HIDROGRÁFICA DO RIO PIRACICABA}

\subsection{INTRODUÇÃO}

A relevância dos estudos em bacias hidrográficas se deve ao fato de que esses ambientes são áreas com limites físicos definidos, o que favorece a interação entre os meios biótico e abiótico. Tem-se, portanto, uma unidade de ecossistema específica para a avaliação dos impactos decorrentes da ocupação humana e a tomada de decisão (ODUM, 1971; TUNDISI, 2003; POSTEL; THOMPSON, 2005; MOULTON; SOUZA, 2006).

Conforme Luzio, Srinivasan e Arnold (2004), Sistemas de Informações Geográficas (SIGs) garantem significativas melhoras na análise e gerenciamento na área de recursos hídricos. Além das funções tradicionais de compilação, armazenamento, edição, manipulação, apresentação, análise e combinação de dados geográficos (BERNHARDSEN, 1992; LONGLEY et al., 1999; CÂMARA; QUEIROZ, 2001), agrega potencial para aplicação de avançados métodos analíticos na caracterização hidrológica de bacias hidrográficas objetos de estudo (LUZIO; SRINIVASAN; ARNOLD, 2004).

Um Modelo Digital de Elevação (MDE) é um banco de dados numérico ordenado, o qual representa a espacialização das cotas altimétricas em uma paisagem (MOORE; GRAYSON; LADSON, 1991). O uso de MDEs através de SIGs é uma efetiva ferramenta para análises em bacias hidrográficas, uma vez que existe a possibilidade de utilização de métodos automáticos na extração e combinação de informações, com reduzido gasto computacional (VALERIANO et al., 2006).

Variados aspectos derivados de MDEs possuem representatividade na análise do comportamento hidrológico. Entre eles, citam-se elevação, declividade, área de drenagem, distância da rede de drenagem, entre outros (MOORE; GRAYSON; LADSON, 1991). Assim, a complexidade inerente a processos hidrológicos e a bacias hidrográficas cada vez mais abre 
caminho para a utilização de técnicas de operação de SIGs, segundo abordagem de base física e distribuída (SMEDT; YONGBO; GEBREMESKEL, 2000).

Exemplos de aplicação de MDEs em pesquisas para definição de redes de drenagem, delimitação de bacias hidrográficas, direção do escoamento, conforme aplicações em Whitaker et al. (2003), Cuo et al. (2006), Hancock et al. (2006), Valeriano et al. (2006), Callow, Van Niel e Boggs (2007), Paz e Collischonn (2007), Paz et al. (2008), Rennó et al. (2008), Mantelli, Barbosa e Bitencourt (2011) e Nobre et al. (2011).

A compreensão da dinâmica hidrológica em uma bacia hidrográfica se faz importante para o desenvolvimento de atividades humanas. Além da topografia, fornecida pelo MDE, deve-se avaliar a distribuição e intensidade da precipitação, pedologia, uso da terra, variabilidade climática, entre outros fatores na bacia (SARTORI; NETO; GENOVEZ, 2005; SIRIWARDENA; FINLAYSON; MCMAHON, 2006; LI et al., 2009; TOMER; SCHILLING, 2009; LIN, 2010; PRICE, 2011; MELLO; CURI, 2012).

Faz-se importante a caracterização da área a ser estudada, com relação aos temas ligados ao ciclo hidrológico da mesma. Além disso, deve-se estabelecer um sistema de monitoramento confiável, para que o comportamento natural e os impactos locais possam ser quantificados e analisados, simulados e previstos.

O objetivo deste capítulo é promover a caracterização da bacia hidrográfica do Rio Piracicaba, bem como demonstrar as etapas de processamento dos dados coletados que foram utilizados nos capítulos a seguir.

\section{2. ÁREA DE ESTUDO}

A área de estudo corresponde à bacia hidrográfica do Rio Piracicaba (Figura 3). Segundo SMA/CRH (2009), é uma importante bacia do sudeste brasileiro, inserida no trecho intermediário da bacia do Tietê, que por sua vez compõe a Região Hidrográfica da Bacia do Paraná.

A região está situada entre as coordenadas geográficas $46^{\circ} 00^{\prime}$ e $49^{\circ} 00^{\prime}$ de longitude oeste e $22^{\circ} 00^{\prime}$ e $23^{\circ} 30^{\prime}$ de latitude sul. Abrange territórios desde o estado de São Paulo até pequeno trecho de Minas Gerais, totalizando uma área de $12.589,73 \mathrm{~km}^{2}$. Estão total ou parcialmente inseridos nesta bacia 61 municípios dos estados de São Paulo e Minas Gerais. 


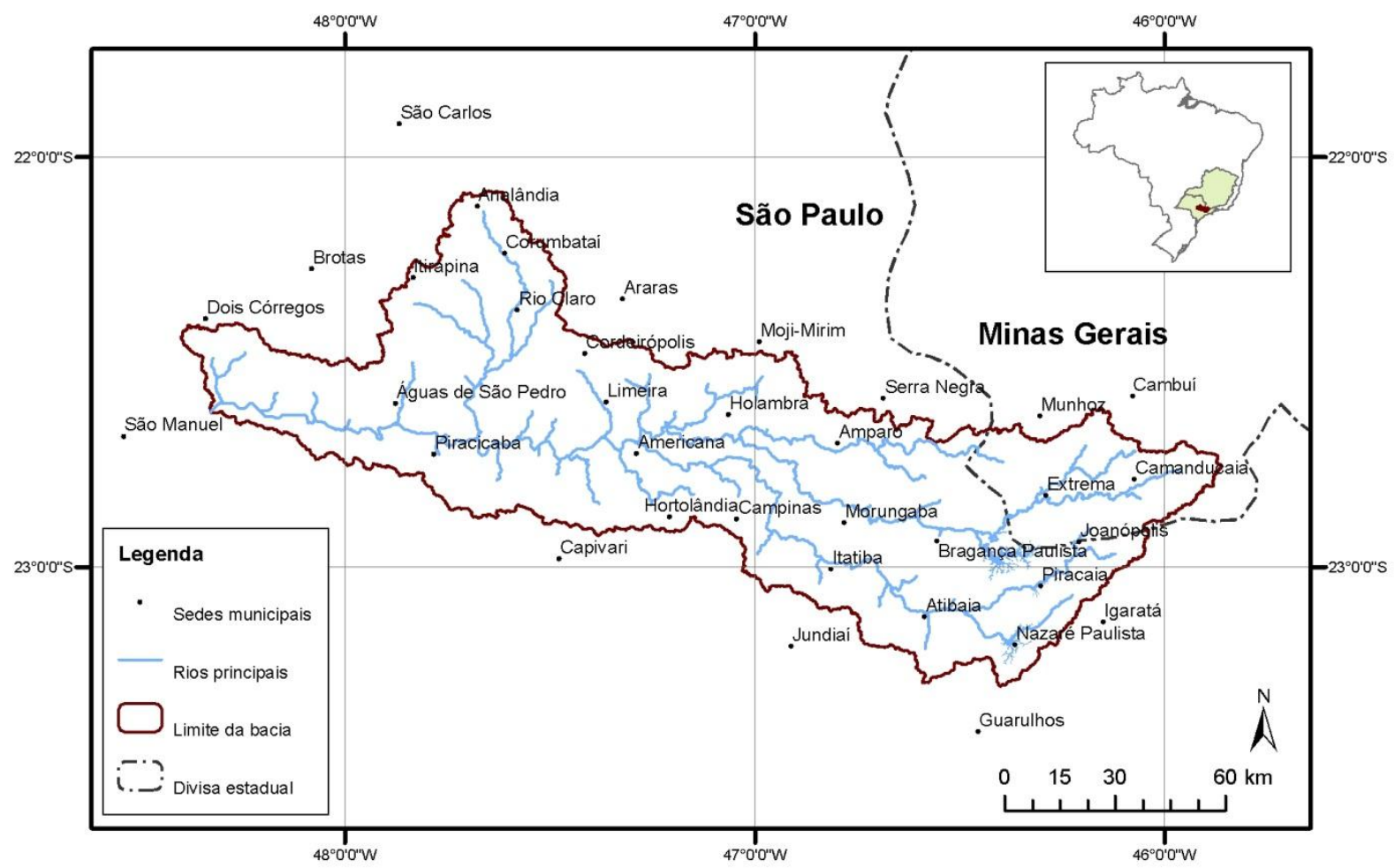

Figura 3. Localização da bacia hidrográfica do Rio Piracicaba (Fonte: Elaborado pelo autor).

No âmbito Federal, a bacia é gerenciada pelo Comitê PCJ Federal (Comitê dos Rios Piracicaba, Capivari e Jundiaí Federal). Na esfera estadual há dois órgãos distintos, correspondentes a cada um dos estados inseridos na bacia. Em São Paulo, a responsabilidade é da Unidade de Gerenciamento dos Recursos Hídricos no5 (UGRHI-5). No trecho mineiro, tem-se a Unidade de Planejamento e Gestão de Recursos Hídricos da Bacia Hidrográfica dos Rios Piracicaba e Jaguari - UPGRH - PJ1 (SMA/CRH, 2009).

A escolha desta bacia para o estudo se deu, entre outros fatores, devido ao seu tamanho, pois optou-se por uma abordagem de macro escala para se quantificar os reflexos e impactos da escassez hídrica. Outro fator importante é que no local concentram-se aproximadamente quatro milhões de pessoas, cerca de $10 \%$ da população total do Estado de São Paulo.

Trata-se, ainda, de uma importante bacia sob o aspecto urbano, agrícola e industrial. Somado a isto, tem-se o fato de nesta bacia estar inserido o Sistema Cantareira, conjunto de represas responsável pelo abastecimento de parte da Região Metropolitana de São Paulo, através da transposição de $31 \mathrm{~m}^{3} \cdot \mathrm{s}^{-1}$ de água para a bacia do Alto Tietê. 


\subsection{METODOLOGIA}

Como ponto de partida para a realização deste trabalho, fizeram-se necessários o levantamento e o processamento dos dados relevantes para aplicação das metodologias selecionadas. Os dados levantados foram topografia, hidrografia, pedologia, uso da terra, dados hidrometeorológicos e dados de monitoramento do Sistema Cantareira. A etapa de discretização da bacia, para fins de modelagem hidrológica, também é descrita em seguida.

Nos itens a seguir tem-se a especificação dos tipos de dados utilizados e das metodologias através das quais os mesmos foram obtidos.

\subsubsection{Topografia}

Uma das bases para a simulação do comportamento hidrológico na bacia é a informação extraída de um Modelo Digital de Elevação (MDE). Assim, foi utilizada a base de dados Shuttle Radar Topography Mission - SRTM (JARVIS et al., 2008), com resolução espacial de 90 metros. Entretanto, estas imagens contêm erros e imperfeições caracterizadas por depressões espúrias, picos anômalos e áreas com ausência de dados. A correção dos defeitos das imagens SRTM se deu dentro do software ArcGIS, através da utilização do conjunto de ferramentas do modelo ArcHydro Tools (MAIDMENT, 2002), desenvolvido pelo Centro de Pesquisas em Recursos Hídricos, da Universidade do Texas.

Durante o processamento e modelagem hidrológica, devem-se utilizar dados no formato raster. Somado a isso, os dados devem estar posicionados conforme o mesmo sistema de coordenadas e com a mesma resolução espacial. Por isso, optou-se pela definição do MDE como arquivo base para a geração dos demais arquivos. Assim, todos os demais arquivos foram reamostrados para um pixel com 90 metros de lado.

\subsubsection{Hidrografia}

A hidrografia da bacia do Rio Piracicaba foi derivada do processamento do MDE, também através de ferramentas do ArcHydro Tools. Utilizou-se como critério a definição de um limiar, a partir de área de drenagem acumulada a ser considerada, para delimitar os canais. Buscou-se, através desta etapa, a melhor representação dos principais cursos d'água 
da bacia. Esta rede de drenagem será considerada pelo modelo hidrológico no cálculo e determinação da propagação do escoamento nas células da bacia.

\subsubsection{Pedologia}

No que diz respeito à pedologia da bacia, foram utilizadas duas fontes de dados de classificação de solos diferentes para os estados de São Paulo e Minas Gerais, respectivamente. Para o primeiro estado, utilizaram-se dados do mapeamento realizado pelo Instituto Agronômico de Campinas - IAC (OLIVEIRA et al., 1999), escala 1:500.000. Para o estado de Minas Gerais, utilizou-se a base de dados do Sistema Compartilhado de Informações Ambientais (SISCOM/IBAMA), gerado pelo Projeto RADAM-BRASIL, escala 1:1.000.000.

Para fins de modelagem hidrológica, foi necessário o agrupamento dos tipos de solo segundo critérios propostos por Sartori, Neto e Genovez (2005) e Caram (2010), conforme Tabela 1. Tais critérios contemplam principalmente a profundidade até a rocha matriz, a capacidade de infiltração e o potencial de geração de escoamento superficial.

Tabela 1. Agrupamento dos tipos de solos na bacia hidrográfica do Rio Piracicaba segundo características físicas e hidrológicas.

\begin{tabular}{ccl}
\hline Grupo & Tipos de solos & \multicolumn{1}{c}{ Descrição } \\
\hline 1 & Latossolo e Nitossolo & $\begin{array}{l}\text { Solos profundos, com elevada capacidade de infiltração } \\
\text { e baixo potencial de geração de escoamento. }\end{array}$ \\
2 & Argissolo & $\begin{array}{l}\text { Solos profundos, com moderada capacidade de } \\
\text { infiltração e baixo potencial de geração de escoamento. }\end{array}$ \\
3 & Cambissolo e Neossolo & $\begin{array}{l}\text { Solos variando de profundos a pouco profundos, com } \\
\text { moderada capacidade de infiltração e moderado } \\
\text { potencial de geração de escoamento. }\end{array}$ \\
4 & Gleissolo & $\begin{array}{l}\text { Solos rasos, com baixa capacidade de infiltração e } \\
\text { elevado potencial de geração de escoamento. }\end{array}$
\end{tabular}

Fonte: Elaborado pelo autor, segundo critérios de Sartori, Neto e Genovez (2005) e Caram (2010). 


\subsubsection{Uso da terra}

O mapeamento do uso da terra tem significativa importância para a modelagem hidrológica em bacias hidrográficas, haja visto que está relacionado com diversos processos do ciclo hidrológico, entre elas infiltração e evapotranspiração (DUNN; MACKAY, 1995; ZHANG et al., 2001).

Neste trabalho foram utilizados mapas de uso da terra de dois períodos distintos. 0 primeiro, referente ao ano de 1985, foi elaborado pelo Projeto PiraCena (CENA/USP). Já o segundo período, referente a 2010 , foi produzido no decorrer desta pesquisa, segundo classificação de imagens do satélite Landsat-5, do mesmo período, com resolução especial de 30 metros. As imagens do satélite Landsat-5 foram obtidas junto á Divisão de Geração de Imagens do Instituto Nacional de Pesquisas Espaciais (DGI/INPE).

Para gerar o mapa de uso da terra de 2010 foi aplicada a técnica de classificação supervisionada (CRÓSTA, 1992; ITC-ILWIS, 2001; RICHARDS; JIA, 2006), através do método da máxima verossimilhança, no software ILWIS 3.4. Além das bandas do satélite, a classificação utilizou a análise dos componentes principais do conjunto de bandas e o NDVI (índice de vegetação). Para isto, foram coletadas amostras para cada tipo de uso a ser classificado, para que se pudesse representar sua assinatura digital. Nesta etapa foram considerados critérios como tom, textura, padrão e forma, além do comportamento espectral dos alvos (FLORENZANO, 2002).

Assim, procedeu-se à classificação e interpretação dos seguintes tipos de uso da terra:

- Agropecuária: áreas destinadas para fins agropecuários em geral, com ausência de grandes áreas construídas e sem pavimentação. Esta categoria também abrange pastagens naturais/cultivadas e áreas de solo exposto.

- Água: locais com significativa superfície coberta por água, sejam rios, lagos naturais e/ou represas construídas pelo homem.

- Área urbana: áreas para fins urbanos, composta por casas, prédios, ruas, estradas, indústrias e áreas edificadas em geral. 
- Vegetação: área coberta por formações florestais nativas, em diferentes estágios de sucessão, bem como áreas utilizadas para fins silviculturais, tais como plantios de eucalipto e pinus.

A divisão nas classes acima se deu com base em orientações de Fan et al. (2010), que sugerem a adoção de um número reduzido de classes de uso da terra. Isto se deve ao fato de que, segundo os autores, uma subdivisão excessiva de classes não garante melhores resultados para a modelagem hidrológica, além de aumentarem o gasto computacional. Assim, por questões de compatibilidade entre os mapas de uso da terra, foi feita a reclassificação do mapa de 1985, com base nas classes definidas para a elaboração do mapa de 2010.

\subsubsection{Dados hidrometeorológicos observados}

Este item trata dos dados obtidos através de estações de monitoramento hidrológico e climático. A seguir são descritas as fontes dos dados utilizados referentes ao clima, pluviometria e fluviometria.

\subsubsection{Clima}

Os dados climatológicos utilizados foram obtidos em escala diária, conforme monitoramento realizado pelo Instituto Nacional de Meteorologia - INMET, inserido na base de dados do Sistema de Informações Hidrológicas HidroWeb, da Agência Nacional de Águas ANA. Trata-se de uma base de dados pública, com dados de todo o Brasil, disponíveis para acesso de pesquisadores e demais usuários no país.

Os registros necessários para entrada no modelo hidrológico foram os de temperatura, umidade relativa, velocidade do vento, pressão atmosférica e insolação. Apesar do grande número de estações selecionadas nas proximidades da bacia, totalizando 23 unidades, nem todas possuem um registro constante de dados diários. Com isto, para os dias em que não havia registros referentes para aquele período, foram utilizados dados de médias mensais, calculados pelo modelo hidrológico MGB-IPH. 


\subsubsection{Pluviometria}

Com relação à pluviometria, foram selecionados 106 postos, com disponibilidade variada de dados diários de chuva em diferentes pontos da bacia. Assim como os dados de clima, os dados pluviométricos foram obtidos do banco de dados HidroWeb/ANA. Após a localização geográfica dos postos na bacia, o modelo realiza a interpolação dos dados de chuva de cada posto para assim fornecer a chuva diária espacializada em cada minibacia estudada.

\subsubsection{Fluviometria}

Para os dados de vazão diária observados na bacia, foram consultadas as bases de dados do HidroWeb/ANA e do Banco de Dados Fluviométricos do Estado de São Paulo, abastecido pelo Departamento de Águas e Energia Elétrica - DAEE.

Ao todo, foram pré-selecionados 25 postos fluviométricos. Foi necessária avaliação da disponibilidade temporal dos mesmos, para adequar a existência de dados aos períodos de calibração e validação do modelo. Também foi considerada a distribuição espacial dos postos na bacia, na busca por uma distribuição homogênea dos mesmos em relação à área total. Assim, foram selecionados 10 postos, com relevante quantidade de dados para a realização das etapas de ajuste e validação do modelo.

\subsubsection{Dados do Sistema Cantareira}

Devido à existência das represas do Sistema Cantareira na bacia, responsável pela transposição de $31 \mathrm{~m}^{3} . \mathrm{s}^{-1}$ para a bacia do Alto Tietê, a vazão nos rios nos pontos a jusante das mesmas é alterada. Com isso, tem-se o represamento de significativa parte do escoamento superficial a montante das barragens. As vazões liberadas pelo sistema são reguladas por regras de operação dos reservatórios, que variam durante o ano.

Segundo Whately e Cunha (2007), a bacia do Rio Piracicaba abriga três dos quatro reservatórios que compõem o sistema de transposição de águas da bacia, sendo eles: 
- Reservatório Jaguari-Jacareí: Em operação desde maio de 1982, é composto por duas barragens interligadas nos rios Jaguari e Jacareí, formando um único reservatório. Os municípios que contêm as águas deste reservatório são Vargem, Bragança Paulista, Joanópolis e Piracaia.

- Reservatório Cachoeira: Entrou em operação em novembro de 1974, como parte das obras da primeira etapa do Sistema Cantareira, e está localizado no município de Piracaia, em posição intermediária entre os reservatórios Jaguari-Jacareí e Atibainha.

- Reservatório Atibainha: Em operação a partir de fevereiro de 1975, está inserido no município de Nazaré Paulista. Além das contribuições naturais do Rio Atibainha, recebe as águas provenientes dos rios Jaguari, Jacareí e Cachoeira.

O conhecimento das vazões nos trechos a jusante dos reservatórios se faz importante, uma vez que a vazão liberada não corresponde à vazão natural naquele trecho. Se não contabilizada, esta variação das vazões tem influência nos hidrogramas dos postos a jusante das represas e, consequentemente, reflete na propagação do erro e das incertezas na modelagem. Assim, foram utilizados os valores das vazões monitoradas em dois postos localizados a jusante das represas, com o intuito de substituir as vazões calculadas pelo modelo nas minibacias correspondentes à área de contribuição destes postos.

\subsubsection{Discretização da bacia}

A partir das informações fornecidas pelo MDE, pôde-se realizar a determinação das áreas de drenagem acumuladas, a extração dos comprimentos e declividades dos trechos dos rios, a geração das direções de fluxo das células e a geração da rede de drenagem. Além disso, foi realizada a delimitação bacia, das sub-bacias e das minibacias.

Todas estas etapas foram realizadas através do software ArcGIS, mediante a utilização do conjunto de ferramentas do modelo ArcHydro Tools, desenvolvido pelo Centro de Pesquisas em Recursos Hídricos, da Universidade do Texas. 


\subsection{RESULTADOS E DISCUSSÃO}

Ao final da coleta e processamento dos dados inerentes à bacia, foram produzidos mapas temáticos sobre cada um dos tópicos acima mencionados. Os resultados obtidos para cada tema de dados são exibidos nos itens a seguir.

\subsubsection{Topografia}

A análise da topografia permitiu concluir que, na bacia, as altitudes variam entre 443 e 2030 metros, após a correção das imperfeições e falhas. A Figura 4 representa a classificação da imagem SRTM da área, conforme os valores de altitude.

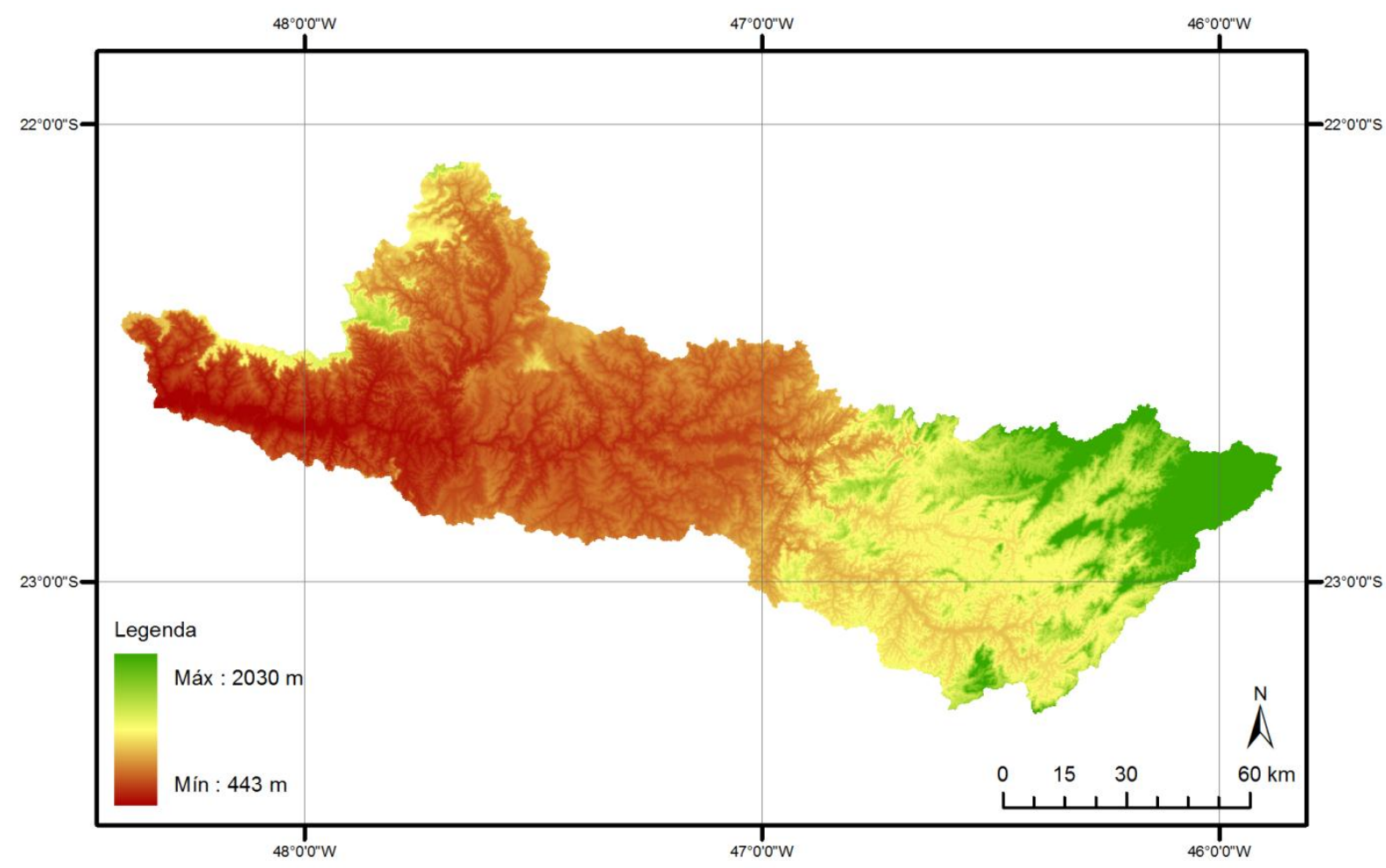

Figura 4. Topografia da bacia hidrográfica do Rio Piracicaba (Fonte: Elaborado a partir de JARVIS et al., 2008).

\subsubsection{Hidrografia}

A rede hidrográfica, gerada a partir da simulação das direções do escoamento através do $M D E$, representa os principais cursos d'água na bacia. Ao todo, foram gerados 97 
segmentos, sendo que cada um corresponde a um trecho de rio. A Figura 5 ilustra esta informação.

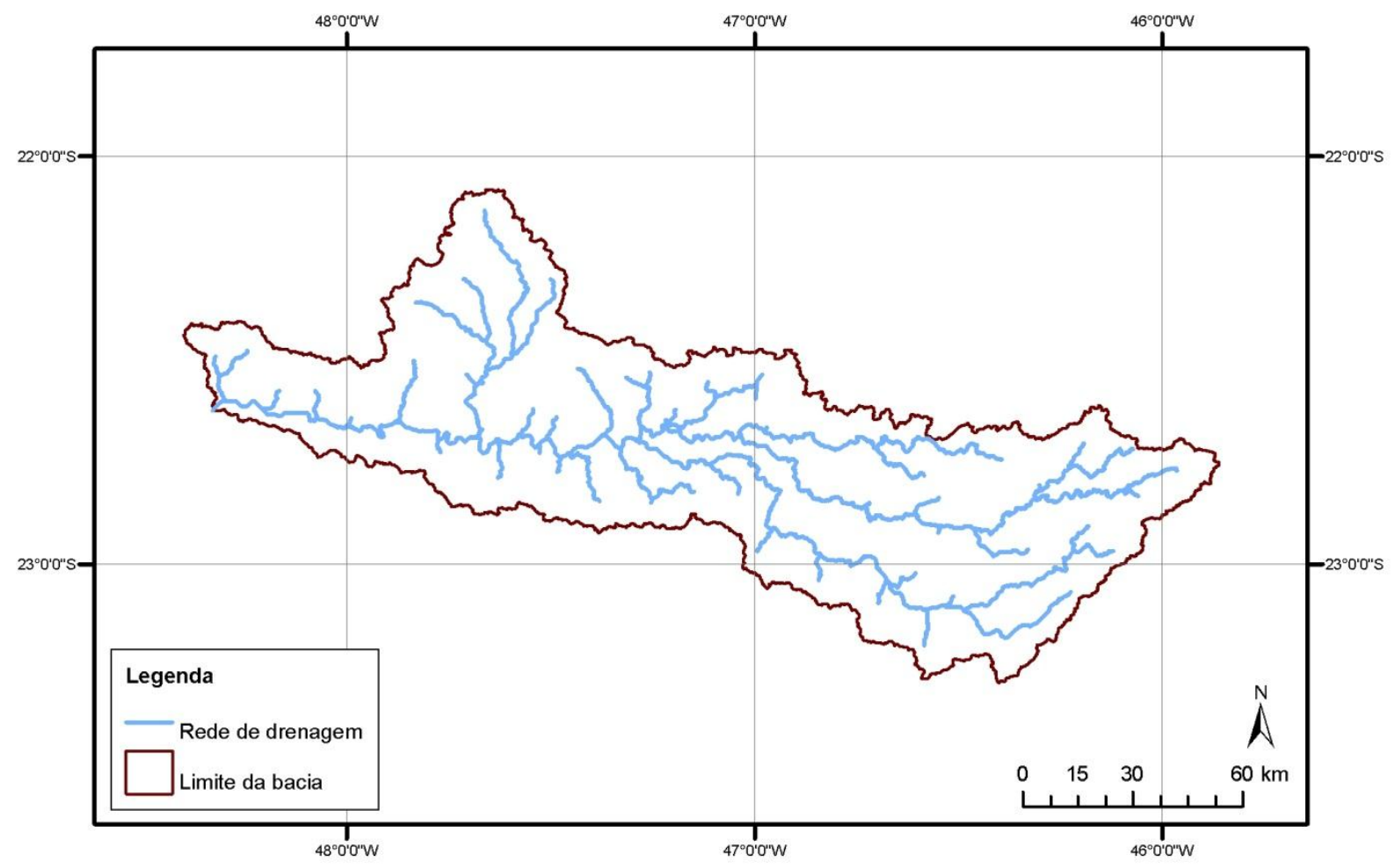

Figura 5. Rede de drenagem da bacia hidrográfica do Rio Piracicaba obtida a partir do MDE (Fonte: Elaborado pelo autor).

Entretanto, esta situação não tem o objetivo de representar a totalidade dos cursos d'água na bacia, conforme anteriormente mencionado. Isto porque, para fins de modelagem, fez-se necessária a simplificação da drenagem na bacia, com o objetivo de reduzir a complexidade e viabilizar o cálculo do escoamento em cada trecho de rio.

\subsubsection{Pedologia}

A reclassificação e agrupamento dos tipos de solos na bacia, segundo seu comportamento hidrológico, resultaram em quatro principais grupos, além das áreas cobertas por água (cursos d'água e represas). Assim, a distribuição dos grupos se deu conforme Tabela 2. Na Figura 6, tem-se o gráfico com o percentual de cada grupo na bacia, conforme seu comportamento hidrológico. 
Tabela 2. Grupos de solos segundo características físicas e hidrológicas.

\begin{tabular}{cccc}
\hline Grupo & Tipos de solos & Área $\left(\mathbf{k m}^{2}\right)$ & $\%$ \\
\hline 1 & Latossolo e Nitossolo & $4.906,48$ & 38,97 \\
2 & Argissolo & $6.603,05$ & 52,45 \\
3 & Cambissolo e Neossolo & 716,07 & 5,69 \\
4 & Gleissolo & 209,47 & 1,66 \\
- & Água & 154,52 & 1,23 \\
\hline & & $12.589,59$ & 100,00
\end{tabular}

Fonte: Elaborado pelo autor.

\section{Principais tipos de solos segundo sua classificação hidrológica}
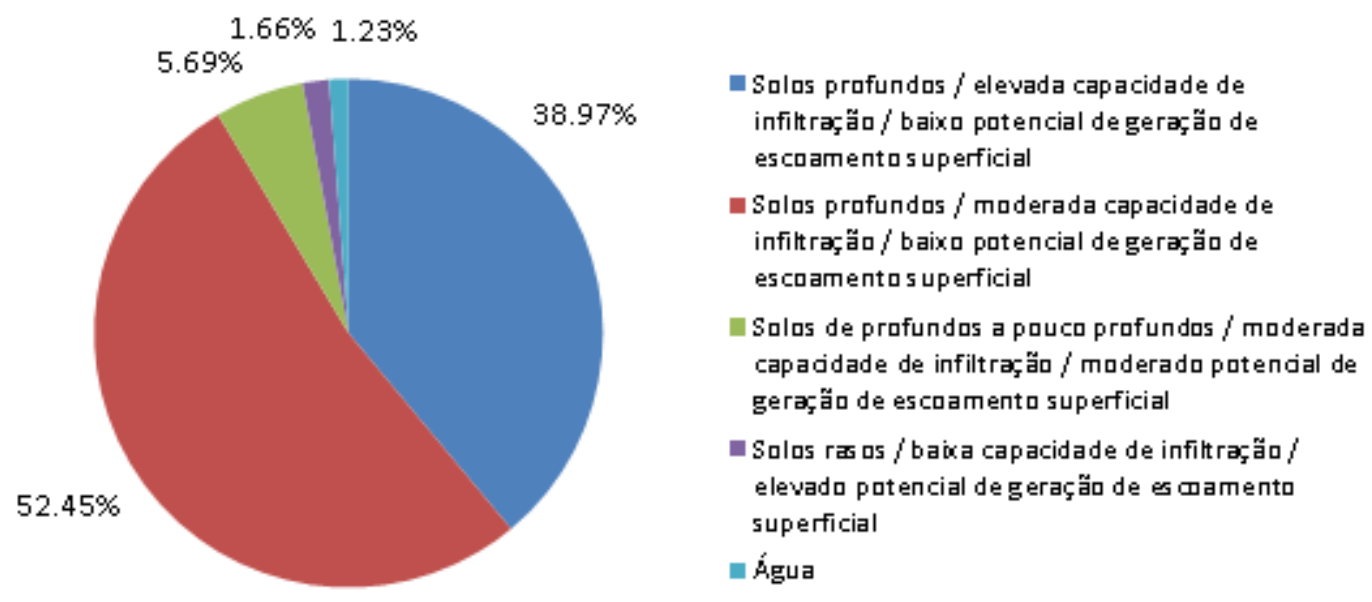

Figura 6. Porcentagem de ocorrência dos principais tipos de solos na bacia do Rio Piracicaba, segundo seu comportamento hidrológico (Fonte: Elaborado pelo autor).

A análise da tabela e figura anteriores permite concluir que em aproximadamente 90\% do território da bacia ocorrem solos profundos e que possuem baixo potencial de geração de escoamento superficial.

Na Figura 7, tem-se a espacialização dessa classificação dos solos da bacia, o que permite observar que nas áreas de cabeceira, predominam solos que geram pouco escoamento superficial. Apenas nos trechos intermediários e de jusante da bacia, pôde-se notar a ocorrência de solos com maior potencial de geração de escoamento superficial, como gleissolos (elevado potencial) e cambissolos e neossolos (moderado potencial). 


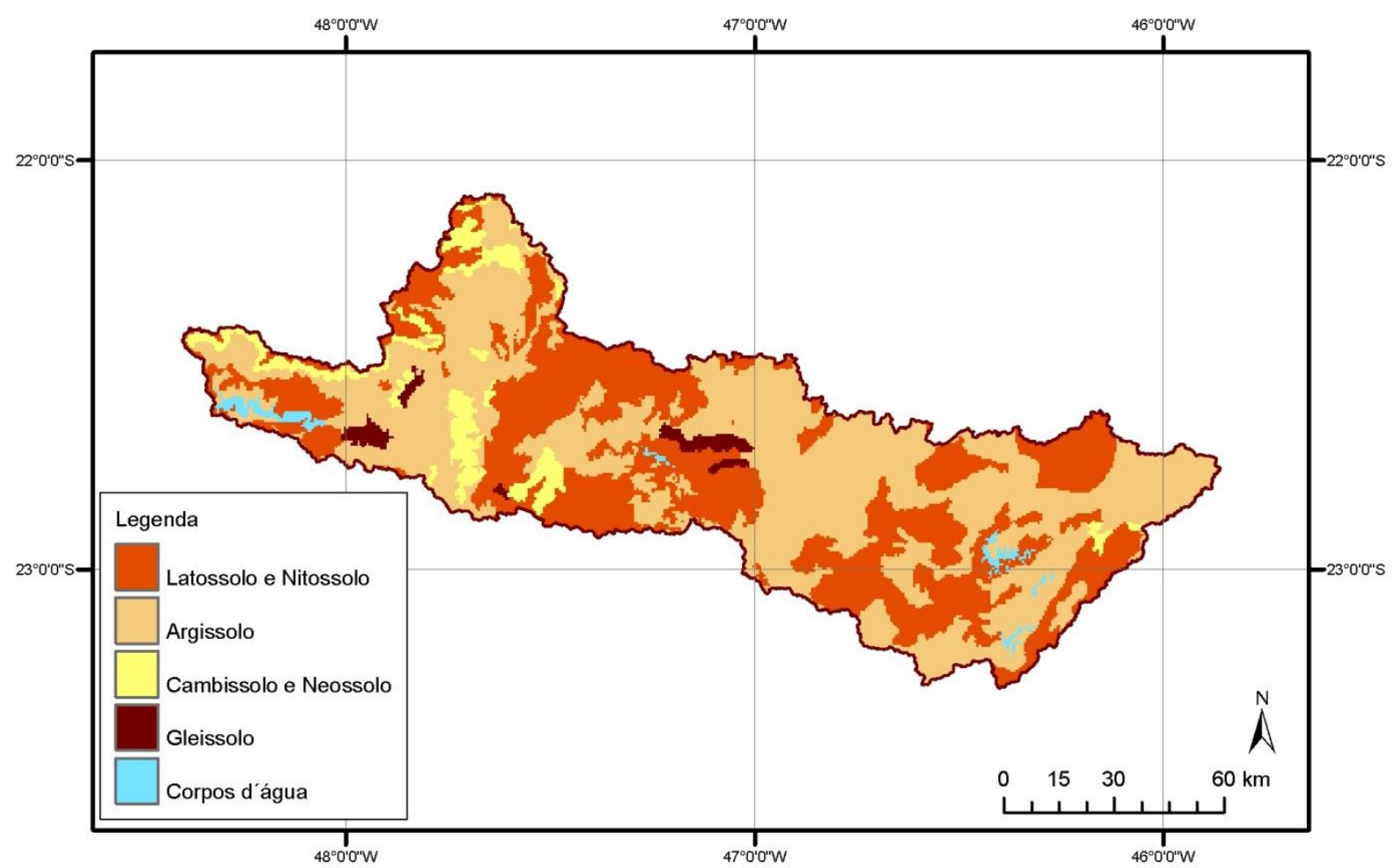

Figura 7. Pedologia da bacia hidrográfica do Rio Piracicaba (Fonte: Elaborado pelo autor a partir do Projeto RADAM-BRASIL e OLIVEIRA et al., 1999).

\subsubsection{Uso da terra}

Após a reclassificação do mapa de uso da terra do período de 1985 (Figura 8), para que houvesse compatibilidade entre as classes utilizadas para o ano de 2010 (Figura 9), foram calculadas as porcentagens que cada tipo de uso identificado ocupa na bacia. A Tabela 3 demonstra o quadro de áreas para os tipos de uso da terra definidos, para os dois períodos estudados.

Tabela 3. Distribuição das classes de uso da terra na bacia hidrográfica do Rio Piracicaba, períodos 1985 e 2010.

\begin{tabular}{lcc}
\hline Uso da terra & Área em 1985 (\%) & Área em 2010 (\%) \\
\hline Agropecuária & 89,30 & 75,00 \\
Água & 1,64 & 1,75 \\
Área urbana & 2,64 & 6,86 \\
Vegetação & 6,42 & 16,39 \\
\hline
\end{tabular}

Fonte: Elaborado pelo autor. 


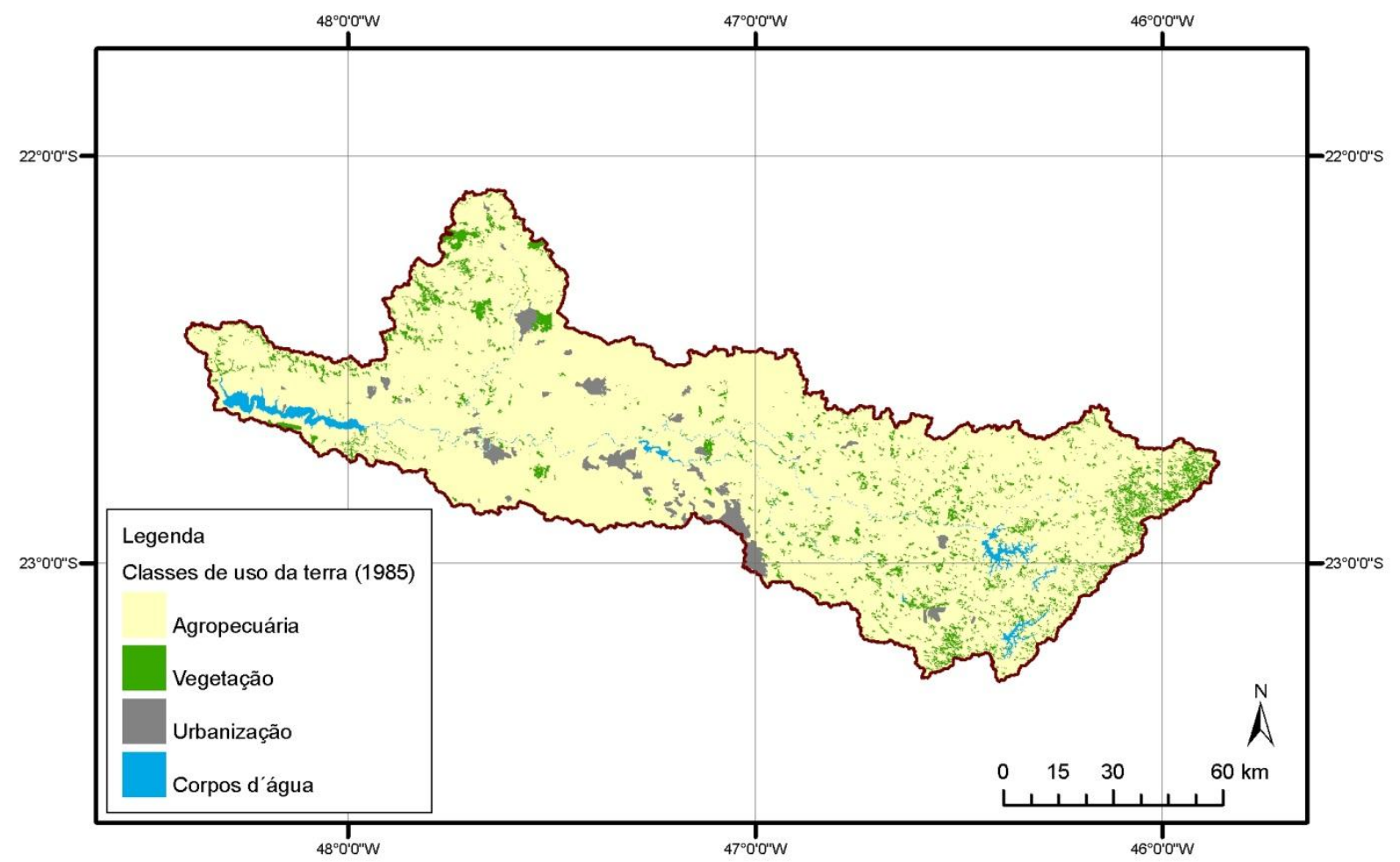

Figura 8. Uso da terra na bacia hidrográfica do Rio Piracicaba para o ano de 1985 (Fonte: Projeto PiraCena/USP).

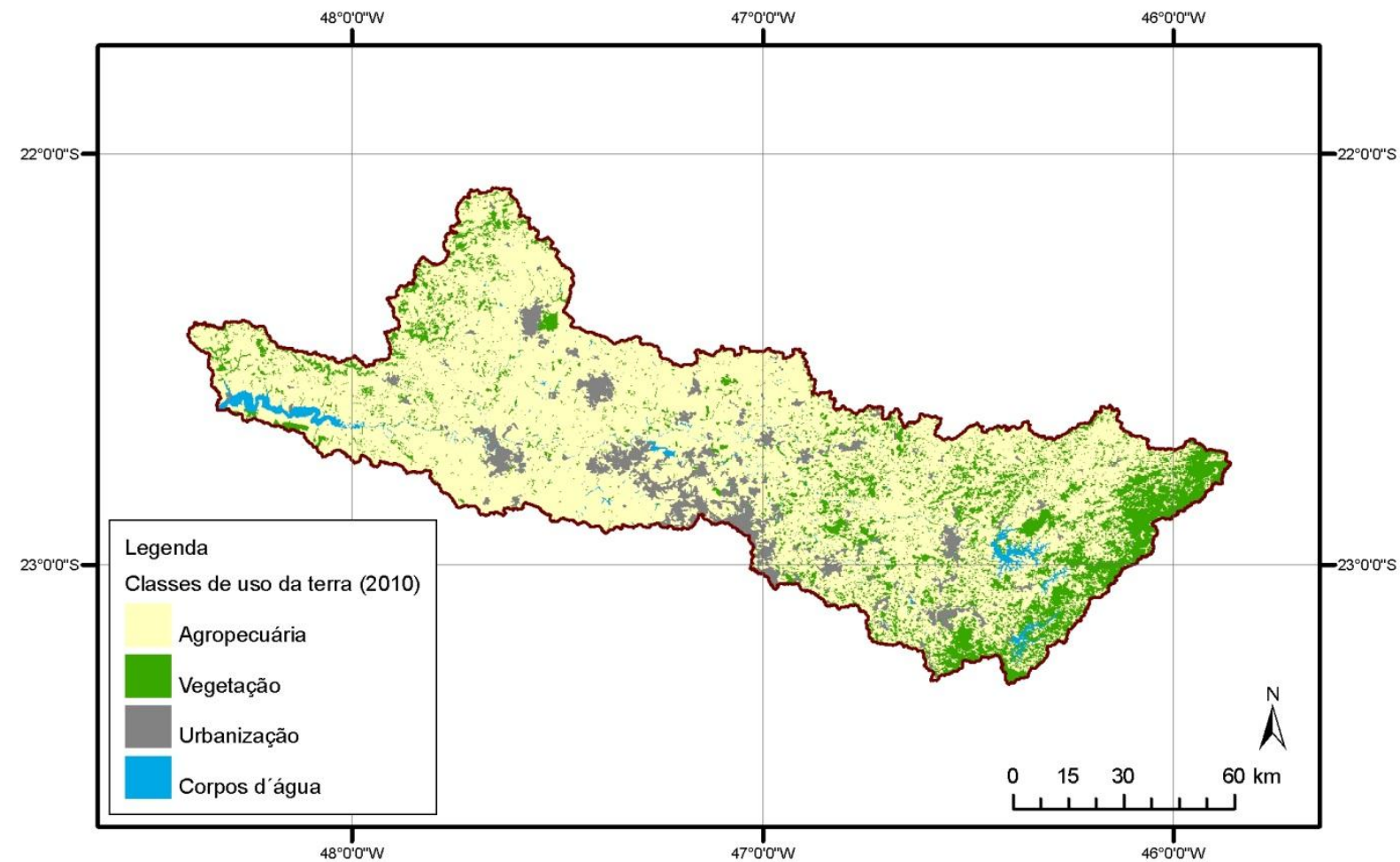

Figura 9. Uso da terra na bacia hidrográfica do Rio Piracicaba para o ano de 2010 (Fonte: Elaborado pelo autor). 
As principais alterações observadas de um período a outro foram com relação às áreas urbanas e também das áreas cobertas por vegetação. $O$ aumento de áreas urbanas já era esperado, devido ao crescente processo de industrialização e urbanização estabelecido na bacia neste período, principalmente na Região Metropolitana de Campinas - RMC (GALLO, 2001; RIBEIRO; GALLERANI, 2004).

Observou-se um aumento de aproximadamente $160 \%$ na área de mancha urbana na bacia entre o período dos anos 1985 e 2010. As áreas onde houve maior expansão foram municípios integrantes da RMC, como Americana, Campinas e Paulínia, além de municípios bem desenvolvidos do interior do estado de São Paulo, como Atibaia, Limeira, Piracicaba e Rio Claro.

Nas áreas cobertas por vegetação também foi observado um significativo aumento, da ordem de $150 \%$. Essa classe de uso da terra compreende áreas cobertas por vegetação nativa, independentemente do estágio de sucessão em que se encontrem, e também áreas com silvicultura. Por conta disto, e também do aumento das áreas urbanizadas, as áreas utilizadas pela agropecuária na bacia foram reduzidas de $89,3 \%$ a 75\%. A Figura 10 exibe o cálculo da evolução de cada tipo de uso da terra, no período estudado.

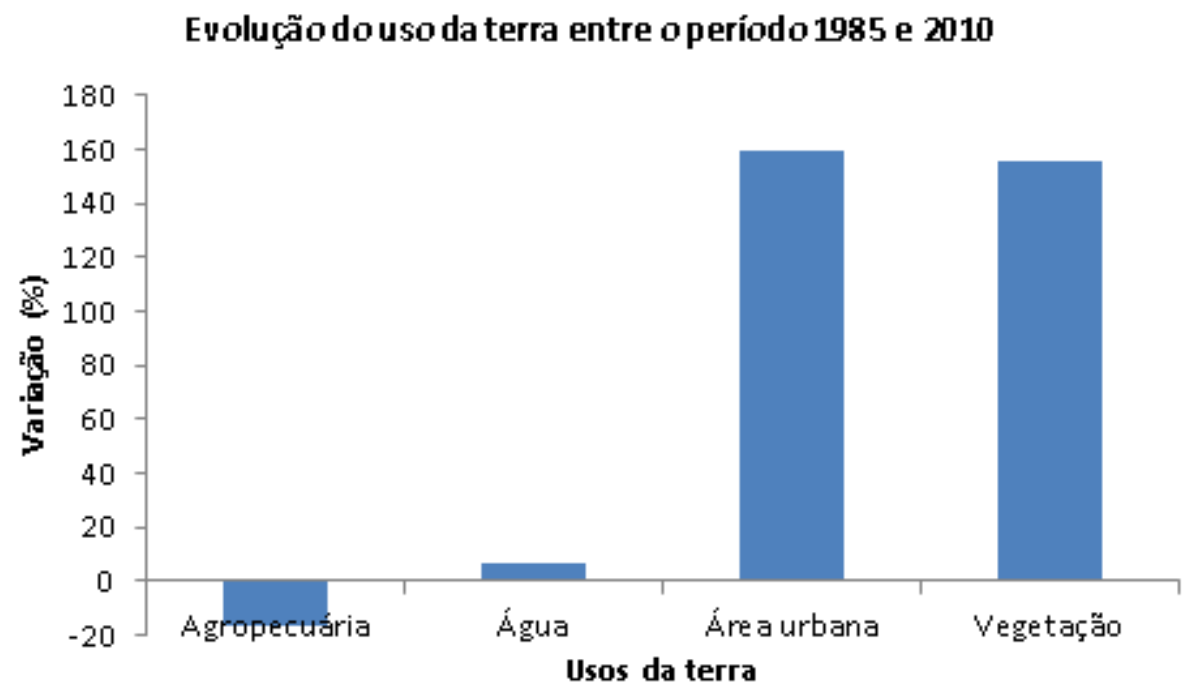

Figura 10. Evolução das áreas ocupadas por cada uso da terra na bacia hidrográfica do Rio Piracicaba, período 1985-2010 (Fonte: Elaborado pelo autor).

Merece destaque o aumento da cobertura vegetal na bacia. Entre as principais causas desse aumento, destacam-se os critérios de classificação do mapa de uso das terras entre um período e outro, o que pode provocar a variação temporal desta classe. Além 
disso, a redução das taxas de desmatamento e a regeneração natural em áreas abandonadas podem contribuir para o aumento deste valor entre um período e otro.

\subsubsection{Dados hidrometeorológicos observados}

As 23 estações meteorológicas selecionadas são ilustradas pela Figura 11. No Apêndice $A$, tem-se a listagem de todas as estações meteorológicas utilizadas, bem como suas coordenadas geográficas.

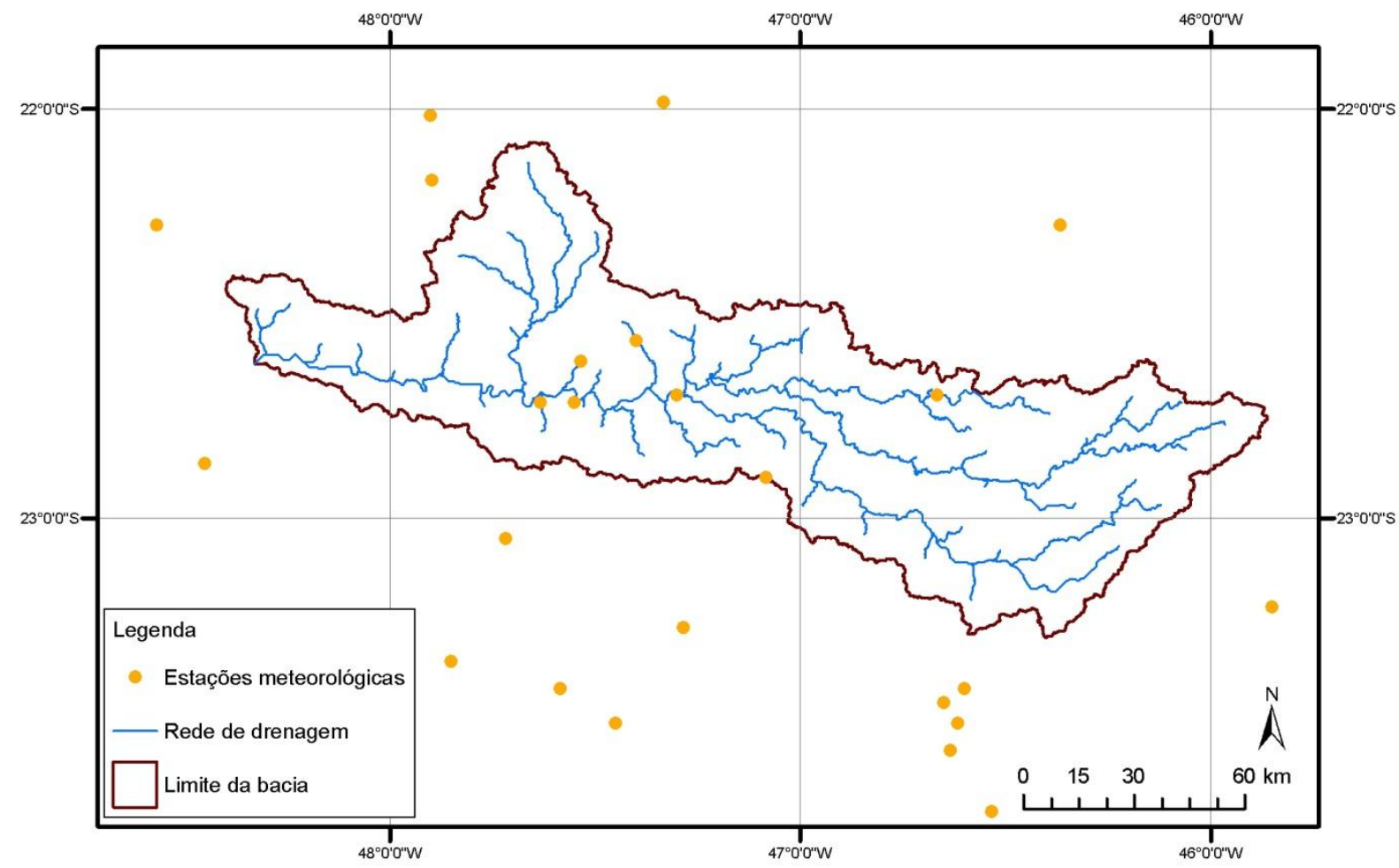

Figura 11. Localização geográfica dos postos com informações climatológicas na bacia hidrográfica do Rio Piracicaba (Fonte: HidroWeb/ANA).

Na Figura 12, tem-se a distribuição dos postos pluviométricos na bacia. A listagem dos mesmos também pode ser encontrada no Apêndice $A$ deste trabalho. 


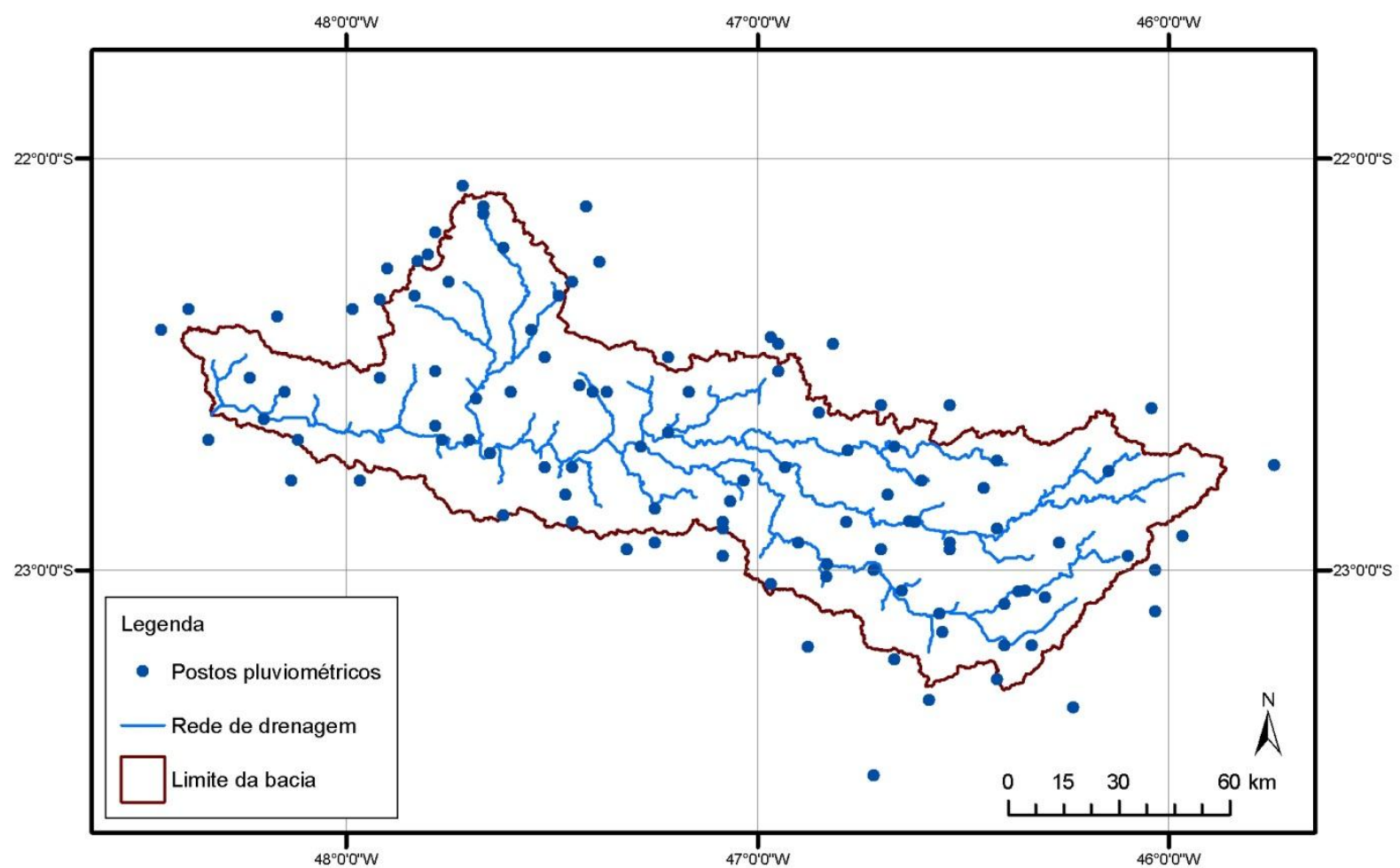

Figura 12. Localização geográfica dos postos pluviométricos selecionados na bacia hidrográfica do Rio Piracicaba (Fonte: HidroWeb/ANA).

Na Figura 13, tem-se a representação da localização dos postos fluviométricos escolhidos para análise, enquanto a Tabela 4 apresenta as características dos mesmos, como o nome do posto, o rio em que o mesmo está localizado e a área da bacia de drenagem correspondente ao ponto de monitoramento. 


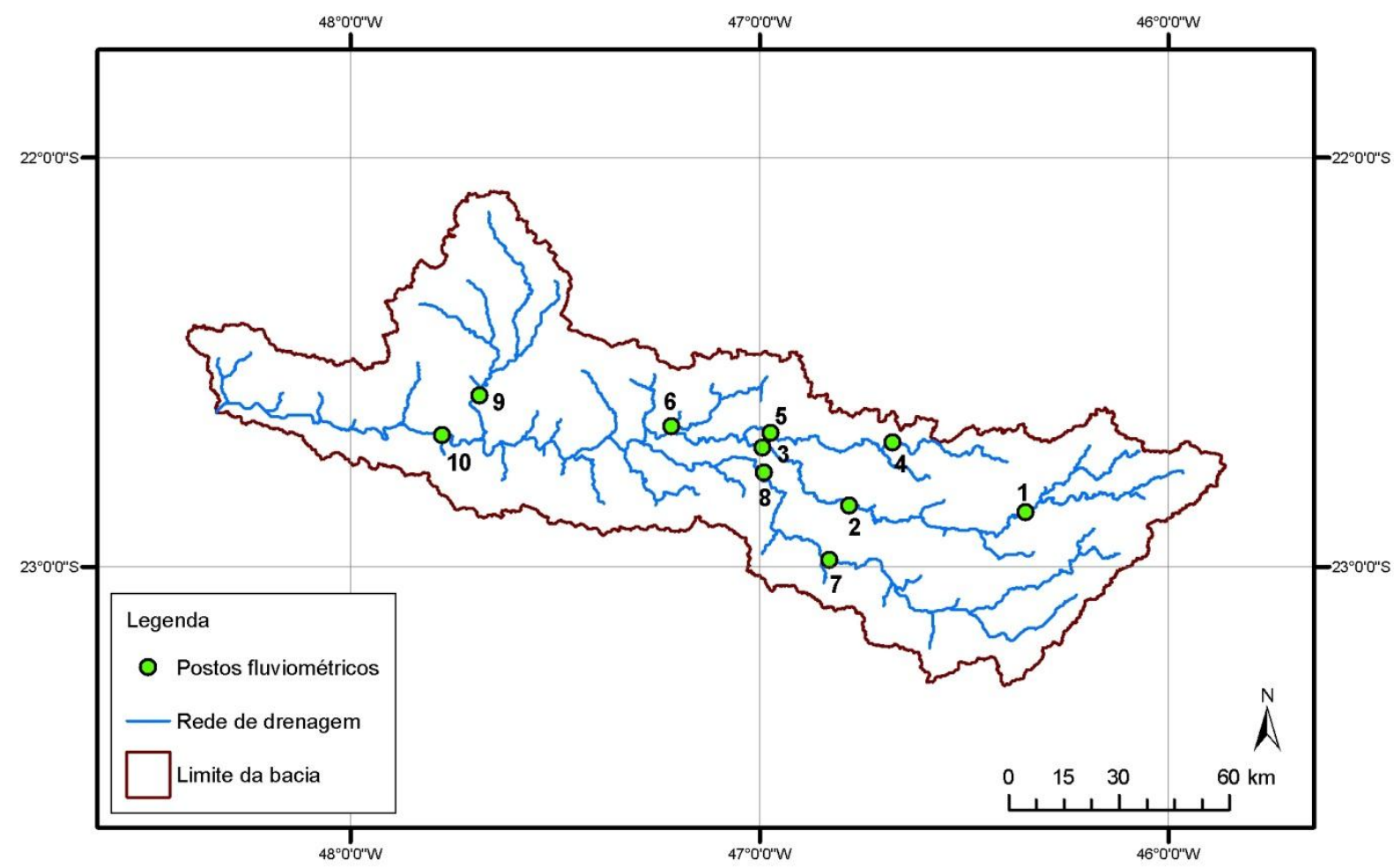

Figura 13. Localização geográfica dos postos fluviométricos na bacia (Fonte: HidroWeb/ANA).

Tabela 4. Características dos postos fluviométricos selecionados.

\begin{tabular}{ccccc}
\hline Número & Código & Nome do Posto & Rio & $\begin{array}{c}\text { Área HidroWeb } \\
\left(\mathbf{k m}^{\mathbf{2}} \mathbf{)}\right.\end{array}$ \\
\hline 1 & 62590000 & Rires & Rio Jaguari & 967 \\
2 & 62605000 & Buenópolis & Rio Jaguari & 1.950 \\
3 & 62615000 & Jaguariúna & Rio Jaguari & 2.180 \\
4 & 62622000 & Monte Alegre do Sul & Rio Camanducaia & 387 \\
5 & 62628000 & Fazenda Barra & Rio Camanducaia & 928 \\
6 & 62632000 & Usina Ester & Rio Jaguari & 3.394 \\
7 & 62676000 & Bairro da Ponte & Rio Atibaia & 1.920 \\
8 & 62680000 & Desembargador Furtado & Rio Atibaia & 2.490 \\
9 & 62709000 & Recreio & Rio Corumbataí & 1.581 \\
10 & 62715000 & Artemis & Rio Piracicaba & 11.040 \\
\hline
\end{tabular}

Fonte: HidroWeb/ANA. 


\subsubsection{Dados do Sistema Cantareira}

Os dados fluviométricos monitorados a jusante dos reservatórios do Sistema Cantareira contidos na bacia foram utilizados durante a etapa de modelagem hidrológica. Essa estratégia foi adotada na tentativa de minimizar o efeito das incertezas na operação do sistema nas vazões simuladas nos trechos de jusante da bacia.

Para o reservatório Jaguari-Jacareí, considerou-se o posto Guapirocaba (código 62597000) para substituir as vazões calculadas neste trecho. Já o posto Atibaia (código 62670000), localizado a jusante dos reservatórios Cachoeira e Atibainha, foi utilizado para substituir a vazão dos mesmos. Na Figura 14, tem-se a ilustração da localização dos reservatórios na bacia.

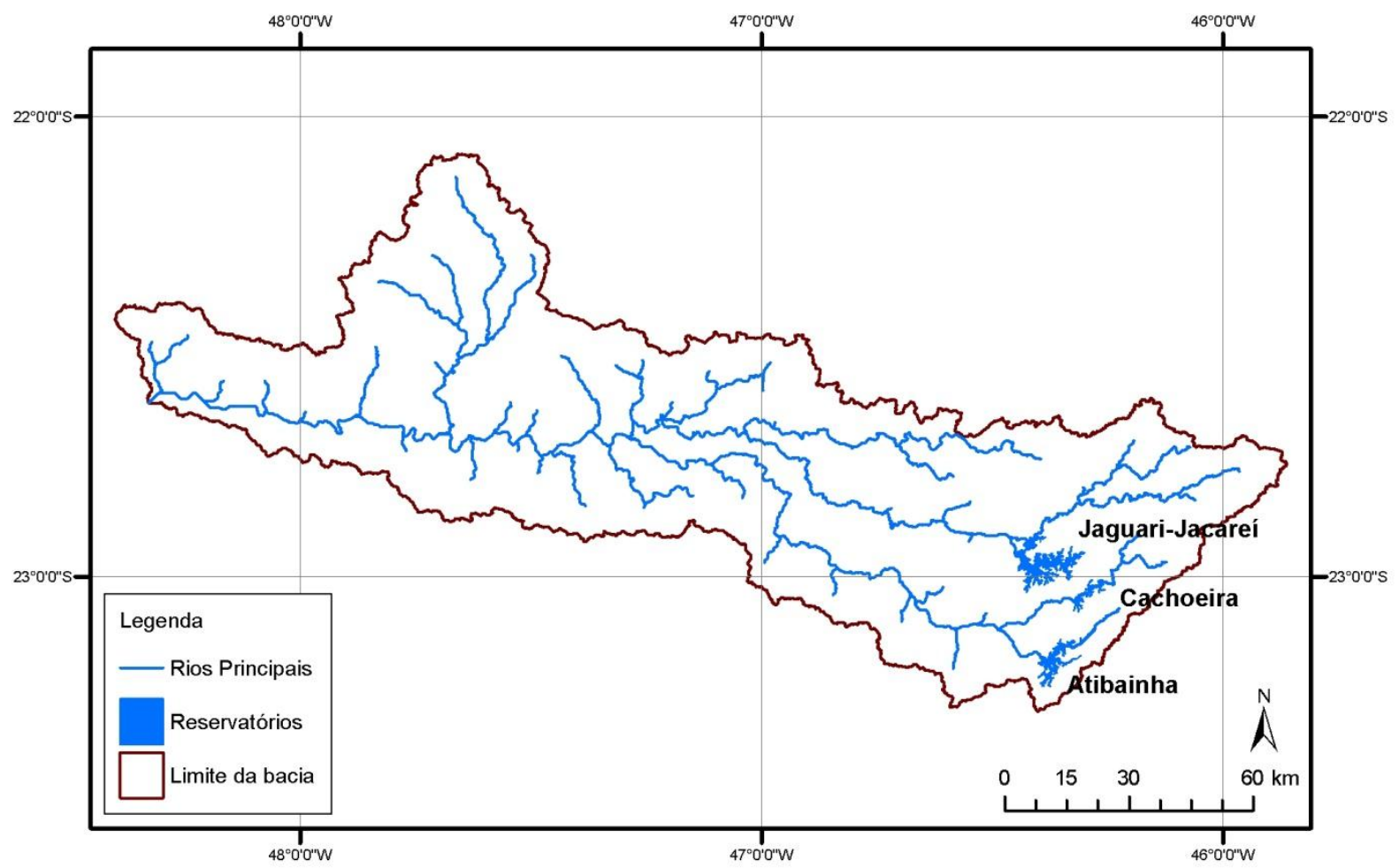

Figura 14. Reservatórios na bacia hidrográfica do Rio Piracicaba integrantes do Sistema Cantareira (Fonte: Elaborado pelo autor). 


\subsubsection{Discretização da bacia}

As sub-bacias foram definidas através da espacialização dos postos fluviométricos e outros pontos de interesse dentro da bacia, como os reservatórios do Sistema Cantareira. Com isso, obteve-se o total de 18 sub-bacias, conforme Figura 15.

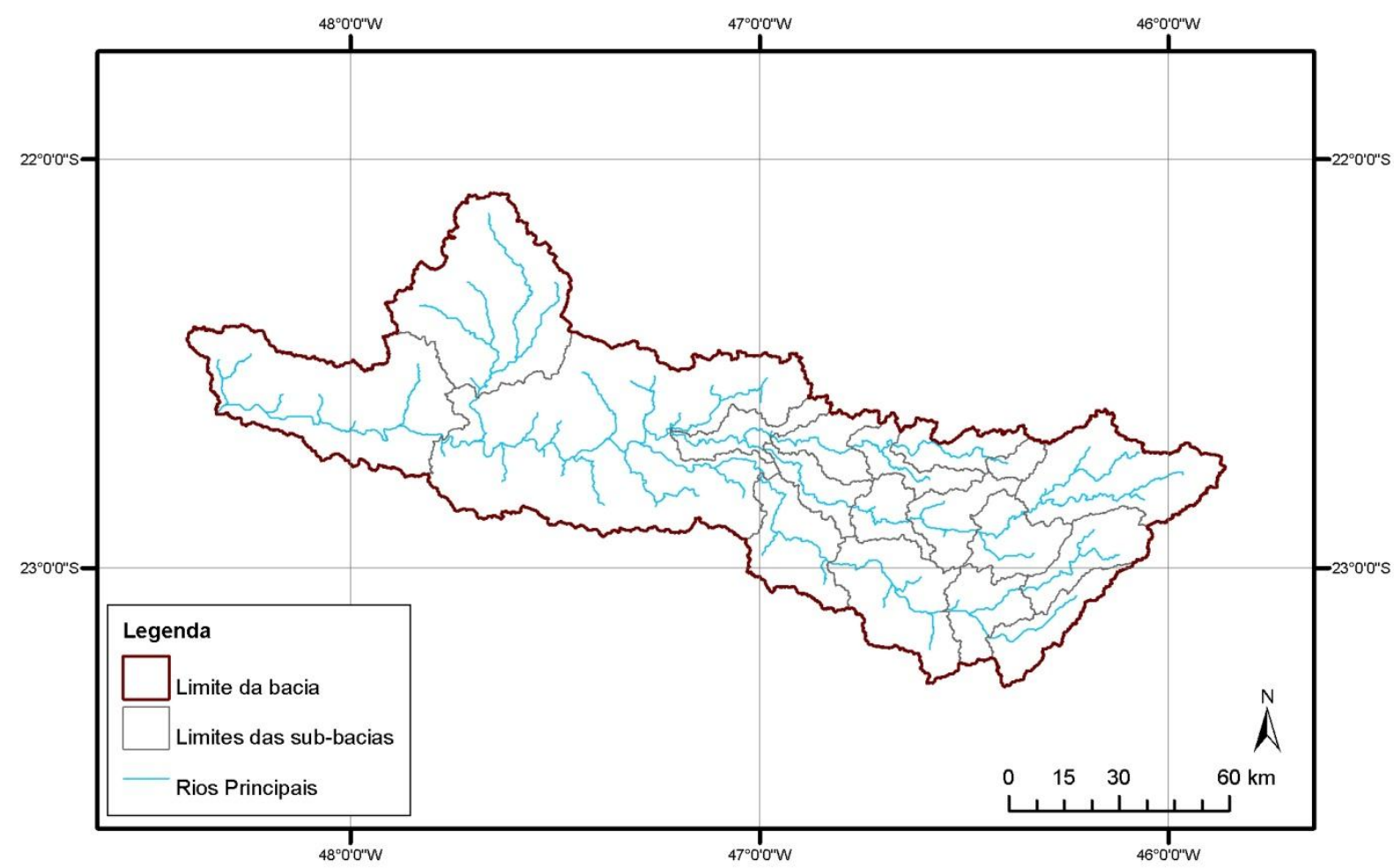

Figura 15. Sub-bacias para modelagem hidrológica, definidas a partir da localização de postos fluviométricos de interesse (Fonte: Elaborado pelo autor).

A discretização da bacia é a etapa onde ocorre a subdivisão da bacia em áreas menores, com o objetivo de melhorar a representação da heterogeneidade da mesma. Tais áreas são chamadas minibacias, obtidas a partir de cada trecho de rio extraído do MDE, considerando também as sub-bacias formadas pelos pontos de interesse na modelagem.

Assim, a bacia do Rio Piracicaba foi subdividida em 114 minibacias (Figura 16), de acordo com definição de um limiar de drenagem mínima. A área média das minibacias foi igual a $111,02 \mathrm{~km}^{2}$ por unidade. Dos valores de áreas obtidos, 25,44\% ficaram abaixo de $50 \mathrm{~km}^{2}, 54,39 \%$ entre $50 \mathrm{~km}^{2}$ e $150 \mathrm{~km}^{2}$, e $20,18 \%$ ficaram maiores que $150 \mathrm{~km}^{2}$. 


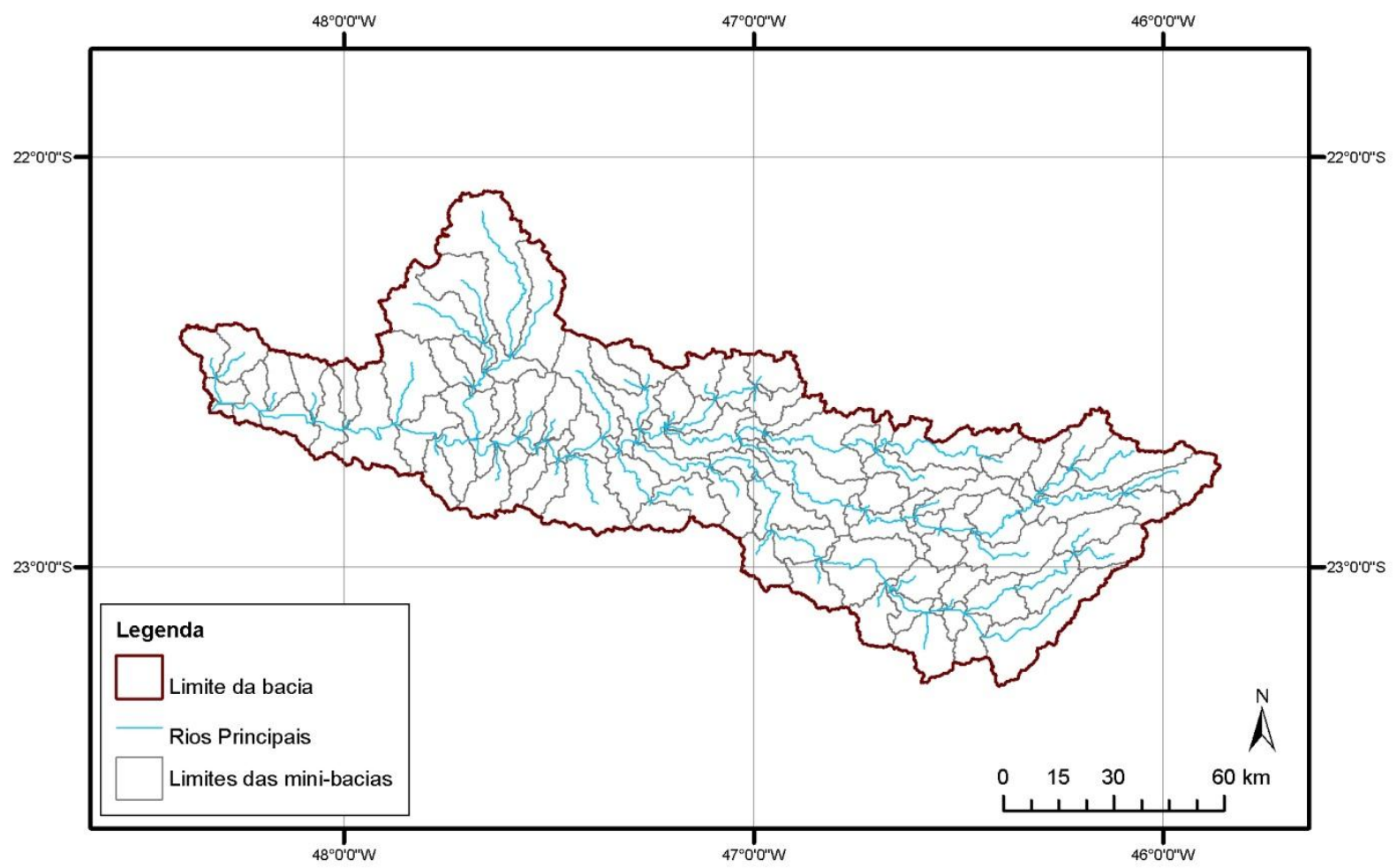

Figura 16. Minibacias resultantes da discretização da bacia hidrográfica do Rio Piracicaba com base no limiar de área de drenagem mínima (Fonte: Elaborado pelo autor).

\subsection{CONSIDERAÇÕES FINAIS}

Neste capítulo realizou-se a caracterização da bacia hidrográfica do Rio Piracicaba, além do tratamento e o processamento dos dados que foram utilizados em outras etapas.

Pôde-se concluir que a área necessita que o gerenciamento dos recursos hídricos se dê de maneira justa, organizada e otimizada. Um fato que aumenta a complexidade e a necessidade de abordagens inovadoras e eficientes no gerenciamento de recursos hídricos da bacia é a existência do Sistema Cantareira. Isso porque, além dos usuários da bacia, há mais cerca de oito milhões de pessoas interessadas nas águas da mesma, porém que vivem em outra região (bacia hidrográfica do Alto Tietê).

Além disso, outros fatores de mudança como a variabilidade climática no futuro, podem aumentar os riscos de escassez hídricas e/ou incapacidade de honrar as demandas por abastecimento de água. Somado a isto, tem-se que o aumento da urbanização, entre outras mudanças no uso da terra, interfere no balanço hídrico e na demanda por água na bacia. Nos capítulos seguintes serão abordados esses vetores, seus impactos no futuro e a resposta da bacia frente a situações de estresse hídrico. 


\section{CALIBRAÇÃO E VALIDAÇÃO DO MODELO HIDROLÓGICO MGB-IPH NA BACIA HIDROGRÁFICA DO RIO PIRACICABA}

\subsection{INTRODUÇÃO}

Tucci (2005, p. 19) define sistema como "qualquer engenho que responde, através de uma saída, a uma entrada", ao passo que um modelo é a "representação do comportamento de um sistema".

A simulação de um modelo divide-se em três fases. A primeira é a estimativa ou ajuste, onde ocorre a determinação dos parâmetros que serão considerados. Após esta, vem a etapa de verificação, onde é validado o ajuste realizado para cada um dos parâmetros estimados. Por fim, tem-se a previsão, onde o modelo simula o funcionamento do sistema em situações desconhecidas, produzindo resultados quantitativos de saídas para diferentes situações de entrada (TUCCI, 2005).

Modelagem hidrológica, foco deste capítulo, pode ser definida como a interpretação de fenômenos físicos do ciclo hidrológico terrestre, através da criação de instrumentos matemáticos para planejamento, gestão e controle dos recursos hídricos (BEVEN; O'CONNELL, 1982; FRANCHINI; PACCIANI, 1991; SINGH; WOOLHISER, 2002). A compreensão da dinâmica da bacia é uma etapa fundamental para a reprodução de fenômenos hidrológicos (WAGENER; MONTANARI, 2011).

A heterogeneidade de bacias hidrográficas ao redor do globo necessita de definição dos parâmetros para que o modelo consiga simular os processos hidrológicos. O processo de ajuste desses parâmetros, com o objetivo de melhorar a eficiência do modelo, é denominado calibração (GUPTA; SOROOSHIAN; YAPO, 1999). A calibração de modelos hidrológicos está repleta de dificuldade e complexidade. Por isso, a aplicação de metodologias de calibração automática tem sido frequentemente aplicada em diversos 
estudos (YAPO; GUPTA; SOROOSHIAN, 1996; ECKHARDT; ARNOLD, 2001; WAGENER et al., 2001; MADSEN, 2003; VRUGT et al., 2003).

Tucci (2005) salienta a complexidade dos fenômenos naturais envolvidos no ciclo hidrológico. O comportamento dos processos hidrológicos em uma bacia hidrográfica depende da inter-relação de água, energia e vegetação (WAGENER; GUPTA, 2005). Entretanto, aspectos quantitativos relacionados à incerteza na simulação hidrológica são a estrutura do modelo, a sensibilidade do mesmo às condições iniciais da simulação, os parâmetros considerados e confiabilidade dos dados monitorados (MENDIONDO; TUCCI, 1997; WAGENER; GUPTA, 2005).

O grau de confiabilidade relacionado à aplicação de modelos hidrológicos depende do nível de incertezas remanescentes após sua calibração (YAPO; GUPTA; SOROOSHIAN, 1996). Para que a representação dos fenômenos do mundo real seja eficiente, deve-se buscar a simplificação do objeto da simulação. Além disso, proceder à avaliação das incertezas, do desempenho e do realismo do inerente ao modelo (WAGENER, 2003; GUPTA; WAGENER; LIU, 2008).

A justificativa para utilização de modelos hidrológicos encontrada na literatura, além de melhor representação dos processos da bacia, é voltada para a predição e antecipação das respostas da mesma a determinados eventos. Entre esses eventos, têm-se as alterações decorrentes das mudanças de uso das terras nas vazões, avaliação descarga máxima em corpos d'água para dimensionamento de estruturas de armazenamento e controle, previsão de enchentes em tempo real, ocorrência de eventos extremos, movimentação de poluentes e sedimentos e impactos da alteração de um corpo d'água (BEVEN; O'CONNELL, 1982; FRANCHINI; PACCIANI, 1991; GUPTA; SOROOSHIAN; YAPO, 1999; YU; YANG, 2000; BEVEN, 2001; SINGH; WOOLHISER, 2002; TUCCI, 2005; RIBEIRO NETO et al., 2008; BAHAT et al., 2009).

Além das aplicações citadas anteriormente, outro uso importante de modelos hidrológicos consiste na predição de variáveis e respostas para bacias onde dados de séries históricas são limitados ou inexistentes (YU; YANG; CHEN, 2001; SIVAPALAN et al., 2003; YOUNG, 2006; BOUGHTON; CHIEW, 2007; GETIRANA et al., 2009; CASTIGLIONI et al., 2010; MAKUNGO et al., 2010).

Este capítulo tem como objetivo o detalhamento da metodologia utilizada para calibração e validação do modelo MGB-IPH na bacia hidrográfica do Rio Piracicaba, com base 
em dados hidrológicos observados no período 1971-1990. O foco da calibração é a representação das vazões de alta permanência na bacia, ou seja, as vazões mínimas.

Trata-se de uma bacia com demanda crescente, onde a representação de vazões extremas durante o período de estiagem é uma importante estratégia de gestão. Além disso, pretende-se avaliar o desempenho do Modelo de Transferência de Riscos Hidrológicos acoplado ao MGB-IPH (Capítulo 5), pela primeira vez sob o tema de vazões mínimas.

\subsection{METODOLOGIA}

Os critérios e a justificativa para a seleção do modelo hidrológico, bem como as bases metodológicas utilizadas durante o processo de calibração e validação do modelo MGB-IPH, são descritas nos itens a seguir.

\subsubsection{Seleção do modelo hidrológico}

O modelo selecionado para simular as vazões mínimas na bacia do Rio Piracicaba foi o Modelo de Grandes Bacias MGB-IPH (COLLISCHONN, 2001; COLLISCHONN; TUCCI, 2001; COLLISCHONN et al., 2007). Trata-se de um modelo hidrológico chuva-vazão, distribuído, acoplado a um Sistema de Informações Georreferenciadas (SIG), para aplicação em bacias hidrográficas de grande porte. Neste trabalho utilizou-se a versão com interface, acoplada ao software gratuito MapWindow GIS.

A determinação dos parâmetros e os cálculos do modelo se dão com base em Unidades de Resposta Hidrológica - URHs (COLLISCHONN et al., 2007), a serem pré-definidas pelo usuário. Tais unidades são entidades heterogeneamente distribuídas, expostas a condições similares de clima e uso da terra, cuja dinâmica hidrológica de cada uma é regulada por associações entre a pedologia, topografia e geologia (KOUWEN et al., 1993; FLÜGEL, 1995).

Segundo Collischonn et al. (2007), o MGB-IPH foi concebido segundo adaptações dos modelos LARSIM (LUDWIG; BREMICKER, 2006) e VIC (LIANG et al., 1994; NIJSSEM et al., 1997). O modelo considera algoritmos para o balanço de água no solo, evapotranspiração, escoamento em cada célula (superficial, sub-superficial e subterrâneo) e o escoamento na rede de drenagem. O cálculo da evapotranspiração se dá através da equação de Penman- 
Monteith (SHUTTLEWORTH, 1993; WIGMOSTA; VAIL, LETTENMAIER, 1994). A propagação na rede de drenagem utiliza o método Muskingum-Cunge.

A determinação dos parâmetros para calibração do modelo se dá com base em informações como o uso da terra, cobertura vegetal, topografia e tipos de solo, entre outras. Algumas aplicações do MGB-IPH encontradas na literatura são descritas em Allasia et al. (2006), Collischonn et al. (2007), Paz e Collischonn (2007), Collischonn, Collischonn e Tucci (2008), Ribeiro Neto et al. (2008), Caram (2010), Getirana (2010) Nóbrega et al. (2011) e Paiva et al. (2011). A Figura 17 demonstra o fluxograma de etapas de processamento de dados de entrada do MGB para a realização da modelagem.

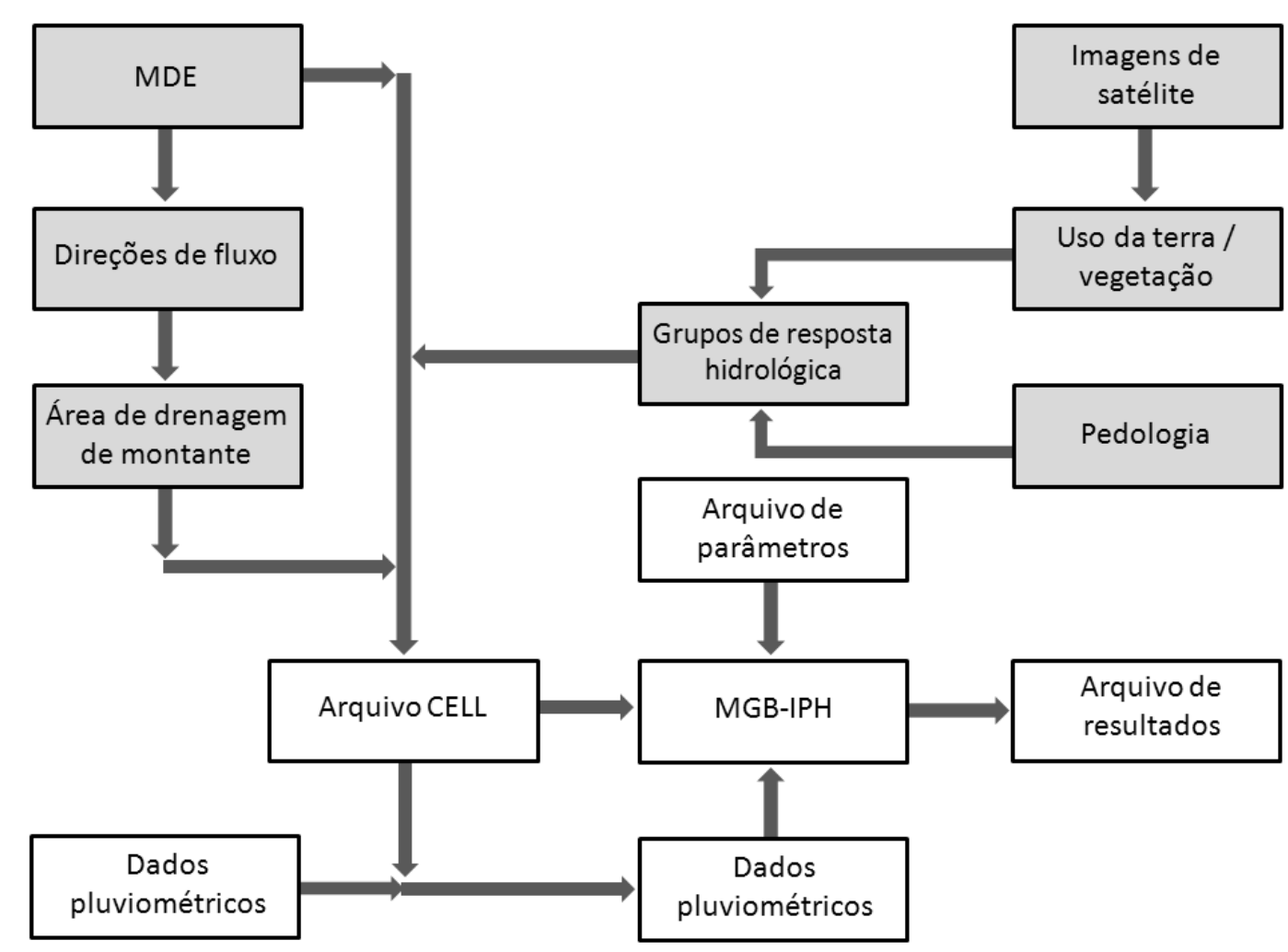

Figura 17. Fluxograma de operações de processamento de dados (em branco) e operações de SIG convencionais (em cinza) durante a execução do modelo (Fonte: Adaptado de COLLISCHONN et al., 2007).

Como justificativas para a escolha deste modelo, no âmbito desta pesquisa, citam-se:

- O fato de ser um modelo desenvolvido no Brasil, adequado para representar peculiaridades de bacias brasileiras;

- A escala da bacia hidrográfica de estudo, com área de $12.589,73 \mathrm{~km}^{2}$, que demanda o uso de um modelo aplicável a grandes bacias; 
- A quantidade reduzida de parâmetros necessários para a calibração do modelo, fato que facilita a representação da hidrologia da bacia através da modelagem;

- A possibilidade de acoplagem a modelos climáticos para simular diferentes cenários de mudanças globais; e

- A capacidade de acoplagem a modelos de seguros, em escala concentrada.

\subsubsection{Definição das Unidades de Resposta Hidrológica (URHs)}

As URHs foram definidas a partir das combinações entre os usos da terra e os tipos de solos mapeados na bacia. Obteve-se um total de dez URHs, ordenadas conforme os usos da terra, sendo que o uso Água foi deixado intencionalmente por último, conforme orientações de Fan et al. (2010).

Na Tabela 5 tem-se a comparação entre áreas ocupadas por cada URH para os dois períodos (1985 e 2010). O período de 1985 foi utilizado durante a etapa de calibração e validação do modelo, ao passo que o mapa de 2010 serviu como base para a modelagem hidrológica nos cenários, a ser descrita em detalhes no Capítulo 4.

Tabela 5. Unidades de Resposta Hidrológica (URHs) resultantes das combinações entre os tipos de solo e os usos da terra na bacia.

\begin{tabular}{|c|c|c|c|c|}
\hline URH & Uso da terra & Tipo de solo & $\begin{array}{c}\text { Área em } 1985 \\
\text { (\%) }\end{array}$ & $\begin{array}{c}\text { Área em } 2010 \\
\text { (\%) }\end{array}$ \\
\hline 1 & Agropecuária & Latossolo e Nitossolo & 35,39 & 30,00 \\
\hline 2 & Agropecuária & Argissolo & 47,32 & 38,98 \\
\hline 3 & Agropecuária & Cambissolo e Neossolo & 5,06 & 4,61 \\
\hline 4 & Agropecuária & Gleissolo & 1,53 & 1,42 \\
\hline 5 & Vegetação & Latossolo e Nitossolo & 1,96 & 4,91 \\
\hline 6 & Vegetação & Argissolo & 3,75 & 10,16 \\
\hline 7 & Vegetação & Cambissolo e Neossolo & 0,68 & 1,10 \\
\hline 8 & Vegetação & Gleissolo & 0,03 & 0,22 \\
\hline 9 & Áreas urbanas & Todos & 2,64 & 6,86 \\
\hline 10 & Corpos d'água & Todos & 1,64 & 1,75 \\
\hline & TOTAL & & 100,00 & 100,00 \\
\hline
\end{tabular}

Fonte: Elaborado pelo autor. 
A distribuição espacial das URHs na bacia, para os períodos de 1985 e de 2010, são ilustradas pelas Figura 18 e Figura 19.

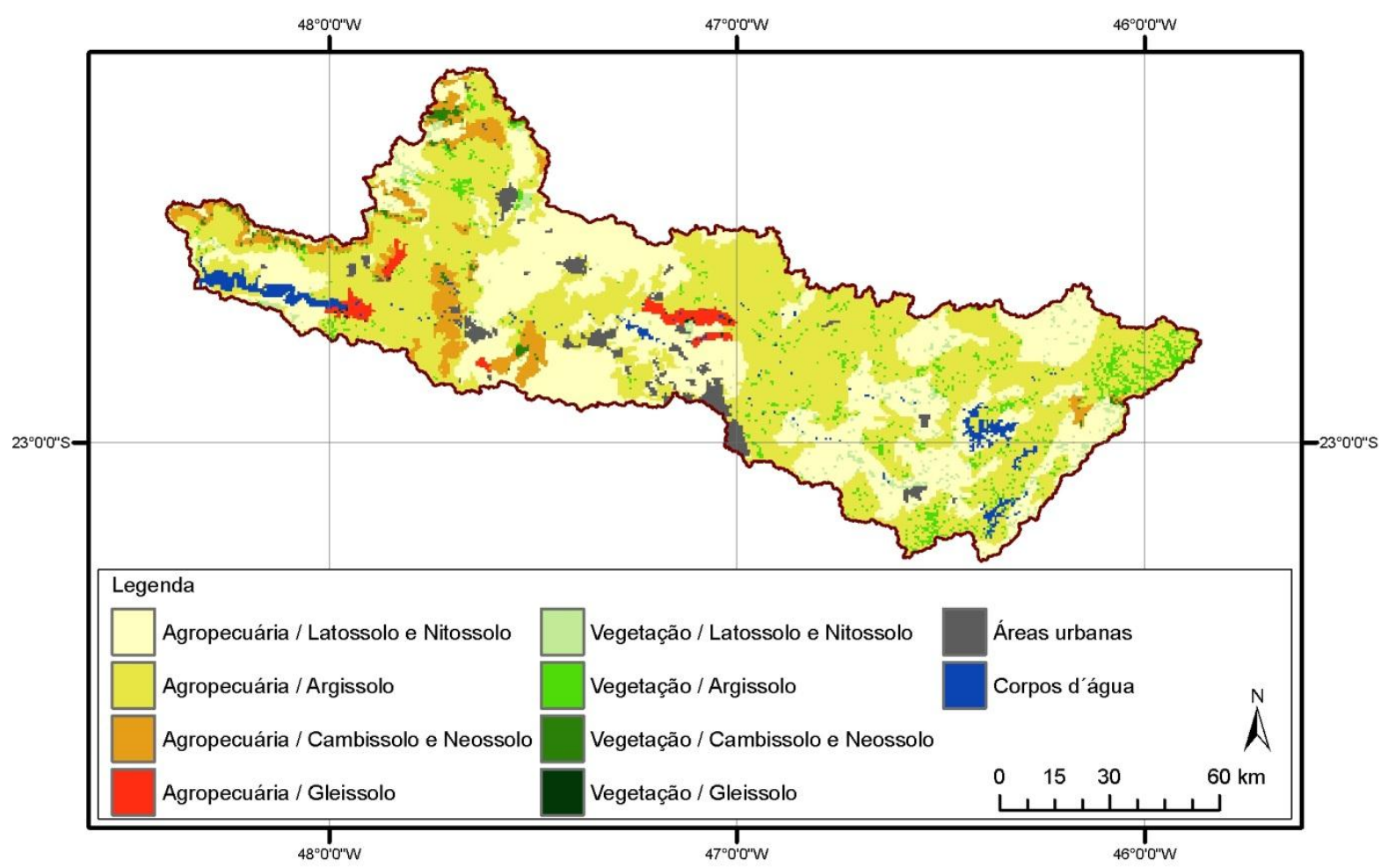

Figura 18. Unidades de Resposta Hidrológica para o ano de 1985 (Fonte: Elaborado pelo autor).

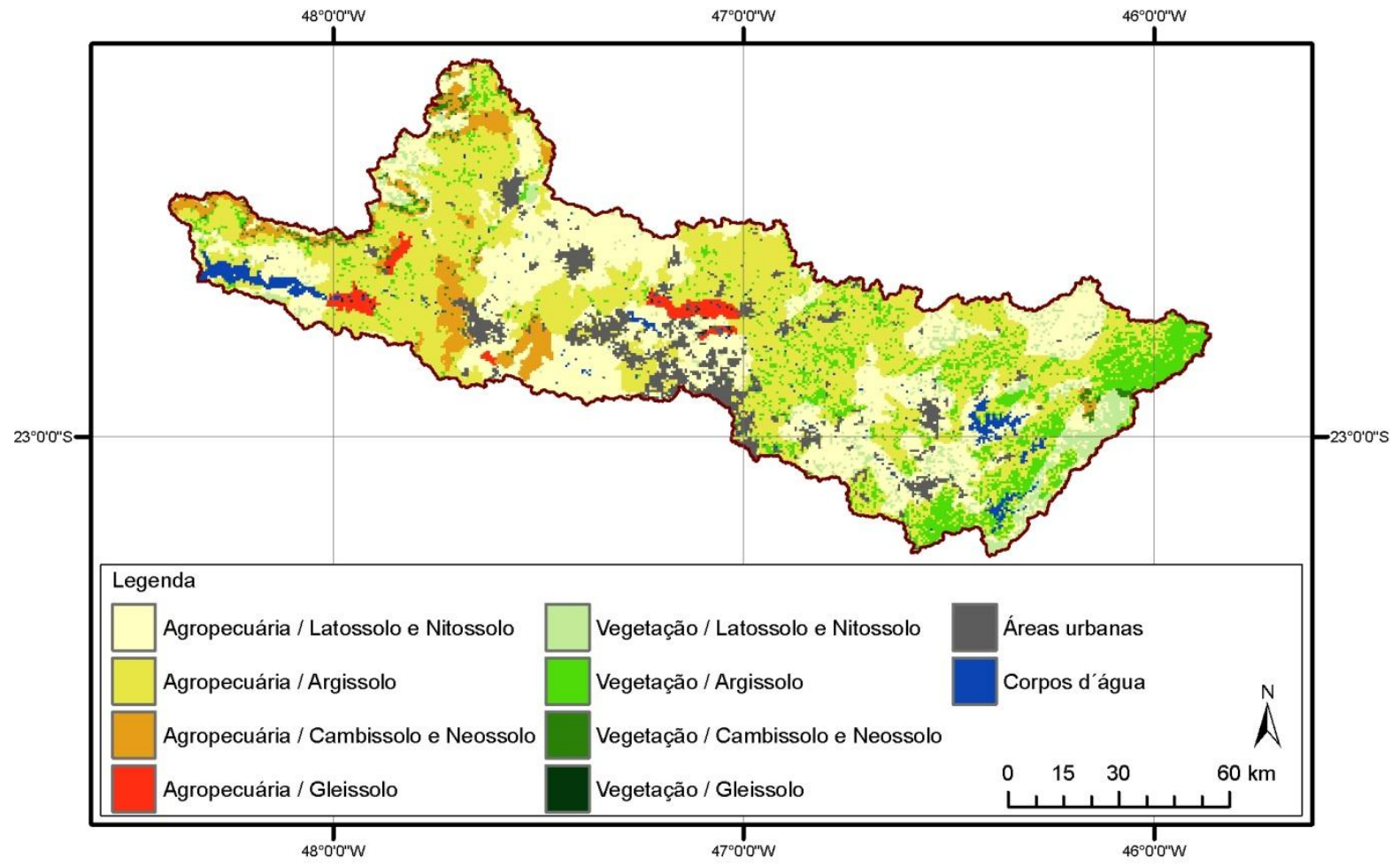

Figura 19. Unidades de Resposta Hidrológica para o ano de 2010 (Fonte: Elaborado pelo autor). 


\subsubsection{Preparação dos dados de entrada do modelo MGB-IPH}

A preparação dos dados de entrada é fundamental para que sejam obtidos os arquivos necessários para o estudo. Além disso, é feito o tratamento dos dados, para que as informações relevantes sejam identificadas e extraídas. Assim, tem-se a composição de uma base de dados georreferenciada, composta pelo Modelo Digital de Elevação (MDE), postos pluviométricos, postos climatológicos, postos fluviométricos, mapa de uso das terras e pedologia.

Para que a etapa de modelagem hidrológica pudesse ser iniciada, executou-se o processamento dos arquivos gerados nos passos anteriores (MDE, rede de drenagem, subbacias, minibacias, direções de fluxo e URHs). Assim, os arquivos em formato raster referentes a cada um destes temas citados anteriormente foram convertidos para o formato de entrada do modelo MGB-IPH, segundo ferramenta desenvolvida no Instituto de Pesquisas Hidráulicas (IPH) da Universidade Federal do Rio Grande do Sul (UFRGS).

Além desses arquivos, foram gerados os arquivos com as informações dos postos fluviométricos, pluviométricos e climatológicos. Esta etapa se deu através da interface do MGB-IPH, versão elaborada para rodar em ambiente Windows, dentro do software MapWindow GIS (COLLISCHONN; FAN, 2012). A definição dos períodos de calibração e validação do modelo MGB-IPH se deu conforme a disponibilidade de dados nos postos, segundo análise das séries históricas obtidas.

\subsubsection{Calibração e ajuste do modelo}

Durante a calibração, buscou-se o ajuste dos valores das saídas do modelo hidrológico (valores de vazões diárias simuladas) aos valores observados nos postos fluviométricos. Procedeu-se, portanto, à busca pelos valores ótimos do conjunto de parâmetros do modelo.

Conforme mencionado no item 2 deste capítulo, que trata dos objetivos, a calibração do modelo priorizou o ajuste das vazões mínimas entre os dados simulados e observados. Uma vez obtidos resultados significativos neste aspecto, foram melhoradas outras características dos hidrogramas, como os picos e as recessões. Para a etapa de calibração, foram considerados dados de vazão de 01/01/1971 a 31/12/1980 nos postos selecionados. 


\subsubsection{Definição dos parâmetros}

Para a execução do MGB-IPH, devem ser definidos e calibrados 15 parâmetros, os quais são divididos entre parâmetros fixos e parâmetros calibráveis. Os parâmetros fixos são parâmetros a serem definidos anteriormente ao início da calibração, e que se manterão constantes durante a evolução da mesma. Já os parâmetros calibráveis, são os parâmetros que serão constantemente alterados, até que o ajuste entre os hidrogramas observado e simulado seja considerado satisfatório.

A seguir tem-se uma breve descrição dos parâmetros utilizados, bem como dos critérios assumidos para a determinação dos mesmos.

\section{Parâmetros fixos}

São parâmetros fixos, ou seja, parâmetros que permanecem constantes durante o ajuste do modelo, os seguintes:

- Albedo: A definição e os valores de albedo considerados foram determinados com base em Shuttleworth (1993). Trata-se do coeficiente de reflexão de uma parcela da radiação ao atingir o solo. Os valores podem variar de acordo com a hora do dia, sazonalidade, latitude e cobertura de nuvens. No MGB-IPH a variação é sazonal.

- Índice de Área Foliar (IAF): Índice comumente utilizado para expressar a densidade de folhas em um dossel, medido em unidades de área foliar por unidade de área de uma superfície (JORDAN, 1969). Os valores de IAF considerados foram adaptados do estudo realizado por Xavier e Vettorazi (2004), que avaliaram a variação mensal do índice para diferentes usos da terra, em uma bacia hidrográfica do município de Piracicaba, estado de São Paulo.

- Altura média das árvores: valor médio da altura da cobertura vegetal na bacia.

- Resistência superficial: parâmetro necessário para o cálculo da evapotranspiração, representa a resistência ao fluxo entre o solo e a atmosfera, através da vegetação.

Os valores dos parâmetros fixos considerados durante a modelagem constam no Apêndice $B$. 


\section{Parâmetros calibráveis}

Os parâmetros calibráveis são os parâmetros aos quais o modelo possui maior sensibilidade (COLLISCHONN, 2001). Devem, portanto, ser ajustados de modo a melhorar a representação da realidade simulada pelo modelo. São calibráveis os seguintes parâmetros:

- Wm: Capacidade de armazenamento do solo, gerado pouco ou nenhum escoamento superficial.

- $\quad b$ : Parâmetro de forma da relação entre armazenamento e saturação.

- Kbas: Controla a vazão durante a estiagem.

- Kint: Controla a quantidade de água da camada de solo que é escoada subsuperficialmente.

- $X L$ : Controla a forma da curva de redução da drenagem sub-superficial do solo.

- CAP: Controla o fluxo do reservatório subterrâneo para a camada superficial do solo.

- Wc: Limita o escoamento sub-superficial e o subterrâneo.

- CS: Calibração da propagação superficial nas células.

- Cl: Calibração da propagação sub-superficial nas células.

- $\quad C B$ : Retardo do reservatório subterrâneo.

- $Q B$ : Vazão de referência específica.

A definição dos valores dos parâmetros em fase inicial da calibração considerou experiências de aplicações do MGB-IPH em outros trabalhos, como em Collischonn (2001), Collischonn e Tucci (2001), Collischonn et al. (2007) e Caram (2010). Na Tabela 6 são exibidas as faixas de valores sugeridos para início da calibração do modelo. Esses valores estão disponíveis para consulta na versão do modelo com interface MapWindow GIS. A definição dos parâmetros calibráveis considerou, além dos blocos de uso da terra, a variabilidade espacial na bacia. Assim, os grupos de valores de parâmetros foram escolhidos para cada uma das sub-bacias definidas na discretização, descritas no capítulo anterior. No Apêndice $B$ são demonstrados os valores considerados em cada sub-bacia. 
Tabela 6. Valores recomendados para os parâmetros calibráveis do MGB-IPH.

\begin{tabular}{cccc}
\hline Parâmetro & Mínimo sugerido & Máximo sugerido & Unidades \\
\hline Wm & 50 & 1000 & $\mathrm{~mm}$ \\
B & Aprox. 0,12 & 1,6 & - \\
Kbas & 0,05 & 5 & $\mathrm{~mm} \cdot \mathrm{dia}^{-1}$ \\
Kint & 4 & 40 & $\mathrm{~mm} \cdot \mathrm{dia}^{-1}$ \\
XL & 0,67 & 0,67 & - \\
CAP & Zero & Zero & mm.dia ${ }^{-1}$ \\
Wc & 0,1 & 0,1 & - \\
CS & 1 & 20 & - \\
Cl & 50 & 200 & - \\
CB & A calcular* & A calcular* & horas \\
QB & 0,01 & 0,01 & - \\
\hline
\end{tabular}

* Valor a ser calculado utilizando a ferramenta "Filtro de vazão de base" do MGB-IPH.

Fonte: Interface do modelo MGB-IPH/MapWindow GIS.

\subsubsection{Calibração manual}

Nesta etapa, foram definidos os valores iniciais dos parâmetros fixos e dos parâmetros calibráveis. Os parâmetros calibráveis foram ajustados manualmente através de tentativa e erro, ou seja, os valores dos parâmetros foram alterados por diversas vezes, na busca pelo melhor ajuste entre os dados simulados e observados.

A análise dos resultados da calibração manual se deu de maneira visual e numérica. Com isso, foi avaliado o ajuste das vazões mínimas, a forma dos hidrogramas, o ajuste dos picos das cheias, as recessões do hidrogramas, o volume calculado (curva de permanência) e o período de recorrência dos eventos extremos.

O que se buscou nesta etapa foi o ajuste parcial dos hidrogramas simulados e observados. Também foram comparados os valores das funções objetivo (FO) para avaliar os resultados obtidos. Para isso, as FO escolhidas foram a Eficiência de Nash e Sutcliffe (NSE, Equação 1), Eficiência de Nash e Sutcliffe do logaritmo das vazões ( $\mathrm{NSE}_{\log }$, Equação 2), Módulo do erro no volume total ( $\Delta V$, Equação 3) e Erro da Q90 ( $\Delta Q 90$, Equação 4), 
$N S E=1-\frac{\sum\left(Q_{o b s}(t)-Q_{s i m}(t)\right)^{2}}{\sum\left(Q_{o b s}(t)-Q_{o b s \_m e ́ d i o}\right)^{2}}$

Equação 1

$N S E_{l o g}=1-\frac{\sum\left(\ln \left(Q_{o b s}(t)\right)-\ln \left(Q_{\text {sim }}\right)\right)^{2}}{\sum\left(\ln \left(Q_{o b s}(t)\right)-\ln \left(Q_{\text {obs_média }}\right)\right)^{2}}$

Equação 2

$\Delta V=\frac{\sum\left(Q_{s i m}(t)\right)-\sum\left(Q_{o b s}(t)\right)}{\sum\left(Q_{o b s}(t)\right)} \cdot 100 \%$

Equação 3

$\Delta Q 90=\frac{Q 90_{\text {sim }}-Q 90_{o b s}}{Q 90_{o b s}} .100 \%$

Equação 4

sendo $Q_{o b s}(t)$ a vazão observada, em $\mathrm{m}^{3} \cdot \mathrm{s}^{-1}$, no tempo $t ; Q_{\text {sim }}(t)$ a vazão simulada pelo modelo, em $\mathrm{m}^{3} \cdot \mathrm{s}^{-1}$, durante o tempo $t ; Q_{o b s \_m e ́ d i o}$ a média aritmética dos valores de vazões observadas, em $\mathrm{m}^{3} . \mathrm{s}^{-1} ; \Delta V$ é o erro do volume calculado pelo modelo, em porcentagem; $\triangle Q 90$ é o erro do modelo no cálculo da vazão de $90 \%$ de permanência, em porcentagem; $Q 90_{\text {sim }}$ a vazão associada à permanência de $90 \%$ simulada pelo modelo, $\mathrm{em} \mathrm{m}^{3} \cdot \mathrm{s}^{-1} ; Q 90_{o b s}$ a vazão de permanência $90 \%$ observada, em $\mathrm{m}^{3} \cdot \mathrm{s}^{-1}$.

Ao final da calibração, também foi realizada análise estatística da correlação entre os dados de vazões diárias observadas e simuladas. Para isso, foi feita a avaliação do coeficiente de determinação ( $r^{2}$, Equação 5), em cada posto fluviométrico simulado,

$$
r^{2}=\frac{\sum Q_{o b s}(t) Q_{s i m}(t)-\frac{\sum Q_{o b s}(t) \sum Q_{s i m}(t)}{n}}{\sqrt{\left[\sum Q_{o b s}{ }^{2}-\frac{\left(\sum Q_{o b s}\right)^{2}}{n}\right]\left[\sum Q_{s i m}{ }^{2}-\frac{\left(\sum Q_{s i m}\right)^{2}}{n}\right]}}
$$

sendo $Q_{o b s}(t)$ a vazão observada, em $\mathrm{m}^{3} \cdot \mathrm{s}^{-1}$, no tempo $t ; Q_{\text {sim }}(t)$ a vazão simulada pelo modelo, em $\mathrm{m}^{3} \cdot \mathrm{s}^{-1}$, durante o tempo $t ; n$ o número de amostras.

\subsubsection{Calibração automática}

Após a calibração manual do modelo, onde se obteve um ajuste razoável do modelo, realizou-se a calibração automática. Foi utilizado o algoritmo MOCOM-UA (YAPO; GUPTA; 
SOROOSHIAN, 1998), um algoritmo de otimização multi-objetivo, acoplado à interface do MGB-IPH. Exemplos de aplicações deste algoritmo, encontrados na literatura, foram observados em Yapo, Gupta e Sorooshian (1998), Wagener et al. (2001), Beldring (2002), Collischonn e Tucci (2003) e Getirana (2010).

Durante esta etapa, foram escolhidos quais os parâmetros a serem calibrados, onde se considerou a análise de sensibilidade realizada por Collischonn (2001). Os valores dos parâmetros $W m$ para cada tipo de uso da terra, aos quais o modelo é bastante sensível, foram fixados durante o ajuste manual do mesmo. Tal estratégia foi adotada porque julgouse satisfatória a definição deste parâmetro durante a etapa anterior.

Por sua vez, foram selecionados os parâmetros $b$, Kbas, Kint, CS e Cl para comporem a calibração automática multi-objetivo. Para que a otimização fosse iniciada, foram definidas as faixas de valores dentro das quais o algoritmo pôde variar os valores dos parâmetros, gerando conjuntos (Tabela 7), bem como o tamanho da população de pontos a serem gerados.

Tabela 7. Valores mínimos e máximos permitidos para que o algoritmo variasse cada um dos parâmetros a serem calibrados.

\begin{tabular}{ccc}
\hline Parâmetro & Mínimo & Máximo \\
\hline B & 0,3 & 1,8 \\
Kbas & 0,3 & 1,8 \\
Kint & 0,3 & 1,8 \\
CS & 0,1 & 2,0 \\
Cl & 0,4 & 1,7 \\
\hline
\end{tabular}

Fonte: Elaborado pelo autor.

As FO escolhidas para comporem a otimização foram NSElog, $\Delta \mathrm{V}$ e $\Delta \mathrm{Q} 90$. Optou-se por excluir da análise os valores de NSE, pois este prioriza o ajuste entre os hidrogramas observado e simulado, sendo fortemente influenciado pelas vazões máximas. Conforme o objetivo desta pesquisa, que foi simular vazões mínimas, priorizou-se a otimização de $\Delta Q 90$, na tentativa de melhor representar a simulação das vazões mínimas.

Feito isso, o algoritmo promoveu a hierarquização dos valores das FO obtidos para cada conjunto de variação aleatória dos parâmetros, segundo critérios de dominância e nãodominância. Em suma, cada conjunto de parâmetros recebe um índice que, quanto menor, 
melhor é o conjunto de parâmetros, melhor o valor para o objetivo selecionado e, portanto, mais próximo da região de Pareto na superfície de resposta.

Ao final da execução do algoritmo, obteve-se um conjunto de parâmetros que representavam bons resultados das FO selecionadas. Ainda assim, priorizou-se a escolha pelo conjunto que representasse bons resultados para $\Delta Q 90$, sem piorar demasiadamente os valores das demais FO.

\subsubsection{Validação da calibração}

Para que a calibração do modelo pudesse ser verificada, foi realizada a etapa de validação. O período de validação é importante para se determinar o grau de incerteza remanescente na modelagem (YAPO; GUPTA; SOROOSHIAN, 1996).

Nesta etapa utilizou-se o modelo previamente calibrado para representar um período diferente do utilizado na calibração. Assim, utilizaram-se os valores dos parâmetros definidos para representar o período 1971 a 1980, sem qualquer tipo de alteração, para a simulação dos valores de vazões diárias no período 1981-1990.

Após a simulação procedeu-se à análise visual da semelhança entre os hidrogramas observado e calculado. Também se comparou a evolução dos valores das FO em cada posto fluviométrico, para avaliar a habilidade do modelo calibrado em reproduzir as vazões em períodos diferentes ao da calibração.

\subsection{RESULTADOS E DISCUSSÃO}

Neste item são apresentados e discutidos os resultados da calibração e validação do modelo MGB-IPH para a bacia hidrográfica do Rio Piracicaba. Foram avaliados os valores das FO obtidos, o ajuste entre os hidrogramas observado e simulado, a correlação entre as vazões observadas e simuladas através do coeficiente de determinação $\left(r^{2}\right)$, e as curvas de permanência das vazões diárias.

As FO, além de terem sido utilizadas como critérios para a calibração automática, foram consideradas indicadores do ajuste realizado, para os períodos de calibração (19711980) e validação (1981-1990). 


\subsubsection{Calibração do modelo}

A comparação visual entre os hidrogramas calculado e observado permite considerar satisfatório o procedimento de calibração. Isto porque foi obtido um ajuste significativo entre as vazões diárias em ambos os casos, para os diferentes postos.

Foi alcançado um bom ajuste das vazões mínimas, das recessões e da forma dos hidrogramas. A variabilidade e a sazonalidade das vazões também foram bem representadas. As vazões de pico, em alguns casos, não foram tão bem ajustadas, haja visto o foco da calibração ser na representação de vazões mínimas.

Os hidrogramas nas estações Pires (Figura 20), Buenópolis (Figura 21), Jaguariúna (Figura 22), Monte Alegre do Sul (Figura 23), Fazenda Barra (Figura 24), Usina Ester (Figura 25), Bairro da Ponte (Figura 26), Desembargador Furtado (Figura 27), Recreio (Figura 28) e Artemis (Figura 29) demonstram tais afirmações.

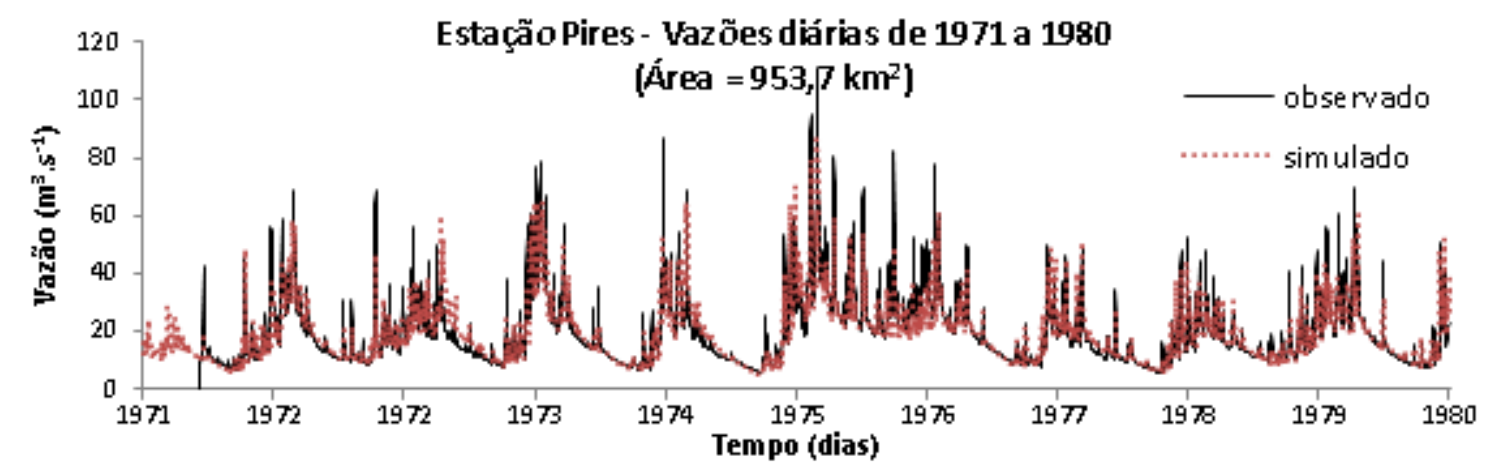

Figura 20. Hidrograma de vazões diárias observadas (linha contínua preta) e simuladas (linha pontilhada vermelha) na estação Pires $\left(953,7 \mathrm{~km}^{2}\right)$, durante a calibração, no período de 1971 a 1980 (Fonte: Elaborado pelo autor).

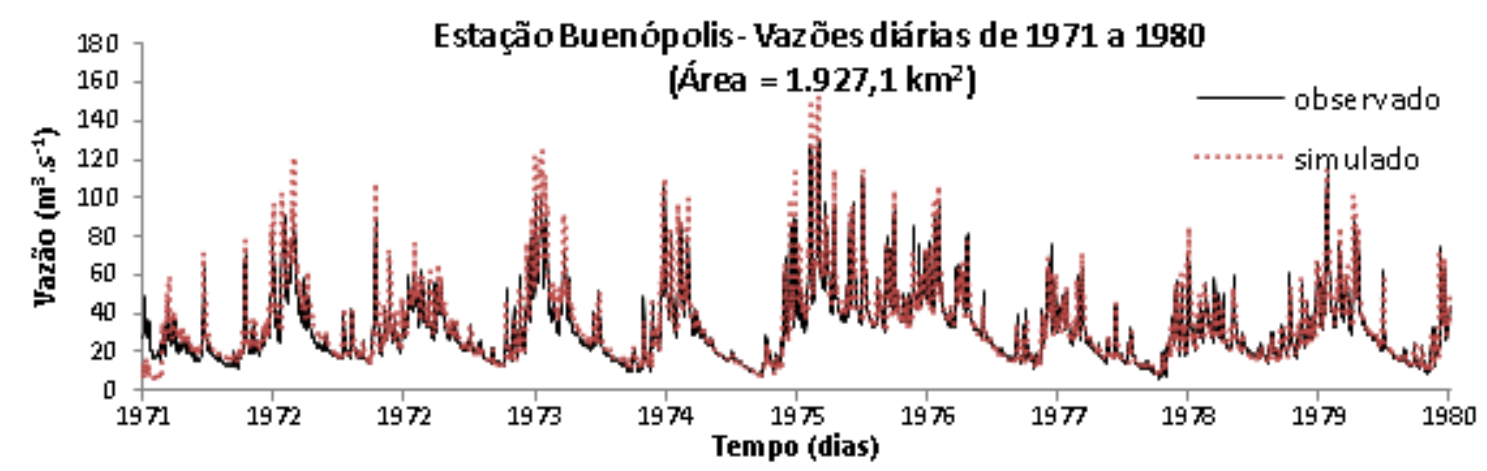

Figura 21. Hidrograma de vazões diárias observadas (linha contínua preta) e simuladas (linha pontilhada vermelha) na estação Buenópolis $\left(1.927,1 \mathrm{~km}^{2}\right)$, durante a calibração, no período de 1971 a 1980 (Fonte: Elaborado pelo autor). 


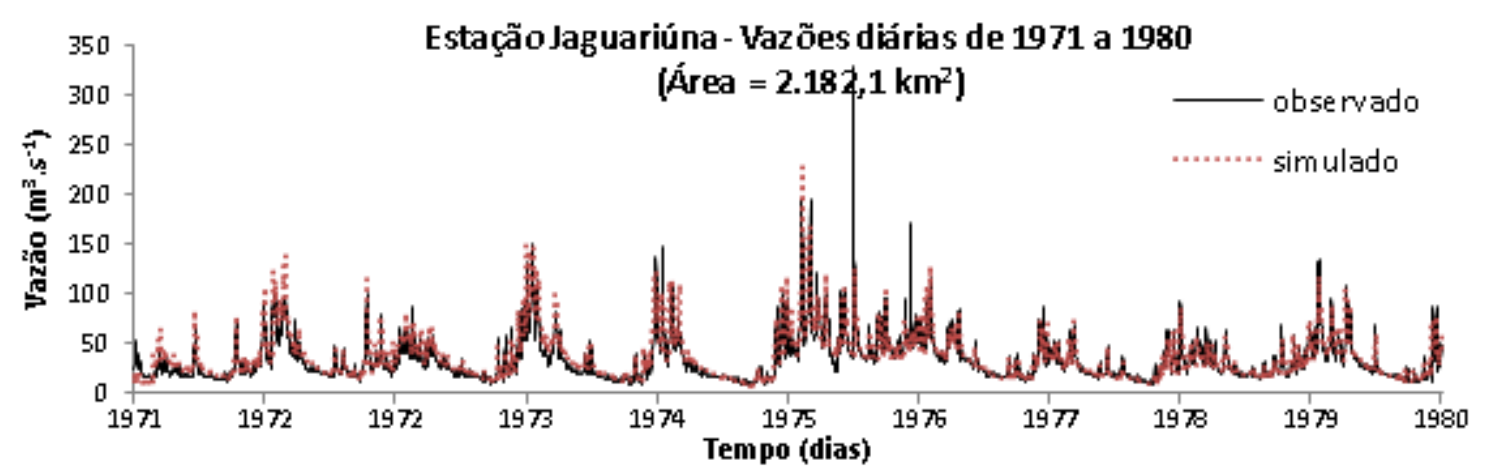

Figura 22. Hidrograma de vazões diárias observadas (linha contínua preta) e simuladas (linha pontilhada vermelha) na estação Jaguariúna $\left(2.182,1 \mathrm{~km}^{2}\right)$, durante a calibração, no período de 1971 a 1980 (Fonte: Elaborado pelo autor).

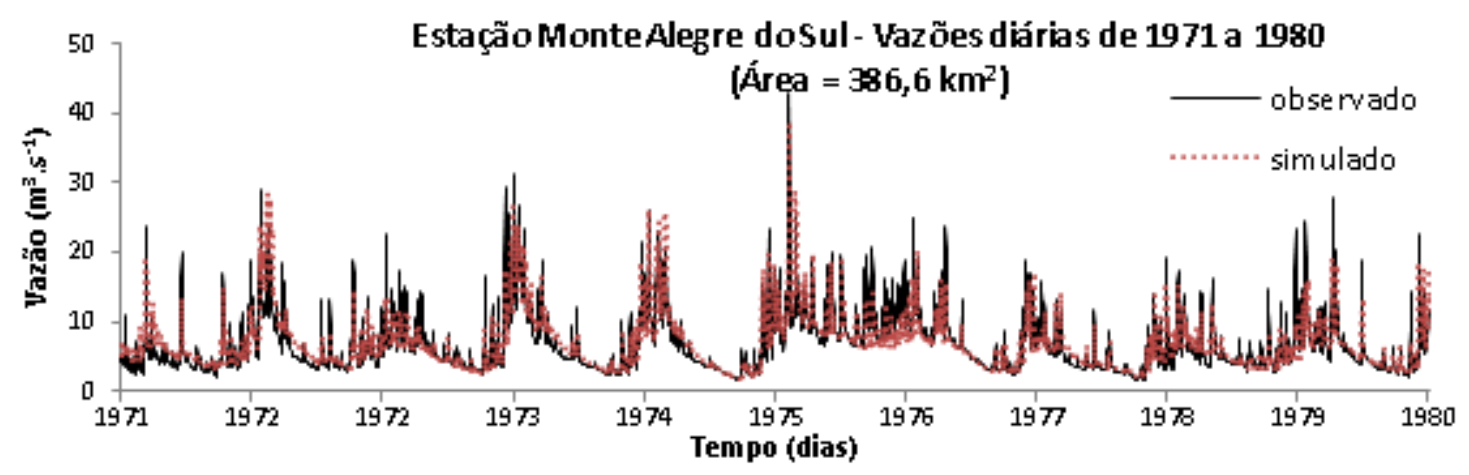

Figura 23. Hidrograma de vazões diárias observadas (linha contínua preta) e simuladas (linha pontilhada vermelha) na estação Monte Alegre do Sul $\left(386,6 \mathrm{~km}^{2}\right)$, durante a calibração, no período de 1971 a 1980 (Fonte: Elaborado pelo autor).

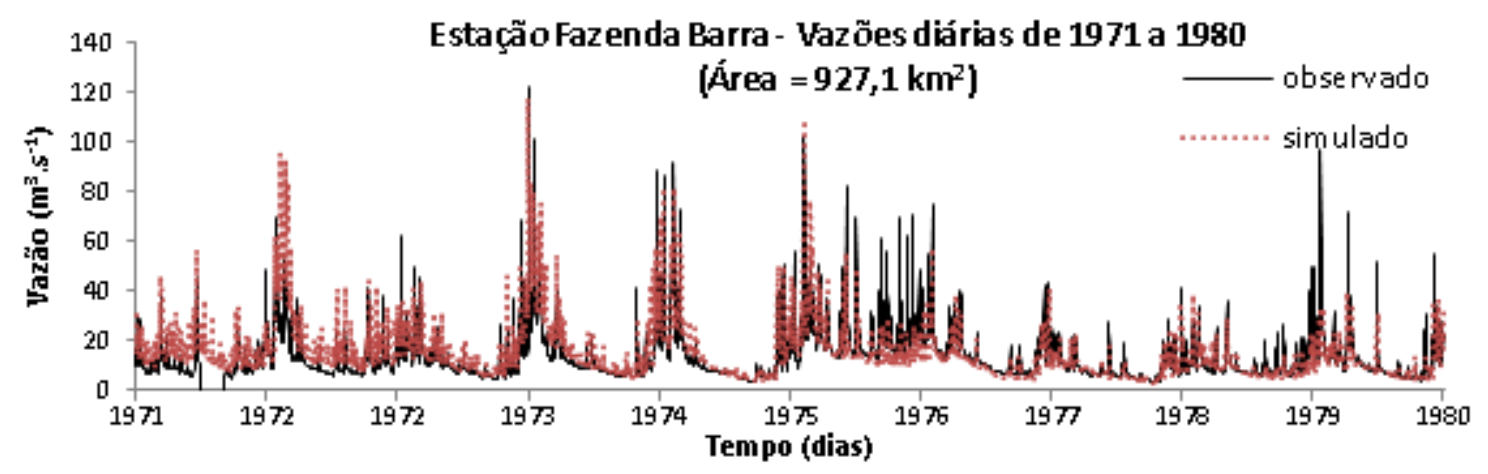

Figura 24. Hidrograma de vazões diárias observadas (linha contínua preta) e simuladas (linha pontilhada vermelha) na estação Fazenda Barra $\left(927,1 \mathrm{~km}^{2}\right)$, durante a calibração, no período de 1971 a 1980 (Fonte: Elaborado pelo autor). 


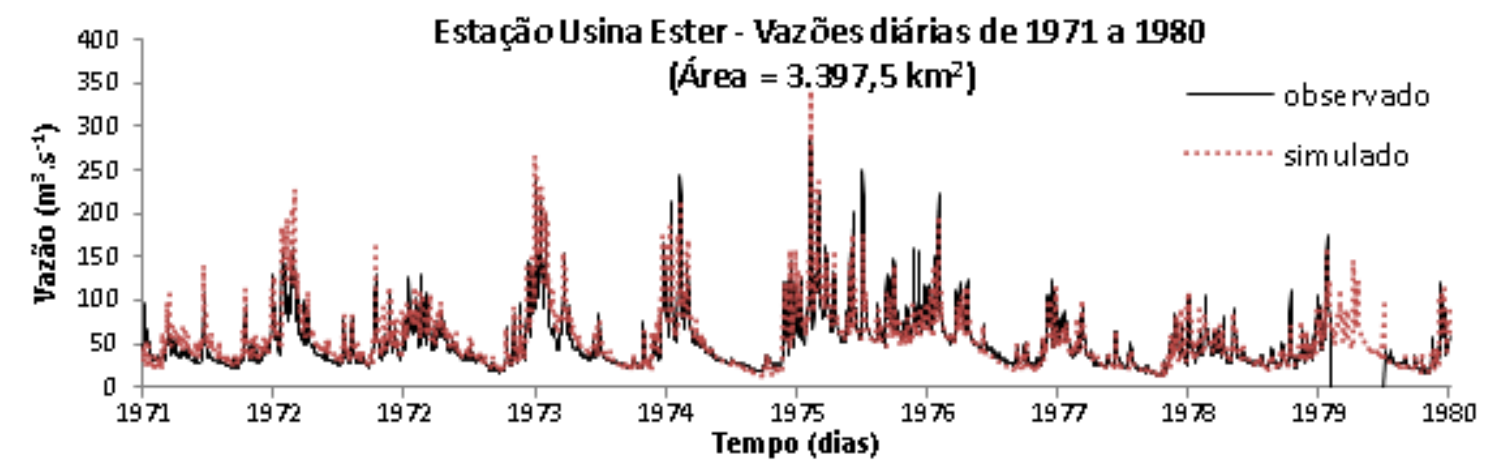

Figura 25. Hidrograma de vazões diárias observadas (linha contínua preta) e simuladas (linha pontilhada vermelha) na estação Usina Ester $\left(3.397,5 \mathrm{~km}^{2}\right)$, durante a calibração, no período de 1971 a 1980 (Fonte: Elaborado pelo autor).

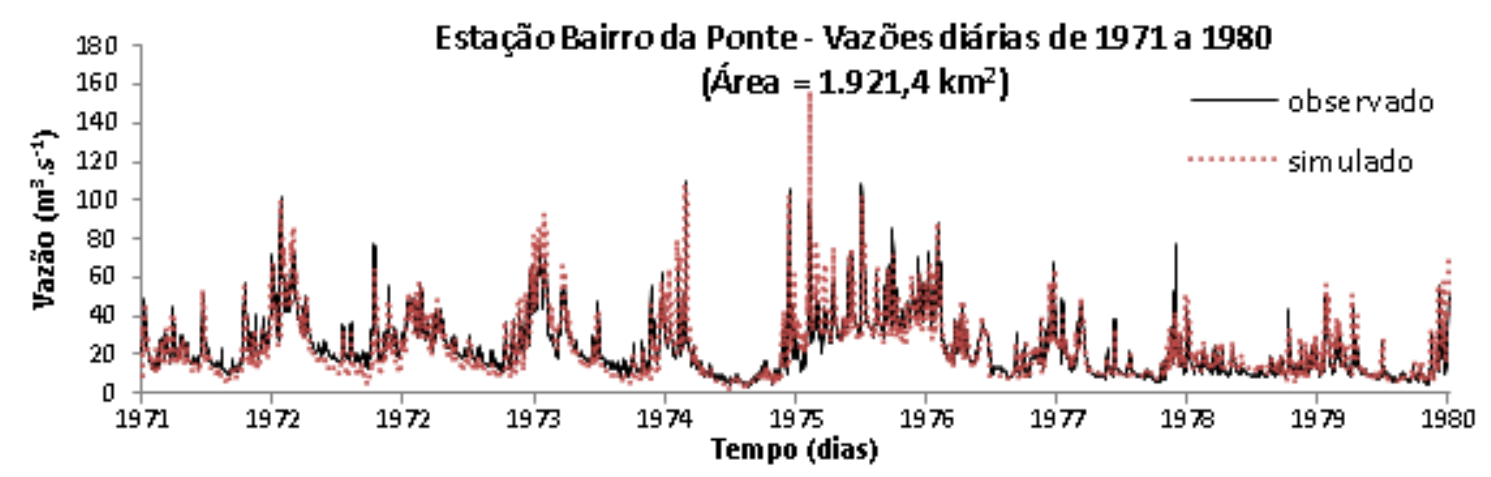

Figura 26. Hidrograma de vazões diárias observadas (linha contínua preta) e simuladas (linha pontilhada vermelha) na estação Bairro da Ponte $\left(1.921,4 \mathrm{~km}^{2}\right)$, durante a calibração, no período de 1971 a 1980 (Fonte: Elaborado pelo autor).

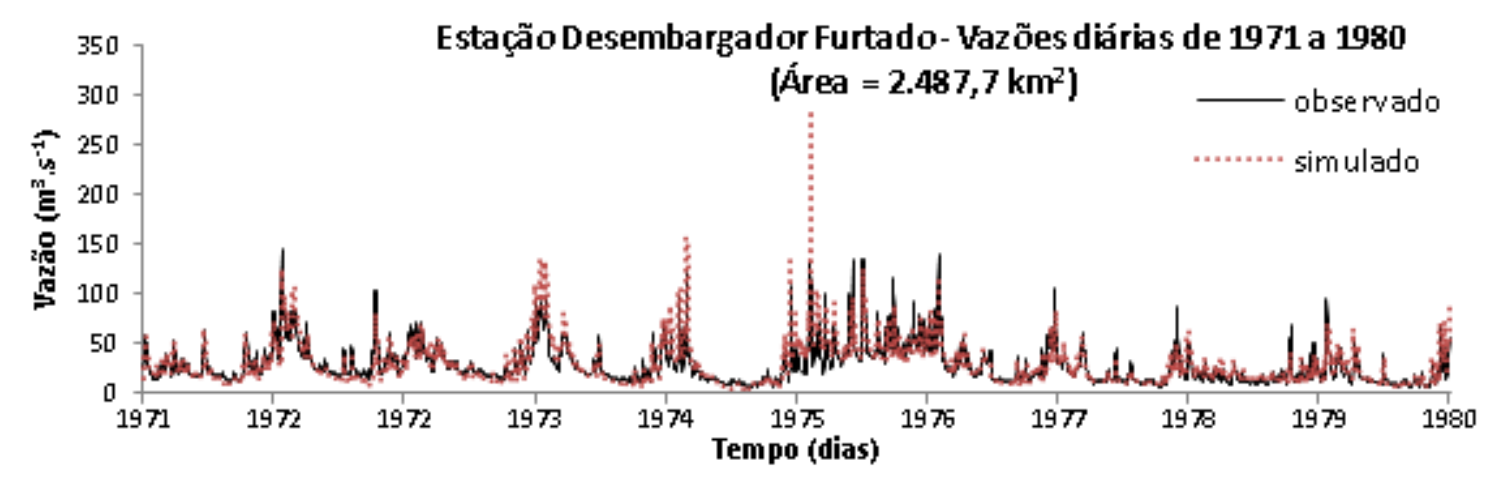

Figura 27. Hidrograma de vazões diárias observadas (linha contínua preta) e simuladas (linha pontilhada vermelha) na estação Desembargador Furtado $\left(2.487,7 \mathrm{~km}^{2}\right)$, durante a calibração, no período de 1971 a 1980 (Fonte: Elaborado pelo autor). 


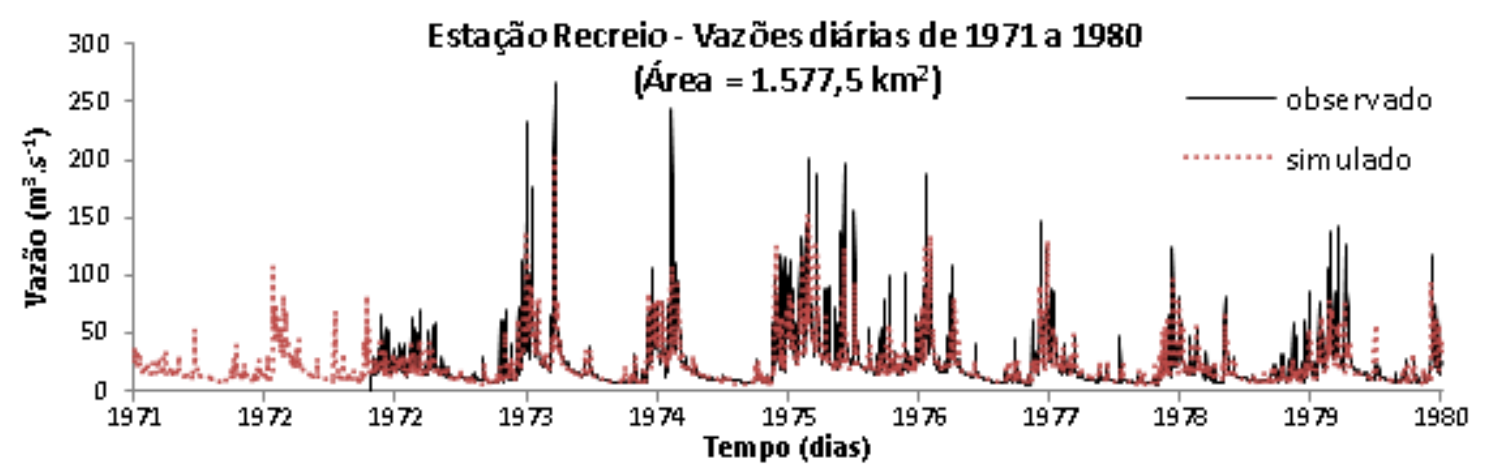

Figura 28. Hidrograma de vazões diárias observadas (linha contínua preta) e simuladas (linha pontilhada vermelha) na estação Recreio $\left(1.577,5 \mathrm{~km}^{2}\right)$, durante a calibração, no período de $1971 \mathrm{a}$ 1980 (Fonte: Elaborado pelo autor).

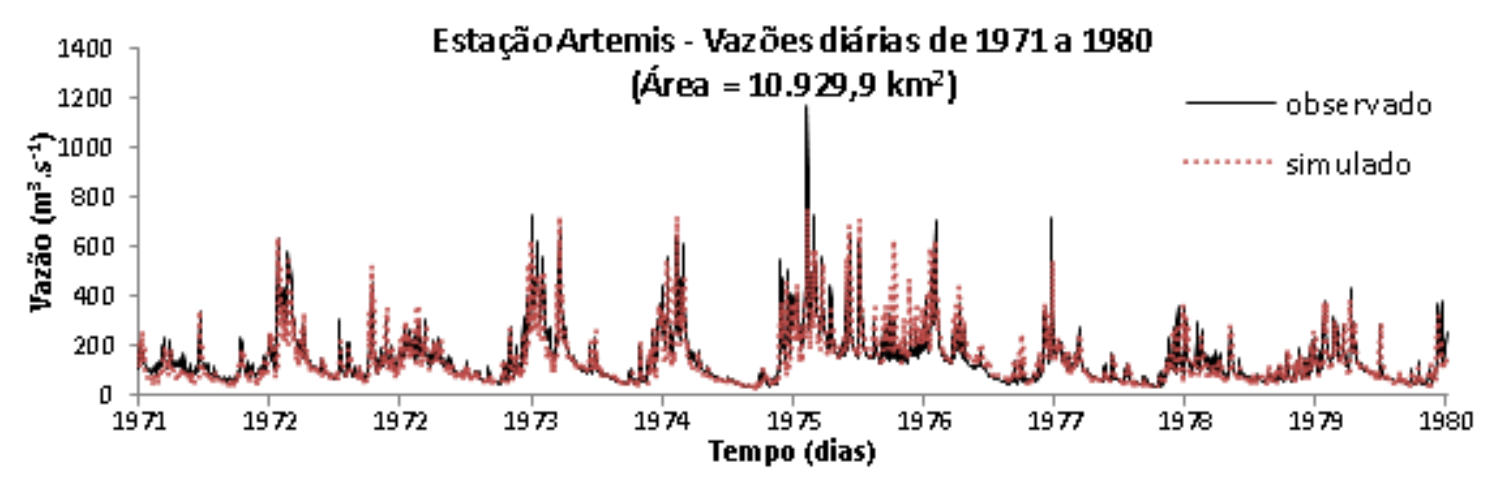

Figura 29. Hidrograma de vazões diárias observadas (linha contínua preta) e simuladas (linha pontilhada vermelha) na estação Artemis $\left(10.929,9 \mathrm{~km}^{2}\right)$, durante a calibração, no período de 1971 a 1980 (Fonte: Elaborado pelo autor).

Os resultados das FO analisadas para a etapa de calibração são demonstrados na Tabela 8. De modo geral, áreas maiores apresentaram maiores valores do NSE, devido a melhores resultados do modelo em grandes áreas (COLLISCHONN et al., 2007). 
Tabela 8. Resultados das FO para o período de calibração (1971-1980) do MGB-IPH na bacia hidrográfica do Rio Piracicaba.

\begin{tabular}{cccccc}
\hline Posto & $\begin{array}{c}\text { Área } \\
\left(\mathbf{k m}^{2}\right)^{*}\end{array}$ & NSE & NSE $_{\text {log }}$ & $\begin{array}{c}\Delta \mathbf{V} \\
(\%)\end{array}$ & $\begin{array}{c}\Delta \mathbf{Q 9 0} \\
(\%)\end{array}$ \\
\hline Pires & 953,7 & 0,77 & 0,87 & $-5,51$ & $-3,18$ \\
Buenópolis & $1.927,1$ & 0,90 & 0,90 & 3,92 & $-1,68$ \\
Jaguariúna & $2.182,1$ & 0,82 & 0,87 & 6,19 & $-2,54$ \\
Monte Alegre do Sul & 386,6 & 0,78 & 0,85 & $-0,46$ & 5,71 \\
Fazenda Barra & 927,1 & 0,53 & 0,68 & 7,69 & $-6,97$ \\
Usina Ester & $3.397,5$ & 0,84 & 0,87 & 5,39 & $-5,26$ \\
Bairro da Ponte & $1.921,4$ & 0,86 & 0,85 & $-2,00$ & $-9,77$ \\
Desembargador Furtado & $2.487,7$ & 0,74 & 0,83 & 1,31 & $-10,64$ \\
Recreio & $1.577,5$ & 0,75 & 0,86 & $-11,63$ & 1,17 \\
Artemis & $10.929,9$ & 0,87 & 0,90 & 2,85 & 3,74 \\
\hline
\end{tabular}

*área considerada na modelagem, através da discretização da bacia segundo informações do MDE.

Fonte: Elaborado pelo autor.

Os melhores valores de NSE foram 0,90 na estação Buenópolis $\left(1.927,1 \mathrm{~km}^{2}\right), 0,87$ na Artemis $\left(10.929,9 \mathrm{~km}^{2}\right)$ e 0,86 na Bairro da Ponte $\left(1.921,4 \mathrm{~km}^{2}\right)$. A faixa de variação do NSE é de menos infinito a um, sendo que quanto mais próximos do valor um, maior a confiabilidade do modelo em representar as vazões na bacia (GUPTA; SOROOSHIAN; YAPO, 1999). Para valores acima de 0,75 , o ajuste do modelo foi considerado muito bom (MORIASI et al., 2007).

A mesma lógica do NSE vale para o $\mathrm{NSE}_{\log }$, com relação ao valor da $\mathrm{FO}$ obtido resultante da comparação entre os dados observados e simulados. A análise deste ajuste, por sua vez, considera também a habilidade do modelo em representar as vazões mínimas observadas (KRAUSE; BOYLE; BÄSE, 2005). De modo geral, os valores obtidos para os postos foram maiores que 0,8, com exceção do posto Fazenda Barra $\left(927,1 \mathrm{~km}^{2}\right)$, que apresentou um coeficiente de 0,68 .

Os erros de volume $(\Delta \mathrm{V})$ e da Q90 $(\Delta \mathrm{Q} 90)$ também foram considerados aceitáveis, sendo mais vantajosos se próximos de zero. Aceitou-se uma variação em até 15 pontos percentuais, para mais ou para menos em relação aos dados observados, conforme sugerido 
por Moriasi et al. (2007). As incertezas inerentes aos dados de entrada do modelo e à operação do Sistema Cantareira na bacia contribuem para uma piora nos valores destas FO.

Na Figura 30 são plotados os valores específicos $\left(1 . \mathrm{s}^{-1} \cdot \mathrm{km}^{-2}\right)$ das vazões médias e da Q90 (observadas e simuladas), com relação à área de drenagem dos postos.

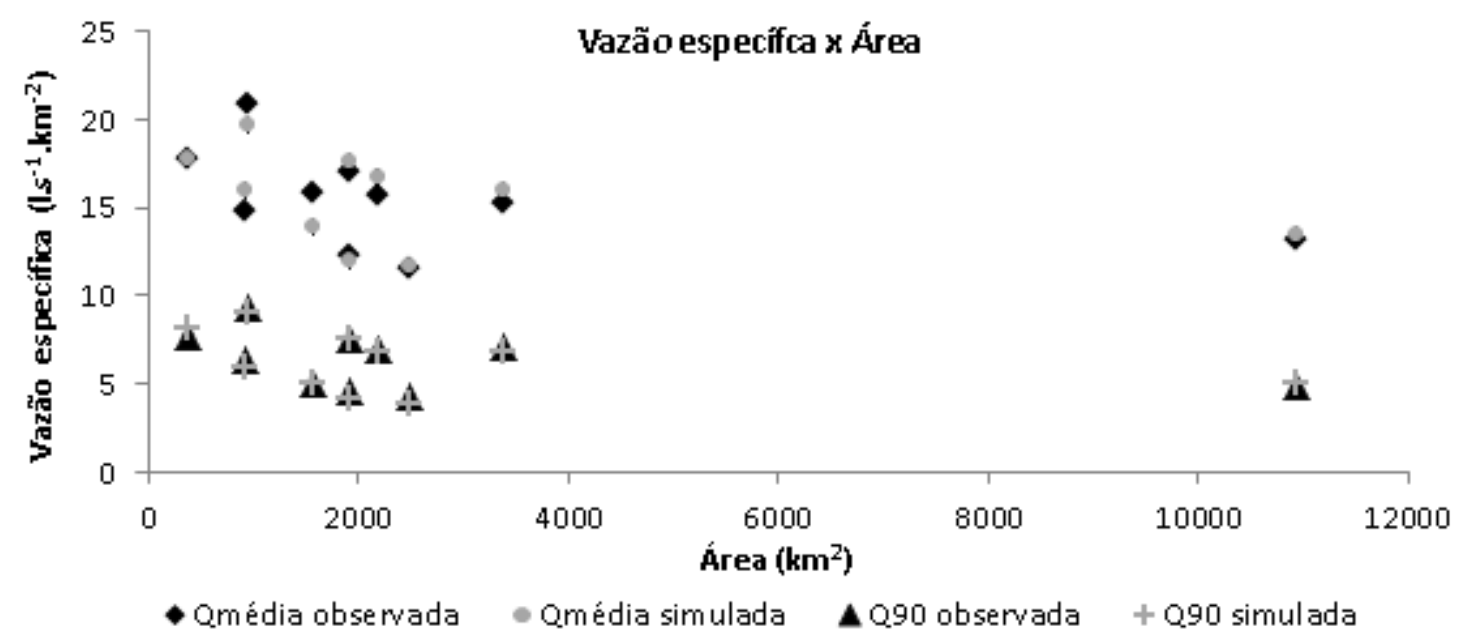

Figura 30. Comparação dos valores de vazões específicas diárias médias (observadas e simuladas) e de $90 \%$ de permanência (observadas e simuladas), com relação à área de drenagem (Fonte: Elaborado pelo autor).

Observou-se significativa oscilação nos valores de vazão específica com relação à mudança do tamanho das bacias. Também se constatou uma tendência de queda nos valores de vazão específica com o aumento da área de drenagem. Alguns dos fatores que interferem neste índice podem ser tanto a operação do Sistema Cantareira quanto a variabilidade da precipitação dentro da bacia.

A análise estatística da correlação entre os valores observados e simulados, mediante avaliação do valor obtido para o coeficiente de determinação $\left(r^{2}\right)$, também é comumente aplicada em análises hidrológicas (NAGHETINI; PINTO, 2007). Através de plotagem em diagramas de dispersão para cada posto fluviométrico (Figura 31), avaliou-se o grau de associação entre dados reais e os calculados na modelagem. 

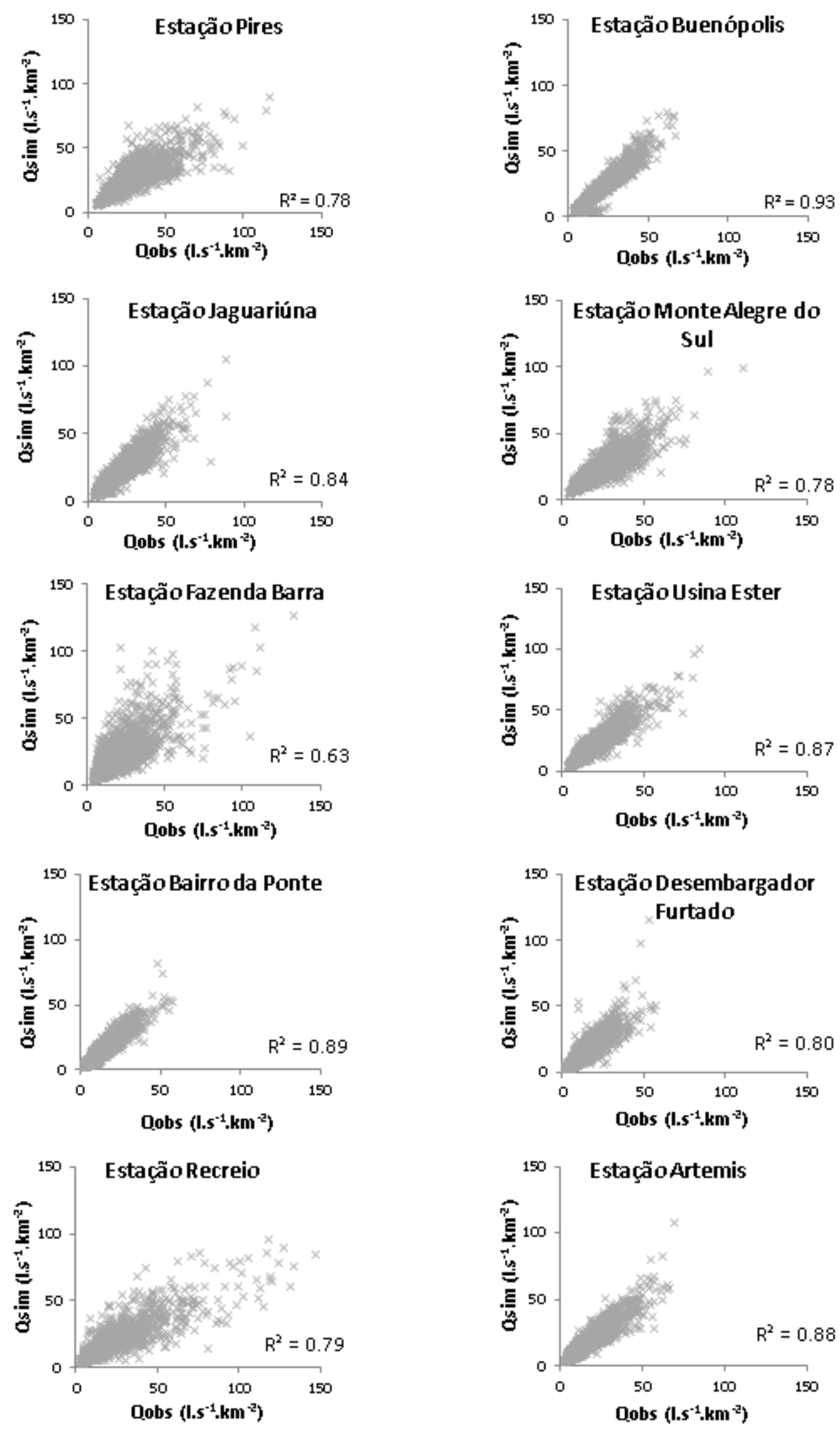

Figura 31. Diagramas de dispersão entre os dados de vazões diárias simuladas (eixo das ordenadas) e observadas (eixo das abscissas) para cada posto fluviométrico (Fonte: Elaborado pelo autor). 
Em suma, pôde-se observar boa correlação entre dados observados e simulados, principalmente com relação às vazões mínimas. A variação dos valores de $r^{2}$ foi de 0,63 para a estação Fazenda Barra $\left(\mathrm{km}^{2}\right)$ e 0,93 na Buenópolis $\left(\mathrm{km}^{2}\right)$. Em apenas quatro, dos dez postos analisados, foi obtido um valor de $r^{2}$ inferior a 0,8. Tratam-se das estações Pires $\left(953,7 \mathrm{~km}^{2}\right)$, Monte Alegre do Sul $\left(386,6 \mathrm{~km}^{2}\right)$, Fazenda Barra $\left(927,1 \mathrm{~km}^{2}\right)$ e Recreio $\left(1.577,5 \mathrm{~km}^{2}\right)$.

Como um teste adicional às simulações realizadas pelo modelo MGB-IPH, foram construídas as curvas de permanência (observada e simulada) para todas as estações fluviométricas utilizadas na calibração. O objetivo deste teste foi avaliar a capacidade do modelo em representar as vazões em diferentes percentis na bacia.

Observou-se um bom ajuste entre as curvas em todos os postos, principalmente no que diz respeito às vazões mínimas, de alta permanência na bacia, objeto deste estudo. Os valores de vazão observada e simulada em cada ponto, no período 1971-1980, são exibidos na Figura 32.

Para as vazões de baixa permanência, não foi observada nenhuma tendência comum a todos os pontos de calibração. Em algumas estações, como por exemplo Buenópolis, Jaguariúna, Fazenda Barra e Usina Ester, o modelo superestimou os valores de vazão com relação aos dados observados. Já nos postos Pires e Recreio, foi representativa a subestimação por parte do modelo. 

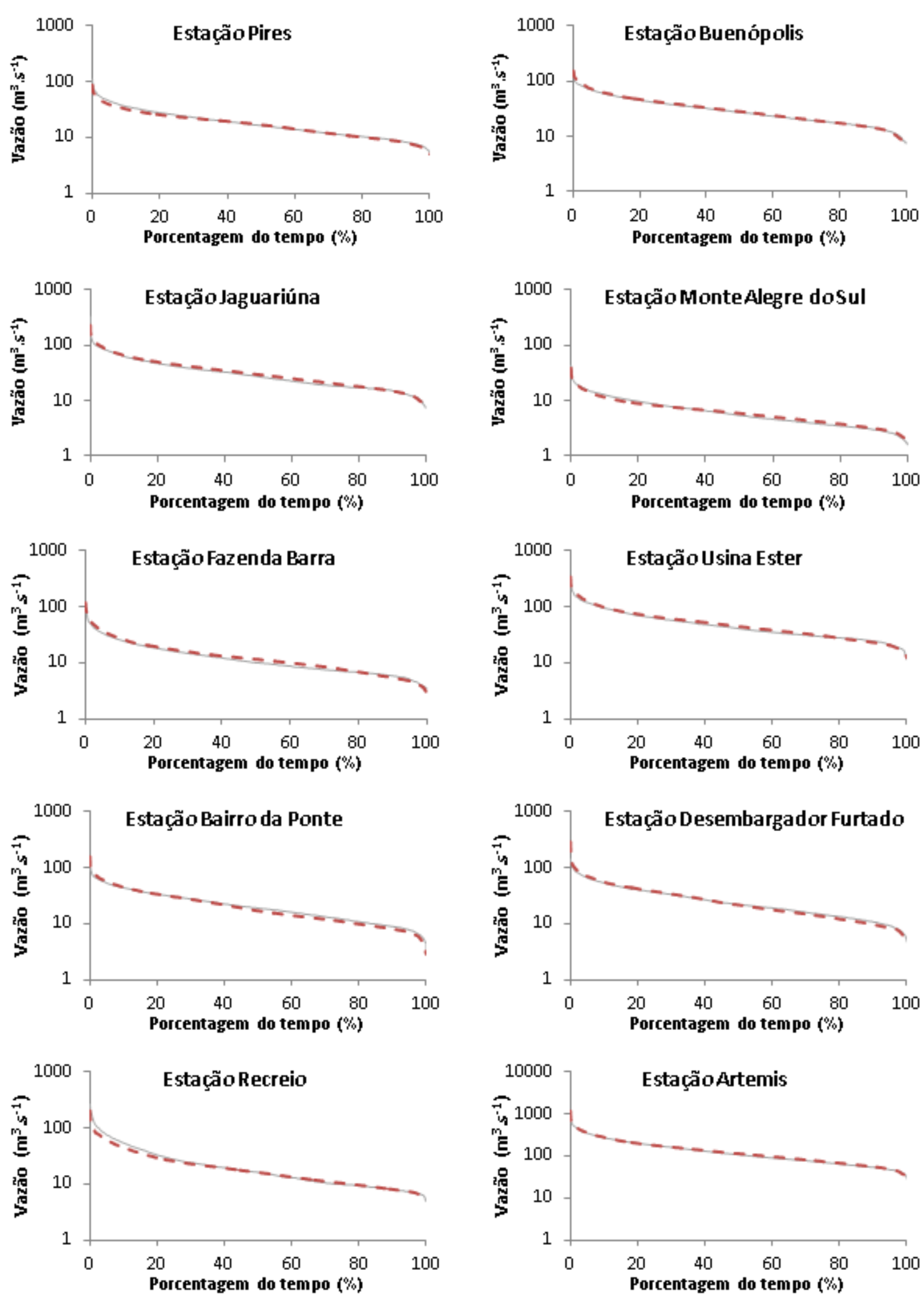

Figura 32. Curvas de permanência dos postos fluviométricos durante a calibração, comparando os dados observados (linha cinza contínua) e simulados (linha vermelha tracejada) (Fonte: Elaborado pelo autor). 


\subsubsection{Validação}

A validação considerou a simulação de um período distinto do utilizado na calibração, que se deu para 1971-1980. O período escolhido para validar o ajuste do modelo correspondente ao intervalo 1981-1990. Contudo, os valores dos parâmetros definidos não sofreram nenhuma alteração com relação ao período anterior.

Assim como na calibração, considerou-se adequada a representação do hidrograma de vazões diárias observadas, através do hidrograma das vazões calculadas na simulação. Em cada um dos postos avaliados pôde-se visualizar aspectos similares entre as duas séries plotadas. Os hidrogramas nas estações Pires (Figura 33), Buenópolis (Figura 34), Jaguariúna (Figura 35), Monte Alegre do Sul (Figura 36), Fazenda Barra (Figura 37), Usina Ester (Figura 38), Bairro da Ponte (Figura 39), Desembargador Furtado (Figura 40), Recreio (Figura 41) e Artemis (Figura 42) demonstram tais afirmações.

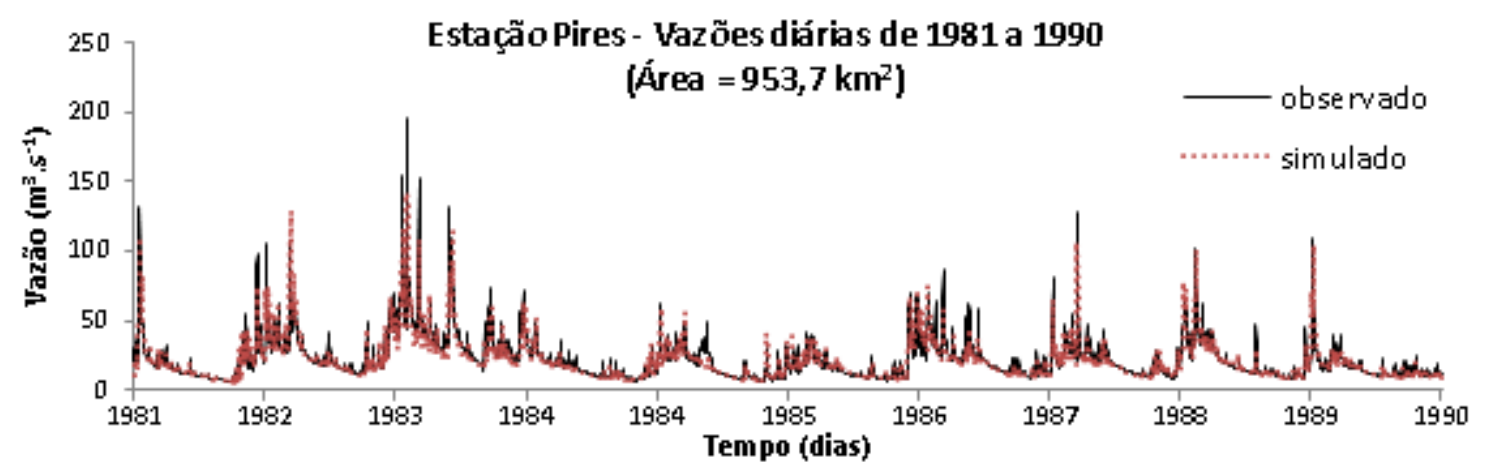

Figura 33. Hidrograma de vazões diárias observadas (linha contínua preta) e simuladas (linha pontilhada vermelha) na estação Pires $\left(953,7 \mathrm{~km}^{2}\right)$, durante a validação, no período de 1981 a 1990 (Fonte: Elaborado pelo autor).

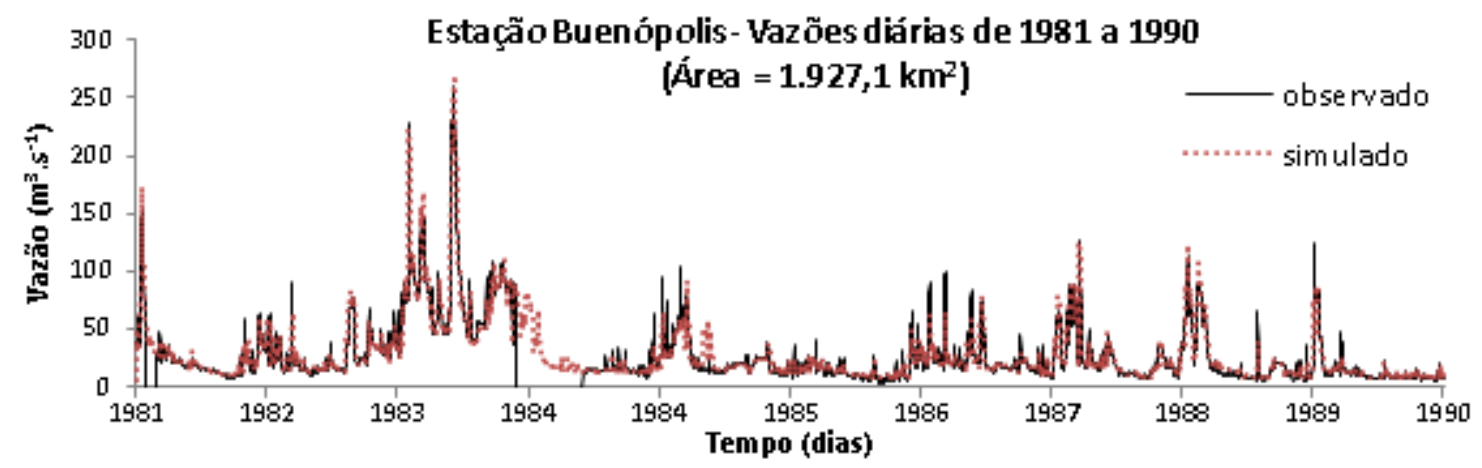

Figura 34. Hidrograma de vazões diárias observadas (linha contínua preta) e simuladas (linha pontilhada vermelha) na estação Buenópolis $\left(1.927,1 \mathrm{~km}^{2}\right)$, durante a validação, no período de 1981 a 1990 (Fonte: Elaborado pelo autor). 


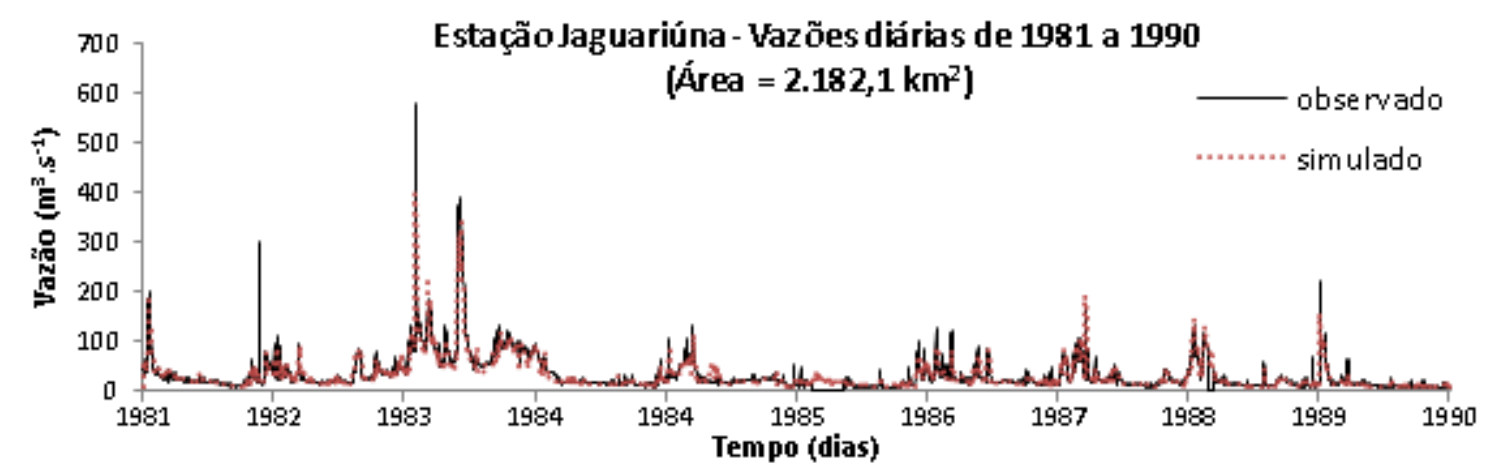

Figura 35. Hidrograma de vazões diárias observadas (linha contínua preta) e simuladas (linha pontilhada vermelha) na estação Jaguariúna $\left(2.182,1 \mathrm{~km}^{2}\right)$, durante a validação, no período de $1981 \mathrm{a}$ 1990 (Fonte: Elaborado pelo autor).

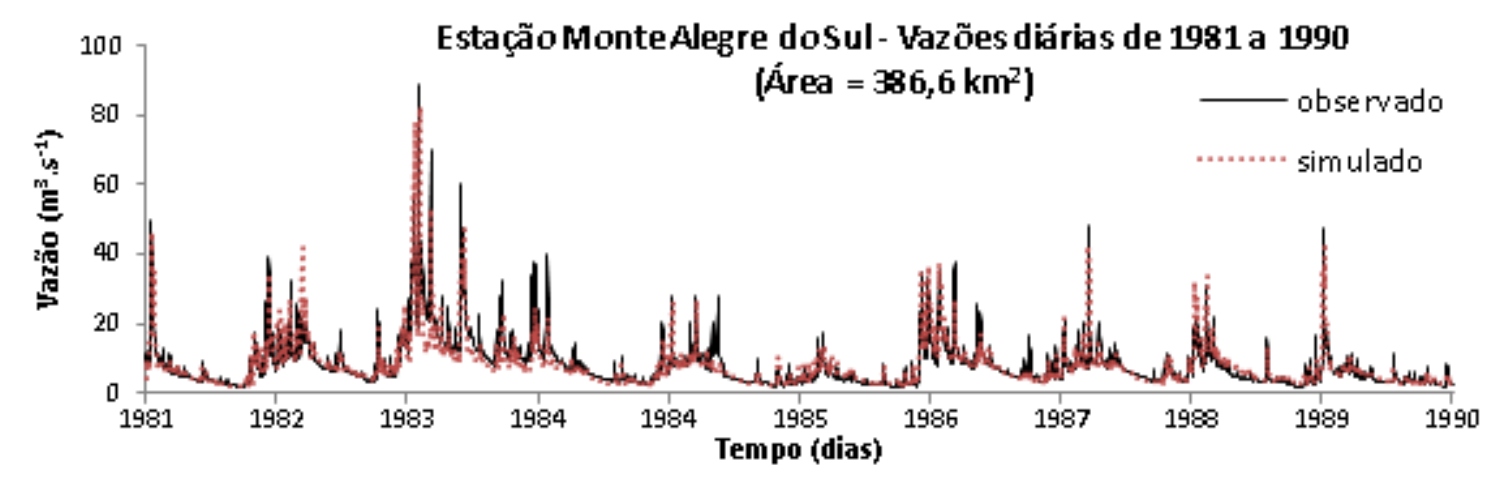

Figura 36. Hidrograma de vazões diárias observadas (linha contínua preta) e simuladas (linha pontilhada vermelha) na estação Monte Alegre do Sul $\left(386,6 \mathrm{~km}^{2}\right)$, durante a validação, no período de 1981 a 1990 (Fonte: Elaborado pelo autor).

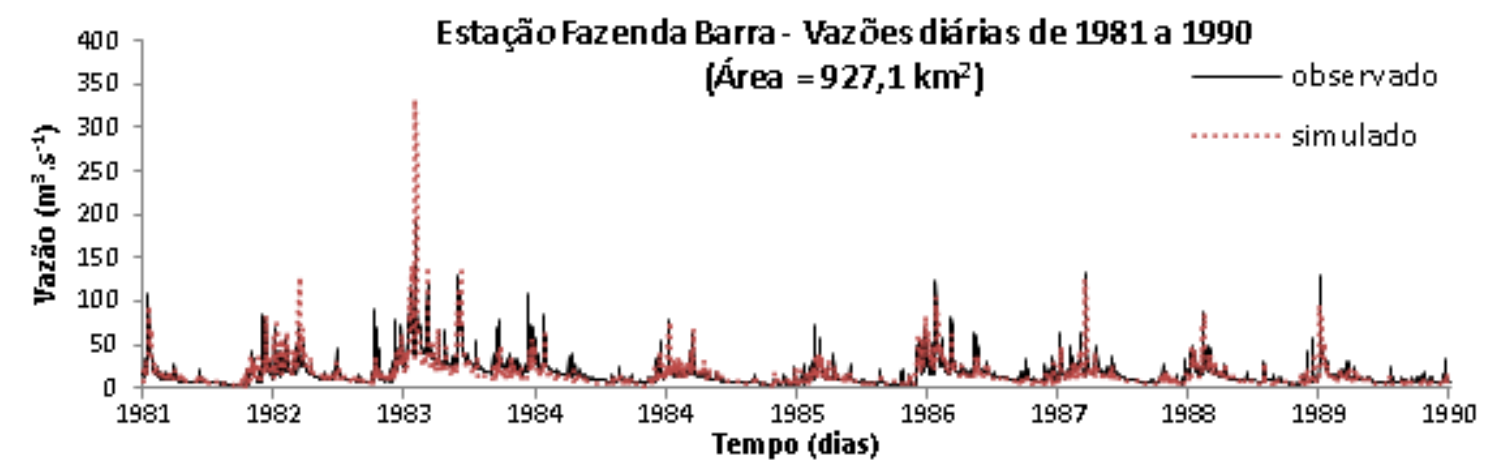

Figura 37. Hidrograma de vazões diárias observadas (linha contínua preta) e simuladas (linha pontilhada vermelha) na estação Fazenda Barra $\left(927,1 \mathrm{~km}^{2}\right)$, durante a validação, no período de 1981 a 1990 (Fonte: Elaborado pelo autor). 


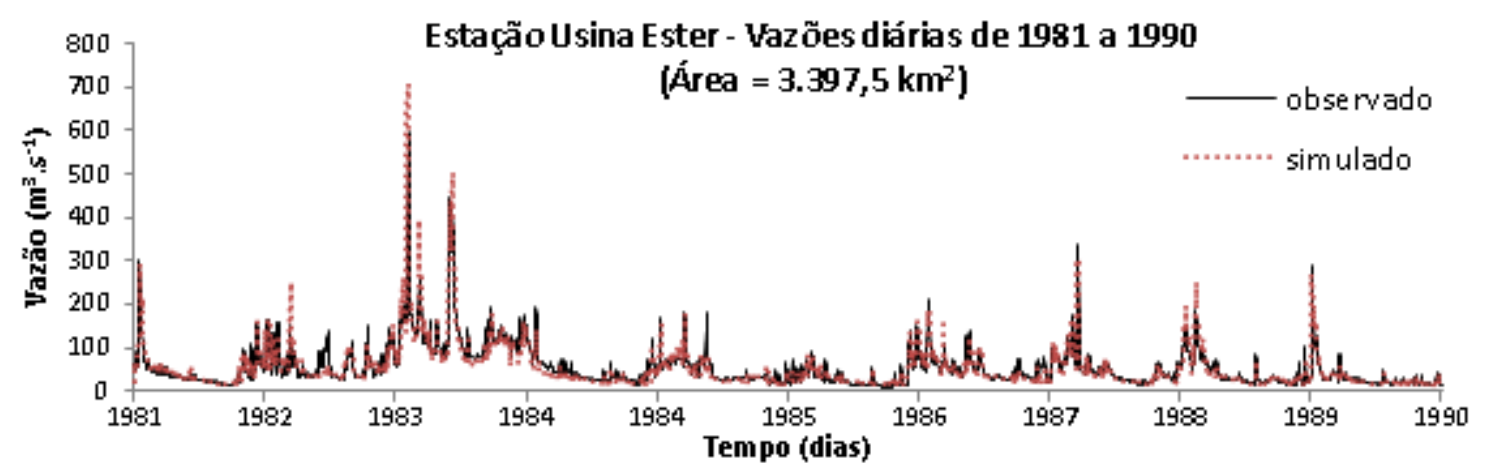

Figura 38. Hidrograma de vazões diárias observadas (linha contínua preta) e simuladas (linha pontilhada vermelha) na estação Usina Ester $\left(3.397,5 \mathrm{~km}^{2}\right)$, durante a validação, no período de 1981 a 1990 (Fonte: Elaborado pelo autor).

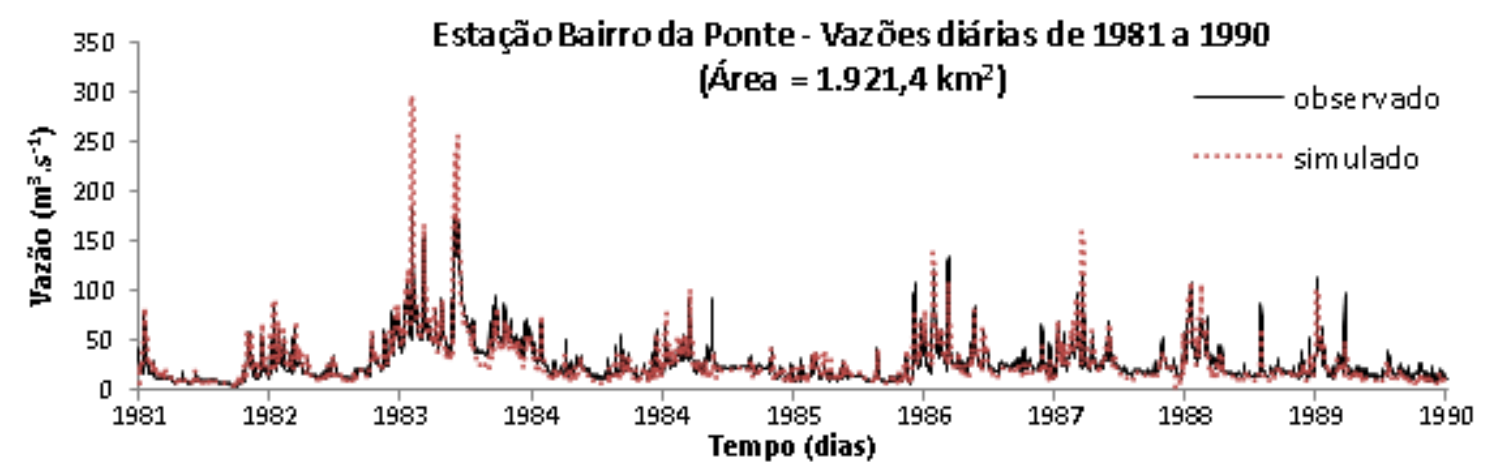

Figura 39. Hidrograma de vazões diárias observadas (linha contínua preta) e simuladas (linha pontilhada vermelha) na estação Bairro da Ponte $\left(1.921,4 \mathrm{~km}^{2}\right)$, durante a validação, no período de 1981 a 1990 (Fonte: Elaborado pelo autor).

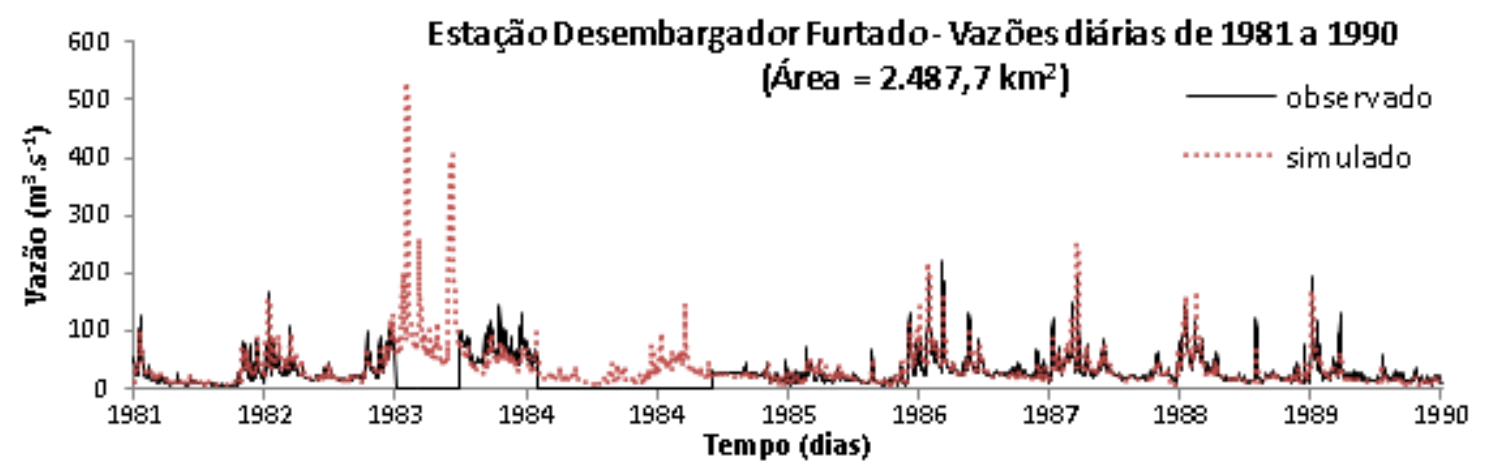

Figura 40. Hidrograma de vazões diárias observadas (linha contínua preta) e simuladas (linha pontilhada vermelha) na estação Desembargador Furtado $\left(2.487,7 \mathrm{~km}^{2}\right)$, durante a validação, no período de 1981 a 1990 (Fonte: Elaborado pelo autor). 


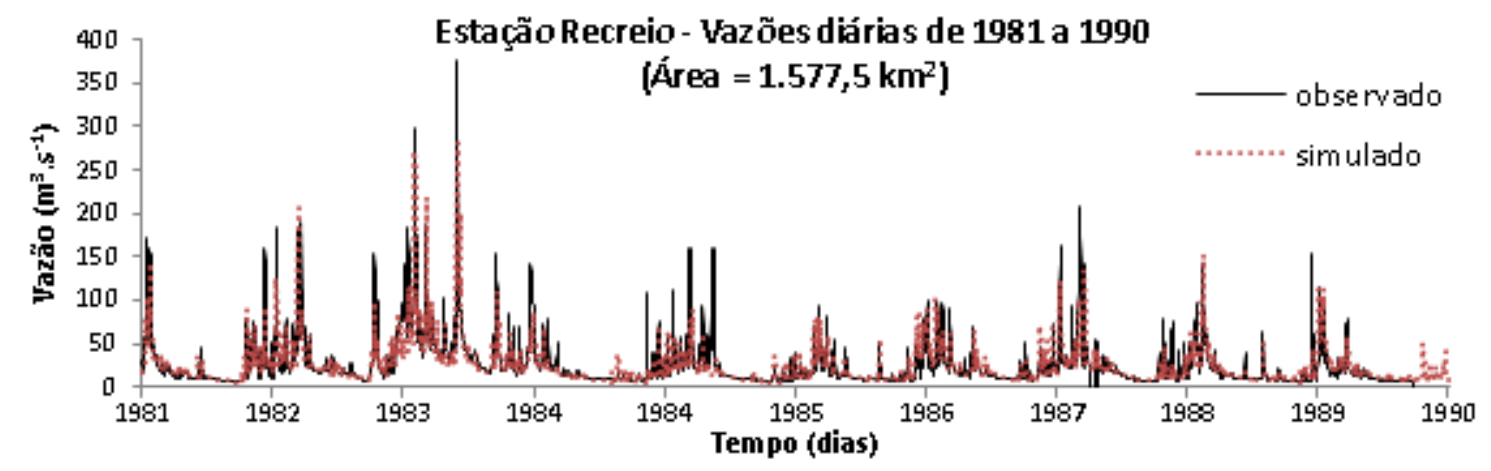

Figura 41. Hidrograma de vazões diárias observadas (linha contínua preta) e simuladas (linha pontilhada vermelha) na estação Recreio $\left(1.577,5 \mathrm{~km}^{2}\right)$, durante a validação, no período de 1981 a 1990 (Fonte: Elaborado pelo autor).

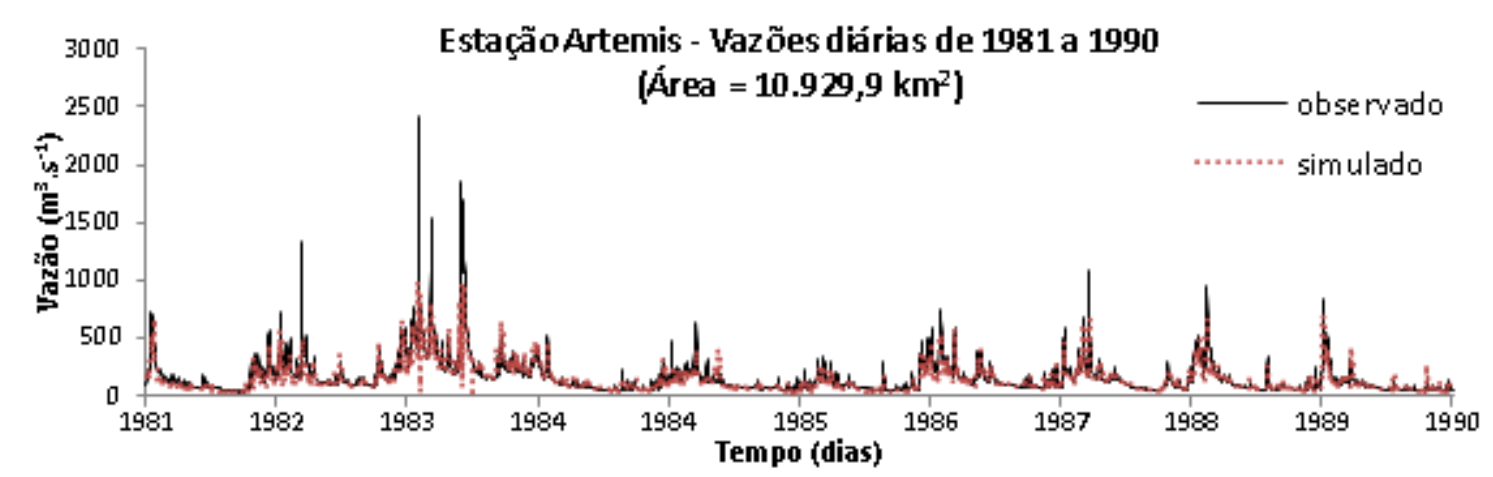

Figura 42. Hidrograma de vazões diárias observadas (linha contínua preta) e simuladas (linha pontilhada vermelha) na estação Artemis $\left(10.292,9 \mathrm{~km}^{2}\right)$, durante a validação, no período de 1981 a 1990 (Fonte: Elaborado pelo autor).

Com relação aos resultados para o NSE, os melhores valores foram alcançados nos postos Pires $\left(953,7 \mathrm{~km}^{2}\right)$, Buenópolis $\left(1.927,1 \mathrm{~km}^{2}\right)$ e Jaguariúna $\left(2.182,1 \mathrm{~km}^{2}\right)$. Em seis, dos dez postos avaliados, obteve-se um aumento no valor de NSE para o período de validação em relação à calibração. Nos postos Recreio $\left(1.577,5 \mathrm{~km}^{2}\right)$ e Artemis $\left(10.929,9 \mathrm{~km}^{2}\right)$ houve uma significativa redução no valor deste índice. A evolução dos valores das FO para os dois períodos estão listados na Tabela 9. 
Tabela 9. Resultados das FO para o período de calibração (1971-1980) e validação (1981-1990) do MGB-IPH na bacia hidrográfica do Rio Piracicaba.

\begin{tabular}{|c|c|c|c|c|c|c|c|c|c|}
\hline \multirow[b]{2}{*}{ Posto } & \multirow{2}{*}{$\begin{array}{c}\text { Área } \\
\left(\mathbf{k m}^{2}\right)^{*}\end{array}$} & \multicolumn{4}{|c|}{ Calibração } & \multicolumn{4}{|c|}{ Validação } \\
\hline & & NSE & $\mathrm{NSE}_{\text {log }}$ & $\begin{array}{l}\Delta V \\
(\%)\end{array}$ & $\begin{array}{c}\Delta Q 90 \\
(\%)\end{array}$ & NSE & $\mathrm{NSE}_{\log }$ & $\begin{array}{l}\Delta V \\
(\%)\end{array}$ & $\begin{array}{c}\Delta Q 90 \\
(\%)\end{array}$ \\
\hline Pires & 953,7 & 0,77 & 0,87 & $-5,51$ & $-3,18$ & 0,86 & 0,91 & $-7,39$ & $-4,25$ \\
\hline Buenópolis & $1.927,1$ & 0,90 & 0,90 & 3,92 & $-1,68$ & 0,95 & 0,94 & $-0,60$ & 6,23 \\
\hline Jaguariúna & $2.182,1$ & 0,82 & 0,87 & 6,19 & $-2,54$ & 0,85 & 0,92 & $-5,55$ & 1,71 \\
\hline Monte Alegre do Sul & 386,6 & 0,78 & 0,85 & $-0,46$ & 5,71 & 0,83 & 0,90 & $-5,28$ & 1,84 \\
\hline Fazenda Barra & 927,1 & 0,54 & 0,68 & 7,69 & $-6,97$ & 0,79 & 0,83 & $-10,25$ & $-17,98$ \\
\hline Usina Ester & $3.397,5$ & 0,84 & 0,87 & 5,39 & $-5,26$ & 0,78 & 0,88 & $-5,44$ & $-0,86$ \\
\hline Bairro da Ponte & $1.921,4$ & 0,86 & 0,85 & $-2,00$ & $-9,77$ & 0,84 & 0,81 & $-4,58$ & $-17,21$ \\
\hline Desembargador Furtado & $2.487,7$ & 0,74 & 0,83 & 1,30 & $-10,64$ & 0,80 & 0,85 & $-4,16$ & $-3,67$ \\
\hline Recreio & $1.577,5$ & 0,75 & 0,86 & $-11,63$ & 1,17 & 0,68 & 0,80 & $-9,87$ & 3,51 \\
\hline Artemis & $10.929,9$ & 0,87 & 0,90 & 2,85 & 3,74 & 0,49 & 0,86 & 11,76 & 2,82 \\
\hline
\end{tabular}

*área considerada na modelagem, referente à discretização da bacia segundo informações do MDE.

Fonte: Elaborado pelo autor.

Para $\mathrm{NSE}_{\mathrm{log}}$, os valores obtidos foram similares aos da calibração. Em alguns postos, inclusive, houve melhora no valor do índice. Esta informação permite afirmar que a manutenção do ajuste com relação ao $\mathrm{NSE}_{\text {log }}$ e a piora nos valores de NSE estão relacionados a representação de vazões máximas na bacia. Isto porque essas vazões interferem no valor de NSE, ao passo que $\mathrm{NSE}_{\text {log }}$ é também influenciado pelas vazões mínimas, sendo estas melhor representadas pelo modelo que as vazões de baixa permanência (máximas).

Com relação aos erros no volume calculado $(\Delta V)$, não foi observada a manutenção de alguma tendência entre os dois períodos de cálculo do modelo. Na grande maioria dos postos os erros foram inferiores a $15 \%$ para mais ou para menos, faixa considerada aceitável (MORIASI et al., 2007). Durante a calibração, em nenhum posto foram obtidos valores de $\Delta \mathrm{V}$ fora desta faixa. Na validação, os resultados desta FO ficaram acima deste limite nas estações Fazenda Barra $\left(927,1 \mathrm{~km}^{2}\right)$ e Artemis $\left(10.929,9 \mathrm{~km}^{2}\right)$.

No erro da simulação da Q90 ( $\Delta$ Q90), também não foram identificadas tendências na diferença entre as vazões geradas pelo modelo e as observadas. Durante a calibração, a 
estação Desembargador Furtado $\left(2.487,7 \mathrm{~km}^{2}\right)$ ficou fora da faixa desejável. Na validação, Fazenda Barra $\left(927,1 \mathrm{~km}^{2}\right)$ e Bairro da Ponte $\left(1.921,4 \mathrm{~km}^{2}\right)$ foram os postos com os maiores erros percentuais.

A aptidão do modelo em representar as vazões na bacia foi mantida durante a validação. Apesar dos resultados para a vazão média específica terem sido um pouco piores do que durante a calibração, a representação da Q90 pelo modelo se manteve bastante satisfatória (Figura 43).

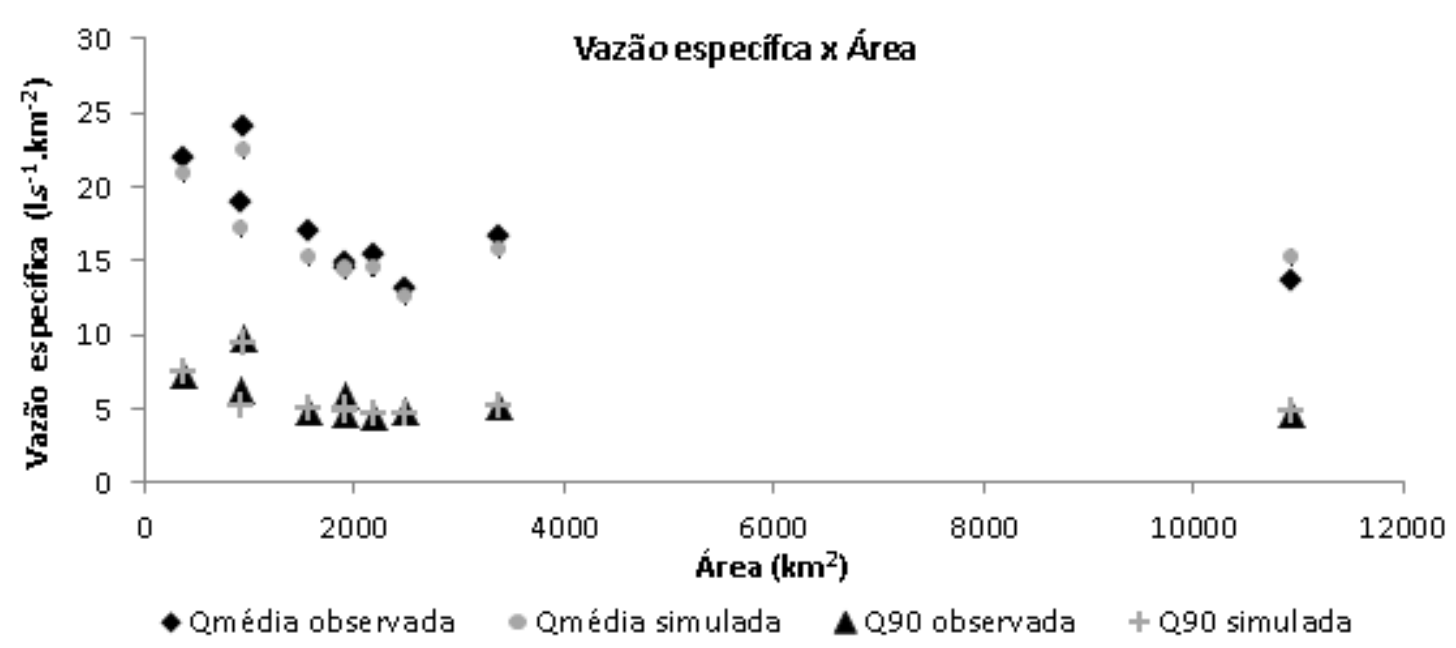

Figura 43. Comparação dos valores de vazões específicas diárias médias (observadas e simuladas) e de $90 \%$ de permanência (observadas e simuladas), com relação à área de drenagem (Fonte: Elaborado pelo autor).

Os coeficientes de determinação $\left(r^{2}\right)$ para cada posto fluviométrico, decorrentes da correlação entre os dados observados e simulados, são exibidos na Figura 44. Assim como os coeficientes, têm-se os diagramas de dispersão entre as saídas do modelo e os dados observados. 

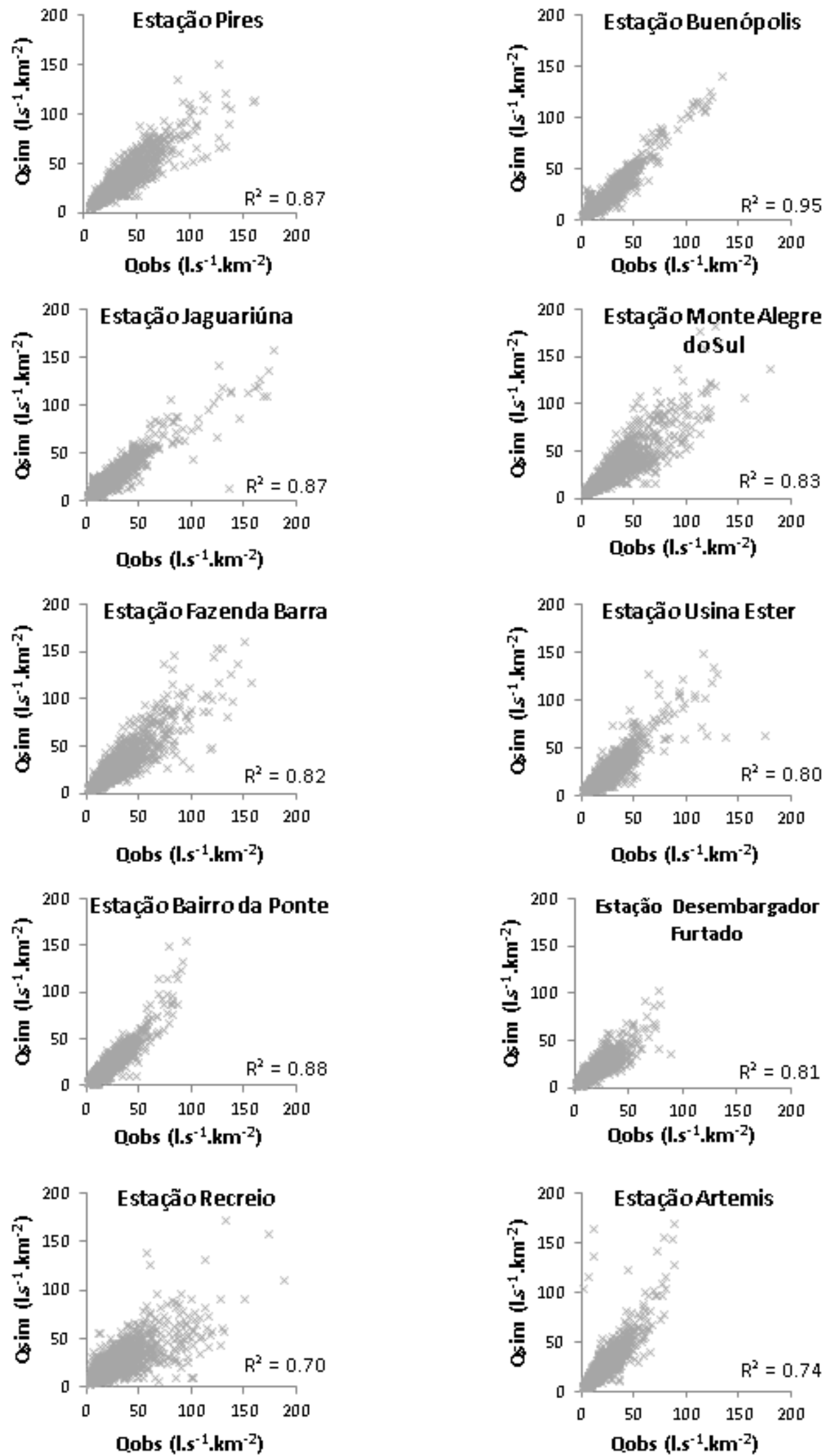

Figura 44. Diagramas de dispersão entre dados de vazões diárias simuladas (eixo das ordenadas) e observadas (eixo das abscissas) para cada posto fluviométrico (Fonte: Elaborado pelo autor). 
A construção das curvas de permanência também possibilitou a análise dos resultados da validação. $\mathrm{O}$ ajuste das vazões simuladas, de acordo com a possibilidade de excedência, foi bastante próximo da realidade observada na bacia. A Figura 45 demonstra as curvas de permanência obtidas em todos os postos considerados. 

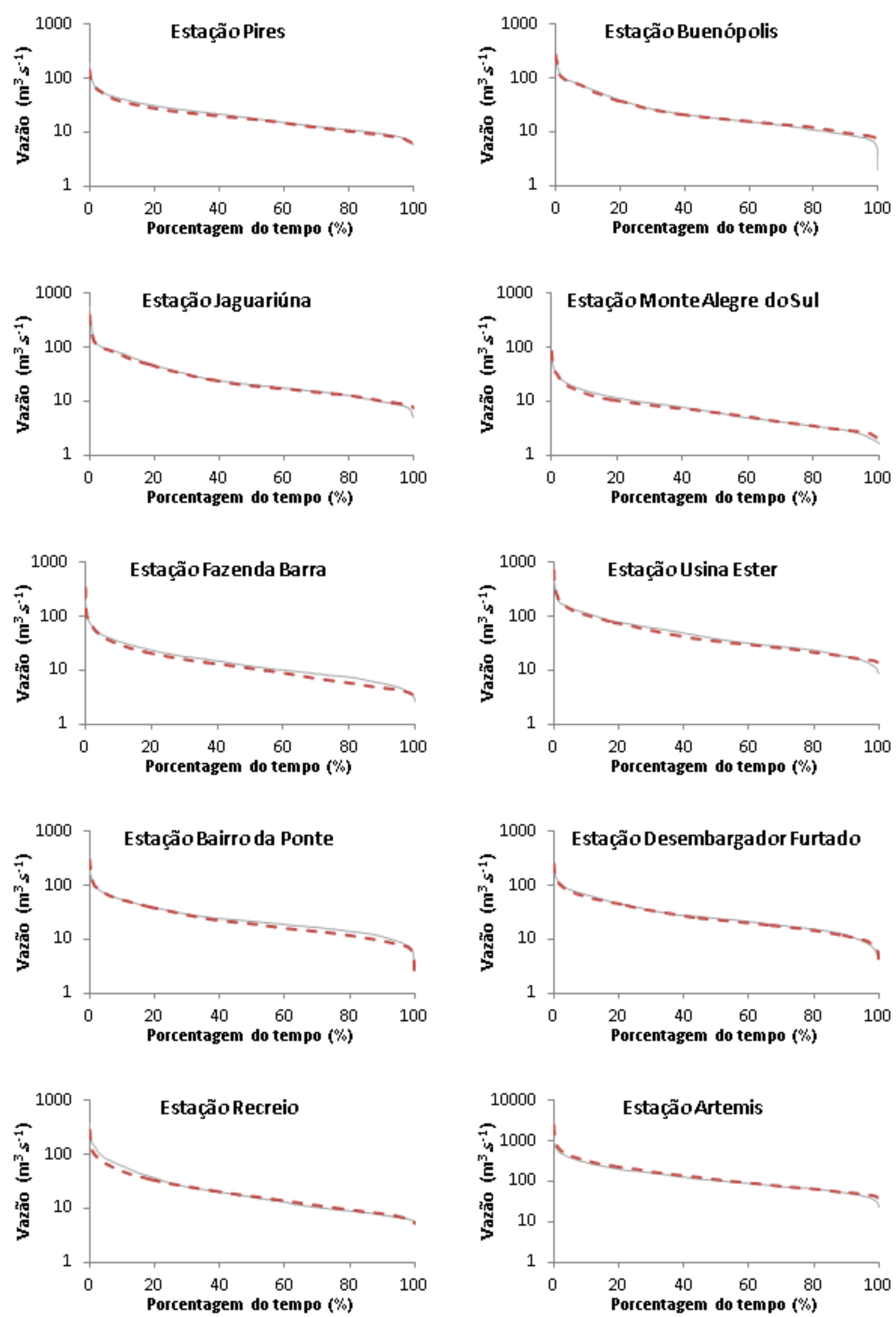

Figura 45. Curvas de permanência dos postos fluviométricos durante a validação, referentes a dados observados (linha contínua) e simulados (linha tracejada) (Fonte: Elaborado pelo autor). 


\subsection{CONSIDERAÇÕES FINAIS}

Foi realizada a calibração e a validação do modelo MGB-IPH na bacia hidrográfica do Rio Piracicaba, para 10 bacias afluentes, com áreas de drenagem entre 386,6 km² e 10.929,9 $\mathrm{km}^{2}$. Apesar das incertezas envolvidas, os resultados demonstraram que o modelo pode ser considerado apto a representar as vazões médias e a Q90.

Obteve-se um bom ajuste das FO, para os períodos de calibração (1971-1980) e validação (1981-1990). O NSE variou entre 0,54 e 0,9 durante a calibração e 0,49 e 0,95 na validação. O NSElog variou entre 0,68 e 0,9 no primeiro período e 0,8 e 0,94 no segundo. 0 $\Delta V$ foi semelhante entre os períodos, com variações de $-11,6 \%$ a $7,69 \%$ na calibração e $10,3 \%$ a $11,8 \%$ na validação. O $\Delta Q 90$ variou entre $-10,6 \%$ e 5,7\% na calibração e -18 e 6,2 na validação. 


\section{PROJEÇÕES DE VAZÕES MÍNIMAS NA BACIA DO RIO PIRACICABA COM BASE EM CENÁRIOS DE MUDANÇAS GLOBAIS PARA O PERÍODO 2013-2099}

\subsection{INTRODUÇÃO}

As mudanças globais abrangem a complexidade das mudanças no clima, ecossistemas, economia e sociedade. Diretamente causadas ou não por atividades antrópicas, atuam em escalas global e local. Essas escalas se inter-relacionam, sendo reflexos e causas de impactos entre si (WILBANKS; KATES, 1999). Uma técnica comumente utilizada na compreensão entre as complexas interações entre esses atores de mudança é o desenvolvimento e utilização de cenários (MOSS et al., 2010).

As mudanças climáticas podem ocasionar o aumento da ocorrência de eventos extremos, causando enchentes e estiagens mais intensas e recorrentes (IPCC, 2007; 2012). Mudanças climáticas, associadas a mudanças no uso das terras e atividades antrópicas, causam alterações nas propriedades físicas e processos na superfície terrestre. Essas modificações causam impactos no ciclo hidrológico e no balanço de energia (FOHRER et al., 2001; POFF; BLEDSOE; CUHACIYAM, 2006; KUNDZEWICZ et al., 2007; DUFEK; AMBRIZZI, 2008; LI et al., 2009; GOSLING et al., 2011; MANGO et al., 2011; TONG et al., 2011; WADA; VAN BEEK; BIERKENS, 2011).

$\mathrm{Na}$ escala de bacias hidrográficas, induzidas ou não pelo homem, as mudanças impõem grande desafio aos hidrólogos. Isto devido à baixa disponibilidade de dados observados que possam ser utilizados na calibração de modelos hidrológicos ou na extrapolação temporal sob condições de mudanças (WAGENER et al., 2010).

O uso de modelos no estudo do comportamento de variáveis hidrológicas, sob diferentes condições de mudança, é importante na análise dos riscos e na gestão sustentável dos recursos hídricos (BERGSTRÖM et al., 2001; VAN PELT et al., 2009; BUYTAERT et al., 2010; KINGSTON; TAYLOR, 2010; TE LINDE et al., 2010; TERINK et al., 2010; WAGENER et al., 
2010; ARNELL, 2011; GOSLING et al., 2011; HAGEMANN et al., 2011; NÓBREGA et al., 2011). Todavia, o comportamento dos parâmetros de calibração dos modelos, sob condições de mudanças globais, ainda é incerto (SINGH et al., 2011).

A acoplagem entre modelos hidrológicos e climáticos agrega grande potencial à análise dos efeitos das mudanças globais sobre os recursos hídricos (HURKMANS et al., 2010; PIANI et al., 2010; TERINK et al., 2010; GOSLING et al., 2011). Esta estratégia utiliza o modelo climático como forçante das condições de simulação do modelo hidrológico. Entretanto, essa acoplagem pode ocorrer de diversas maneiras, conforme situações de modelagem e disponibilidade de dados.

Modelos de Circulação Globais (MCGs) simulam numericamente o comportamento de componentes como a atmosfera, hidrologia, uso da terra, pedologia e biosfera. Também consideram as interações entre essas componentes (LAPRISE, 2008; NOBRE; SAMPAIO; SALAZAR, 2008). Tem-se, portanto, nesses modelos, uma importante ferramenta na projeção de cenários que contemplem o comportamento de variáveis climáticas no futuro (FOWLER; BLEKINSOP; TEBALDI, 2007; LAPRISE, 2008; NOBRE; SAMPAIO; SALAZAR, 2008; PESQUERO et al., 2009).

Contudo, antes de serem utilizados, dados oriundos de modelos climáticos podem ser tratados por técnicas de downscaling para correção de erros decorrentes da escala e incertezas da modelagem. O downscaling dinâmico considera a utilização de modelos climáticos regionais (MCRs) para refinamento espacial dos resultados de um MCG (LAPRISE, 2008). Assim, o MCR é rodado segundo condições de contorno e forçantes definidas pelo modelo global. Já o downscaling estatístico utiliza modelos estatísticos para a definição da relação entre os dados climáticos modelados em grande escala (MCG ou MCR) e o clima local (WILBY et al., 2004; SUNYER; MADSEN; ANG, 2012). A principal vantagem de métodos estatísticos são o baixo gasto computacional e a facilidade de aplicação a saídas de MCGs e MCRs (WILBY et al., 2004). Exemplos de aplicações de técnicas de downscalling estatístico (LEANDER; BUISHAND, 2007; MENDES; MARENGO, 2010; TERINK et al., 2010; PIANI et al., 2010; PIANI; HAERTER; COPPOLA, 2010; CHEN; BRISSETTE; LECONTE, 2011; SUNYER; MADSEN; ANG, 2012) e dinâmico (MISRA; DIRMEYER; KIRTMAN, 2003; CASTRO; PIELKE; LEONCINI, 2005; HAYLOCK et al., 2006; CHOU et al., 2011; TAPIADOR et al., 2011; DI LUCA; ELÍA; LAPRISE, 2012; PILOTTO; CHOU; NOBRE, 2012) têm sido objeto de frequente análise em trabalhos científicos. 
As incertezas envolvidas vão, desde a concepção e aplicação do modelo hidrológico (BEVEN, 2012; LOOPER; VIEUX; MORENO, 2012), até a escolha do modelo climático (NÓBREGA et al., 2011; SINGH et al., 2011). Também merecem menção as incertezas devido aos níveis de emissão de gases de efeito estufa que nortearão o MCG (CHEN; BRISSETTE; LECONTE, 2011), a escala dos modelos climáticos para estudos de impactos hidrológicos (WILLEMS; VRAC, 2011) e o método de downscaling dos dados (SUNYER; MADSEN; ANG, 2012). Ainda assim, as incertezas relacionadas à modelagem climática superam as envolvidas na modelagem hidrológica (PRUDHOMME; DAVIES; 2009; GOSLING et al., 2011; SUNYER; MADSEN; ANG, 2012) e o uso de simulações que considerem múltiplos modelos climáticos contribui pela busca de resultados mais coerentes (BAUWENS; SOHIER; DEGRÉ, 2011).

Neste horizonte de mudanças, faz-se importante a projeção da variação de situações decorrentes de situações de precipitação extremas. Uma das variáveis que mais interferem na calibração e nos resultados da aplicação de modelos hidrológicos distribuídos é a precipitação (CHIEW, 2006; CHIEW et al., 2009). Nesse sentido, situações de precipitação extremas interferem na ocorrência de vazões extremas máximas e mínimas.

Em condições de mudanças globais, em longo prazo, a análise do impacto em vazões extremas é de suma importância na quantificação dos riscos em bacias hidrográficas. Sob o ponto de vista de gestão dos recursos hídricos e do gerenciamento de desastres, são mais importantes do que análises com relação a alterações nas vazões médias (HURKMANS et al., 2010; GOSLING et al., 2011).

Este capítulo tem como objetivo realizar projeções de vazões mínimas anuais em cinco sub-bacias da bacia hidrográfica do Rio Piracicaba, para o período 2013-2099. Para a região sudeste do país, onde está localizada a área de estudo, são projetadas situações de vulnerabilidade a eventos extremos de precipitação, bem como a intensas situações de estiagem. Além da influência da componente meteorológica, a região possui alta densidade populacional e a intervenção antrópica nos ecossistemas é intensa (CAVALCANTI, 2012).

Foram considerados cinco cenários de mudança propostos, mediante utilização de dados hidrológicos, climáticos e de uso da terra como entrada no modelo hidrológico MGBIPH calibrado e validado. Para tal, foram necessários tratamentos e correções aos dados de precipitação, decorrentes de projeções climáticas realizadas pelo modelo regional Eta-CPTEC (CPTEC/INPE). Também foram consideradas variações na disponibilidade hídrica da bacia, decorrentes de diferentes condições de operação do Sistema Cantareira. 


\subsection{METODOLOGIA}

Nos itens a seguir são descritos os passos seguidos para realizar a correção dos valores de precipitação gerados pelo modelo Eta-CPTEC, com base nos valores observados no período 1971-1990. Em seguida, tem-se a descrição dos cenários considerados para a projeção das vazões mínimas na bacia, através de modelagem hidrológica utilizando o modelo MGB-IPH.

As condições de variabilidade climática foram utilizadas conforme saídas do modelo Eta-CPTEC. Além das condições climáticas, integraram as mudanças globais a possibilidade de mudança no uso das terras e as variações da disponibilidade hídrica na bacia, para o período de 2013 a 2099.

\subsubsection{Dados de projeções climáticas}

Os dados de clima e precipitação, necessários para entrada no modelo, são saídas resultantes da simulação do modelo regional atmosférico Eta-CPTEC, segundo condições de perturbação do membro controle (CHOU et al., 2011; MARENGO et al., 2012). O modelo EtaCPTEC é um modelo de pontos de grade, operado no Centro de Previsão de Tempo e Estudos Climáticos do Instituto Nacional de Pesquisas Espaciais (CPTEC/INPE).

As saídas do modelo possuem resolução espacial horizontal de $40 \mathrm{~km}$, e os valores das variáveis climáticas foram acumulados em passo de tempo diário, representando as condições climáticas futuras no período 2011-2099. As variáveis utilizadas foram temperatura, velocidade do vento, radiação (convertida para insolação), temperatura do ponto de orvalho (convertida para umidade relativa) e precipitação. As condições de contorno das simulações climáticas foram geradas pelo modelo de circulação global HadCM3 (GORDON et al., 2000; COLLINS; TETT; COOPER, 2001), do UK Met Office Hadley Centre.

O cenário de emissões de gases de efeito estufa considerado na simulação é o A1B (IPCC, 2000) conforme o Quarto Relatório de Avaliação (AR4) do Painel Intergovernamental de Mudanças Climáticas - IPCC (do inglês, Intergovernmental Pannel on Climate Change). Este cenário projeta um rápido crescimento econômico, contemplando um balanço entre o uso de combustíveis fósseis e o crescimento da participação de tecnologias limpas (IPCC, 2007). 


\subsubsection{Acoplagem entre os modelos Eta-CPTEC e MGB-IPH}

Para a realização da modelagem hidrológica de longo prazo, para previsão das vazões, foi necessária a coleta dos dados climáticos e da precipitação. Tais dados foram coletados junto ao CPTEC/INPE, onde o modelo Eta-CPTEC é utilizado para previsão climática desde 1996 (CHOU et al., 2011). A área de abrangência dos dados coletados considerou o retângulo envolvente à bacia hidrográfica do Rio Piracicaba.

Após a coleta dos dados, foi necessário o processamento dos mesmos para que houvesse a conexão entre os modelos propostos. Optou-se pelo método de acoplamento livre (NYERGES, 1991; PULLAR; SPRINGER, 2000), ou seja, os dois modelos são operados separadamente, e a conexão entre os dois se dá via troca de arquivos de saída.

Porém, para que possam ser utilizadas, as saídas do modelo regional Eta-CPTEC devem ser adaptadas para entrada no modelo hidrológico MGB-IPH. Isso porque os dados climáticos encontram-se em formato de pontos de grade regular, conforme ilustrado na Figura 46.

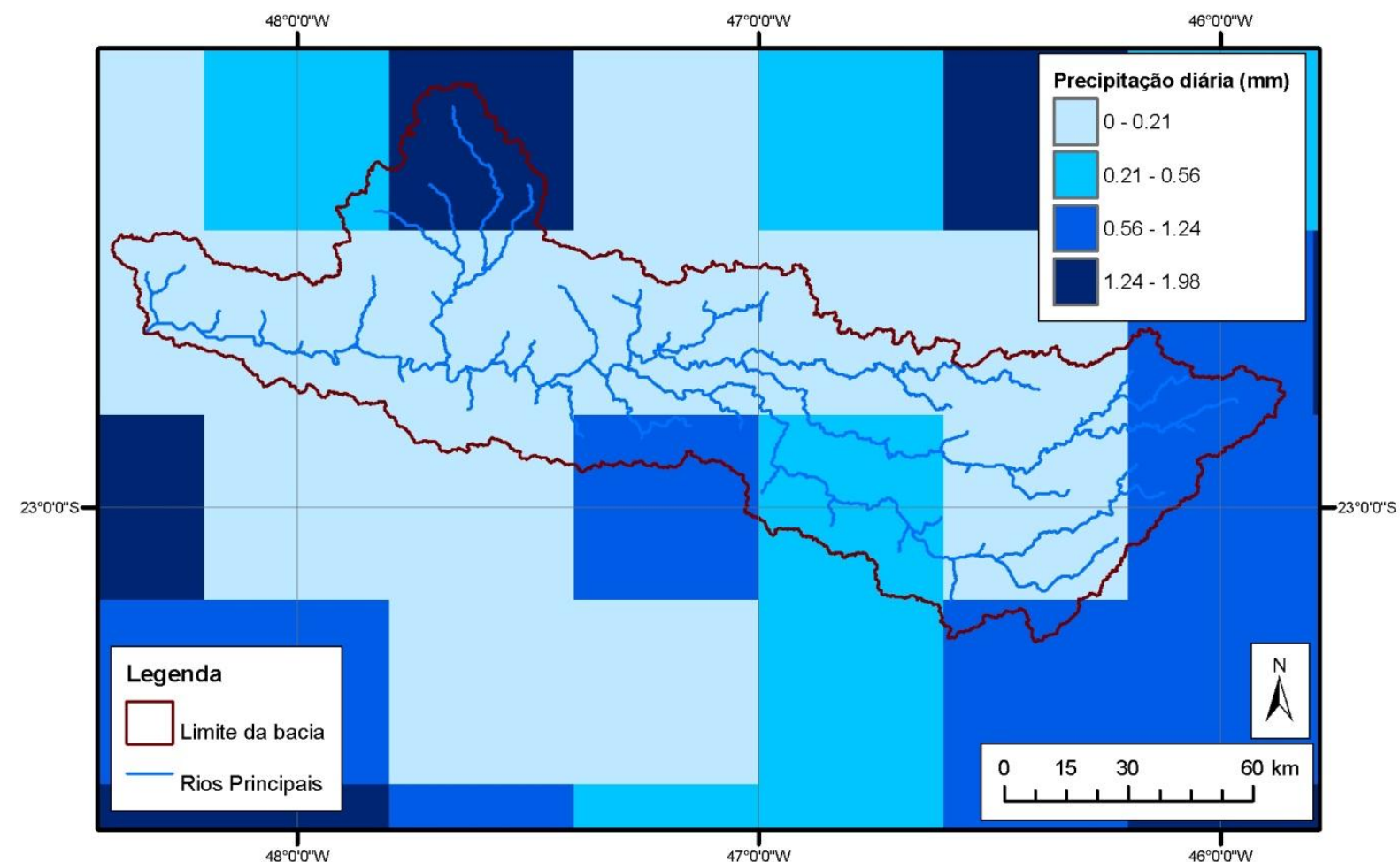

Figura 46. Exemplo de dados de precipitação gerado pelo modelo Eta-CPTEC, no formato de pontos de grade (Fonte: Elaborado pelo autor). 
O código utilizado do MGB-IPH não lê estes dados neste formato. Assim, adotou-se a estratégia de gerar centróides para cada ponto de grade utilizado na modelagem. Foi elaborado um algoritmo simples, responsável pela acumulação dos dados em cada ponto gerado. Esses pontos seriam equivalentes a postos meteorológicos, com dados diários para todas as variáveis climáticas necessárias, já no formato de entrada do MGB-IPH (Figura 47).

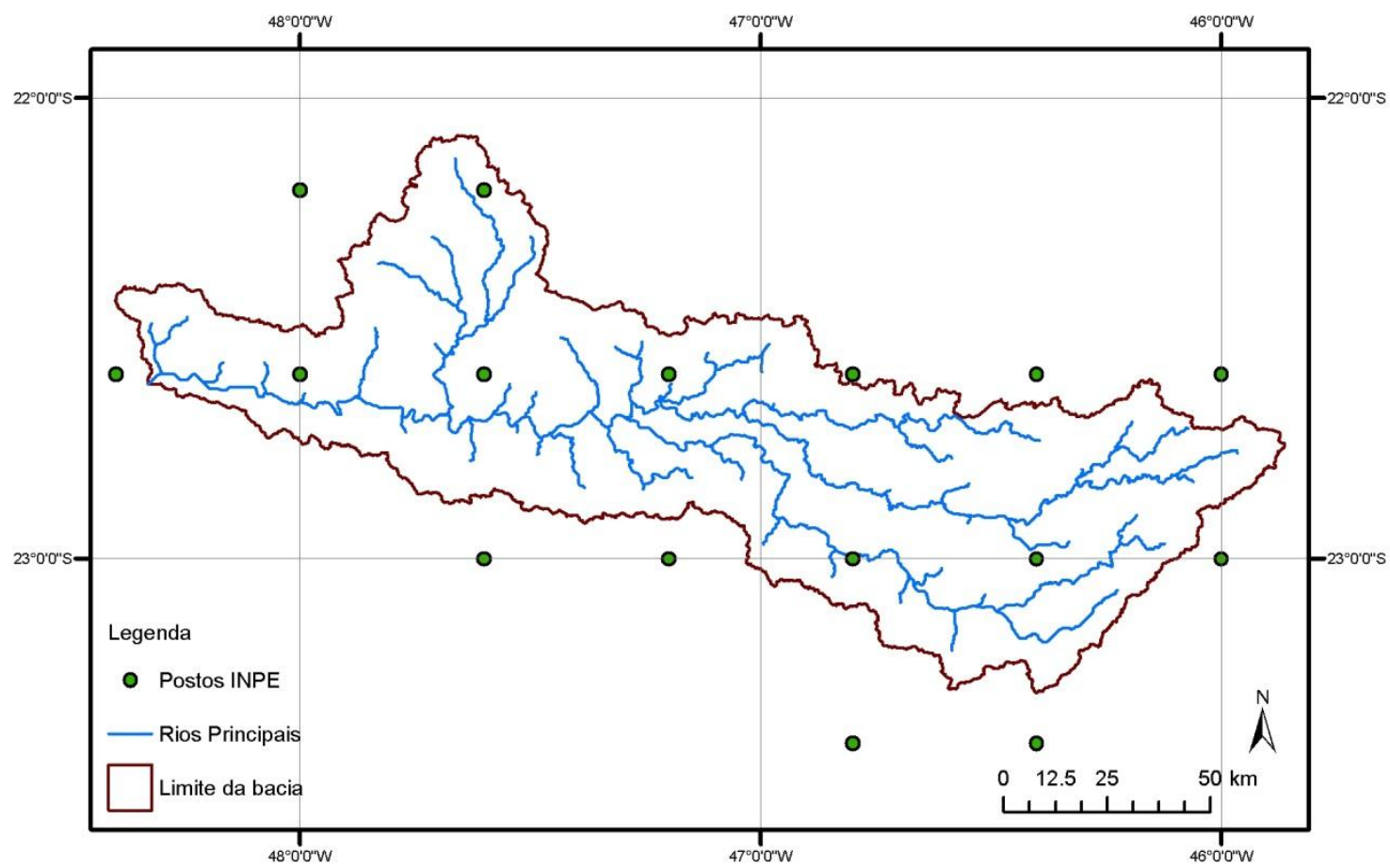

Figura 47. Postos climatológicos gerados a partir da grade do modelo CPTEC-ETA (Fonte: Elaborado pelo autor).

\subsubsection{Conversão de dados de variáveis climáticas}

O código do algoritmo criado também realizou a conversão das unidades do modelo Eta-CPTEC para as unidades usadas como entrada no MGB-IPH. Neste item tem-se a síntese das variáveis utilizadas e do método adotado para conversão das mesmas para o formato adequado, em escala temporal diária. O detalhamento do procedimento e das equações utilizadas encontram-se no Apêndice $C$ deste trabalho.

Após as devidas correções e adaptações, têm-se os valores de todas as variáveis para os períodos passado e futuro. A Tabela 10 exibe uma síntese das variáveis climáticas, as unidades de saída do modelo Eta-CPTEC e as unidades necessárias para entrada no MGB$\mathrm{IPH}$. 
Tabela 10. Unidades das variáveis de saída do modelo Eta-CPTEC e o formato ao qual devem ser convertidas para entrada no MGB-IPH.

\begin{tabular}{|c|c|c|}
\hline Variável & Saída Eta-CPTEC & Entrada MGB-IPH \\
\hline Insolação & Radiação, em W.m ${ }^{-2}$ & $\begin{array}{c}\text { Insolação, em horas diárias } \\
\text { de sol }\end{array}$ \\
\hline Precipitação & Em metros & Em milímetros \\
\hline Pressão atmosférica & $\mathrm{Em} \mathrm{hPa}$ & $\mathrm{Em} \mathrm{kPa}$ \\
\hline Temperatura & Em Kelvin & Em graus Celsius \\
\hline Umidade relativa & $\begin{array}{l}\text { Temperatura da superfície } \\
\text { e temperatura do ponto de } \\
\text { orvalho, em graus Celsius }\end{array}$ & $\begin{array}{c}\text { Umidade relativa do ar, em } \\
\text { porcentagem }\end{array}$ \\
\hline Velocidade do vento & $\begin{array}{c}\text { Em m.s } s^{-1} \text {, a dez metros de } \\
\text { altura }\end{array}$ & $\begin{array}{c}\mathrm{Em} \mathrm{m} \cdot \mathrm{s}^{-1} \text {, a dois metros de } \\
\text { altura }\end{array}$ \\
\hline
\end{tabular}

Fonte: Elaborado pelo autor.

Através da Figura 48 pretende-se apenas ilustrar a situação das variáveis climáticas na bacia. Optou-se aleatoriamente pelo mês de janeiro do ano 2041, onde são demonstrados os valores médios mensais interpolados entre os pontos gerados, para cada variável, na bacia. 


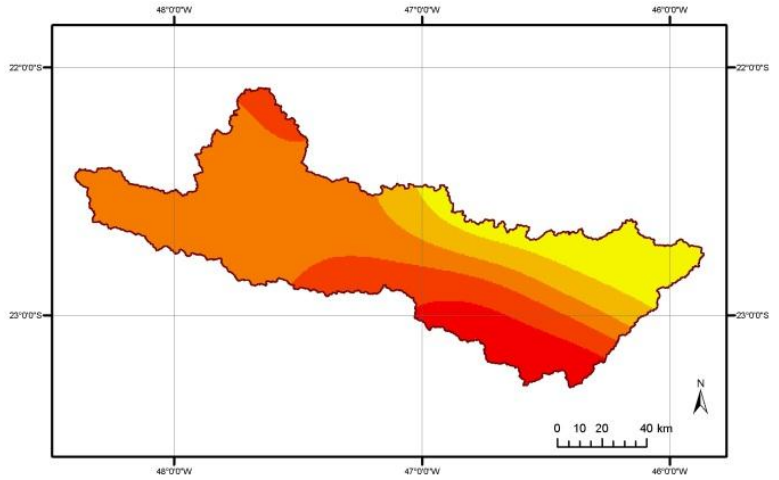

Temperatura média diária (graus Celsius)

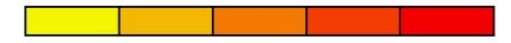

$\begin{array}{llllll}23,17 & 23,83 & 24,39 & 24,88 & 25,48 & 26,57\end{array}$

(a)

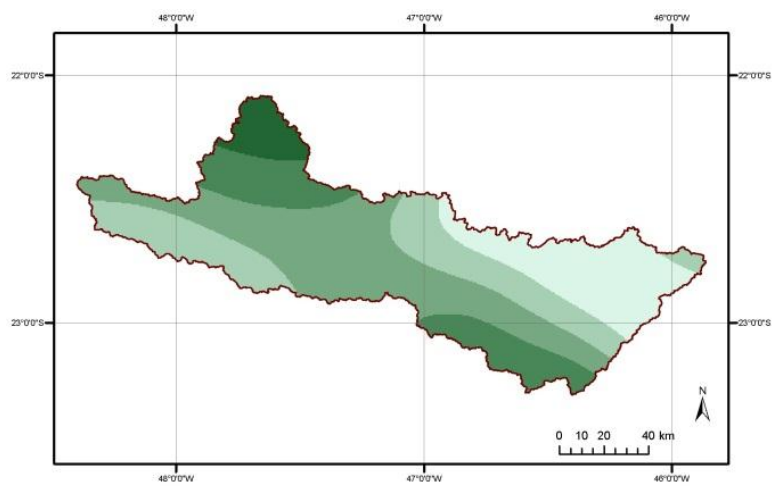

Pressão atmosférica média (hPa)

$\begin{array}{llllll}91,93 & 92,60 & 93,16 & 93,73 & 94,68 & 96,40\end{array}$

(c)

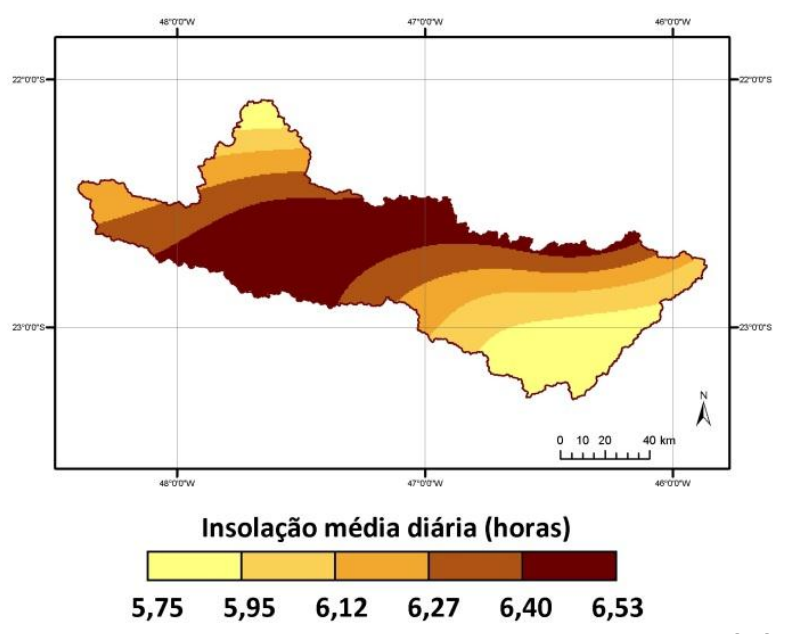

(e)

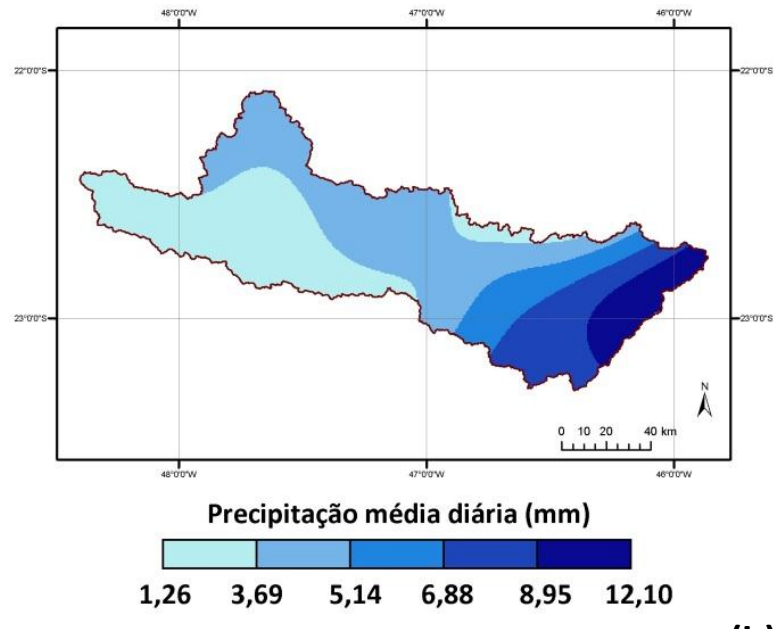

(b)
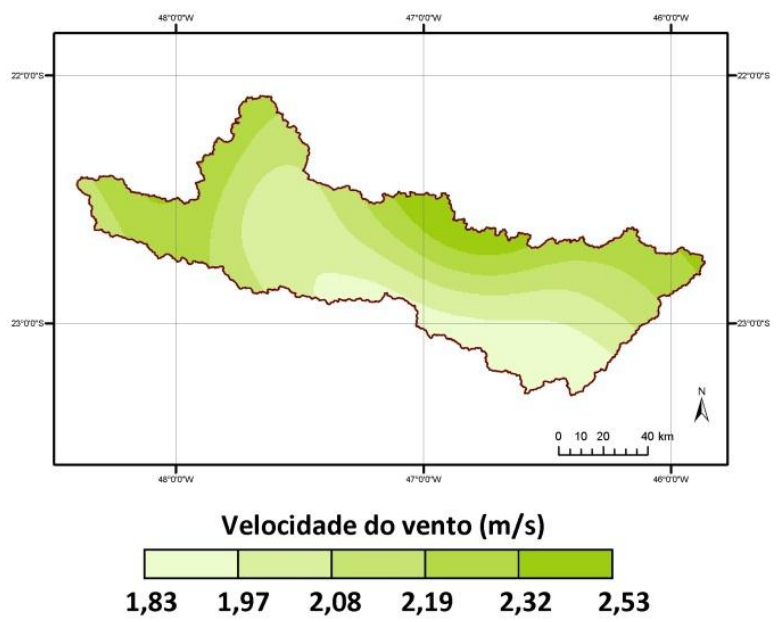

(d)

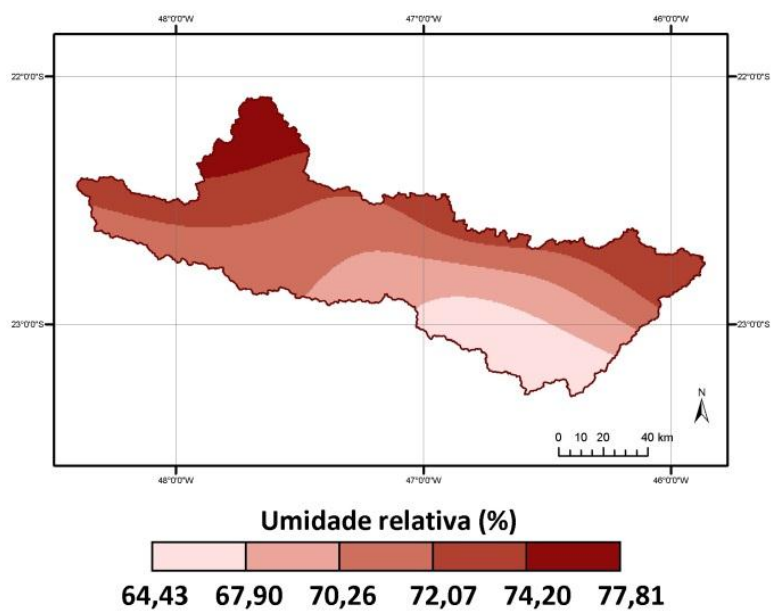

(f)

Figura 48. Temperatura média (a), precipitação (b), pressão atmosférica (c), velocidade do vento (d), insolação (e) e umidade relativa (f) para o mês de Janeiro de 2041 (Fonte: projeções do modelo EtaCPTEC). 


\subsubsection{Correção dos erros de cálculo da precipitação}

Dados de precipitação oriundos de MCGs têm por objetivo a representação desta variável em grande escala, abrangendo o ciclo hidrológico a nível terrestre. Todavia, quando se busca a representação de processos locais, para fins de planejamento, gestão e tomada de decisão, tais dados podem ser inadequados, devido à incompatibilidade de escalas espaciais e pela presença de viés (LEANDER; BUISHAND, 2007; LI; SHEFFIELD; WOOD, 2010; PIANI; HAERTER; COPPOLA, 2010; PIANI et al., 2010).

Deve-se, portanto, realizar a correção desse erro sistemático, de modo que ocorra a adequação entre a escala a ser trabalhada e a validade dos dados utilizados. Assim, realizouse a correção do viés, para os períodos de 1961 a 1990 e de 2011 a 2099. A seguir são descritos estes procedimentos.

\subsubsection{Correção da precipitação passada (1961-1990)}

Foram utilizados também os dados simulados pelo modelo Eta-CPTEC para o período de 1961 a 1990. Feito isso, foram comparadas as vazões mínimas calculadas a partir de dados de precipitação observados, monitorados pelo DAEE, e a partir de dados de precipitação simulada pelo modelo Eta-CPTEC corrigida.

A metodologia utilizada para isto foi proposta por Piani, Haerter e Coppola (2010) e Piani et al. (2010), que desenvolveram uma técnica para correção estatística do viés. A aplicação deste método resultou na aproximação da intensidade de distribuição estatística dos dados simulados, com relação às observações. O objetivo desta aplicação foi ajustar parâmetros estatísticos como a média e a variância dos dados, entre outros, além de melhorar a representação do modelo a índices de extremos de precipitação (chuvas intensas ou escassas).

Dividiu-se o método em duas etapas, aqui nomeadas ajuste e validação. A primeira etapa consistiu no ajuste dos valores diários de precipitação à distribuição gama, tanto observados quanto simulados. Assim, obteve-se uma função de transferência $t f$, em função dos dados de precipitação simulada pelo modelo Eta-CPTEC. Fez-se isto para que o histograma de intensidade da precipitação corrigida ( rec $_{c o r}$ ) fosse aproximado ao da 
precipitação observada (prec obs). A tf foi utilizada na obtenção dos valores de $\operatorname{prec}_{c o r}$, conforme Equação 6,

prec $_{\text {cor }}=a+$ bprec $_{\text {sim }}$

Equação 6

sendo prec $_{c o r}$ o valor de precipitação diária corrigida, em mm; prec sim $_{0}$ o valor da precipitação simulada pelo modelo Eta-CPTEC, a ser corrigida, também em mm; $a$ e $b$ os parâmetros de ajuste da função de transferência.

A correção dos dados diários de precipitação se deu em caráter mensal, ou seja, para cada mês do período analisado obteve-se uma $t$. Procedeu-se à determinação das funções de distribuição de probabilidade (FDPs) e acumuladas (FDAs), resultantes do ajuste à distribuição gama, dos dados observados e simulados. Para determinação dos valores dos parâmetros da tf para correção do viés, realizou-se a plotagem dos dados de precipitação, de modo que a FDA dos dados simulados fosse a mesma dos dados simulados.

A validação da correção dos dados de precipitação se deu através de modelagem hidrológica. Para tal, foram comparados aos valores de vazões observadas nos postos fluviométricos, três séries distintas simuladas no modelo MGB-IPH calibrado, para o período 1971-1990. As condições de simulação foram exatamente idênticas para as três séries, e a única variação de entrada no modelo foi com relação à precipitação.

A primeira série considerou como entrada no modelo hidrológico os valores de precipitação observada nos postos pluviométricos. Essas vazões foram calculadas no Capítulo 3 deste trabalho. Outra série de vazões considerou a série de precipitação calculada pelo modelo Eta-CPTEC, sem qualquer tipo de correção. A terceira série foi produzida também a partir dos dados de precipitação do modelo climático, porém desta vez passaram pelo procedimento de correção descrito. Esta estratégia possibilitou que fosse confirmada a necessidade ou não de correção de dados de precipitação oriundos de modelos climáticos.

\subsubsection{Correção da precipitação futura (2011-2099)}

Para simulação das vazões mínimas no período futuro, também foi necessária a correção dos dados de precipitação para os anos de 2011 a 2099. Aqui, o método aplicado 
foi o descrito em Li, Sheffield e Wood (2010), denominado Método de Ajuste Equidistante da FDA (do inglês Equidistant CDF Matching Method).

Esta abordagem considerou o ajuste dos valores de precipitação observada e simulada pelo modelo climático para o período base (1961-1990), além das simuladas para o período futuro (2011-2099). Assim, obtiveram-se os valores de precipitação corrigida, a partir das projeções simuladas para o período 2011-2099. A correção considerou a diferença entre as funções inversas das FDAs, segundo distribuição gama de probabilidades, entre os dados observados no período base (1961-1990) e os simulados pelo modelo climático para o mesmo período (Equação 7),

$\operatorname{prec}_{C-F}=\operatorname{prec}_{M-F}+F_{O-P}^{-1}\left(F_{M-F}\left(\operatorname{prec}_{M-F}\right)-F_{M-P}^{-1}\left(F_{M-F}\left(\operatorname{prec}_{M-F}\right)\right.\right.$

sendo $\operatorname{prec}_{C-F}$ a precipitação diária do período futuro, corrigida, em mm; $\operatorname{prec}_{M-F}$ a precipitação diária simulada pelo modelo Eta-CPTEC, sem correção, em $\mathrm{mm} ; F^{-1}{ }_{O-p}$ a função inversa da FDA dos dados observados para o período da linha de base, em mm; $F_{M-F}$ a FDA dos dados de precipitação simulados para o futuro; $\operatorname{prec}_{M-F}$ a precipitação simulada pelo modelo climático para o período futuro, em $\mathrm{mm} ; F_{M-P}^{-1}$ a função inversa da FDA dos dados de precipitação simulados pelo modelo climático para o período futuro.

A partir dos valores de precipitação futura corrigidos, foi possível a projeção de vazões mínimas anuais em cada cenário de mudanças, segundo modelagem hidrológica de longo prazo.

\subsubsection{Elaboração de cenários de mudanças}

A elaboração dos cenários considerou combinações de diferentes atores de mudanças capazes de interferir no ciclo hidrológico da bacia hidrográfica do Rio Piracicaba. Foram elaborados cinco cenários, amparados em diferenciadas condições de mudanças globais.

Os atores de mudança considerados foram as condições climáticas, o uso da terra e a disponibilidade hídrica. A definição desses atores contemplou a máxima simplificação dos processos envolvidos em cada cenário, na busca pela facilidade da representação da 
variabilidade na bacia e pela redução da propagação de incertezas. A Tabela 11 apresenta uma síntese dos cenários elaborados e dos atores envolvidos em cada situação.

Tabela 11. Cenários de mudanças elaborados com base nos atores de mudança identificados.

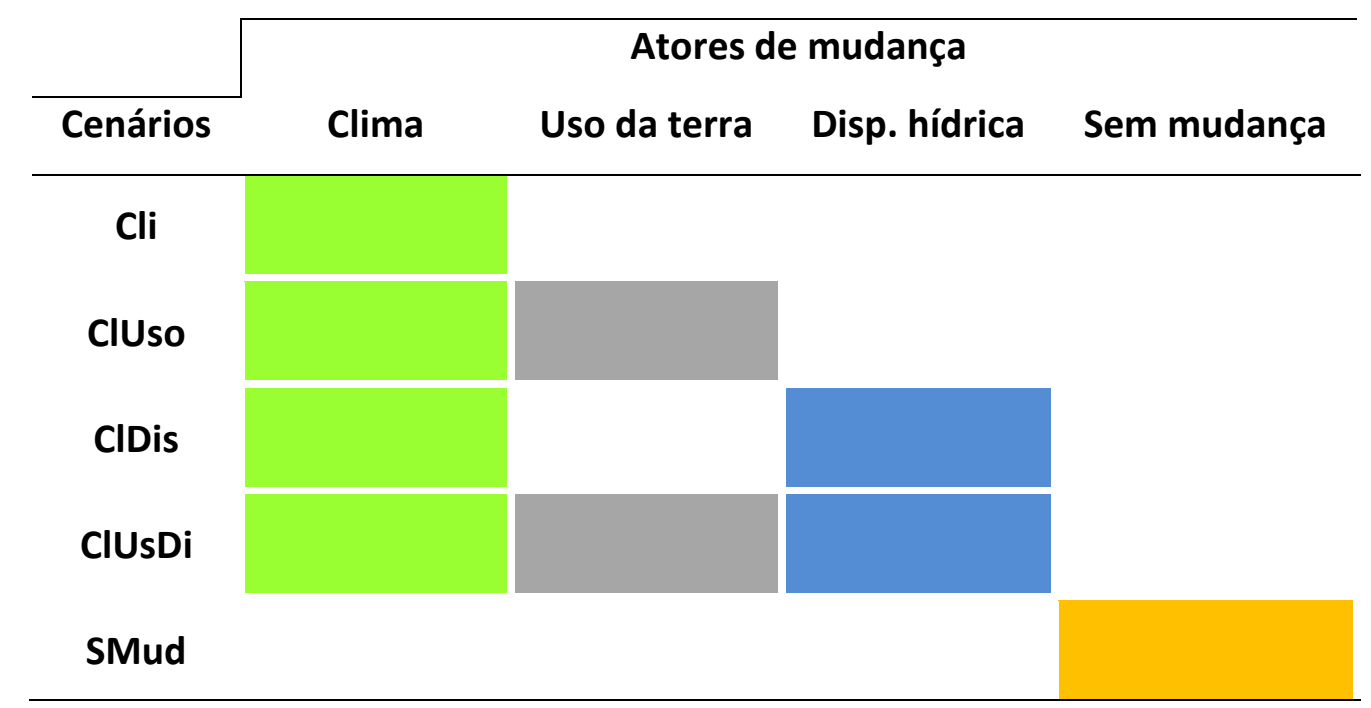

Fonte: Elaborado pelo autor.

Os cenários propostos que consideraram modelagem hidrológica foram Cli, ClUso, CIDis e CIUsDi. O cenário SMud, considerado sem mudanças, contemplou a repetição estatística dos fenômenos e processos atuais na bacia. Nas linhas a seguir são descritos os atores de mudança considerados, e as premissas relacionadas a cada um.

\subsubsection{Mudanças climáticas}

A mudança nas condições climáticas foi considerada através das projeções do modelo climático Eta-CPTEC, para o período 2013-2099, de acordo com o item 4.2 .1 deste capítulo. Cenários que consideraram esta variação utilizaram variáveis climáticas geradas pelo modelo climático, assim como a precipitação corrigida, para a modelagem hidrológica através do modelo hidrológico MGB-IPH. Quatro, dos cinco cenários propostos, consideraram as mudanças em condições climáticas. Trataram-se dos cenários Cli, ClUso, CIDis e CIUsDi. 


\subsubsection{Mudanças no uso da terra}

Alterações no uso da terra foram consideradas em dois cenários, sendo eles o ClUso e o ClUsDi. Considerou-se como alteração apenas a evolução da mancha urbana, ou seja, o aumento das áreas urbanizadas na bacia. Adotou-se esta estratégia, pois a mudança no uso da terra em bacias hidrográficas, por si só, já agrega muitas incertezas. Assim, foi possível a associação entre as alterações hidrológicas na bacia e um específico tipo de uso da terra, neste caso, urbanização.

Para este tipo de mudança na bacia, durante a etapa de modelagem hidrológica, houve a alteração do mapa de uso da terra como entrada do MGB-IPH e, consequentemente, alteração nas URHs e, também, na dinâmica hidrológica da bacia. Para isto, calculou-se a evolução da mancha urbana do ano de 1985, que totalizava 2,64\%, até o ano de $2010,6,86 \%$. Assim, como uma estratégia de aproximação, adotou-se uma taxa anual de incremento de áreas urbanas constante na bacia, calculada com base na evolução 19852010, de 20,43 $\mathrm{km}^{2}$. ano $^{-1}$.

A representação deste aumento se deu no arquivo CELL.HIG, arquivo de entrada do MGB-IPH, através da alteração das porcentagens de ocorrência dos blocos de uso da terra associados aos tipos de solos. A urbanização obedeceu a critérios de expansão pré-definidos, considerando as minibacias como unidade de expansão. Com isso, considerou-se um aumento igualmente distribuído da urbanização em toda a bacia.

Os critérios de expansão obedeceram a prioridades com relação aos usos substituídos. Primeiro, a urbanização avançou, na medida em que fosse necessário, sobre as áreas de agropecuária em cada minibacia. Uma vez esgotado este tipo de uso, e a área urbana ainda necessitasse crescer, considerou-se a supressão de vegetação nativa e florestas plantadas.

Foram considerados três períodos de alteração, com base nos períodos de estudo (2013-2040, 2041-2070 e 2071-2099). Portanto, obtiveram-se situações de uso da terra para os anos-base de 2025 (9,30\% de urbanização), 2055 (14,16\%) e 2085 (19,03\%). A Figura 49 demonstra a evolução dos usos da terra na bacia, conforme o aumento da urbanização. 


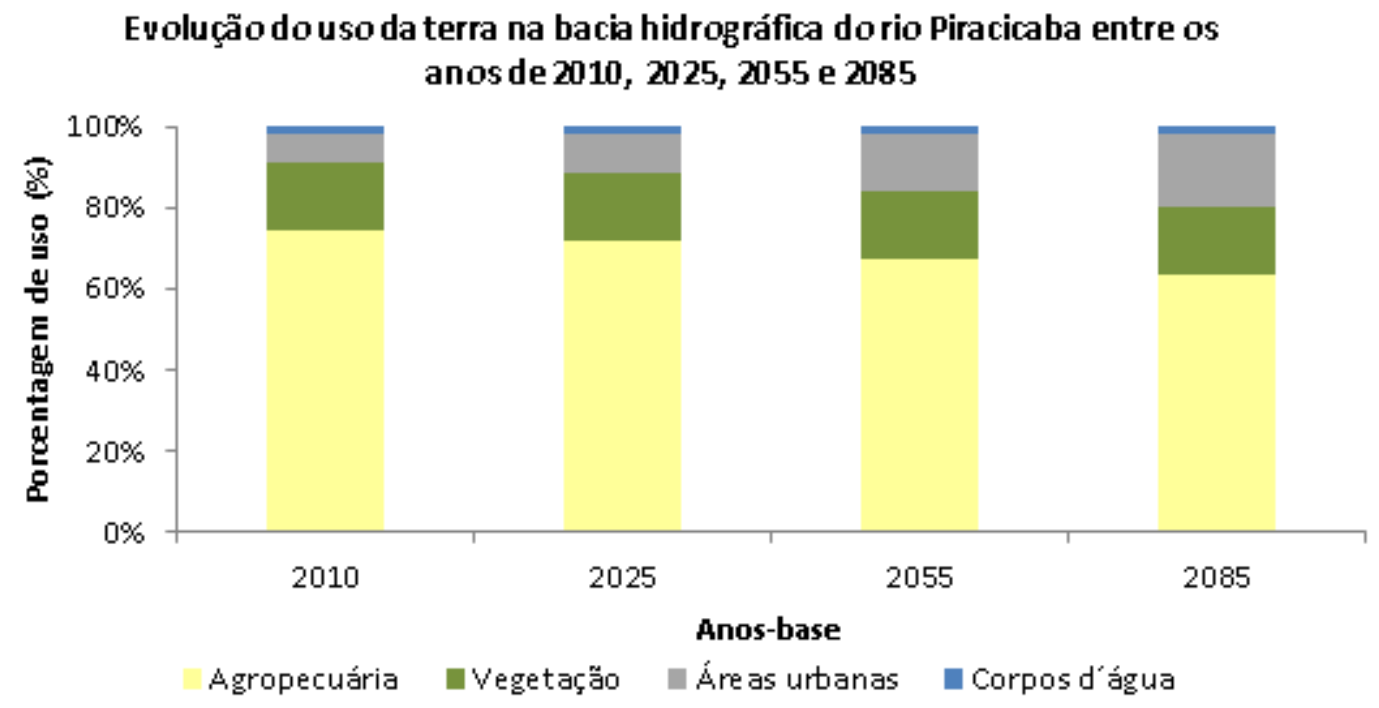

Figura 49. Evolução da mancha urbana na bacia do Rio Piracicaba (Fonte: Elaborado pelo autor).

Foi observada a ocorrência de decréscimo significativo nas áreas rurais com cultivos agrícolas e pecuária. A redução foi de 74,45\%, em 2010, para 63,63\% em 2085. Áreas cobertas por florestas, nativas ou plantadas, tiveram um pequeno decréscimo em termos de porcentagem de área na bacia. A redução foi de $16,58 \%$, com relação também ao ano de 2010, para 16,32\% em 2085.

\subsubsection{Mudanças na disponibilidade hídrica}

Considerou-se como ator na alteração da disponibilidade hídrica na bacia o Sistema Cantareira, responsável pela transposição de $31 \mathrm{~m}^{3} \cdot \mathrm{s}^{-1}$ para a RMSP, na bacia hidrográfica do Alto Tietê. Houve alteração na disponibilidade nos cenários CIDis e CIUsDi. Assim, nestes cenários, a representação da operação do Sistema Cantareira foi inserida na modelagem, através das médias anuais observadas no período 1985-1993 em dois postos à jusante dos reservatórios (postos Guapirocaba e Atibaia). A Figura 50 representa a localização dos postos com relação aos reservatórios. 


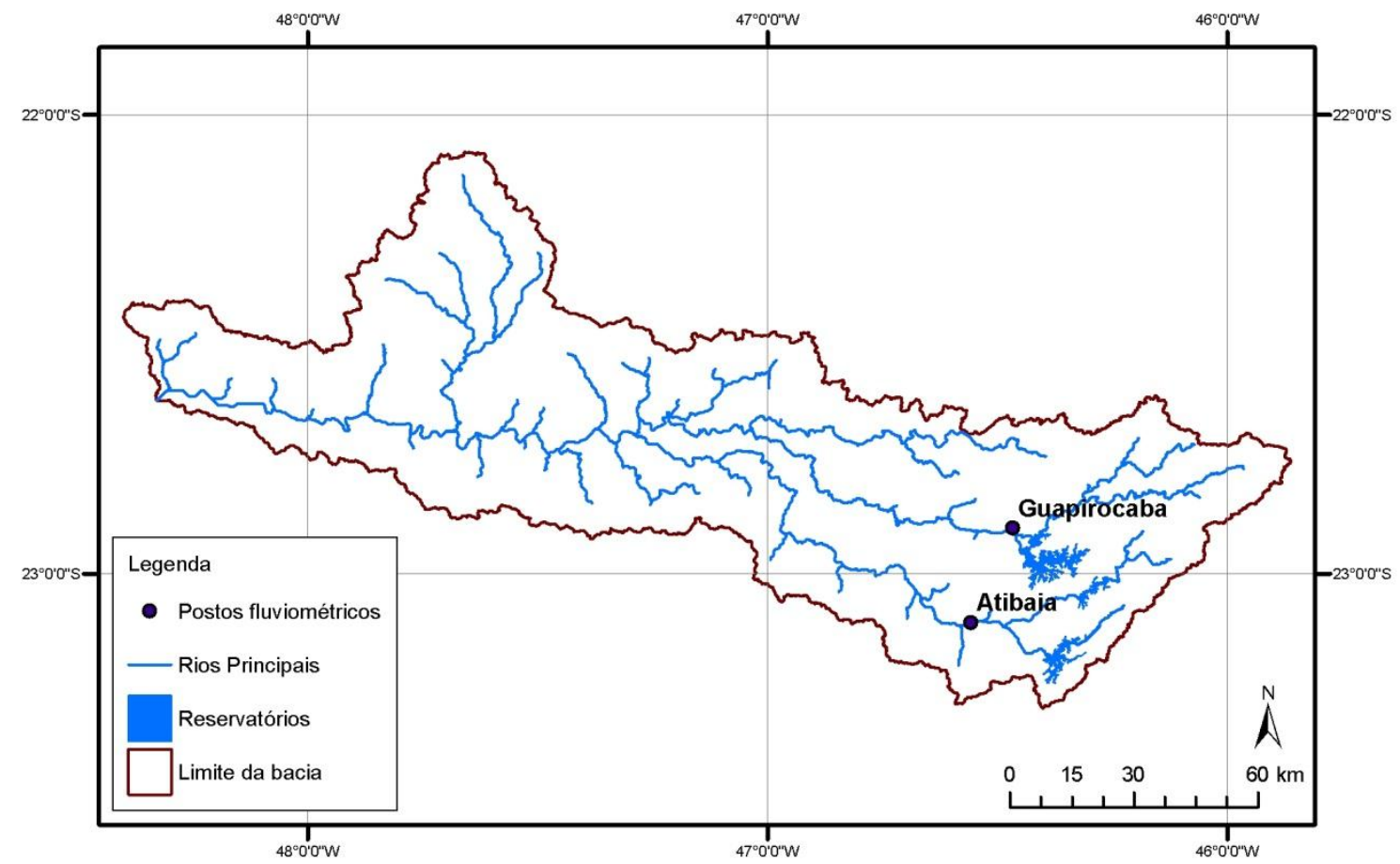

Figura 50. Localização dos postos fluviométricos considerados na modelagem, a jusante dos reservatórios do Sistema Cantareira (Fonte: Elaborado pelo autor).

Foi adotada constante, com o passar do tempo, a demanda da RMSP junto à bacia hidrográfica do Rio Piracicaba. Para isto, procedeu-se ao cálculo das vazões diárias liberadas pelos reservatórios, medidas em dois postos fluviométricos a jusante dos mesmos. Os postos utilizados, Guapirocaba e Atibaia, foram os mesmos considerados para substituir as vazões calculadas pelo modelo durante a calibração e validação.

Considerou-se um ano padrão, a ser repetido a cada ano da modelagem hidrológica. Como a hipótese a ser testada nesta pesquisa está relacionada a vazões mínimas extremas, adotou-se o critério de, para cada dia do ano, foi utilizada a menor vazão observada referente àquele dia, durante o período considerado. Assim, pôde-se avaliar o real impacto da indisponibilidade hídrica para as demandas na bacia.

Como estratégia de seleção do período a ser considerado, além da disponibilidade de dados, foi considerado o critério de proximidade com o período de 1971 a 1990, utilizado na calibração e validação do modelo. Contudo, foram considerados somente os dados monitorados após a operação dos reservatórios. Assim, o período selecionado corresponde aos dados diários de vazões entre os anos de 1985 e 1993.

A Figura 51 representa as vazões médias diárias resultantes de cada ano de operação do Sistema Cantareira no posto Guapirocaba, a jusante do reservatório Jaguari-Jacareí. Já a 
Figura 52 demonstra as vazões médias diárias calculadas para o posto Atibaia, a jusante dos reservatórios Atibainha e Cachoeira.

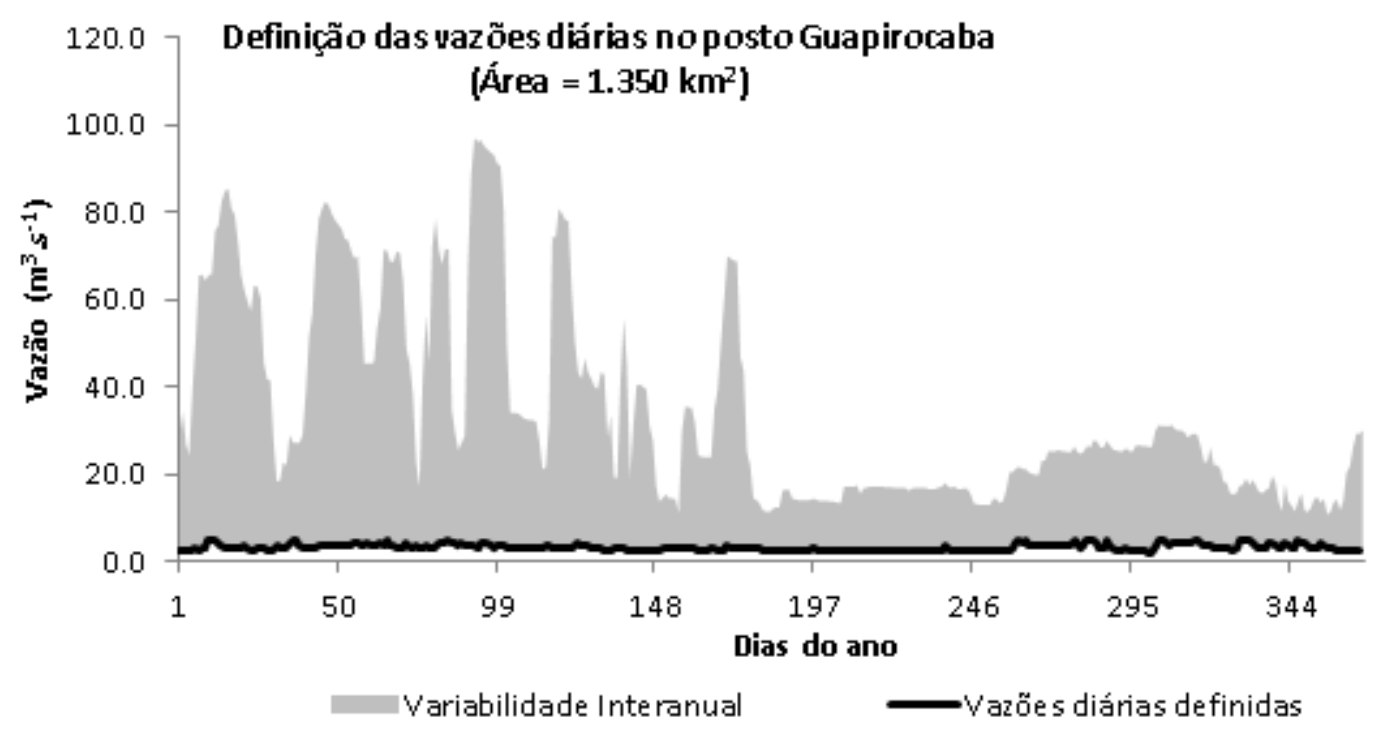

Figura 51. Vazões médias diárias decorrentes da operação do Sistema Cantareira, posto Guapirocaba (Fonte: Elaborado pelo autor).

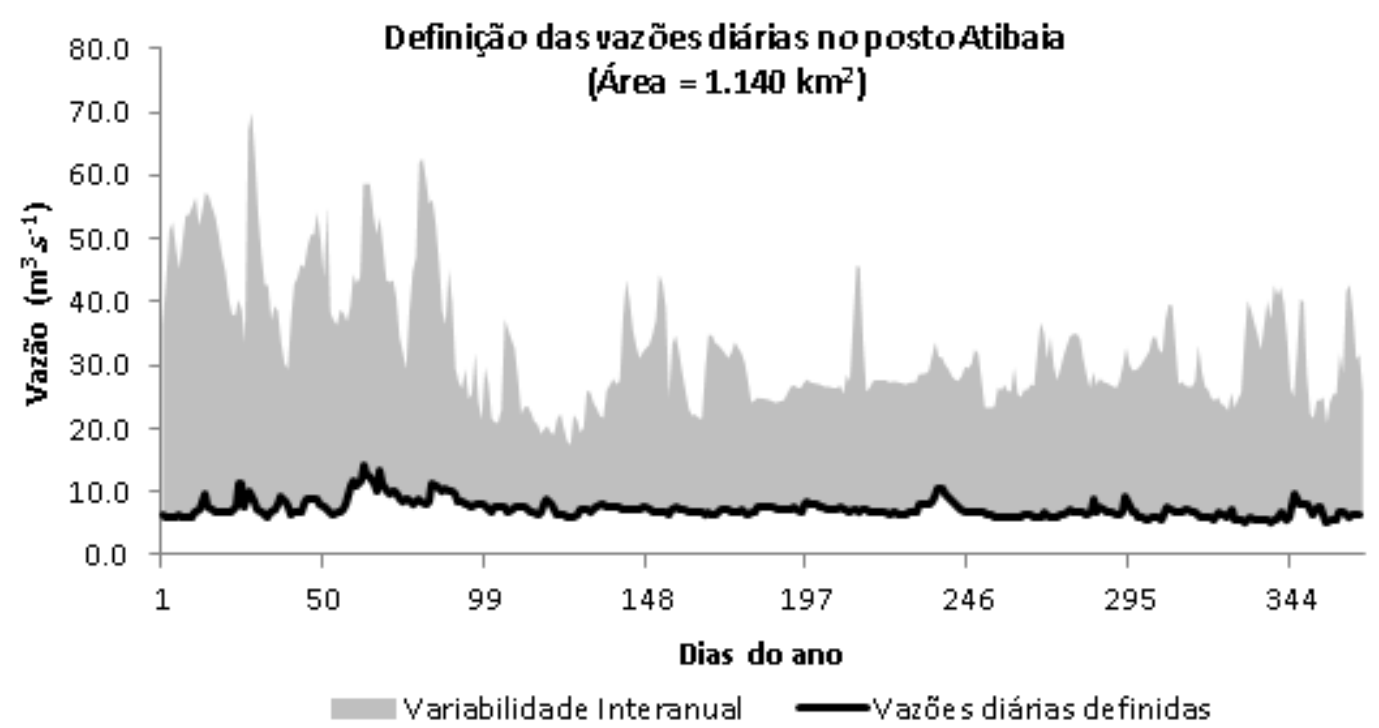

Figura 52. Vazões médias diárias decorrentes da operação do Sistema Cantareira, posto Atibaia (Fonte: Elaborado pelo autor).

Nos cenários Cli e ClUso, que não consideraram a mudança na disponibilidade hídrica, foram simuladas as vazões naturais na bacia, segundo situação hipotética de inexistência do Sistema Cantareira. Para isto, utilizou-se o modelo MGB-IPH calibrado, porém sem se considerar a substituição das vazões a jusante dos reservatórios. O objetivo desta 
abordagem foi avaliar, de maneira simplificada, o impacto do Sistema Cantareira nos riscos de escassez hídrica na bacia.

\subsubsection{Previsão das vazões mínimas anuais}

Uma vez concluída a preparação dos dados a serem considerados em cada cenário, bem como a definição dos cenários em si a serem representados, foi realizada a previsão das vazões mínimas anuais.

Conforme os objetivos citados no Capítulo 1, o foco deste trabalho não é a avaliação da eficiência sobre a utilização de determinada vazão de referência como indicador de disponibilidade hídrica. Assim, apenas aplicaram-se alguns critérios da legislação vigente à metodologia aqui proposta, sem que houvesse o aprofundamento na análise da viabilidade de utilização do indicador.

A vazão mínima de referência utilizada como critério de outorga nos estados de São Paulo e Minas Gerais, estados onde a bacia do Rio Piracicaba está inserida, é a $Q_{7,10}$ (LOPES; FREITAS, 2007). Por definição, a $Q_{7,10}$ é vazão mínima média de sete dias consecutivos e dez anos de recorrência. Assim, buscou-se representar, através da modelagem hidrológica, as vazões anuais mínimas médias de sete dias consecutivos $\left(Q_{7 \min }\right)$.

A escolha dos postos fluviométricos onde foi simulada a vazão mínima, a cada ano, utilizou critérios que procurassem abranger as principais unidades de planejamento da bacia. Na bacia do Rio Piracicaba, as principais unidades de gestão são as sub-bacias hidrográficas dos rios Atibaia $\left(2.868,7 \mathrm{~km}^{2}\right)$, Camanducaia $\left(1.030,0 \mathrm{~km}^{2}\right)$, Corumbataí $\left(1.679,2 \mathrm{~km}^{2}\right)$, Jaguari $\left(3.290,0 \mathrm{~km}^{2}\right)$ e Piracicaba $\left(3.700,8 \mathrm{~km}^{2}\right)$ (PCJ/COBRAPE, 2010).

Desse modo, foram simuladas, e comparadas entre os cenários, as vazões mínimas nos postos que procurassem representar, em termos hidrológicos e de área, essas subbacias. Portanto, foram selecionados os postos Fazenda Barra (sub-bacia do Rio Camanducaia), Usina Ester (sub-bacia do Rio Jaguari), Desembargador Furtado (sub-bacia do Rio Atibaia), Recreio (sub-bacia do Rio Corumbataí) e Artemis (sub-bacia do Rio Piracicaba). A Figura 53 representa a distribuição geográfica dos postos simulados na bacia e a representação das sub-bacias referentes aos mesmos. 


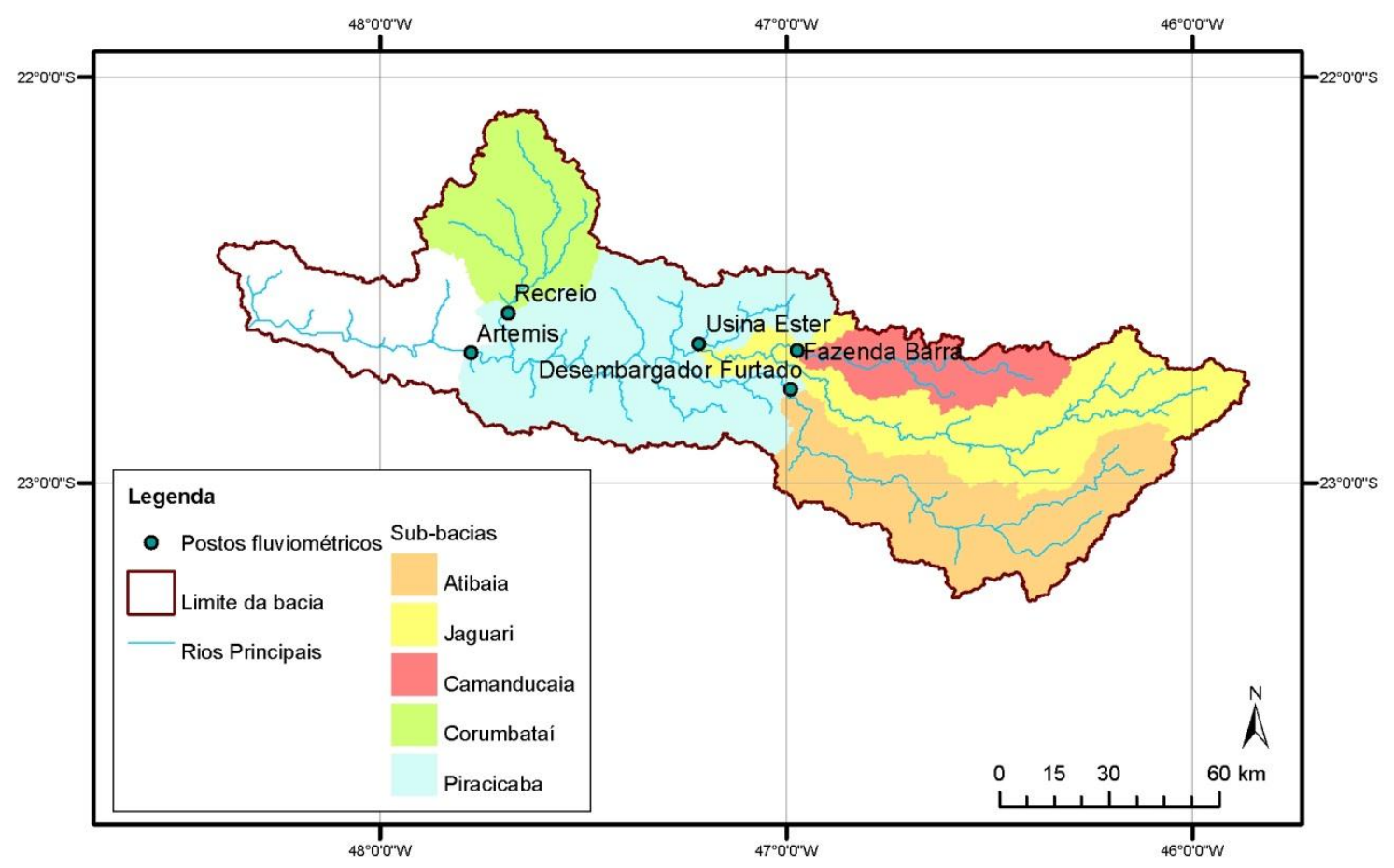

Figura 53. Postos fluviométricos selecionados para a representação das vazões mínimas, conforme arranjo espacial das sub-bacias utilizadas na gestão (Fonte: Elaborado pelo autor).

\subsubsection{Verificação do ajuste do modelo para representar vazões mínimas}

A capacidade do modelo hidrológico MGB-IPH em representar as vazões mínimas foi determinada através da continuidade da análise dos resultados da calibração e validação do mesmo. Assim, foram comparadas duas séries de vazões diárias em cada um dos cinco postos fluviométricos selecionados. Uma delas foi representada pelos dados de vazões observadas, monitoradas nos postos. A segunda, referente aos dados simulados durante o ajuste do modelo, foi obtida através da modelagem hidrológica.

Feito isso, realizou-se a análise das séries selecionadas, para que fosse obtido o menor valor de $Q_{7 m i ́ n}$ simulado e observado, para cada ano do período 1971-1990. Na sequência, procedeu-se à comparação entre os dados obtidos, ao passo que se pudesse avaliar a capacidade do modelo em reproduzir a menor vazão anual, já conhecida.

\subsubsection{Cenários futuros de vazões mínimas}

Para os cenários Cli, ClUso, CIDis e CIUsDi, realizou-se a modelagem hidrológica de longo prazo (2013-2099), conforme características de cada cenário. Feito isso, foram 
avaliadas as séries de vazões simuladas, até que fosse encontrado o menor valor de $Q_{7 \min }$ em cada ano. Com relação ao cenário SMud, a abordagem adotada foi diferente. Foi obtido o valor da $Q_{7 m i n}$ para cada ano das séries de dados observados, nos postos fluviométricos selecionados.

A partir da seleção da $Q_{7 \min }$ de cada ano, obteve-se um novo conjunto de dados, composto pelas vazões mínimas anuais, para cada cenário. No caso dos cenários Cli, ClUso, CIDis e CIUsDi, não foram necessárias modificações na série obtida, já que representavam exatamente o período analisado (2013 a 2099).

Porém, para o cenário SMud, foram obtidos valores referentes ao período passado, em cada posto fluviométrico, com variação conforme a disponibilidade dos dados em cada um. Por isso, foi necessário o ajuste da série a uma distribuição probabilística apropriada para a representação de valores extremos e, neste caso, para valores mínimos.

Optou-se pela distribuição de Gumbel (mínimos) para representar a ocorrência das vazões mínimas anuais, por ser uma distribuição extremal bastante utilizada na análise de frequência de eventos hidrológicos mínimos anuais (NAGHETTINI; PINTO, 2007; GROPPO et al., 2009). Maiores detalhes sobre a distribuição de mínimos serão fornecidos no Capítulo 5 a seguir.

\subsection{RESULTADOS E DISCUSSÃO}

A seguir são demonstrados os resultados obtidos para a correção dos erros da precipitação simulada pelo modelo Eta-CPTEC (períodos passado e futuro) e a projeção das vazões mínimas anuais $\left(Q_{7 m i n}\right)$.

\subsubsection{Correção do erro de precipitação passada}

A correção dos erros sistemáticos da precipitação no período passado, de 1961 a 1990, considerou o ajuste entre os dados simulados e observados. A análise do comportamento da precipitação simulada pelo modelo Eta-CPTEC, sem correção, permitiu observar a imprecisão do modelo em simular a precipitação na bacia hidrográfica do Rio Piracicaba (Figura 54). 


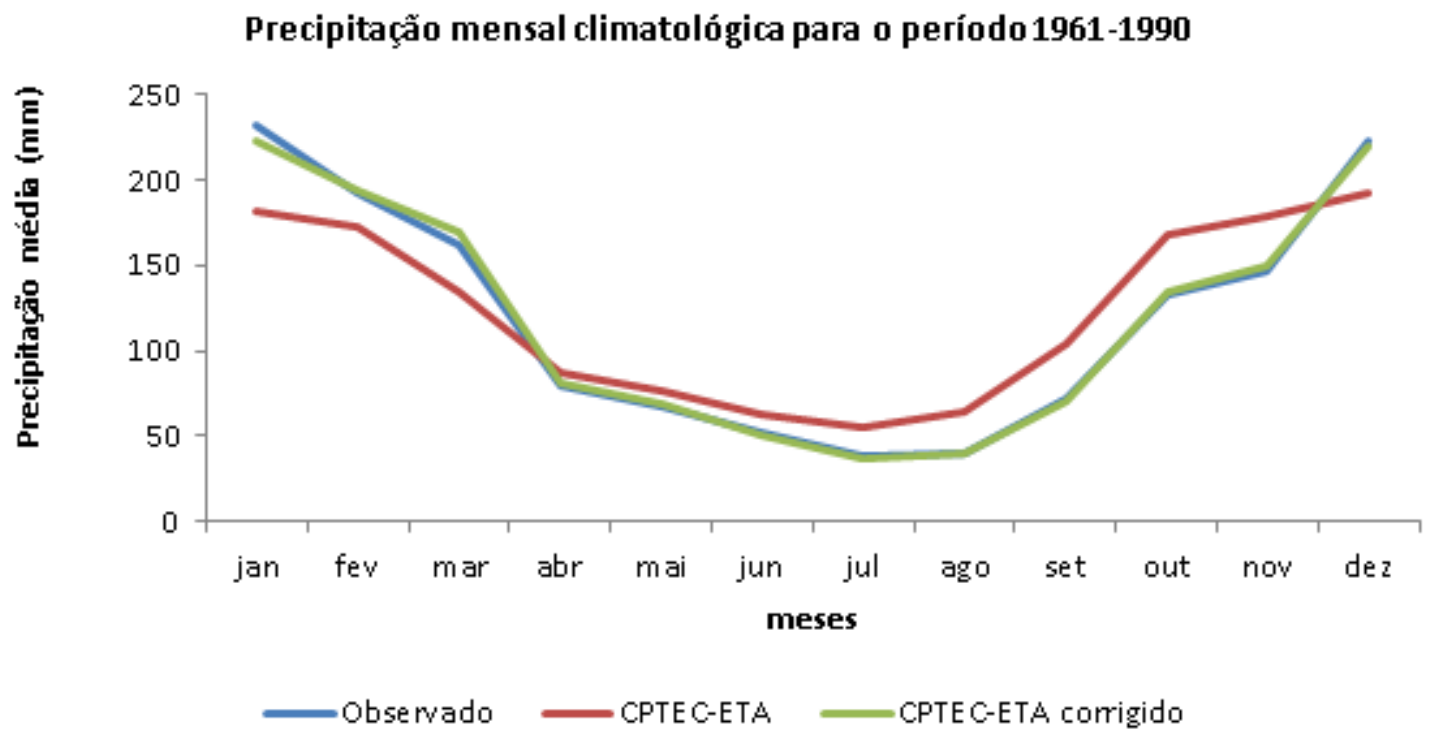

Figura 54. Comparação entre as médias mensais de precipitação observada (linha azul), simulada pelo modelo Eta-CPTEC sem correção (linha vermelha) e simulada corrigida (linha verde), para o período de 1961 a 1990 (Fonte: Elaborado pelo autor).

Observou-se que nos meses mais chuvosos (dezembro a março), houve uma tendência, por parte do modelo, em subestimar a média de chuva mensal. A partir do mês de abril, o modelo superestimou o total precipitado em cada mês. Após a correção da precipitação, obteve-se um bom ajuste entre as curvas de chuva média mensal observada e simulada.

A validação da correção se deu após a comparação dos valores das vazões médias anuais $\left(Q_{m e ́ d}\right)$ e da $Q_{7 m i ́ n}$, observadas em cada posto fluviométrico, aos dados gerados através de simulação hidrológica.

Foram analisadas quatro séries de vazões, sendo: (i) vazões observadas nos postos; (ii) vazões simuladas pelo modelo MGB-IPH a partir de dados de precipitação observada; (iii) vazões simuladas pelo modelo MGB-IPH a partir de dados de precipitação calculados pelo modelo Eta-CPTEC, sem correção; e (iv) vazões simuladas pelo modelo MGB-IPH a partir de dados de precipitação calculados pelo modelo Eta-CPTEC, corrigida.

Assim, procedeu-se à comparação da $Q_{\text {méd }}$ e da $Q_{7 \min }$ dos dados, calculadas para cada situação descrita, para se avaliar a representatividade dos dados climáticos simulados em representar a dinâmica climática e hidrológica da bacia. O período considerado, entre 1971 e 1990, foi o mesmo utilizado para calibração e validação do modelo hidrológico (Capítulo 3). A Tabela 12 demonstra os resultados para a $Q_{\text {méd }}$ nos postos, de acordo com as simulações propostas. 
Tabela 12. Vazões médias nos postos fluviométricos para o período 1971-1990.

\begin{tabular}{|c|c|c|c|c|c|}
\hline \multirow{2}{*}{ Posto } & \multirow{2}{*}{$\begin{array}{l}\text { Área } \\
\left(\mathrm{km}^{2}\right)\end{array}$} & \multicolumn{4}{|c|}{$Q_{\text {méd }}\left(m^{3} \cdot s^{-1}\right)$} \\
\hline & & Obs $^{1}$ & $\operatorname{Sim}^{2}$ & Sim-Eta ${ }^{3}$ & Sim-Eta ${ }_{\text {cor }}{ }^{4}$ \\
\hline Fazenda Barra & 927,1 & 15,5 & 15,2 & 7,8 & 13,1 \\
\hline Usina Ester & $3.397,5$ & 53,2 & 53,2 & 41,6 & 48,9 \\
\hline Desembargado Furtado & $2.487,7$ & 30,1 & 29,8 & 28,8 & 27,3 \\
\hline Recreio & $1.577,5$ & 25,8 & 23,1 & 30,2 & 19,8 \\
\hline Artemis & $10.929,9$ & 143,0 & 153,7 & 141,2 & 138,2 \\
\hline
\end{tabular}

${ }^{1}$ dados observados.

2 dados simulados pelo modelo MGB-IPH a partir de dados observados de precipitação.

${ }^{3}$ dados simulados pelo modelo MGB-IPH a partir de dados de precipitação gerados pelo modelo Eta-CPTEC, sem correção.

${ }^{4}$ dados simulados pelo modelo MGB-IPH a partir de dados de precipitação gerados pelo modelo Eta-CPTEC, corrigidos.

Fonte: Elaborado pelo autor.

O método de correção do viés da precipitação passada, aplicado aos dados climáticos simulados pelo modelo Eta-CPTEC, resultou em boa melhora no desempenho da modelagem hidrológica. Observaram-se melhoras na representação da $Q_{\text {méd }}$ em todos os postos simulados. Bons resultados também foram obtidos em se comparando o desvio padrão entre os dados calculados.

A simulação através de dados de precipitação observados obteve os melhores resultados, com um erro médio de $-2,7 \%$ na representação da $Q_{\text {méd. }}$ Os melhores resultados foram nos postos Usina Ester $\left(3.397,5 \mathrm{~km}^{2}\right)$ e Desembargador Furtado $\left(2.487,7 \mathrm{~km}^{2}\right)$, com erros inferiores a $-1,0 \%$. O maior erro foi encontrado no posto Recreio $\left(1.577,5 \mathrm{~km}^{2}\right)$, com as vazões subestimadas em 10,75\% (erro de -10,75\%).

A correção dos dados de precipitação do modelo Eta-CPTEC, com relação à $Q_{\text {méd, não }}$ modificou significativamente o erro obtido. Sem correção, o erro médio das vazões foi de $6,7 \%$, contra $-7,6 \%$ após a correção. Essa piora não foi considerada significativa, pois o mais relevante nesta análise é o erro em cada posto.

Nos postos, foi significativa a redução do erro. Cabe mencionar os postos Fazenda Barra $\left(927,1 \mathrm{~km}^{2}\right)$, cujo erro melhorou de $-49,4 \%$ para $-15,1 \%$, e Usina Ester $\left(3.397,5 \mathrm{~km}^{2}\right)$, com variação de $-21,9 \%$ para $-8,1 \%$. Na Figura 55 pode-se observar o comportamento das diferentes condições de simulação na representação da $Q_{\text {méd }}$. 


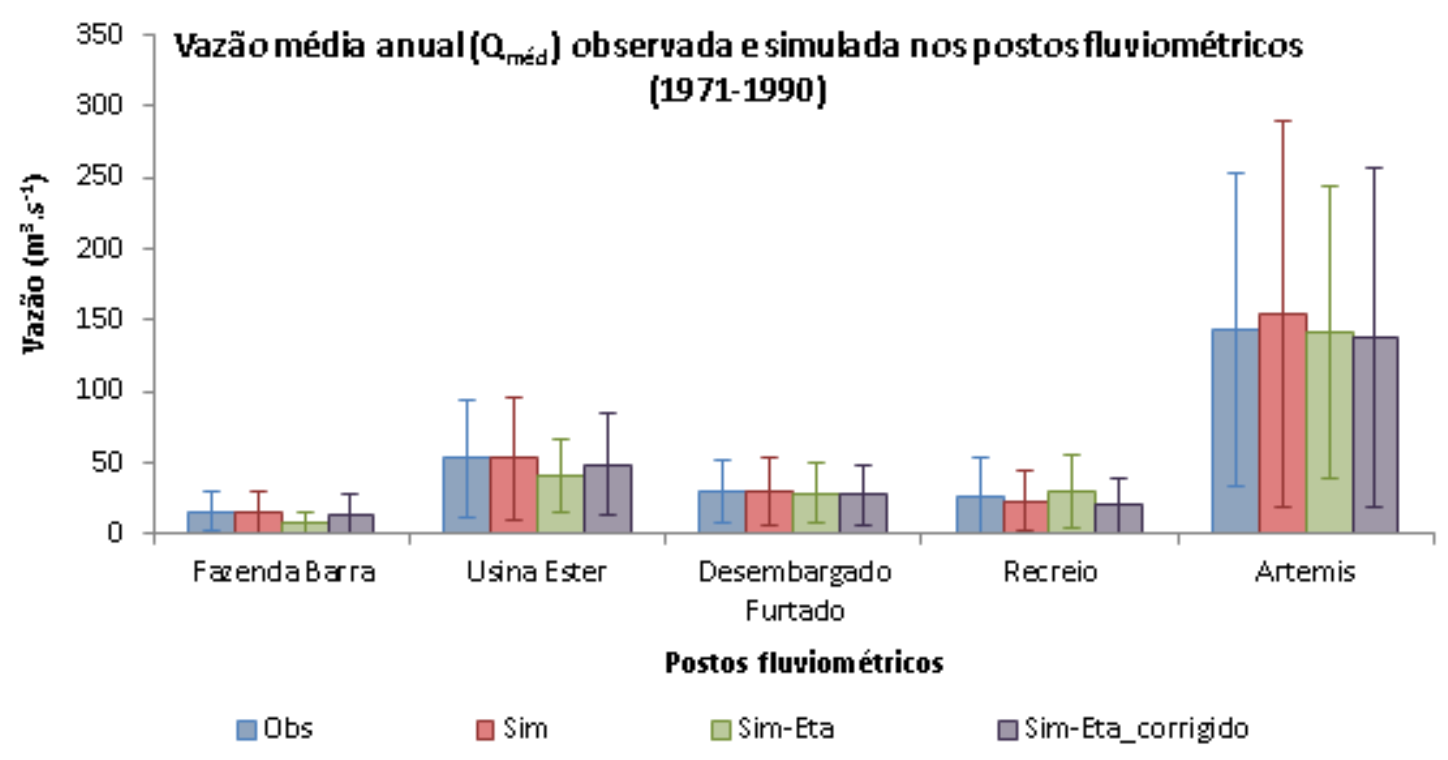

Figura 55. Vazões médias anuais $\left(Q_{\text {méd }}\right)$ e o desvio padrão dos dados observados (azul), simulados com dados de precipitação observados (vermelho) e simulados com dados do modelo climático EtaCPTEC antes (verde) e após a correção (roxo) (Fonte: Elaborado pelo autor).

Em se tratando da $Q_{7 m i ́ n}$, também foram obtidos bons resultados. A satisfatória capacidade do modelo em representar as vazões mínimas foi mantida quando se utilizou como entrada os dados de precipitação corrigidos, simulados pelo modelo climático. A Tabela 13 apresenta os valores obtidos para as quatro situações de modelagem.

Tabela 13. Vazões mínimas, representadas pela $Q_{7 m i n}$, nos postos fluviométricos, para o período 1971-1990.

\begin{tabular}{lrrrrr}
\hline \multirow{2}{*}{ Posto } & $\begin{array}{l}\text { Área } \\
\left(\mathbf{k m}^{2}\right)\end{array}$ & Obs & Sim & Sim-Eta & Sim-Eta \\
\cline { 5 - 6 } & 927,1 & 3,0 & 3,1 & 0,9 & 1,4 \\
\hline Fazendaigido & Barra \\
Usina Ester & $3.397,5$ & 8,9 & 13,2 & 10,0 & 11,3 \\
Desembargado Furtado & $2.487,7$ & 4,3 & 4,5 & 6,0 & 5,9 \\
Recreio & $1.577,5$ & 5,0 & 5,0 & 4,3 & 2,7 \\
Artemis & $10.929,9$ & 25,0 & 32,0 & 31,4 & 28,9 \\
\hline
\end{tabular}

Fonte: Elaborado pelo autor.

Para a representação da $\mathrm{Q}_{7 \mathrm{~min} \text {, }}$ os dados de precipitação observados, quando utilizados como entrada no MGB-IPH, levaram a um erro médio de $24,7 \%$. Os maiores erros foram identificados nos postos Usina Ester $\left(3.397,5 \mathrm{~km}^{2}\right), 47,2 \%$, e Artemis $\left(10.929,9 \mathrm{~km}^{2}\right)$, 
27,7\%. A representação foi considerada muito boa nos postos Recreio $\left(1.577,5 \mathrm{~km}^{2}\right)$, com um erro de $0,3 \%$ e Desembargador Furtado $\left(2.487,7 \mathrm{~km}^{2}\right)$, com 3,2\%. De modo geral, a precipitação observada utilizada na simulação resultou em uma superestimativa da $Q_{7 m i ́ n}$.

Em se tratando de dados do modelo Eta-CPTEC, a correção da precipitação melhorou

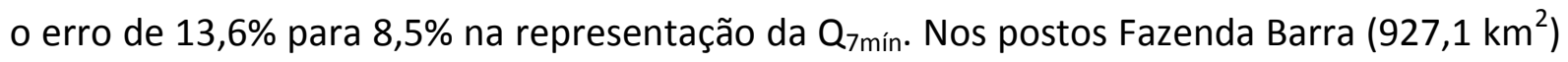
e Artemis $\left(10.929,9 \mathrm{~km}^{2}\right.$ ) foram notados as mais significativas melhoras. Por sua vez, no posto Recreio $\left(1.577,5 \mathrm{~km}^{2}\right)$, observou-se uma relevante piora no cálculo da vazão, caindo de $-12,9 \%$ para $-46,1 \%$. A Figura 56 demonstra os resultados obtidos para a determinação da $Q_{7 m i n}$ anual média em cada posto fluviométrico.

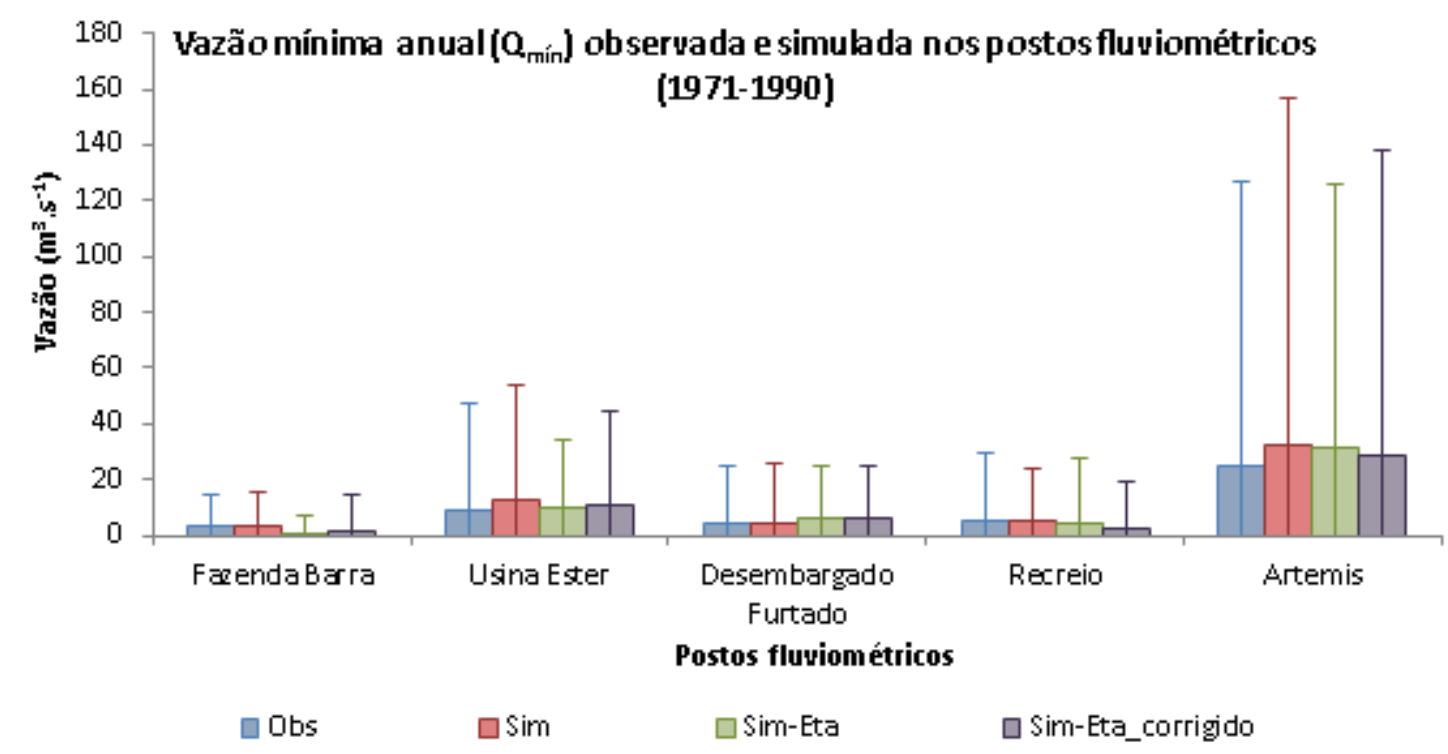

Figura 56. Vazões mínimas médias de sete dias consecutivos $\left(Q_{7 \min }\right)$ e o desvio padrão dos dados observados (azul), simulados com dados de precipitação observados (vermelho) e simulados com dados do modelo climático Eta-CPTEC antes (verde) e após a correção (roxo) (Fonte: Elaborado pelo autor).

O bom ajuste entre as vazões mínimas médias e o desvio padrão, observada e simulada, após a correção da precipitação, demonstrou a eficiência do método de correção empregado. Com isso, pôde-se concluir que é viável a utilização de dados oriundos de modelos climáticos acoplados a modelos hidrológicos distribuídos, desde que aplicada prévia correção aos dados de chuva simulada.

Ainda assim, os resultados da simulação hidrológica com dados observados são melhores do que a simulação com dados de modelagem climática, conforme afirmado em Marke et al. (2011). 


\subsubsection{Correção do erro de precipitação futura}

Com relação aos dados futuros de chuva calculados, também se analisou o comportamento da climatologia da precipitação média mensal. Para efeito de comparação, os valores médios foram divididos em quatro períodos, sendo eles de 1961 a 1990, 2011 a 2040, 2041 a 2070 e 2071 a 2099. Assim, foi possível se avaliar a variabilidade, entre os períodos, dos valores mensais de precipitação, antes da correção desses valores (Figura 57).

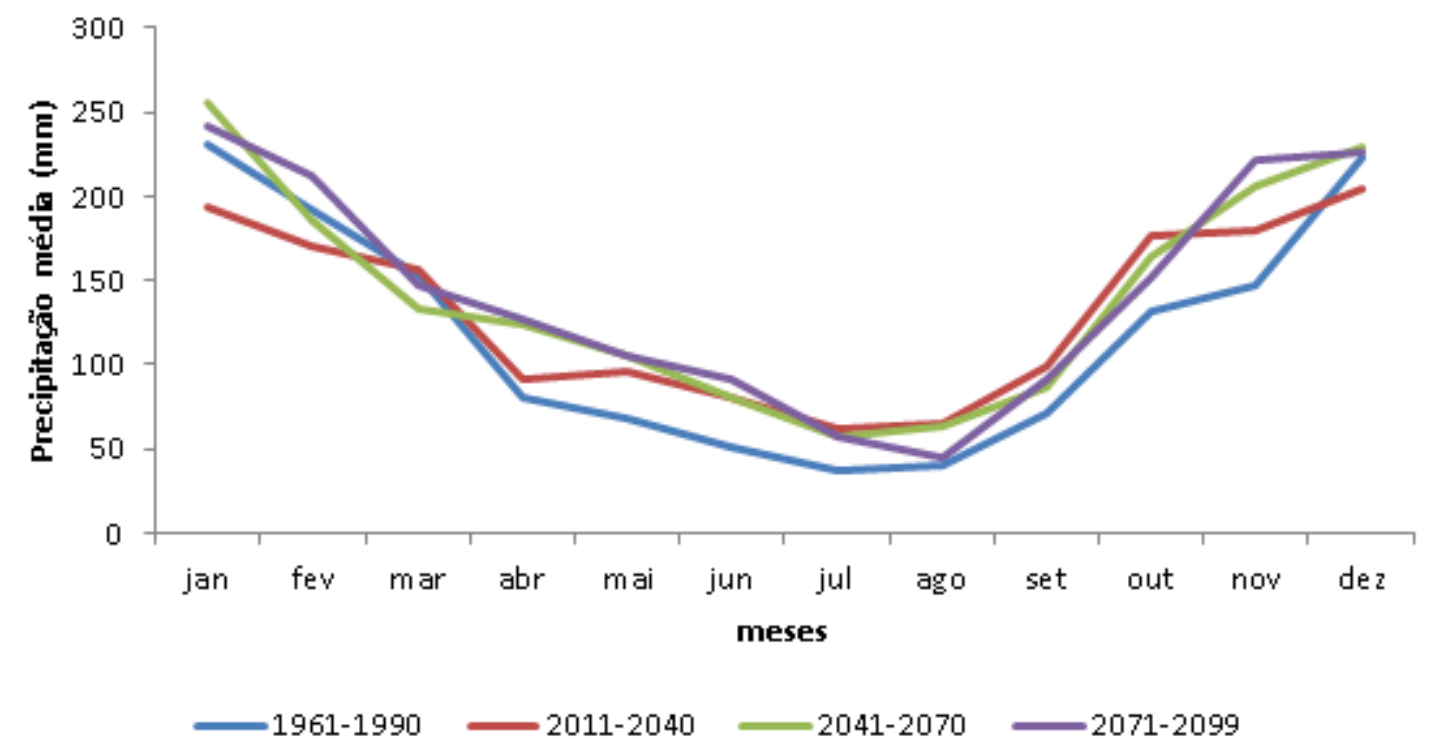

Figura 57. Projeções da precipitação futura do modelo Eta-CPTEC, sem correção, para os períodos 2011-2040 (linha vermelha), 2041-2070 (linha verde), 2071-2099 (linha roxa) comparadas ao período 1961-1990 (linha azul) (Fonte: Elaborado pelo autor).

Essa variabilidade demonstrou o aumento da precipitação mensal, com relação aos dados históricos de 1991 a 1990, em praticamente todos os meses do ano. Apenas em janeiro, fevereiro, março e dezembro foram observados o decréscimo da precipitação futura com relação ao período passado. A Figura 58 permite a interpretação da variação da precipitação mensal entre os períodos considerados, com relação ao período de 1961 a 1990. 


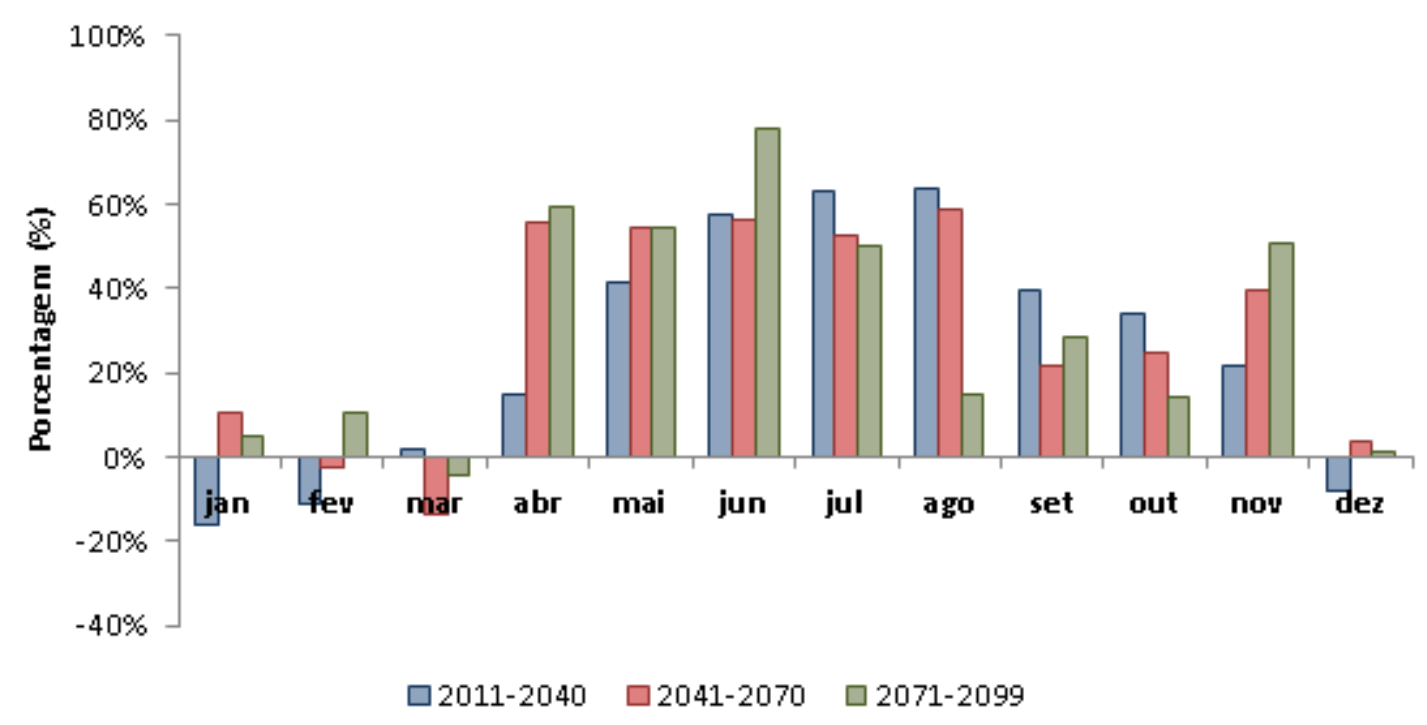

Figura 58. Variação (\%) da precipitação simulada, sem correção, comparada ao período observado (1961-1990) (Fonte: Elaborado pelo autor).

Os meses com maior variação foram os meses de junho e julho. Em condições atuais, trata-se de meses predominantemente secos, com pouca precipitação. Porém, observou-se uma tendência significativa de aumento dessa variável, em todos os períodos considerados, de 2011 a 2099. Nos meses de abril a novembro, ainda que em menor intensidade, também foi observado aumento do total de chuva média mensal nos três períodos futuros considerados.

Já nos meses de dezembro a março, mais chuvosos, notou-se pequena variação nos valores futuros, em comparação ao período observado. Em alguns casos, houve variação positiva, ao passo que em outros a variação foi negativa. Com isso, observou-se que não há uma tendência consolidada no aumento entre esses meses, pois a variação não ocorre no mesmo sentido.

A variação média da precipitação simulada pelo modelo Eta-CPTEC, sem correção, para o período $2011-2099$, foi de $+6,8 \%$ no período outubro a março, em comparação a 1961-1990. Nos meses de abril a setembro, o aumento foi de $+46,5 \%$, quando comparado ao período passado. A aumento da precipitação total anual média, sem a correção do erro sistemático, foi de $+16,5 \%$, com variações de $-29,2 \%$ a $68,2 \%$ entre os anos comparados ao período passado.

Entretanto, após a correção dos erros sistemáticos da precipitação, foi visualizado um melhor alinhamento entre as tendências de aumento ou decréscimo. Na Figura 59 são 
demonstrados os resultados do comportamento das médias de chuva mensais corrigidas em cada período.

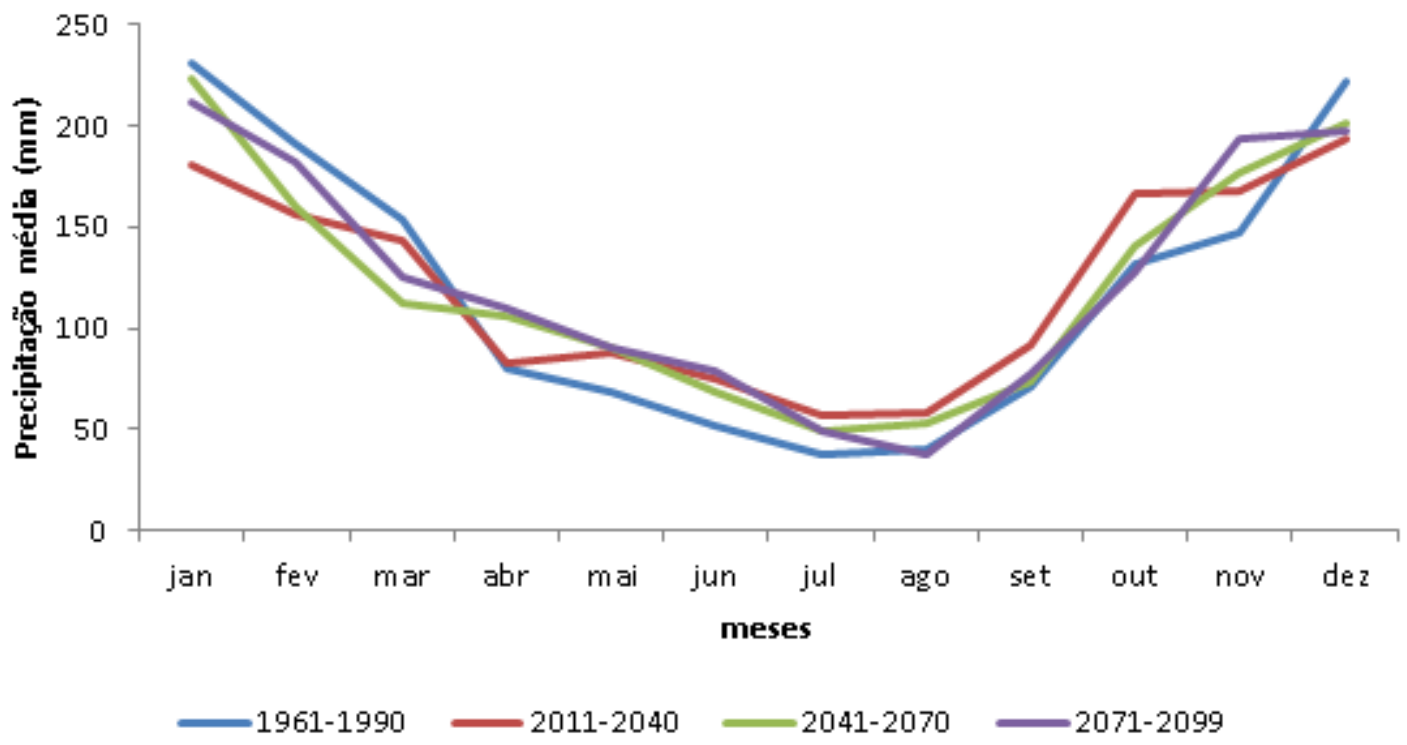

Figura 59. Projeções da precipitação futura do modelo Eta-CPTEC, corrigida, para os períodos 20112040 (linha vermelha), 2041-2070 (linha verde), 2071-2099 (linha roxa) comparadas ao período 19611990 (linha azul) (Fonte: Elaborado pelo autor).

Foi constatada a padronização dos meses que tendem a sofrer aumento nos índices de pluviosidade, entre abril e novembro. Nesse intervalo, aproximadamente em todos os períodos, obteve-se o aumento das chuvas previstas. Em relação ao período de dezembro a março, é previsto o decréscimo nos valores de precipitação média, conforme Figura 60.

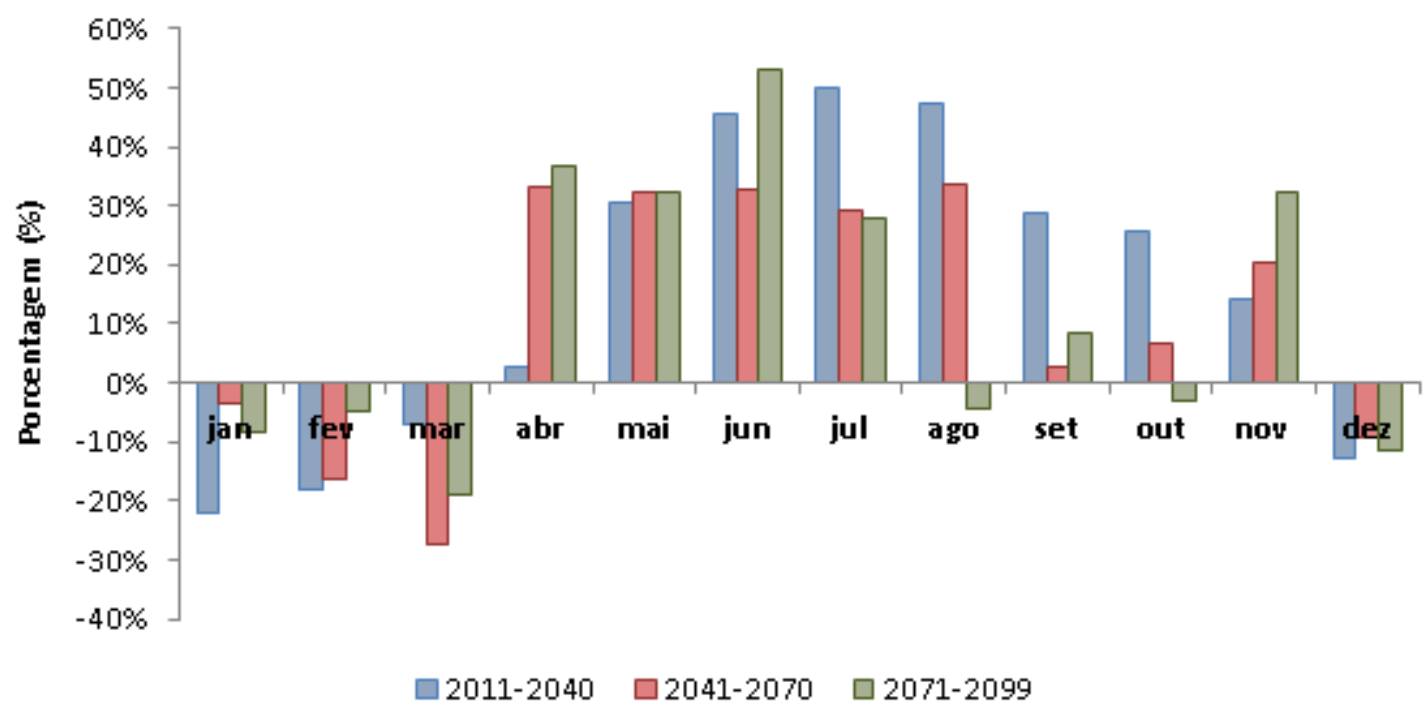

Figura 60. Variação (\%) da precipitação simulada, sem correção, comparada ao período observado (1961-1990) (Fonte: Elaborado pelo autor). 
Em média, foi projetada uma redução na precipitação mensal, nos meses de outubro a março, em $-5,4 \%$. Nos meses de abril a setembro, os cálculos do modelo sugerem o aumento em $+27,8 \%$. Em ambos os casos, comparou-se a condição futura (2011-2099) à condição passada (1961-1990). No âmbito geral, o aumento médio da precipitação total anual foi de $+2,7 \%$, variando anualmente entre $-36,7 \%$ e $51,3 \%$ com relação à média anual do período observado.

Estudos recentes indicaram tendências positivas gerais no aumento da precipitação e na ocorrência de eventos extremos no Brasil e no sudeste brasileiro decorrentes de alterações climáticas (LIEBMANN et al., 2004; HAYLOCK et al., 2006; MARENGO; VALVERDE, 2007; DUFEK; AMBRIZZI, 2008; MARENGO et al., 2010). Groppo et al (2001) realizaram estudos estatísticos na própria bacia do Rio Piracicaba, onde também observaram esta tendência de aumento na precipitação. Silva Dias et al (2012) também identificaram tendências positivas na ocorrência de eventos extremos na região da cidade de São Paulo.

\subsubsection{Simulação das vazões mínimas anuais por posto fluviométrico}

A simulação das vazões se deu conforme critérios definidos para a vazão mínima a ser considerada, neste caso a $Q_{7 m i ́ n}$, referente à mínima vazão média de sete dias consecutivos, dentro do período de um ano.

Realizou-se, portanto, a verificação do ajuste do modelo para a representação deste tipo de vazão nos postos selecionados para análise, durante os períodos de calibração e validação. Uma vez finalizado este item, realizou-se a projeção das $Q_{7 m i ́ n}$ anuais, no período 2013-2099, através de modelagem hidrológica e segundo condições impostas pelos cenários produzidos. Nos itens a seguir foram descritos estes procedimentos.

\subsubsection{Verificação do modelo para simular vazões mínimas no período 1971-1990}

Conforme calibração e validação descritas no Capítulo 3, realizou-se a projeção das $\mathrm{Q}_{7 \text { mín }}$ anuais na bacia. Para isso, foi necessário testar a capacidade do modelo calibrado em representar essas vazões. Da Figura 61 até a Figura 65, tem-se a representação da simulação das $Q_{7 \min }$ a cada ano pelo modelo MGB-IPH, em cada posto fluviométrico, no período 19711990. 


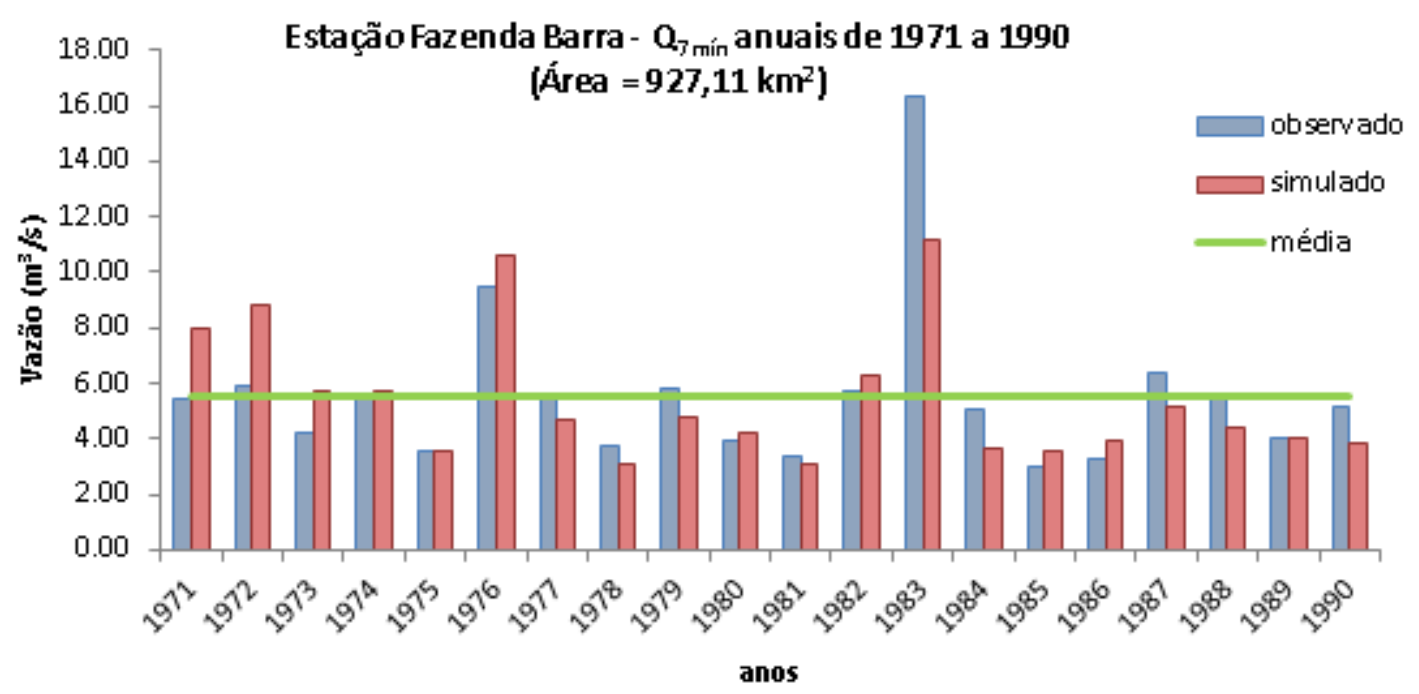

Figura 61. Vazões mínimas médias anuais observadas (barra azul), simuladas (barra vermelha) e média observada (linha verde) na estação Fazenda Barra, período 1971-1990 (Fonte: Elaborado pelo autor).

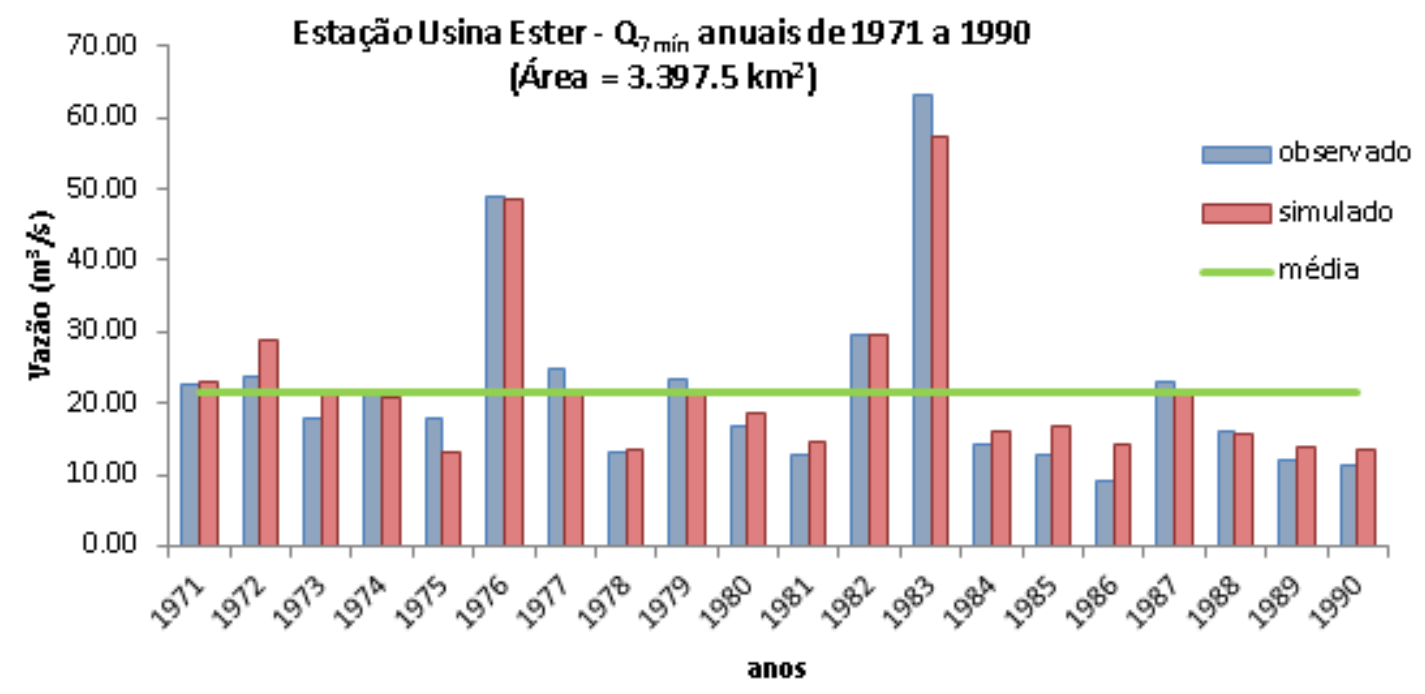

Figura 62. Vazões mínimas médias anuais observadas (barra azul), simuladas (barra vermelha) e média observada (linha verde) na estação Usina Ester, período 1971-1990 (Fonte: Elaborado pelo autor). 


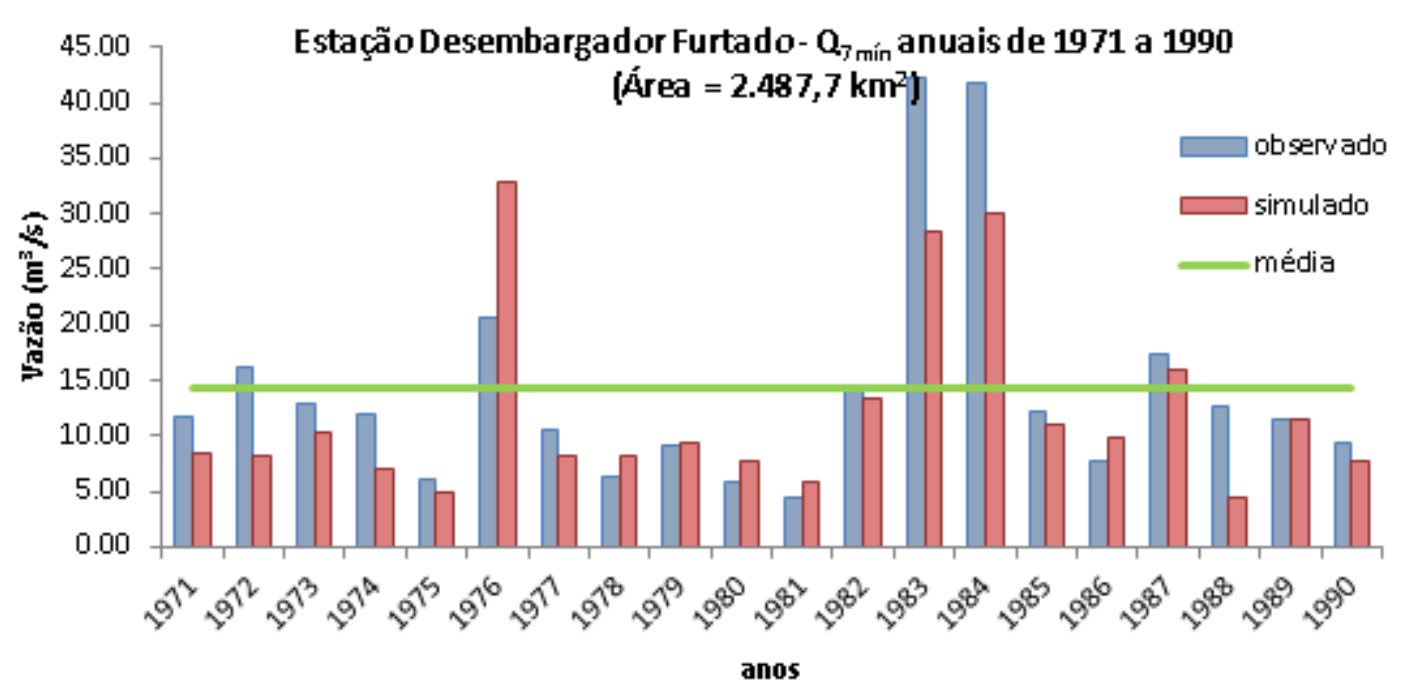

Figura 63. Vazões mínimas médias anuais observadas (barra azul), simuladas (barra vermelha) e média observada (linha verde) na estação Desembargador Furtado, período 1971-1990 (Fonte: Elaborado pelo autor).

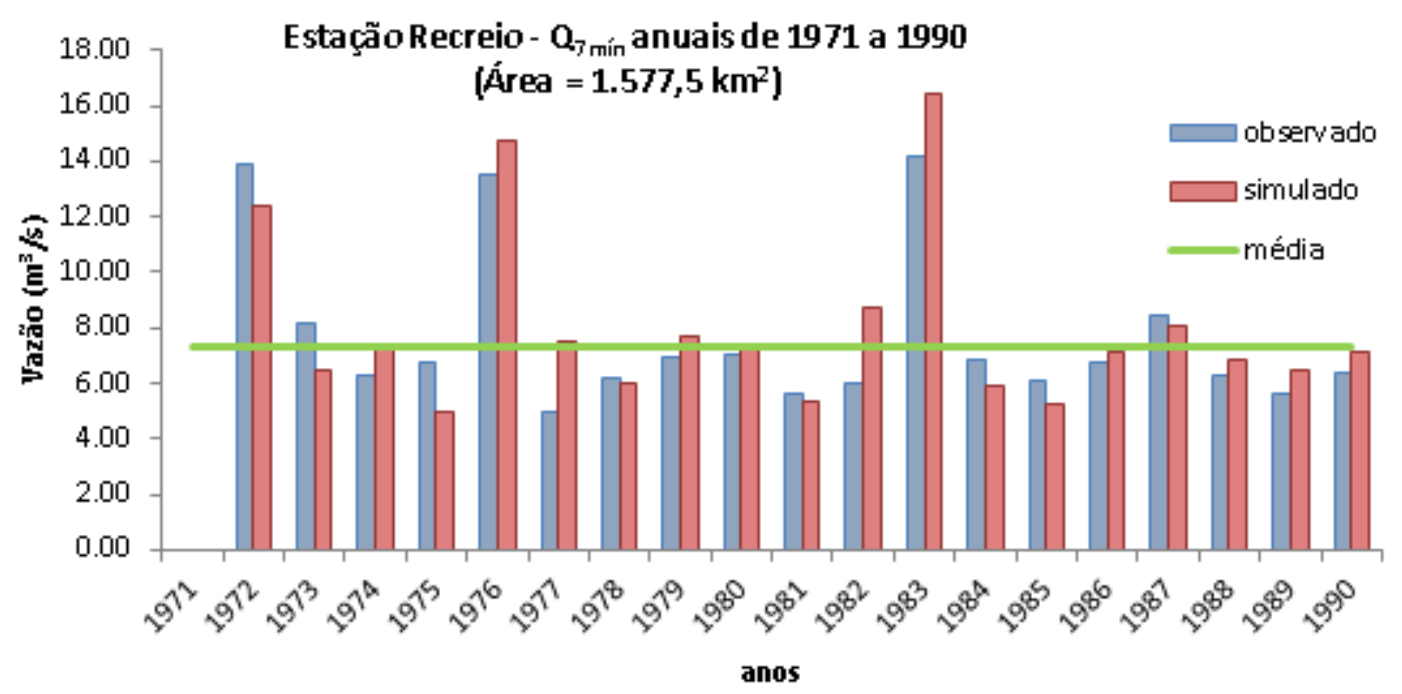

Figura 64. Vazões mínimas médias anuais observadas (barra azul), simuladas (barra vermelha) e média observada (linha verde) na estação Recreio, período 1971-1990 (Fonte: Elaborado pelo autor). 


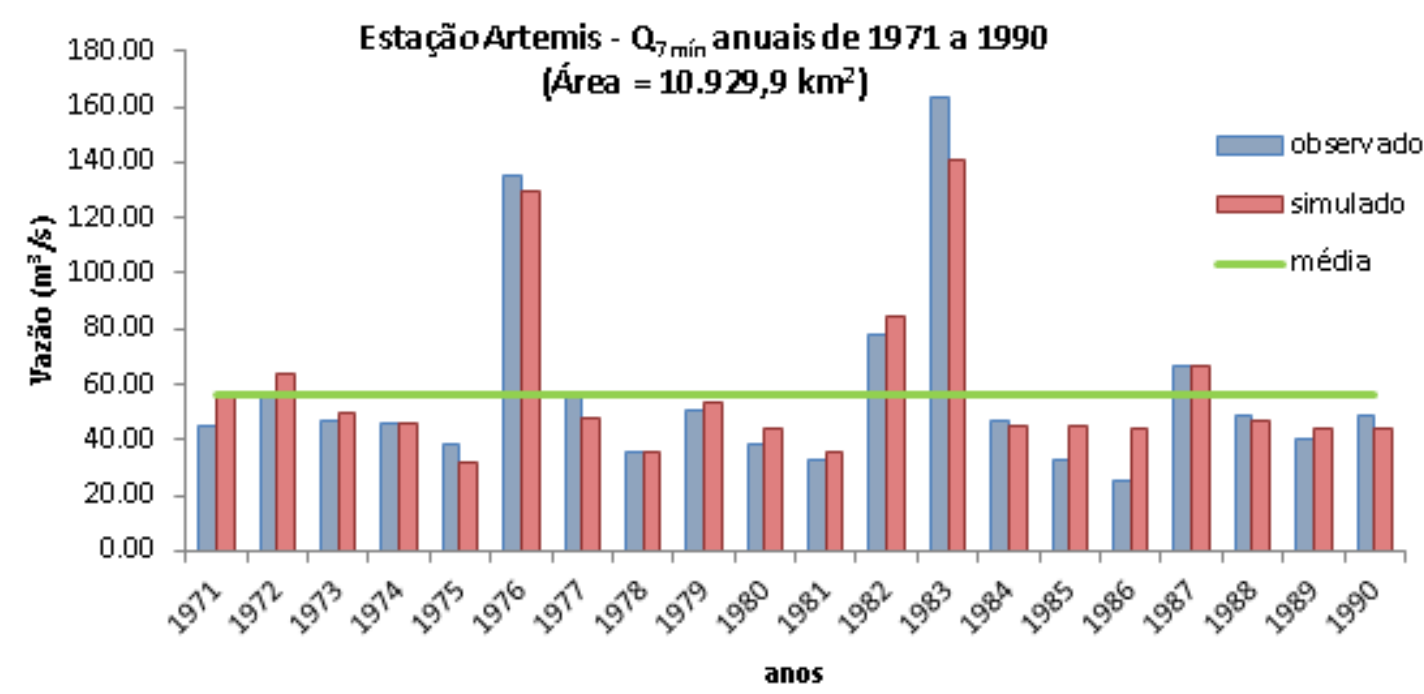

Figura 65. Vazões mínimas médias anuais observadas (barra azul), simuladas (barra vermelha) e média observada (linha verde) na estação Artemis, período 1971-1990 (Fonte: Elaborado pelo autor).

Notou-se desempenho satisfatório do modelo na representação destas vazões, pois na maioria dos anos os valores simulados foram muito próximos aos observados. Também se procedeu à análise da compatibilidade entre os valores de $Q_{7 m i n}$ anuais, simuladas $e$ observadas, através do $r^{2}$, na Tabela 14 . De modo geral, observaram-se melhores valores deste parâmetro em postos com áreas de drenagem maiores.

Tabela 14. Valores de $Q_{7 \min }$ simulados e observados e de $r^{2}$, para o período 1971-1990, por posto fluviométrico.

\begin{tabular}{lcccc}
\hline \multirow{2}{*}{ Posto fluviométrico } & \multirow{2}{*}{ Área $\left(\mathbf{k m}^{2}\right)$} & \multicolumn{2}{c}{$\mathbf{Q}_{\mathbf{7 m i n}}$ média $\left(\mathbf{m}^{3} \cdot \mathbf{s}^{-1}\right)$} & \multirow{2}{*}{$\mathbf{r}^{\mathbf{2}}$} \\
\hline Fazenda Barra & 927,1 & Observada & Simulada & \\
Usina Ester & $3.397,5$ & 21,7 & 5,6 & 0,67 \\
Desembargador Furtado & $2.487,7$ & 14,2 & 12,2 & 0,96 \\
Recreio & $1.577,5$ & 7,7 & 8,0 & 0,71 \\
Artemis & $10.929,9$ & 56,5 & 57,7 & 0,87 \\
\hline
\end{tabular}

Fonte: Elaborado pelo autor.

Nos postos sem interferência do Sistema Cantareira (Fazenda Barra e Recreio), o ajuste foi considerado pior do que nos demais postos, porém ainda assim satisfatório. Foram obtidos, respectivamente, valores de $r^{2}$ de 0,67 e 0,87 nesses postos.

Além do fato de possuírem menor área de drenagem, pode-se atribuir esta afirmação ao ajuste das condições de contorno da modelagem. Isto porque, nas áreas a jusante dos 
reservatórios (postos Desembargador Furtado, Usina Ester e Artemis), o modelo tomou como base as condições impostas pelas vazões substituídas na modelagem, portanto, vazões conhecidas e monitoradas.

O valor de $r^{2}$ nos postos influenciados pelo Sistema Cantareira foi de 0,71 , no posto Desembargador Furtado, até a estação Usina Ester, com resultado de 0,96. Para a estação Artemis, com maior área de drenagem entre todos os postos, o valor obtido foi de 0,95 .

Somado às análises citadas anteriormente, o cálculo dos erros de simulação permite a afirmação que o modelo foi capaz de representar satisfatoriamente a $Q_{7 \text { mín. }} A$ média de erro das vazões médias, observada e simulada, entre todos os postos, foi de $-0,2 \%$, conforme Tabela 15.

Tabela 15. Valores de $Q_{7 \min }$ simulados e observados e do percentual de erro, para o período 19711990, por posto fluviométrico.

\begin{tabular}{|c|c|c|c|c|c|}
\hline \multirow[b]{2}{*}{ Posto fluviométrico } & \multirow{2}{*}{$\begin{array}{l}\text { Área } \\
\left(\mathrm{km}^{2}\right)\end{array}$} & \multicolumn{2}{|c|}{$Q_{7 \min }$ média $\left(m^{3} \cdot s^{-1}\right)$} & \multicolumn{2}{|c|}{ ERRO (\%) } \\
\hline & & Observada & Simulada & $\begin{array}{l}\text { Faixa de } \\
\text { variação }\end{array}$ & Médio \\
\hline Fazenda Barra & 927,1 & 5,6 & 5,4 & $-31,4 a+48,2$ & $-2,5$ \\
\hline Usina Ester & $3.397,5$ & 21,7 & 22,2 & $-26,1 a+59,0$ & 2,3 \\
\hline Desembargador Furtado & $2.487,7$ & 14,2 & 12,2 & $-64,5 a+58,9$ & $-14,5$ \\
\hline Recreio & $1.577,5$ & 7,7 & 8,0 & $-25,9 a+50,0$ & 4,1 \\
\hline Artemis & $10.929,9$ & 56,5 & 57,7 & $-16,9 a+76,5$ & 2,0 \\
\hline
\end{tabular}

Fonte: Elaborado pelo autor.

Com relação aos postos, os melhores resultados médios do erro foram obtidos na Artemis $\left(10.929,9 \mathrm{~km}^{2}\right)$, totalizando $+2,0 \%$. Resultados igualmente bons foram alcançados nas estações Fazenda Barra $\left(927,1 \mathrm{~km}^{2}\right)$, Usina Ester $\left(3.397,5 \mathrm{~km}^{2}\right)$ e Recreio $\left(1.577,5 \mathrm{~km}^{2}\right)$. No posto Desembargador Furtado $\left(2.487,7 \mathrm{~km}^{2}\right)$ o erro médio alcançou os piores resultados $(-14,5 \%)$

Apesar dos bons resultados alcançados com relação ao erro médio, quando se avaliou anualmente os erros, obteve-se uma faixa de variação significativa. Em alguns poucos anos, durante a simulação, obteve-se uma variação muito grande entre os resultados observados e simulados. 
Na Figura 66, é exibida a dispersão dos valores de $Q_{7 \text { mín }}$ observados e simulados, de acordo com a variabilidade espacial da área de drenagem dos postos fluviométricos considerados. A proximidade entre pontos observados e simulados, dentro da mesma escala espacial, indica bom ajuste entre as vazões.

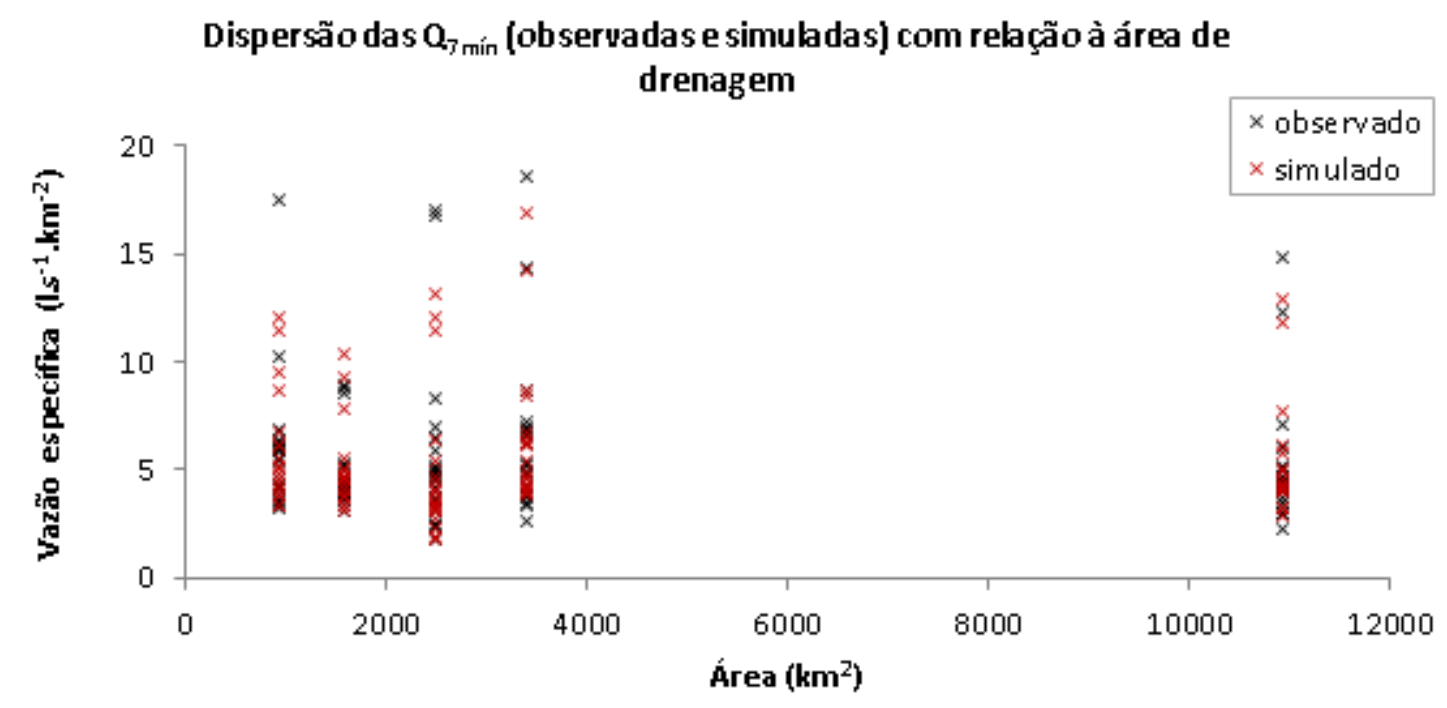

Figura 66. Dispersão dos valores das $Q_{7 \min }$ para o período 1971-1990, por posto fluviométrico, conforme a área do posto fluviométrico (Fonte: Elaborado pelo autor).

O modelo apresentou boa capacidade em representar as vazões $Q_{7 \text { mín }}$ anuais. $O$ fator área também foi determinante, uma vez que o aumento da área de drenagem levou à melhora dos resultados.

\subsubsection{Projeção das vazões mínimas anuais nos cenários}

Uma vez ajustado o modelo, realizou-se a simulação das vazões conforme os cinco cenários propostos. As vazões foram calculadas para o posto Fazenda Barra (Figura 67), Usina Ester (Figura 68), Desembargador Furtado (Figura 69), Recreio (Figura 70) e Artemis (Figura 71). 


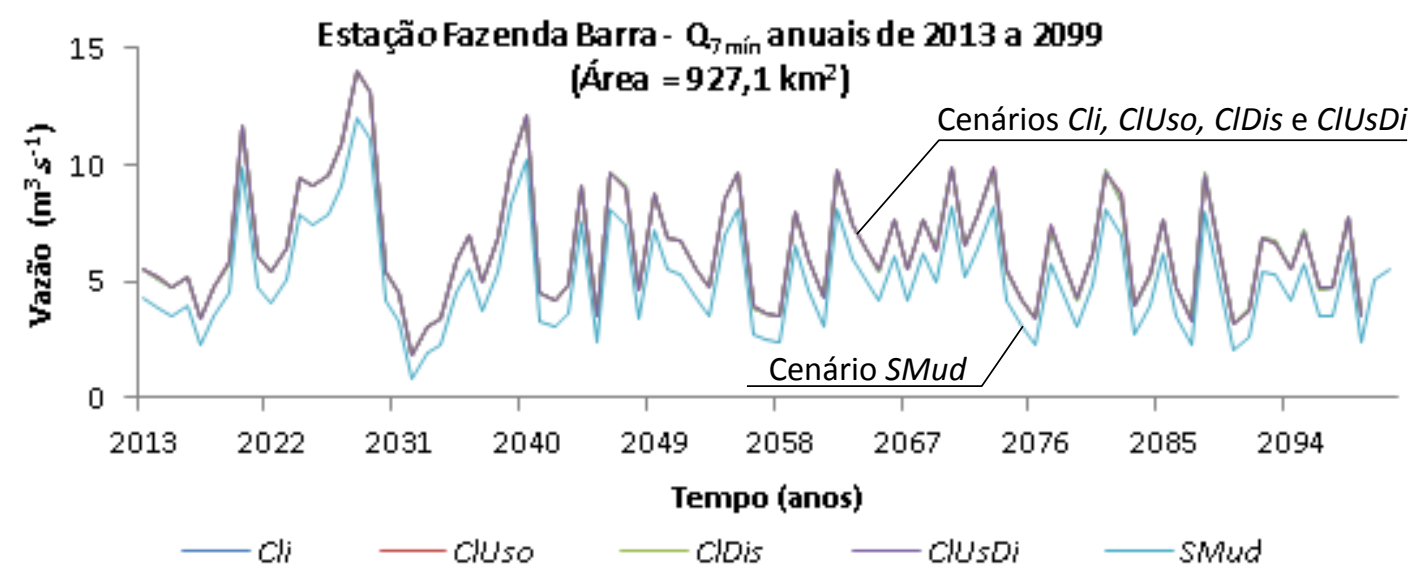

Figura 67. Série de vazões mínimas anuais $\left(Q_{7 \min }\right)$ no posto Fazenda Barra $\left(927,1 \mathrm{~km}^{2}\right)$, no período de 2013 a 2099, para os cenários de mudança.

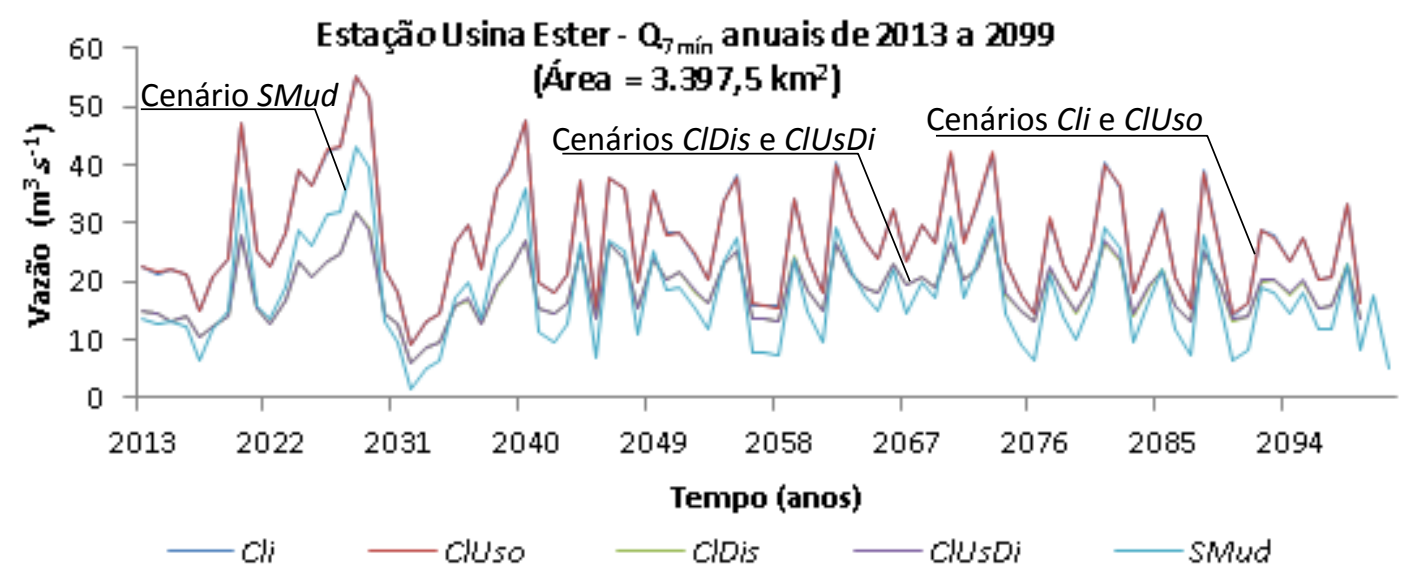

Figura 68. Séries de vazões mínimas anuais $\left(Q_{7 \text { min }}\right)$ no posto Usina Ester $\left(3.397,5 \mathrm{~km}^{2}\right)$, no período de 2013 a 2099, para os cenários de mudança.

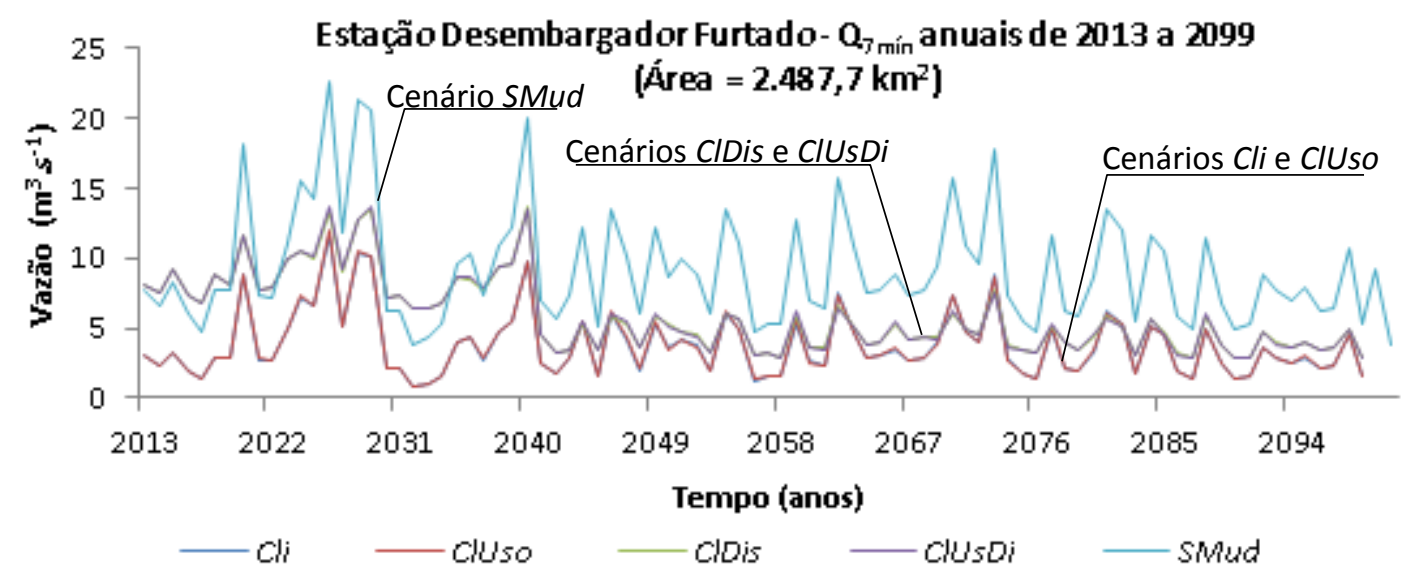

Figura 69. Séries de vazões mínimas anuais $\left(Q_{7 \min }\right)$ no posto Desembargador Furtado $\left(2.487,7 \mathrm{~km}^{2}\right)$, no período de 2013 a 2099, para os cenários de mudança. 


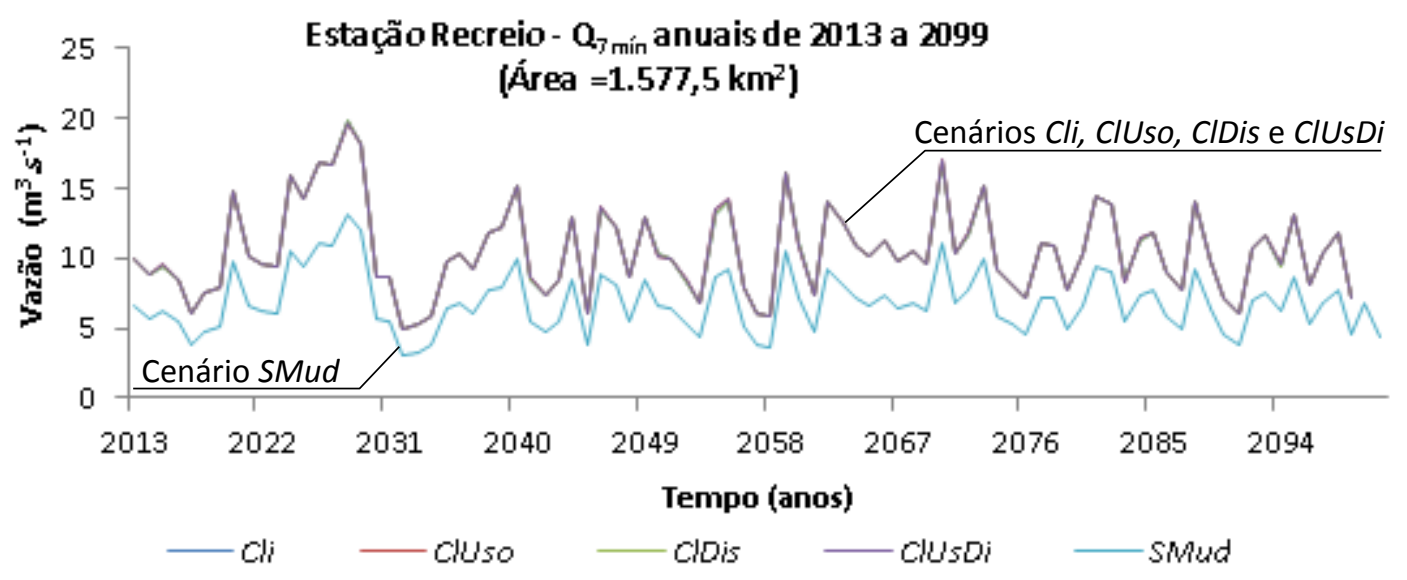

Figura 70. Séries de vazões mínimas anuais $\left(Q_{7 \min }\right)$ no posto Recreio $\left(1.577,5 \mathrm{~km}^{2}\right)$, no período de 2013 a 2099, para os cenários de mudança.

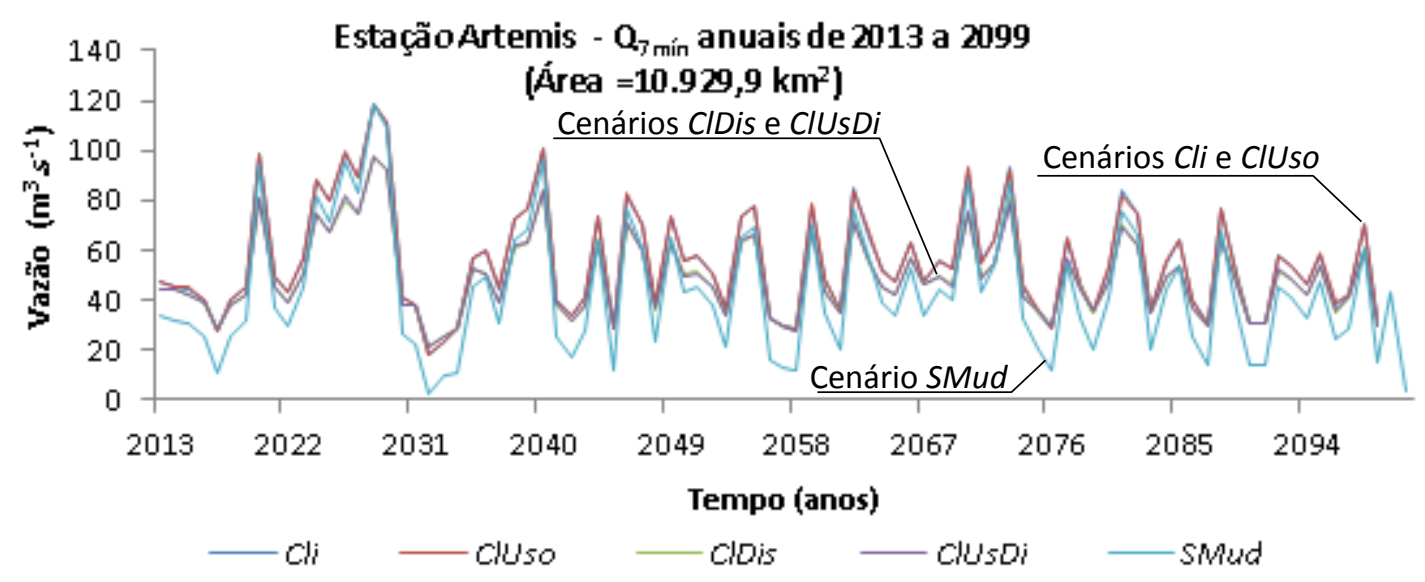

Figura 71. Séries de vazões mínimas anuais $\left(Q_{7 \min }\right)$ no posto Artemis $\left(10.929,9 \mathrm{~km}^{2}\right)$, no período de 2013 a 2099, para os cenários de mudança.

O comportamento dos quatro cenários de mudanças futuras propostos variou conforme condições peculiares de cada bacia hidrográfica. Através da análise visual dos gráficos, de modo geral, observou-se que as mudanças no uso da terra, quando consideradas isoladamente, resultaram em pequena variação entre os cenários. As alterações decorrentes de mudanças climáticas, por sua vez, foram muito mais significativas, conforme também afirmado em Li et al. (2009). A operação do Sistema Cantareira também proporcionou importantes mudanças nas vazões, principalmente nas bacias em que estavam inseridos os reservatórios.

Nos postos cujas sub-bacias não sofrem interferência do Sistema Cantareira, sendo eles Fazenda Barra e Recreio, não foi observada alteração significativa entre os cenários de mudança. Esses postos estão localizados, respectivamente, nos rios Camanducaia e 
Corumbataí. Nessas sub-bacias não ocorre a retirada de água nas bacias para transposição para a RMSP. Consequentemente, não foram identificadas diferenças significativas entre os cenários Cli, ClDis, ClUso e ClUsDi. Notou-se, em todos os cenários, o aumento da $Q_{7 m i ́ n}$ anual, quando comparados ao cenário SMud. Outros estudos realizados na bacia obtiveram constatações similares (Groppo et al., 2001; 2009). Nos demais postos têm-se efeitos variados, conforme cada cenário de mudança.

Alterações mais significativas, comparadas ao cenário SMud, ocorreram nos postos Usina Ester e Desembargador Furtado, respectivamente instalados nos rios Jaguari e Atibaia. Estas oscilações se devem basicamente à interferência do Sistema Cantareira. No Rio Jaguari, representado pelo posto Usina Ester, os impactos são maiores. Apesar da tendência de aumento da $Q_{7 m i n}$ anual devido a influências climáticas, a operação do sistema (cenários CIDis e ClUsDi) diminui os valores das vazões mínimas extremas encontradas no trecho a jusante do reservatório Jaguari-Jacareí. Esta alteração é relevante quando os resultados são comparados aos cenários que não consideram a operação dos reservatórios (Cli e ClUso).

Na sub-bacia correspondente ao posto Desembargador Furtado (Rio Atibaia) estão localizados dois reservatórios: Atibainha e Cachoeira. Em todos os cenários foi projetada a redução da $Q_{7 \min }$ anual em se comparando a situações presentes. Pode-se concluir que, nesta bacia, ainda que sob condições extremas de operação dos reservatórios (cenários CIDis e ClUsDi), o resultado das vazões mínimas extremas seria maior quando comparado a condições naturais. A ausência dos reservatórios (cenários Cli e ClUso) resultaria nos piores resultados da $Q_{7 \min }$. Cabe lembrar que neste estudo não são considerados e avaliados os impactos da operação dos reservatórios nas vazões média e máxima anuais na bacia.

No último posto, Artemis, localizado no Rio Piracicaba no trecho final da bacia, observou-se pequena variação entre os cenários. Por estar mais distante dos reservatórios, os impactos da operação do Sistema Cantareira na $Q_{7 \min }$ projetada neste ponto são menores. Condições de mudanças climáticas tendem a aumentar a $Q_{7 \min }$ (cenários Cli e ClUso). Através da simulação dos reservatórios considerada no futuro, conforme cenários CIDis e CIUsDi, observou-se pequena alteração de aumento entre os dados projetados e a tendência do cenário SMud. Ainda assim, apesar da pequena diferença, os maiores resultados de $\mathrm{Q}_{7 \mathrm{~min}}$ anuais ocorreriam em condições naturais, sem a operação dos reservatórios. 
Na Tabela 16 são explicitados os valores de $Q_{7 \min }$ média específica, para cada um dos cenários definidos. Foram considerados três horizontes temporais, sendo eles 2013-2040, 2041-2070 e 2071-2099.

Tabela 16. Vazões mínimas $\left(Q_{7 \min }\right)$ médias anuais em cada cenário considerado, no período 20132099.

\begin{tabular}{|c|c|c|c|c|c|c|}
\hline \multirow{2}{*}{ Posto } & \multirow{2}{*}{ Período } & \multicolumn{5}{|c|}{$Q_{7 \min }$ média $\left(1 . \mathrm{s}^{-1} \cdot \mathrm{km}^{-2}\right)$} \\
\hline & & $\mathrm{Cli}$ & ClUso & CIDis & ClUsDi & SMud \\
\hline \multirow{3}{*}{ Fazenda Barra } & 2013-2040 & 7,5 & 7,5 & 7,5 & 7,5 & 6,0 \\
\hline & 2041-2070 & 7,0 & 7,0 & 7,0 & 7,0 & 5,6 \\
\hline & 2071-2099 & 6,5 & 6,5 & 6,5 & 6,5 & 5,0 \\
\hline \multirow{3}{*}{ Usina Ester } & 2013-2040 & 8,5 & 8,5 & 5,1 & 5,1 & 5,8 \\
\hline & 2041-2070 & 8,0 & 8,0 & 5,8 & 5,8 & 5,2 \\
\hline & 2071-2099 & 7,5 & 7,5 & 5,5 & 5,6 & 4,8 \\
\hline \multirow{3}{*}{ Desembargador Furtado } & 2013-2040 & 1,8 & 1,8 & 3,6 & 3,6 & 4,2 \\
\hline & 2041-2070 & 1,5 & 1,5 & 1,8 & 1,8 & 3,6 \\
\hline & 2071-2099 & 1,3 & 1,3 & 1,7 & 1,7 & 3,3 \\
\hline \multirow{3}{*}{ Recreio } & $2013-2040$ & 6,9 & 6,9 & 6,9 & 6,9 & 4,5 \\
\hline & 2041-2070 & 6,6 & 6,6 & 6,6 & 6,6 & 4,3 \\
\hline & 2071-2099 & 6,5 & 6,5 & 6,5 & 6,5 & 4,2 \\
\hline \multirow{3}{*}{ Artemis } & $2013-2040$ & 5,5 & 5,5 & 4,8 & 4,8 & 4,5 \\
\hline & 2041-2070 & 5,0 & 5,0 & 4,5 & 4,5 & 3,9 \\
\hline & 2071-2099 & 4,7 & 4,7 & 4,2 & 4,2 & 3,5 \\
\hline
\end{tabular}

Fonte: Elaborado pelo autor.

A partir dos resultados acima descritos, realizou-se a análise dos impactos, de forma isolada, de cada um dos atores de mudança definidos, em cada um dos postos simulados. Também foi feita a análise numérica das médias das vazões mínimas extremas anuais.

Para que fossem isolados os atores de mudanças, foi realizada a comparação entre os cenários. Os efeitos das mudanças climáticas foram calculados através das informações do cenário $\mathrm{Cli}$, quando comparadas ao cenário SMud. A variação relacionada à mudança no uso das terras foi quantificada através da comparação entre os cenários ClUso e Cli. A interferência do Sistema Cantareira pôde ser quantificada através do percentual de variação entre os resultados dos cenários Cli e CIDis.

Observou-se uma tendência média de aumento da $Q_{7 m i n}$ anual, sob condições de mudança climática, da ordem de $+26,8 \%$ (Fazenda Barra) e $+53,4 \%$ (Recreio). De acordo com os resultados notou-se que a expansão da mancha urbana, quando analisada isoladamente, 
também tem impactos positivos nas vazões mínimas nessas bacias, com aumento de $+0,1 \%$ e $+0,2 \%$, respectivamente. Por não sofrerem influência dos reservatórios do Sistema Cantareira, não houve variação na disponibilidade hídrica nessas bacias.

$\mathrm{Na}$ bacia representada pelo posto Desembargador Furtado, no Rio Atibaia, foi observada a tendência de diminuição das vazões em $-59,2 \%$, sob condições de mudanças climáticas e na condição de inexistência do Sistema Cantareira (cenário Cli). Com a operação do sistema, porém ainda sob condições climáticas de mudança (cenário CIDis), observou-se redução de $-37,8 \%$ na vazão em comparação ao cenário SMud. Esta foi a única bacia estudada onde se observou impacto positivo do Sistema Cantareira nas vazões a jusante dos reservatórios, com um aumento médio de $1,8 \mathrm{~m}^{3} \cdot \mathrm{s}^{-1} \cdot \mathrm{km}^{-2}$ na $Q_{7 \text { mín }}$ anual com a operação dos reservatórios. $O$ aumento da urbanização, nesta bacia, resultou num aumento de $+0,4 \%$ na vazão em comparação à situação sem mudanças. Tem-se, nessa área, o maior aumento de vazão ocasionado pelo aumento das áreas urbanizadas.

No posto Usina Ester, sob condições de variabilidade climática, constatou-se variação média de $+52,7 \%$ na $Q_{7 m i ́ n}$ anual. A operação do Sistema Cantareira, em condições futuras, resultaria numa redução em $-31,8 \%$ do valor mencionado anteriormente. É neste ponto o maior impacto decorrente da transposição das águas da bacia, porém, ainda assim, o aumento seria de $+4,9 \%$ com relação ao cenário SMud. O aumento decorrente da expansão urbana seria de $+0,1 \%$.

No último posto avaliado, Artemis, foi observada a redução em -11\%, decorrente da operação do Sistema Cantareira. Este dado vai ao encontro do descrito em Groppo et al. (2001; 2009), que argumenta que os impactos da operação dos reservatórios é mais significativo nos trechos mais próximos às barragens. Nos trechos rio abaixo, foi observada a atenuação do efeito das barragens, embora esse efeito ainda seja perceptível. Com relação à variabilidade climática, projetou-se um aumento de $27,2 \%$ na $Q_{7 m i ́ n}$ média anual. $A$ urbanização, nesta sub-bacia e nas sub-bacias a montante, influenciaram o aumento das vazões em +0,2\% em comparação ao cenário dito sem mudanças.

A análise das projeções calculadas pelo modelo Eta-CPTEC indicaram o aumento da precipitação na bacia para o período 2013-2099. Todavia, foi observada uma tendência de redução das vazões mínimas extremas anuais a longo prazo. Em suma, excetuando-se o posto Usina Ester, em todos os cenários relativos a todos os postos fluviométricos simulados houve a redução progressiva da $Q_{7 \text { mín }}$ média entre os períodos considerados. 


\subsection{CONSIDERAÇÕES FINAIS}

Neste capítulo realizou-se a projeção de vazões mínimas extremas anuais em subbacias da bacia hidrográfica do Rio Piracicaba, para o período 2013-2099. Para tal, foram elaborados cenários de mudanças globais, resultantes da acoplagem entre o modelo hidrológico MGB-IPH e o modelo climático regional Eta-CPTEC. A realização deste objetivo foi realizada de maneira satisfatória e foi possível a representação da $Q_{7 \text { mín }}$ anual na bacia sob diferentes condições de mudanças.

A correção dos dados de precipitação calculados pelo modelo Eta-CPTEC fez-se necessária para sua aplicação na escala da bacia de estudo. Os resultados obtidos desta correção demonstraram que é projetada a tendência de aumento da precipitação na bacia. Nos meses de outubro a março, foi observada uma média de redução de $-5,4 \%$ com relação ao período 1961-1990. Já para os meses de abril a setembro, as projeções demonstraram estimativas de aumento em $+27,8 \%$ com relação ao mesmo período. No âmbito anual, o aumento médio foi de $+2,7 \%$.

Com relação aos cenários, foi possível se obter bons indicadores da interferência de cada um dos atores de mudança na bacia. Avaliando-se em separado cada um desses atores, pôde-se concluir que a maior influência nas vazões mínimas, especificamente nas sub-bacias estudadas, ocorre devido à mudança climática. A variação do comportamento de variáveis do clima na bacia tem impacto médio de $+24,8 \%$ na $Q_{7 \text { mín }}$ média futura.

Outro importante fator de mudança com interferência na bacia é a existência do Sistema Cantareira. Devido à operação dos reservatórios na bacia, tem-se a média de redução em $-14,6 \%$ na disponibilidade da $Q_{7 \operatorname{mín}}$ média entre as sub-bacias. $A$ expansão da mancha urbana também tem impacto em $+0,2 \%$ nas vazões mínimas, porém esta variação é pequena quando comparada às outras anteriormente citadas. 


\section{SIMULAÇÃO DO MODELO DE TRANSFERÊNCIA DE RISCOS HIDROLÓGICOS COMO ESTRATÉGIA DE ADAPTAÇÃO A EVENTOS DE ESCASSEZ HÍDRICA}

\subsection{INTRODUÇÃO}

Desastres naturais são fenômenos que ocorrem na natureza em escalas espaciais e temporais definidas, que resultam em algum tipo de dano, afetando direta ou indiretamente a população e que comprometem o desenvolvimento do local impactado (ALCÁNTARAAYALA, 2002; UNISDR, 2004; 2009).

Condições de mudanças globais resultam no aumento da vulnerabilidade e da exposição a desastres naturais e eventos extremos. Alterações no uso e ocupação das terras, na dinâmica de bacias hidrográficas, na demanda dos recursos hídricos e nos padrões climáticos do planeta tendem a favorecer a ocorrência de estiagens e enchentes, além de precipitações intensas e outros eventos que se enquadram nesta categoria (MENDIONDO; VALDÉS, 2002; BENSON; CLAY, 2003; SIVAPALAN et al 2003; UNDP, 2004; IPCC, 2007; FRANCZYK; CHANG, 2009; UNISDR, 2009; IPCC; 2012).

Define-se risco como a probabilidade de ocorrência de prejuízos e danos, ao homem ou ao ambiente, resultantes de interações entre desastres de origem natural ou humana, segundo condições de vulnerabilidade. O risco é resultado de interação complexa entre processos que resultem em condições de perigo, exposição, vulnerabilidade e resiliência - os chamados componentes do risco (UNISDR, 2004; 2009).

O perigo é o potencial de dano agregado a um evento, fenômeno ou atividade humana. Trata-se de uma variável que está sempre presente na dinâmica de ambientes naturais. Porém, alterações ambientais e a urbanização alteram a distribuição espacial, magnitude e frequência de diversos tipos de desastres. A exposição aumenta quando ocorre 
desenvolvimento humano e econômico, bem como maior concentração de pessoas, em áreas propensas a elevados índices de perigo.

A vulnerabilidade é uma função do grau de exposição aos riscos. Está associada a atributos físicos, sociais, políticos, econômicos, culturais e institucionais de uma comunidade, bem como a sua propensão ou susceptibilidade a sofrer danos e perdas. Resiliência é a associação entre a capacidade de um sistema em absorver as perdas e danos, se adaptar e iniciar sua recuperação até um nível aceitável de funcionamento. Para Folke (2006), a resiliência tem potencial para promover a renovação, a reorganização e/ou o desenvolvimento de novos fenômenos e processos, desencadeados a partir de uma perturbação decorrente de um impacto.

Segundo Mendiondo e Valdés (2002), a gestão do risco de desastres e eventos extremos deve considerar três etapas em sua concepção:

(1) Avaliação dos riscos, mediante identificação do perigo associado a determinado evento extremo, bem como a quantificação de suas consequências e impactos;

(2) Redução dos riscos segundo medidas estruturais e não-estruturais;

(3) Transferência dos riscos através de mecanismos de seguros.

Mendiondo (2010) recomenda que a gestão dos riscos seja o produto de variáveis como perigo, exposição e vulnerabilidade. Devem ser considerados aspectos antes, durante e depois da ocorrência dos eventos extremos. A resiliência é maior quando se consideram políticas proativas para o gerenciamento dos desastres, conforme o também encontrado em Bouwer e Aerts (2006), O’Brien et al. (2006) e Wilby et al. (2010).

Exemplos de intervenções que podem ser adotadas na gestão do risco e adaptação são sistemas de alerta antecipado, delegação de responsabilidades a nível local, intervenções estruturais de controle, planejamento da ocupação de áreas vulneráveis e, inclusive, transferência dos riscos através de seguros (MENDIONDO, 2005; SCHNEIDER; SEMENOV; PATWARDHAN, 2007; DIXIT; MCGRAY, 2009; MENDIONDO, 2010; TRAVIS, 2010).

Seguros são ferramentas úteis e relevantes para a restauração do bem-estar e reestruturação de comunidades após um desastre. Além disso, se um fundo de seguros for bem projetado e estabelecido, pode se transformar em uma ferramenta voltada à prevenção e redução de comportamentos de risco, bem como transferência do risco de perdas econômicas (KLEIN; HUQ, 2007; UNEP FI, 2007; DIXIT; MCGRAY, 2009; UNISDR, 2009). Se 
bem fundamentado, um fundo de seguros pode ser útil na adaptação, através da preparação prévia à ocorrência de eventos, da redução de comportamentos de risco, bem como do aumento da resiliência (UNEP FI, 2007; HALLEGATTE, 2009; MENDIONDO, 2010; DAWSON et al., 2011; IPCC, 2012; LYBBERT; SUMNER, 2012).

Considerando-se aspectos econômicos, as perdas resultantes de desastres naturais e eventos extremos são cada vez maiores e possuem impactos sociais, ecológicos e econômicos (MECHLER, 2003). Vörösmarty et al. (2010) afirmam que aproximadamente 80\% da população mundial encontra-se exposta a níveis de ameaça à segurança hídrica.

A interpretação de resultados de estimativas oficiais indica um aumento do Produto Interno Bruto (PIB) mundial exposto a danos decorrentes de desastres naturais em mais de 200\% nos dias de hoje, em comparação à década de 70 (UNISDR, 2011). Dados da Munich Re (2006; 2011), empresa do ramo de seguros, vão ao encontro dessas informações. Na década de 50 , os prejuízos decorrentes de desastres naturais e eventos extremos resultaram em US\$48,1 bilhões em prejuízos a indivíduos direta ou indiretamente afetados. Nos anos 90, esse valor aumentou para US\$728,8 bilhões. Dados do ano de 2010 , considerado isoladamente, contabilizaram prejuízos de aproximadamente US\$150 bilhões.

O compartilhamento de informações de dados de danos decorrentes de eventos de diferentes magnitudes, bem como outros avanços na área de gestão de desastres, devem ser amparados e divulgados em um Sistema Global de Observação do Clima (SGOC). O objetivo desta estrutura é relacionar a produção, a disponibilidade, o compartilhamento e a aplicação de dados e resultados de pesquisas referentes à gestão do clima do planeta e dos riscos associados. Trata-se de uma estrutura importante na difusão de estratégias e dos níveis de adaptação obtidos através das mesmas (UNEP FI, 2011; WMO, 2011).

Adaptação pode ser definida como o ajuste em processos, práticas e estruturas de sistemas ecológicos, sociais ou econômicos. Tais ajustes estão relacionados à redução ou compensação dos danos potenciais decorrentes das alterações nos padrões do clima, de modo a favorecer a redução da vulnerabilidade e o aumento da resiliência de uma atividade, comunidade ou região exposta a determinado evento ou impacto. Para seu estabelecimento, devem ser considerados aspectos geográficos, climáticos e o desenvolvimento econômico da área avaliada, bem como os setores e atores envolvidos (SMIT ET AL., 2001; SMIT; WANDEL, 2006; ADGER ET AL., 2007; TOMPKINS et al., 2010). 
Este capítulo tem como objetivo realizar a análise de risco a eventos anuais de escassez hídrica na bacia hidrográfica do Rio Piracicaba, para posterior simulação do Modelo de Transferência de Riscos Hidrológicos (MTRH-SHS). Também foi avaliado o desempenho de cada cenário simulado frente à ocorrência dos sinistros, com base em indicadores de eficiência, solvência e sinistralidade. As considerações finais discutem a viabilidade da adoção da estratégia de adaptação proposta.

\subsection{METODOLOGIA}

Nos itens a seguir ocorre o detalhamento metodológico dos procedimentos realizados neste capítulo. Primeiramente, fez-se a descrição da estratégia de adaptação a condições de escassez hídrica na bacia. Em seguida, são descritas as etapas da metodologia consideradas para a viabilização de tal estratégia e para a análise dos resultados obtidos.

\subsubsection{Descrição da estratégia de adaptação}

A evolução e o amadurecimento da concepção do MTRH-SHS e da estratégia de adaptação aqui proposta se deram no âmbito do Núcleo Integrado de Bacias Hidrográficas NIBH, pertencente ao Departamento de Hidráulica e Saneamento (SHS), da Escola de Engenharia de São Carlos da Universidade de São Paulo (EESC/USP).

Pilar, Mendiondo e Lanna (2001) desenvolveram um modelo de seguros voltado apenas a áreas agrícolas e ao atendimento de demandas rurais. Righetto, Mendiondo e Righetto (2007) trabalharam os danos de enchentes em bacias urbanas, através da simulação de um fundo de seguros sobre funções hidrológicas simplificadas obtidas estatisticamente. Graciosa e Mendiondo (2011) mantiveram a linha de trabalho de seguros para inundações, porém, incorporaram a modelagem hidráulico-hidrológica e a geração de mapas de riscos de inundações ao MTRH-SHS.

A versão mais recente do modelo representa um modelo concentrado, para simulação de um fundo de seguros contra riscos hidrológicos em bacias hidrográficas. A simulação visa à obtenção de um prêmio ótimo a ser pago pelos segurados, capaz de ressarcir os prejuízos decorrentes da ocorrência de eventos extremos. Para isso, são 
simuladas 30 séries sintéticas equiprováveis, segundo geração aleatória, para subsidiar a definição de um prêmio ótimo.

As entradas do modelo são as séries de vazões extremas e as curvas de dano (CDN) associadas à magnitude e período de recorrência dos eventos. São parâmetros do modelo: (i) a faixa de cobertura do fundo (tempo de retorno dos eventos), (ii) a taxa anual de juros (para rendimentos e empréstimos), (iii) o número de parcelas em que serão quitadas as dívidas até o presente ano e (iv) os limites máximo e (v) mínimo de operação do fundo (em reais).

Neste trabalho, utilizou-se a versão de Graciosa e Mendiondo (2011), porém com algumas modificações. Foi avaliada a simulação do MTRH-SHS em grande escala, considerando sub-bacias da bacia hidrográfica do rio Piracicaba $\left(12.589,7 \mathrm{~km}^{2}\right)$, conforme condições de escassez hídrica. Trata-se da primeira aplicação do modelo para quantificar os danos decorrentes de eventos extremos mínimos e em grandes bacias hidrográficas.

Aqui, procurou-se integrar os riscos inerentes aos diversos setores usuários dos recursos hídricos na bacia frente à ocorrência das vazões mínimas, representada pela $Q_{7 m i ́ n}$ anual (maiores detalhes no Capítulo 4). Com isso, tem-se a seleção do valor extremo anual, ou seja, o mínimo valor atingido em determinado ano, conforme a vulnerabilidade em cada cenário.

As contribuições deste trabalho se deram na geração de cenários de longo prazo, para a determinação vulnerabilidade da bacia frente à ocorrência de vazões mínimas. Também houve progresso na quantificação dos riscos e prejuízos decorrentes da escassez hídrica. No âmbito dos cenários, utilizaram-se produtos de modelagem hidrológica (obtidos conforme Capítulo 3) acoplados ao modelo regional Eta-CPTEC e diferentes cenários de mudanças globais (Capítulo 4).

Com relação aos impactos, foi proposto um modelo para avaliação dos riscos de ocorrência de sinistros, denominado AQUA-Risco, acoplado ao MTRH-SHS. O papel do AQUA-Risco se deu na determinação dos danos econômicos associados às vazões mínimas extremas. O modelo avalia os danos tangíveis, ou seja, danos passíveis de serem quantificados em unidades monetárias.

A Figura 72 representa o fluxograma de atividades consideradas no âmbito da estratégia considerada. 


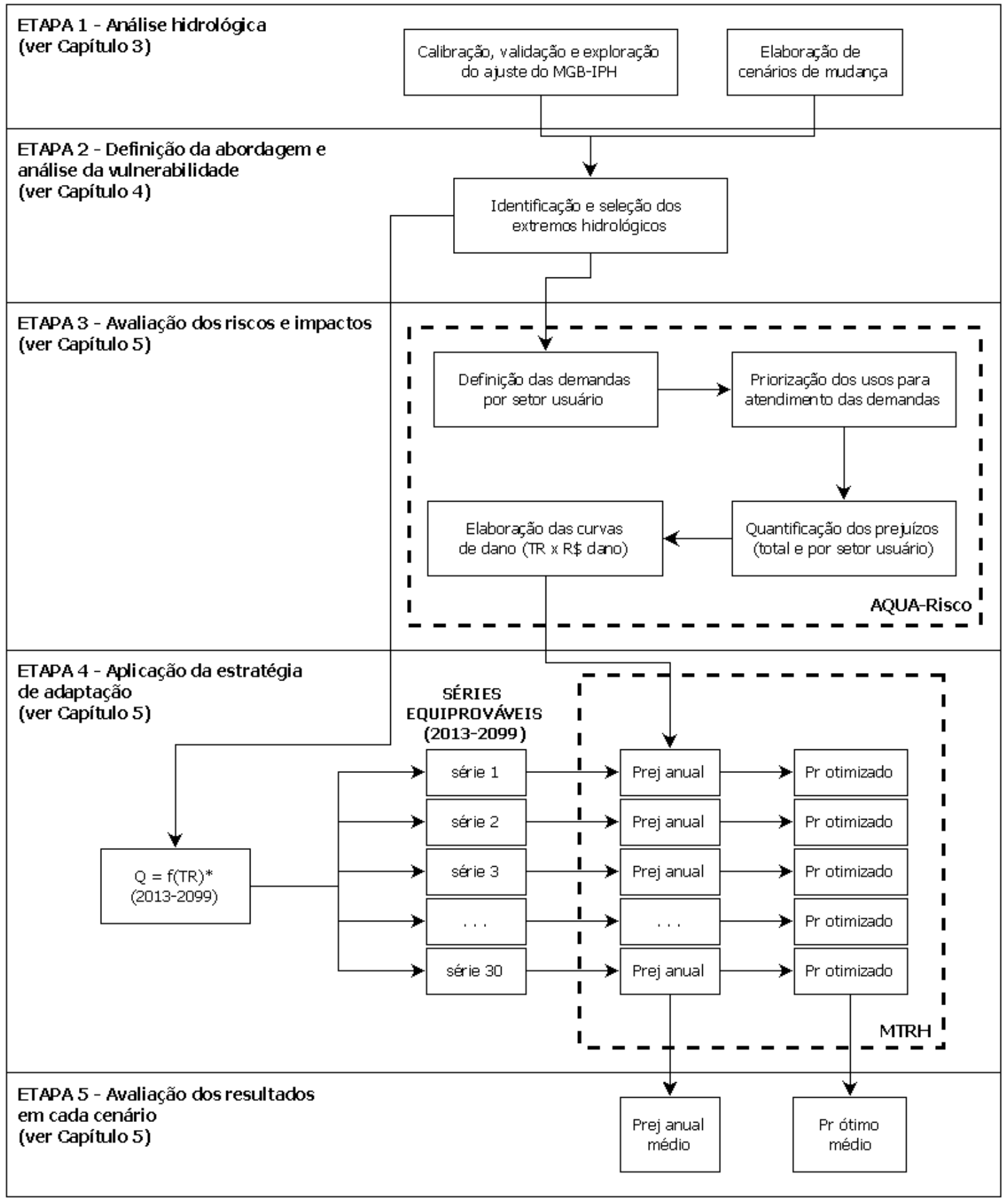

*vazão simulada ajustada para a faixa de cobertura (TR)

Figura 72. Fluxograma de atividades em cada etapa da estratégia de adaptação definida (Fonte: Elaborado pelo autor).

Para aplicação do MTRH-SHS, é imprescindível a avaliação dos impactos das vazões mínimas nos setores usuários. Para isso, após a simulação das séries de vazões diárias no modelo MGB-IPH nos cenários considerados (etapa 1) e da análise de vulnerabilidade das séries de vazões mínimas simuladas (etapa 2), foi realizada a quantificação dos riscos através do modelo AQUA-Risco (etapa 3). 
A geração de 30 séries sintéticas de vazões mínimas (etapa 4), equiprováveis, ocorreu a partir da vulnerabilidade diagnosticada em etapas anteriores. Depois, a simulação do MTRH-SHS ocorre, considerando os impactos e vulnerabilidade diagnosticados. A avaliação dos resultados (etapa 5) considerou a utilização de indicadores, conforme os prejuízos e prêmios calculados.

Foram simuladas as etapas 3, 4 e 5 para todos os cenários considerados. A seguir, são detalhados os procedimentos metodológicos referentes a cada etapa acima mencionada.

\subsubsection{Simulação das séries de vazões (Etapa 1)}

A calibração do modelo hidrológico MGB-IPH, conforme Capítulo 3, permitiu que se utilizasse o modelo para previsão de vazões para o período 2013-2099. Foram adotados os cenários elaborados e descritos no Capítulo 4, sendo eles (i) Cli, com mudanças climáticas; (ii) ClUso, com mudanças climáticas e no uso das terras; (iii) CIDis, com mudanças climáticas e na disponibilidade hídrica; (iv) ClUsDi, com mudanças climáticas, no uso das terras e na disponibilidade hídrica; e (v) SMud, sem mudança.

Foram simuladas as cinco sub-bacias referentes aos postos fluviométricos considerados no Capítulo 4. As bacias consideradas foram representadas pelos postos fluviométricos Fazenda Barra (sub-bacia do rio Camanducaia), Usina Ester (sub-bacia do rio Jaguari), Desembargador Furtado (sub-bacia do rio Atibaia), Recreio (sub-bacia do rio Corumbataí) e Artemis (sub-bacia do rio Piracicaba). Assim, foram obtidas cinco séries de vazões para o período futuro (2013-2099), equivalentes a cada um dos cenários elaborados, para cada sub-bacia (Figura 73). 


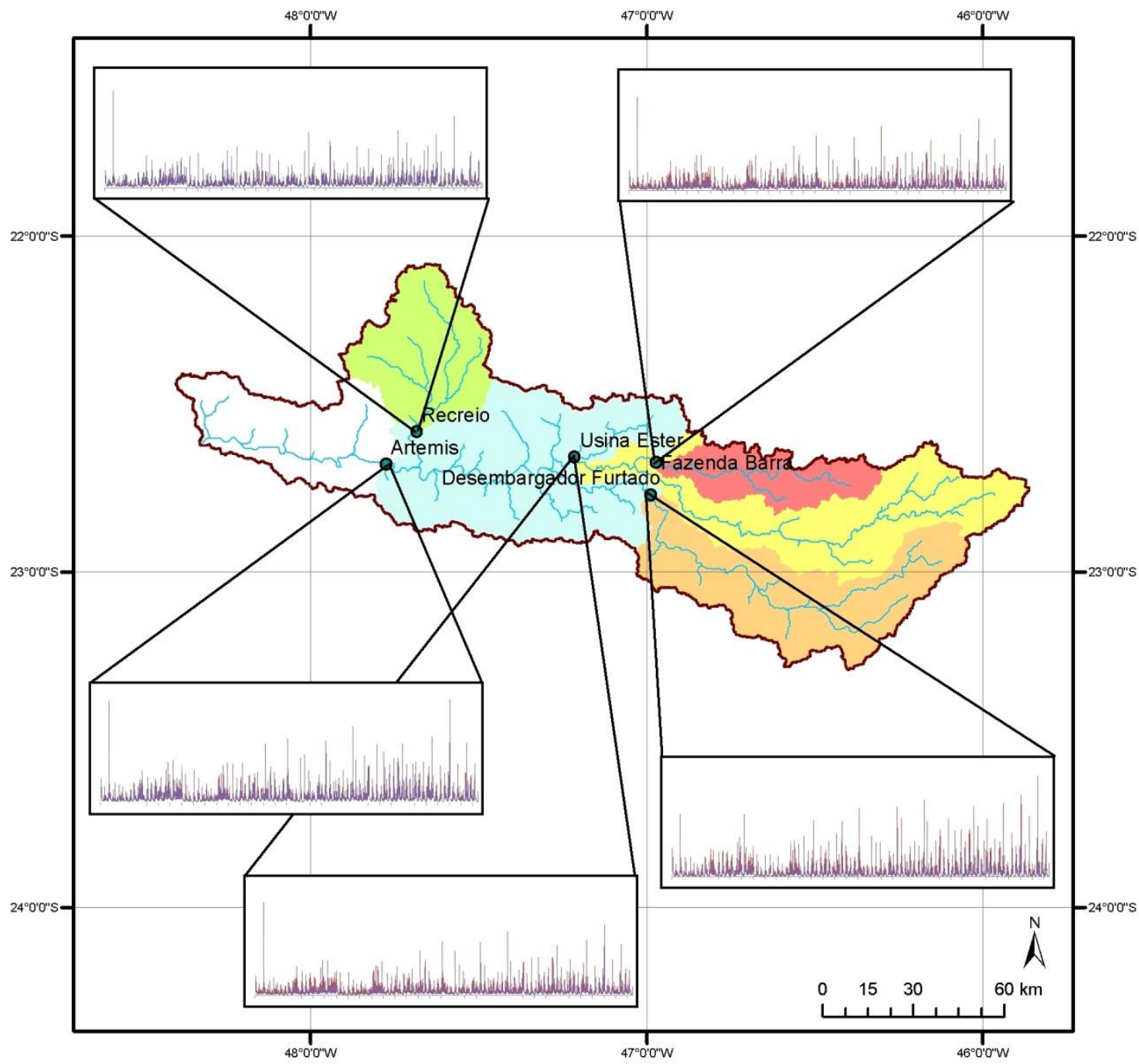

Figura 73. Representação das séries de vazões diárias simuladas para os cenários de mudanças, em cada sub-bacia, no período 2013-2099 (Fonte: Elaborado pelo autor).

\subsubsection{Análise da vulnerabilidade (Etapa 2)}

As séries de vazões mínimas anuais, representadas pela série das $Q_{7 \min }$ anuais, foram obtidas conforme descrito no Capítulo 4. A partir das séries geradas no item anterior, foram selecionados os menores valores de $Q_{7 \text { mín }}$ a cada ano, para cada cenário.

Foi utilizado o modelo MGB-IPH, calibrado e validado para o período 1971-1990, para simular as vazões no período 2013-2099. Cinco séries de vazões mínimas anuais foram geradas, onde cada valor representa a menor vazão média de sete dias consecutivos naquele ano, para cada cenário de mudança. A Figura 74 representa essa situação. 


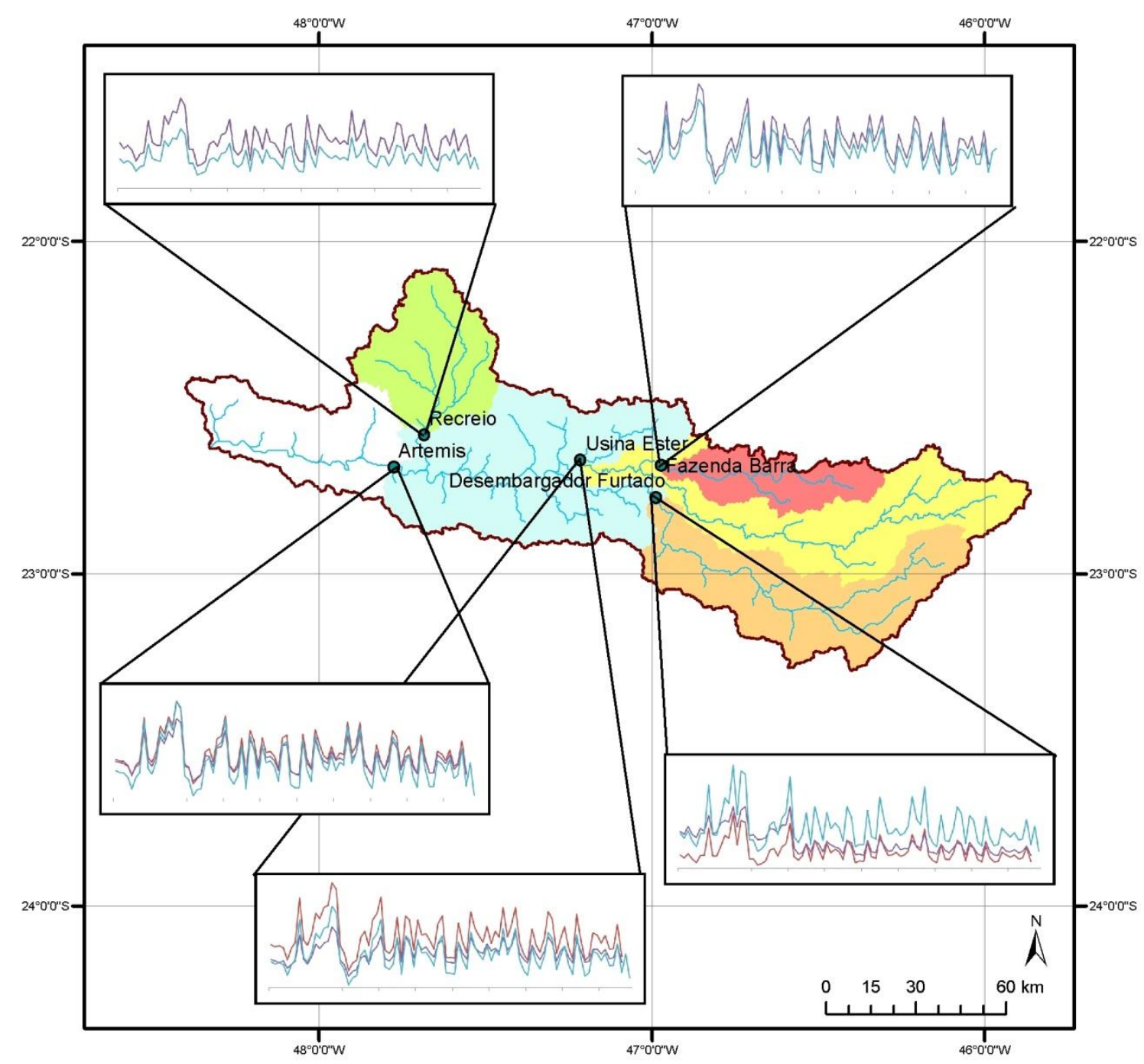

Figura 74. Representação das séries de $Q_{7 \min }$ anuais simuladas para os cenários de mudanças, em cada sub-bacia, no período 2013-2099 (Fonte: Elaborado pelo autor).

\subsubsection{Aplicação do modelo de avaliação dos riscos - AQUA-Risco (Etapa 3)}

Para que se possa simular o MTRH-SHS, é necessário que se tenha conhecimento sobre as demandas hídricas na bacia e dos riscos de não atendimento das mesmas. Além disso, devem-se mensurar os prejuízos decorrentes do não atendimento destas demandas. Assim, através do mecanismo de seguro-indexado (DIXIT; MCGRAY, 2009; CARRIQUIRY; OSGOOD, 2012) tem-se a associação entre o risco de ocorrência de determinada vazão mínima (ou seu período de retorno) com os danos resultantes do não atendimento das demandas em virtude da mesma.

Seguindo esta linha de raciocínio, foi elaborado o AQUA-Risco. Trata-se de um modelo de determinação de riscos hidrológicos, concentrado, acoplado ao MTRH-SHS. O 
modelo é responsável pela representação e quantificação, de forma simplificada, dos riscos econômicos decorrentes da escassez hídrica na bacia aos diversos usuários. A partir do uso do modelo, são obtidas as curvas de dano, que relacionam os TR com os prejuízos econômicos.

O modelo considera usos como o abastecimento humano, industrial, dessedentação animal, agricultura e diluição. São dados de entrada do AQUA-Risco a área da bacia, a vazão captada $\left(Q_{\text {captada }}\right)$, vazão efluente $\left(Q_{\text {efluente }}\right)$, carga do efluente ( $\left.L_{\text {efluente }}\right)$ e classe do corpo hídrico receptor dos efluentes.

Além disso, devem ser calculados os valores dos parâmetros $\alpha$ e $b$ da distribuição Gumbel, para que se determinem as vazões referentes aos períodos de retorno (TR), até o limite da cobertura do fundo. Neste trabalho, adotaram-se como limite máximo da cobertura as vazões de TR menores ou iguais a 100 anos de recorrência.

Nos itens a seguir foram descritas as etapas de aplicação do AQUA-Risco na bacia hidrográfica do rio Piracicaba, ilustradas no fluxograma da Figura 72 exibida anteriormente.

\subsubsection{Determinação das vazões e probabilidades de ocorrência}

As vazões foram calculadas através de ajuste à distribuição de Gumbel (mínimos). Os parâmetros da distribuição foram determinados conforme séries de $Q_{7 m i n}$ simuladas pelo modelo MGB-IPH, para o período 2013-2099.

Para cada cenário de mudança simulado (Cli, ClUso, CIDis e ClUsDi), bem como para o cenário SMud, determinaram-se as vazões associadas a cada período de retorno, de 1 a 100 anos. Consideraram-se TR=100 anos como a máxima cobertura do fundo de seguros e, portanto, o máximo risco nas bacias. Maiores esclarecimentos sobre as equações envolvidas são descritos no item 5.2.5.1, referente à geração das séries sintéticas através da distribuição de Gumbel.

\subsubsection{Definição das demandas}

Os dados de entrada no AQUA-Risco consideraram como base informações do relatório síntese do Plano de Bacias 2004-2007 do Comitê PCJ (SHS, 2006). Os dados foram obtidos para cada sub-bacia considerada. 
A definição das demandas e da quantidade de efluentes lançados se deu por setor usuário, conforme condições diagnosticadas pelo relatório. Por isso, foram calculados coeficientes (em $1 . \mathrm{s}^{-1} \cdot \mathrm{km}^{-2}$ ) para cada setor usuário de água em cada sub-bacia, para simplificar o cálculo. Este método possibilitou a correção da diferença entre as áreas consideradas nos relatórios para cada sub-bacia e a área calculada através do MDE para a modelagem hidrológica.

Na Tabela 17 encontram-se as sub-bacias que foram consideradas, bem como a área e os valores de captação corrigidos para cada usuário.

Tabela 17. Valores de captação corrigidos, por sub-bacia hidrográfica, para cada usuário dos recursos hídricos.

\begin{tabular}{lcccc}
\hline Sub-bacia & $\begin{array}{c}\text { Área } \\
\left(\mathbf{k m}^{\mathbf{2}} \mathbf{)}\right.\end{array}$ & & $\begin{array}{c}\text { Captação } \\
\left(\mathbf{m}^{\mathbf{3}} \cdot \mathbf{s}^{-1} \mathbf{)}\right.\end{array}$ \\
\cline { 3 - 5 } & $3.467,2$ & Urbano & Indústria & Rural \\
\hline Piracicaba & $2.487,7$ & 2,5 & 4,1 & 1,6 \\
Atibaia & 927,1 & 0,3 & 0,6 & 0,6 \\
Camanducaia & $3.397,5$ & 2,7 & 0,1 & 0,6 \\
Jaguari & $1.577,5$ & 5,2 & 2,8 & 1,3 \\
Corumbataí & & & & 1,5 \\
\hline
\end{tabular}

Fonte: Adaptado de SHS (2006).

Da mesma forma, foram corrigidos os valores da quantidade de efluente lançada (Tabela 18) e da carga remanescente nos corpos d'água (Tabela 19). Estas informações foram contabilizadas no cálculo da demanda para diluição.

Tabela 18. Valores de lançamento de efluentes corrigidos, por sub-bacia hidrográfica, para cada usuário dos recursos hídricos.

\begin{tabular}{lcccc}
\hline Sub-bacia & $\begin{array}{c}\text { Área } \\
\left(\mathbf{k m}^{2}\right)\end{array}$ & \multicolumn{3}{c}{$\begin{array}{c}\text { Lançamentos } \\
\left(\mathbf{m}^{\mathbf{3}} \cdot \mathbf{s}^{-\mathbf{1}} \mathbf{)}\right.\end{array}$} \\
\cline { 3 - 5 } & $3.467,2$ & Urbano & Indústria & Rural \\
\hline Piracicaba & $2.487,7$ & 2,8 & 3,5 & 0,1 \\
Atibaia & 927,1 & 0,1 & 2,6 & 0,2 \\
Camanducaia & $3.397,5$ & 0,9 & 0,1 & 0,1 \\
Jaguari & $1.577,5$ & 0,3 & 0,6 & 0,1 \\
Corumbataí & & & & 0,1 \\
\hline
\end{tabular}

Fonte: Adaptado de SHS (2006). 
Tabela 19. Valores da carga remanescente nos efluentes após o tratamento, por sub-bacia hidrográfica, lançados nos corpos d'água.

\begin{tabular}{|c|c|c|c|c|}
\hline \multirow[t]{2}{*}{ Sub-bacia } & \multirow{2}{*}{$\begin{array}{l}\text { Área } \\
\left(\mathrm{km}^{2}\right)\end{array}$} & \multicolumn{3}{|c|}{$\begin{array}{l}\text { Carga remanescente } \\
\left(\mathrm{kg} \cdot \mathrm{DBO}^{-1} \cdot \mathrm{dia}^{-1}\right)\end{array}$} \\
\hline & & Urbano & Indústria & Total \\
\hline Piracicaba & $3.467,2$ & $64.301,9$ & $11.430,0$ & $75.731,8$ \\
\hline Atibaia & $2.487,7$ & $7.326,6$ & $3.781,6$ & $11.108,2$ \\
\hline Camanducaia & 927,1 & $11.599,6$ & 630,1 & $12.229,6$ \\
\hline Jaguari & $3.397,5$ & $4.392,0$ & $1.962,1$ & $6.354,0$ \\
\hline Corumbataí & $1.577,5$ & $33.580,3$ & $1.972,8$ & $35.553,2$ \\
\hline
\end{tabular}

Fonte: Adaptado de SHS (2006).

\subsubsection{Priorização do atendimento das demandas}

Como estratégia para se abordar o déficit hídrico de cada setor, bem como os prejuízos decorrentes da escassez, considerou-se a priorização do atendimento às demandas. Esta escala de prioridades considerou que o atendimento a um usuário de menor prioridade só ocorria quando já foram atendidas as necessidades de usuários mais prioritários. Em suma, consideraram-se, por ordem de prioridade, os seguintes usos:

I. Atendimento das necessidades básicas humanas e abastecimento público urbano;

II. Dessedentação animal e pecuária;

III. Atividades agrícolas;

IV. Atividades industriais;

V. Diluição da poluição.

A priorização dos usos para abastecimento em caso de escassez hídrica tomou como base a Lei Estadual no 9.034/1994 (SÃO PAULO, 1994), que dispõe sobre o Plano Estadual de Recursos Hídricos - PERH. Em seu artigo 12, a referida lei ordena os usos, segundo critérios de prioridades. Esse arranjo de prioridades foi considerado para que se pudessem organizar as atividades na bacia quanto à demanda de cada uma. 
A partir das vazões, e das demandas de cada setor usuário, pôde-se determinar o atendimento ou não das necessidades hídricas da bacia. $O$ déficit $\left(\mathrm{em}^{3}\right.$ ) calculado para os usuários, em cada setor, foi convertido em unidades monetárias ( $\mathrm{R}$ ) de prejuízo.

\subsubsection{Quantificação dos prejuízos por setor usuário}

A quantificação dos prejuízos se deu de maneira setorial. Foram considerados os usos para abastecimento humano, industrial, dessedentação animal, agricultura, e diluição de poluição. O modelo considera a ocorrência de prejuízo econômico quando a demanda diária de determinado uso não é atendida, conforme regras de priorização de atendimento. Para cada vazão correspondente aos TR da cobertura selecionada, entre 1 e 100 anos, ocorre o atendimento ou não da demanda de determinado usuário. A Figura 75 ilustra a aplicação dos critérios de priorização e de quantificação dos prejuízos, 


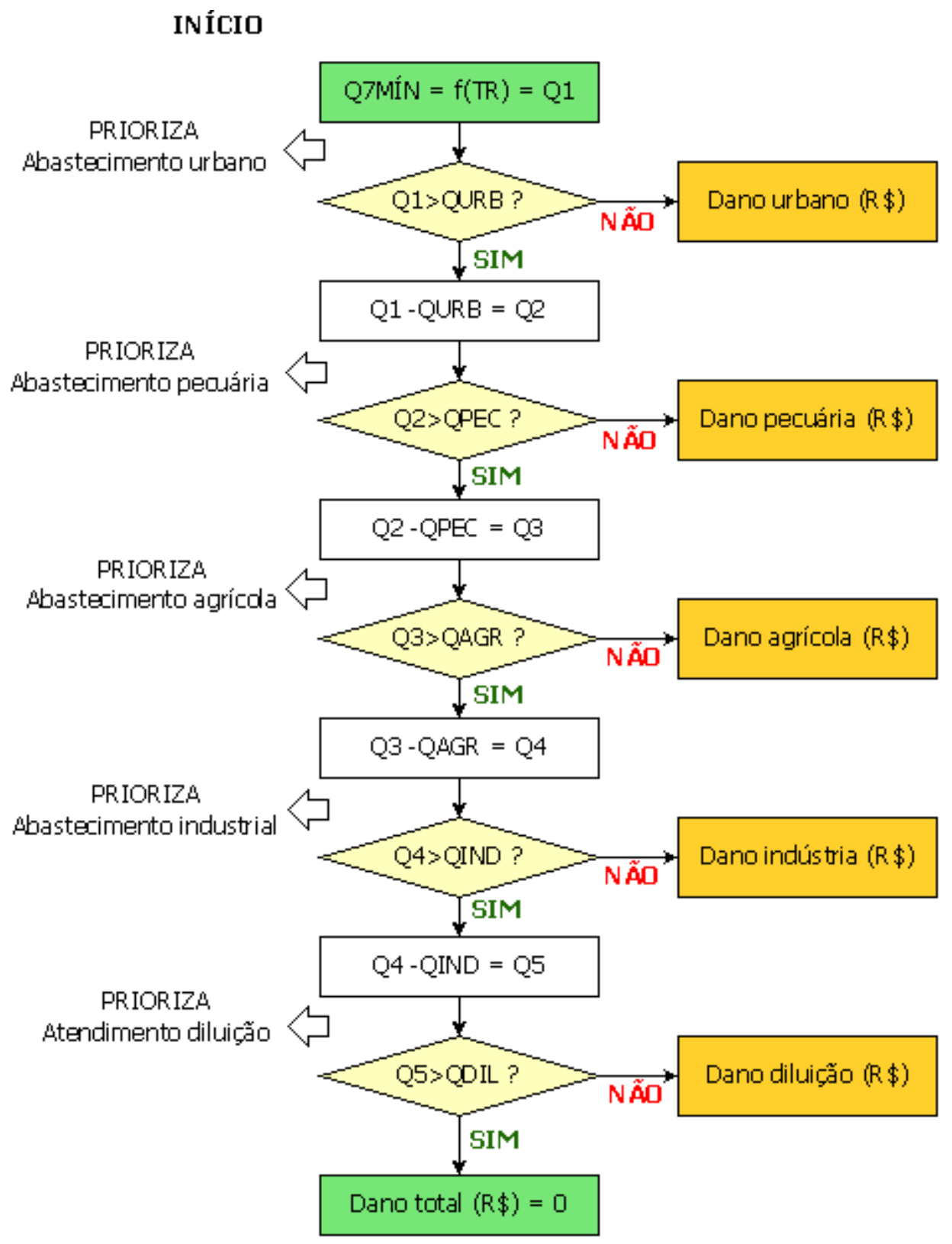

FIM

sendo:

Q7MÍN a vazão mínima média de sete dias consecutwos; TR o tempo de retomo; Qn a vazẫo disponivel na n-ésima priorizaçã̃o; QURB a demanda de água para abastecimento urbano; QPEC a demanda de água para a criação de animais; QAGR a demanda de água para cultivos agríoolas; QIND a demanda de água para a produção industrial; QDIL a demanda de água para a diluição de poluentes lançados nos comos d'água.

Figura 75. Critérios considerados para a priorização do atendimento das demandas entre os usuários identificados (Fonte: Elaborado pelo autor). 


\subsubsection{Cálculo do prejuízo total e composição das curvas de dano}

O dano a determinado setor usuário foi calculado na medida em que a vazão de referência disponível, equivalente à $Q_{7 m i ́ n}$ naquele ano, não foi suficiente para atender a demanda. Assim, o prejuízo se deu em decorrência da parcela não atendida da demanda total de cada usuário. O prejuízo total da bacia foi definido através da soma entre os prejuízos de cada setor, conforme Equação 8,

$$
D_{x, y}^{b}=D_{x, y}^{u}\left(r_{u}\right)+D_{x, y}^{a n}\left(r_{a n}\right)+D_{x, y}^{a g}\left(r_{a g}\right)+D_{x, y}^{i}\left(r_{i}\right)+D_{x, y}^{d}\left(r_{d}\right) \quad \text { Equação } 8
$$

sendo $D_{x, y}{ }^{b}$ o prejuízo total na bacia $x$ no ano $y ; D_{x, y}{ }^{u}$ o prejuízo ao abastecimento público urbano em função do risco $r_{u} ; D_{x, y}{ }^{a n}$ o prejuízo a atividades de pecuária em função do risco $r_{a n ;} D_{x, y}^{a g}$ o prejuízo de atividades agrícolas em função do risco $r_{a g} ; D_{x, y}{ }^{i}$ o prejuízo de atividades industriais em função do risco $r_{i} ; D_{x, y}{ }^{d}$ o prejuízo ambiental para diluição da poluição em função do risco $r_{d}$.

As curvas de dano (CDNs) foram obtidas através da plotagem dos valores de prejuízo associado aos períodos de retorno definidos até a cobertura máxima do fundo (100 anos). Foram geradas cinco CDNs para cada sub-bacia, referentes aos cinco cenários propostos.

\subsubsection{Simulação do MTRH-SHS (Etapa 4)}

O MTRH-SHS considera não somente a probabilidade de ocorrência dos eventos, através de simples análise de probabilidades e da curva de permanência. Ao invés disso, ele considera a ocorrência serial destes eventos, e seus impactos na operação do fundo. Para isto, foram geradas 30 séries equiprováveis, para cada cenário e faixa de cobertura, porém com ordenamento variado e aleatório dos eventos dentro das séries geradas. Assim, tem-se um grupo de séries, estratégia utilizada na tentativa de minimizar as incertezas envolvidas. Maiores detalhes sobre a arquitetura do MTRH-SHS são encontrados em Graciosa (2010) e Graciosa e Mendiondo (2011).

A simulação do MTRH-SHS se deu em duas etapas: a acoplagem do MTRH-SHS ao AQUA-Risco para determinação dos prejuízos decorrentes dos eventos de $Q_{7 \text { mín }}$ anuais nos 
cenários e a otimização do prêmio. Após a conclusão da execução do MTRH-SHS, realizou-se a análise de indicadores da operação do fundo de seguros.

O prejuízo $D$ foi obtido através da CDN gerada no modelo AQUA-Risco, que correlaciona os danos ao TR. O saldo armazenado SA, foi calculado a partir da Equação 9,

$$
S A_{i}=S A_{i-1}(1+t x)+P_{i}-I_{i}-P_{e a, i}(1+J) \quad \text { Equação } 9
$$

sendo $S A_{i}$ o saldo armazenado no ano $i$; tx a taxa de juros incidente sobre o capital armazenado; $P_{i}$ o prêmio pago pelos segurados no ano $i ; l_{i}$ a indenização paga no ano $i ; P_{e a, i}$ a parcela de empréstimo anual paga no ano i; $J$ os juros incidentes sobre os empréstimos.

\subsubsection{Geração de séries sintéticas de vazões mínimas}

A teoria de probabilidades é de suma importância em hidrologia, uma vez que a ocorrência de fenômenos hidrológicos está associada a distribuições da variabilidade espaço-temporal de variáveis aleatórias (NAGHETTINI; PINTO, 2007). O estudo dessas variáveis, em muitos casos, demanda a aplicação de técnicas estatísticas, devido à inexistência de dados observados ou incertezas quanto ao comportamento futuro das mesmas.

Neste trabalho, ajustaram-se os dados observados à distribuição de Gumbel (mínimos), para que se pudesse avaliar a ocorrência dos eventos no futuro, conforme variáveis aleatórias uniformemente distribuídas geradas. Segundo Naghettini e Pinto (2007), trata-se de uma distribuição extremal comumente utilizada em estudos sobre eventos hidrológicos mínimos anuais.

A partir de uma série de vazões mínimas obtidas através de modelagem hidrológica, para cada cenário de mudança, procedeu-se ao ajuste conforme a distribuição selecionada. As variáveis aleatórias, referentes à probabilidade de ocorrência dos eventos, foram geradas pelo método de Monte Carlo.

Uma vez geradas as variáveis aleatórias, agrupadas em 30 séries sintéticas equiprováveis (SEQs) correspondentes ao período 2013-2099, comuns a todos os cenários, foram obtidos o valor de TR e da respectiva vazão. Os valores de vazão e TR foram equivalentes à ocorrência dos eventos mínimos de $Q_{7 \min }$ correspondente a um determinado 
ano dentro do intervalo, em cada cenário. Somente no cenário SMud considerou-se o ajuste à distribuição conforme dados observados no passado. A Figura 76 ilustra este procedimento, reproduzido em todas as sub-bacias estudadas.

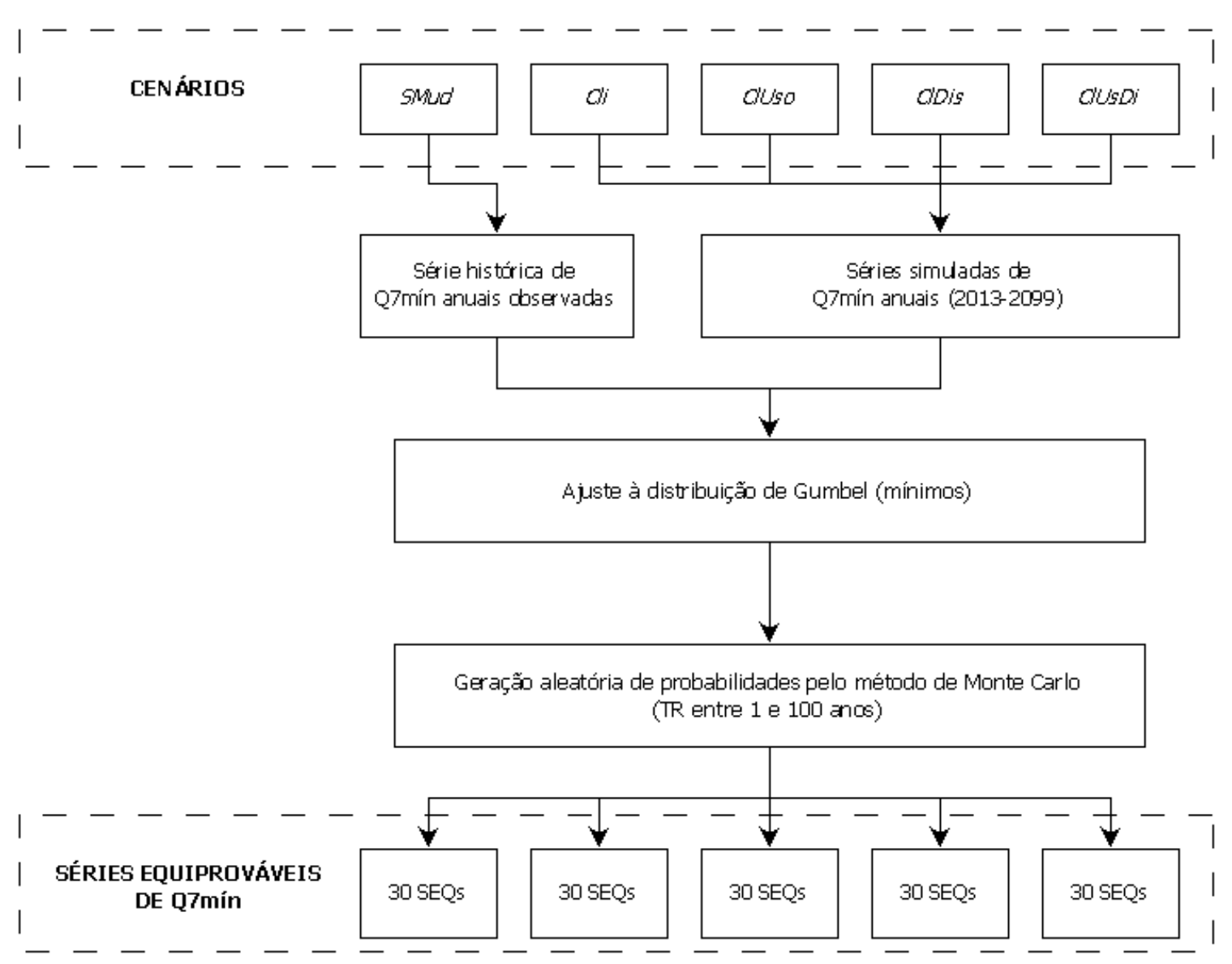

Figura 76. Fluxograma de representação da geração das séries sintéticas equiprováveis (SEQs) de $\mathrm{Q}_{7 \min }$ anual (Fonte: Elaborado pelo autor).

A geração de SEQs é fundamental para a operação do MTRH-SHS. A partir das séries geradas, foi estimada a ocorrência dos sinistros, bem como são calculados os valores dos prejuízos e dos prêmios a serem pagos pelos segurados. Cada simulação do MTRH-SHS envolve a otimização de 30 SEQs, para cada bacia e cenários, sujeito ao limite de TR da cobertura. A partir desta simulação é obtido o prêmio necessário para ressarcimento dos prejuízos, decorrente da média entre o prêmio ótimo em cada SEQ. A determinação da faixa de cobertura definiu o limite de ocorrência de eventos os quais os prejuízos serão ressarcidos no âmbito do MTRH-SHS.

A importância de se utilizar SEQs nas simulações é que foi possível avaliar o impacto de diferentes combinações de ocorrência de eventos, associados a diferentes probabilidades 
aleatórias. O prêmio médio leva em conta o conjunto de diferentes probabilidades de ocorrência dos eventos extremos, sendo que cada SEQ é otimizada em separado dentro do MTRH-SHS. Além disso, tem-se a redução das incertezas, uma vez que para a determinação do prêmio ótimo não se considerada somente uma série, mas sim o prêmio médio de 30 SEQs simuladas e otimizadas.

As SEQs foram geradas através do método de Monte Carlo. Foram gerados números aleatórios entre 0 e 1, representando a função de distribuição de probabilidade acumulada (FDA), $F_{z}(z)$, de cada evento referente ao período 2013-2099. Com a finalidade de ilustrar este procedimento, a Figura 77 demonstra a geração das SEQs, enumeradas de \#1 a \#30, para a sub-bacia do rio Jaguari, conforme cenário Cli.
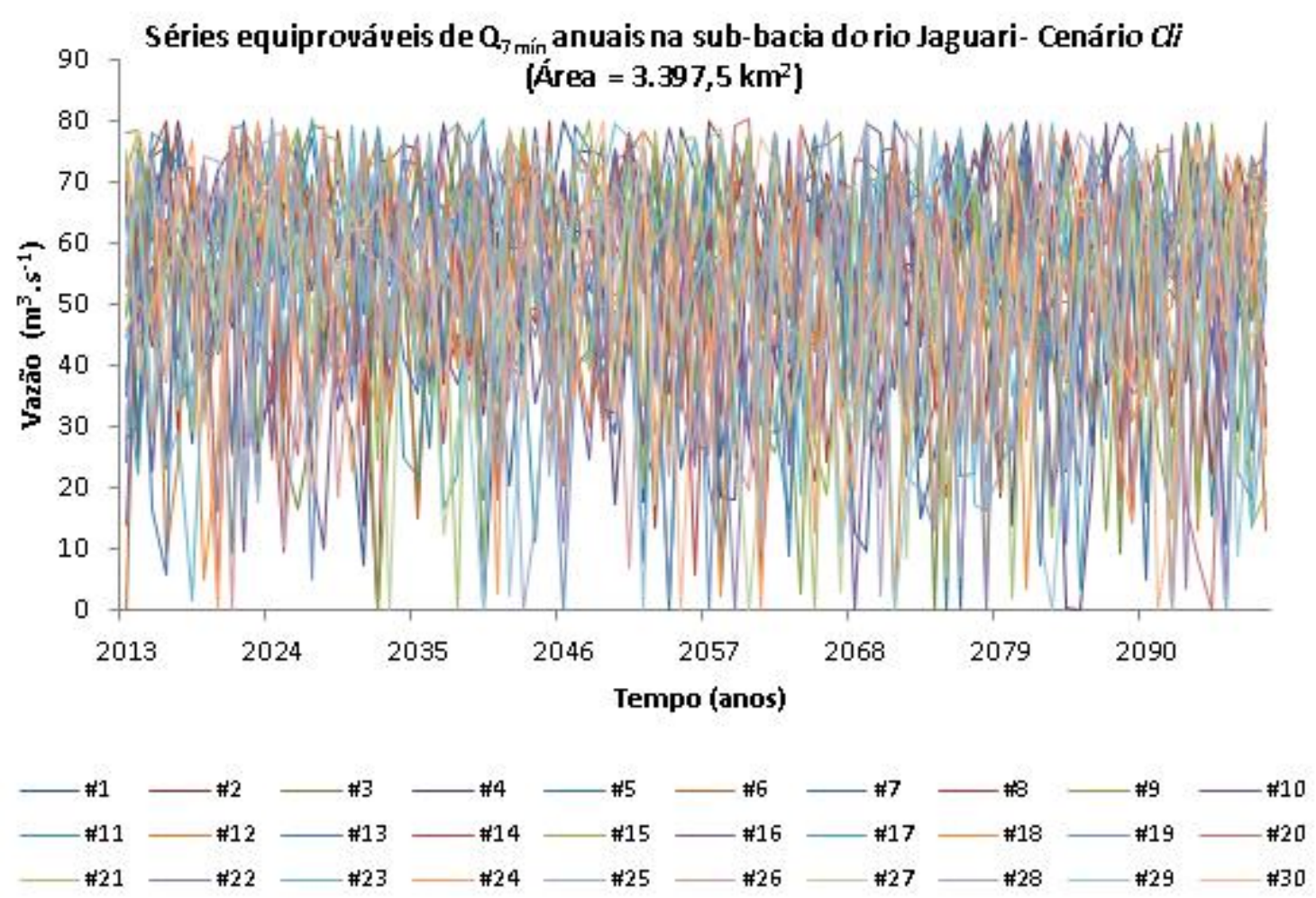

Figura 77. Exemplo de 30 séries equiprováveis (SEQs) geradas, segundo o cenário Cli, para a subbacia hidrográfica do rio Jaguari (Fonte: Elaborado pelo autor).

Por sua vez, a FDA é determinada pela Equação 10,

$$
F_{Z}(z)=1-e^{-e^{\left(\frac{z-\beta}{\alpha}\right)}}
$$


sendo $F_{Z}(z)$ a função de distribuição de probabilidade acumulada do evento $Z$ ser menor ou igual a z; $z$ a $Q_{7 m i n}$ anual, em $\mathrm{m}^{3} \mathrm{~s}^{-1}$; $\alpha$ o parâmetro de escala; 6 o parâmetro de posição.

Em função do período de retorno (TR), a inversa da FDA de Gumbel para mínimos, ou seja, a $Q_{7 m i ́ n}$ num determinado ano, é expressa conforme Equação 11,

$$
z(T R)=\beta+\alpha \ln \left[-\ln \left(1-\frac{1}{T R}\right)\right]
$$

Equação 11

sendo TR o período de retorno, em anos; $\alpha$ o parâmetro de escala; $\beta$ o parâmetro de posição.

A determinação dos parâmetros $\alpha$ e $\beta$ se deu conforme Naghettini e Pinto (2007), através de métodos estatísticos, a partir dos registros históricos dos postos fluviométricos correspondentes a cada sub-bacia. A esperança matemática (E[Z]) e a variância $\left(\sigma_{z}^{2}\right)$, calculadas a partir de dados observados, foram utilizados na determinação dos parâmetros, conforme Equação 12

e Equação 13,

$$
\begin{gathered}
E[Z]=\beta+0,5772 \alpha \\
\sigma_{Z}^{2}=\frac{\pi^{2} \alpha^{2}}{6}
\end{gathered}
$$

Equação 12

Equação 13

sendo $E[Z]$ o valor esperado; 6 o parâmetro de posição; $\alpha$ o parâmetro de escala; $\sigma_{z}^{2}$ a variância da amostra.

\subsubsection{Acoplagem do AQUA-Risco ao MTRH-SHS}

A acoplagem entre os modelos AQUA-Risco e o MTRH-SHS também se deu de maneira livre (NYERGES, 1991; PULLAR; SPRINGER, 2000), assim como os modelos MGB-IPH e Eta-CPTEC. As saídas do AQUA-Risco representam as CDNs para os cinco cenários propostos, no âmbito das cinco sub-bacias hidrográficas, para TR entre 1 e 100 anos. O 
MTRH-SHS se utiliza das informações da CDN para quantificar os prejuízos das $Q_{7 \text { mín }}$ anuais em cada uma das 30 séries equiprováveis consideradas na simulação de cada cenário e faixa de cobertura.

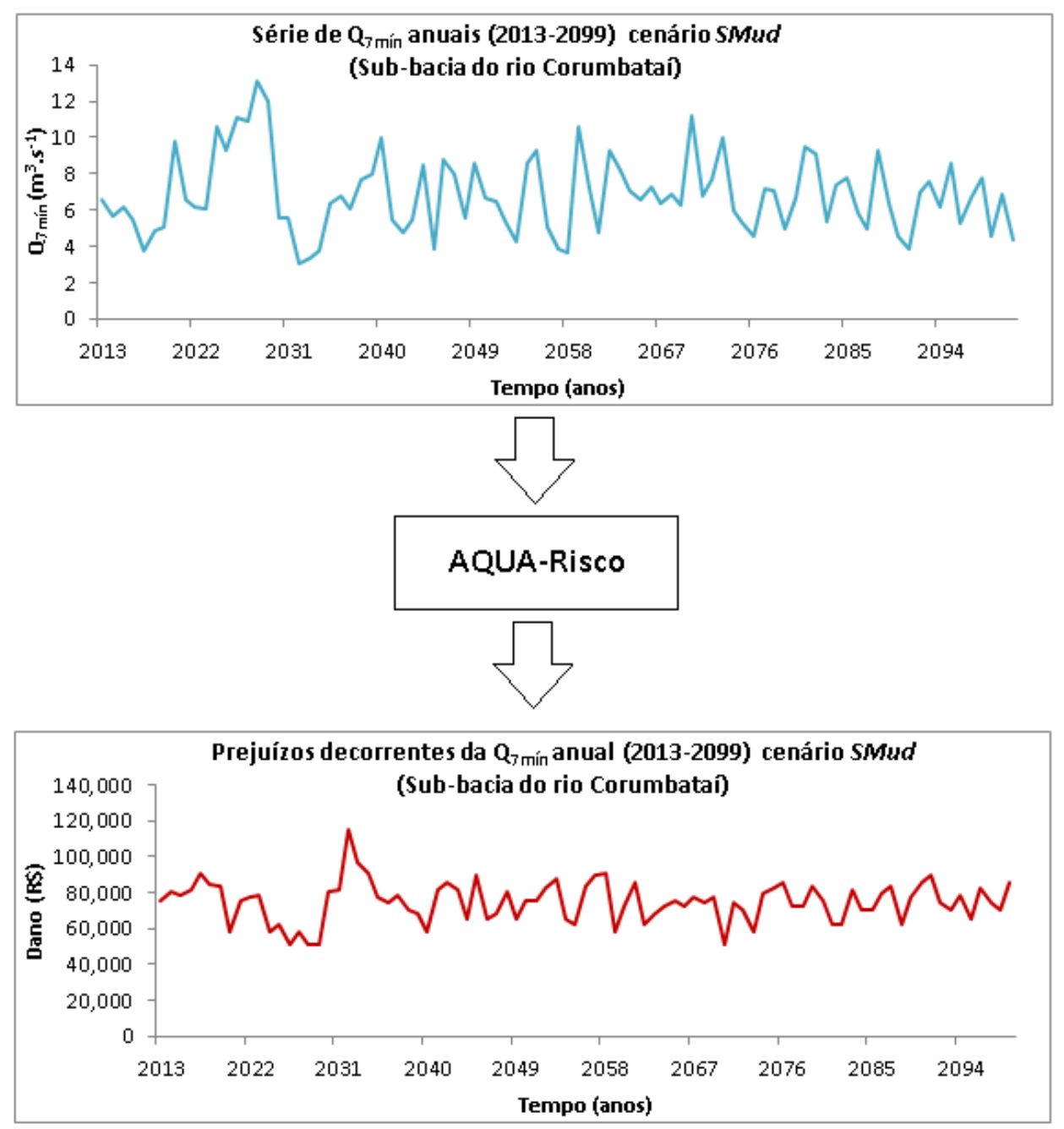

Figura 78. Exemplo da aplicação do AQUA-Risco na sub-bacia do rio Corumbataí, conforme cenário $S M u d$, para obtenção dos valores dos prejuízos decorrentes da série de $Q_{7 \min }$ anuais (Fonte: Elaborado pelo autor).

As saídas do AQUA-Risco, referentes aos sinistros decorrentes de cada série utilizada como entrada, foram utilizadas pelo MTRH-SHS para calcular o prêmio ótimo necessário para o ressarcimento dos prejuízos. 


\subsubsection{Otimização do prêmio}

A otimização dos prêmios, no âmbito do mercado de seguros, faz-se importante para que sejam evitandas situações de insolvência e colapso financeiro (GUPTA; LI, 2007; AZCUE; MULER, 2009). O valor ótimo do prêmio a ser pago pelos segurados visa minimizar a necessidade de empréstimos por parte do fundo, para que o mesmo possa honrar os compromissos dos sinistros (GRACIOSA; MENDIONDO, 2011). Um empréstimo ocorre quando o saldo armazenado é inferior ao prejuízo em determinado ano. Os prejuízos são delimitados de acordo com a faixa de cobertura do TR definida na simulação.

A otimização do prêmio, em cada série equiprovável, foi realizada no software Microsoft Excel, através da ferramenta Solver. Utilizou-se a função objetivo descrita pela Equação 14,

$$
F O=\min \sum_{i=1}^{N}(D-S A)
$$

Sujeito a : SAmín $\leq$ SA $\leq$ SAmáx

sendo FO o resultado da função objetivo; $i$ o índice do ano em questão; $D$ o prejuízo, em R\$; $S A$ o saldo armazenado, em $\mathrm{R} \$$, variando entre as restrições de armazenamento mínimo (mín) e o máximo (máx).

O valor de SAmín foi definido conforme legislação vigente no Brasil (BRASIL, 1989), que regula a margem de solvência (MS) por parte de companhias seguradoras em operação no país. A MS do SAmín foi definida como 0,33 vezes o prejuízo médio anual em cada cenário e cobertura.

Para SAmáx, considerou-se o limite proposto por Graciosa e Mendiondo (2011). O valor máximo armazenado pelo fundo ficou, portanto, limitado a duas vezes o valor do prejuízo correspondente à vazão mínima limite da cobertura em cada simulação.

Foram otimizadas 30 SEQs, para cada um dos cinco cenários (Cli, ClUso, CIDis, CIUsDi e SMud) em cada sub-bacia hidrográfica (Atibaia, Camanducaia, Corumbataí, Jaguari e 
Piracicaba). As faixas de cobertura do fundo consideradas, com relação ao TR, foram 10,25 , 50 e 100 anos.

\subsubsection{Análise de indicadores}

Os indicadores resultantes da interpretação dos resultados das simulações do MTRHSHS permitem que sejam feitas análises e observações sobre a operação do fundo de seguros. Foi proposta a análise de três indicadores, sendo eles o coeficiente de solvência, o coeficiente de eficiência e o índice de sinistralidade. A descrição dos indicadores é feita nos itens que seguem.

\section{Coeficiente de solvência (CS)}

Taylor e Buchanan (1988) definem solvência como a capacidade de um fundo de seguros em honrar seus compromissos financeiros, através do uso de bens e ativos próprios. O coeficiente de solvência (CS) aqui utilizado, adaptado de Graciosa e Mendiondo (2011), permite a avaliação simplificada da flutuação dos ativos com relação aos sinistros, em relação ao valor médio do prêmio otimizado. É definido pela Equação 15,

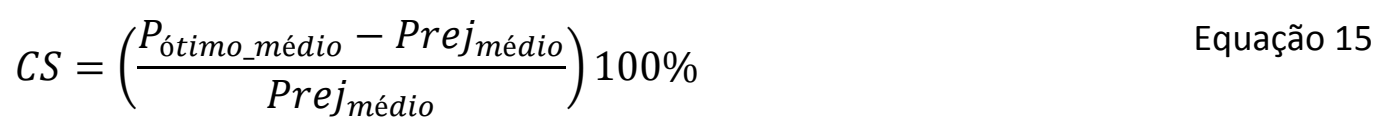

sendo $P_{\text {ótimo_médio }}$ o prêmio ótimo decorrente da otimização das séries em cada cenário, em unidades monetárias; Prejmédio o prejuízo médio das séries simuladas para determinada faixa de cobertura, em unidades monetárias.

A análise do CS pode indicar a capacidade do fundo em honrar seus compromissos, acumular capital e/ou gerar lucro a seus investidores. O acúmulo do capital pode ser investido em medidas estruturais e não-estruturais na bacia, visando à redução dos riscos. Também pode ser revertido aos segurados na forma de bônus sobre os prêmios pagos (GRACIOSA; MENDIONDO, 2011). Melhores situações são obtidas segundo maiores valores de CS. 


\section{Coeficiente de Eficiência (CE)}

O coeficiente de eficiência (CE) permite a avaliação da probabilidade de ocorrência de uma série favorável ou não, por faixa de cobertura considerada, entre as SEQs simuladas (GRACIOSA; MENDIONDO, 2011). Uma vez que o prêmio ótimo é a média dos prêmios otimizados em cada SEQ, tem-se uma série desfavorável quando o prêmio ótimo da série é superior ao prêmio ótimo médio do cenário.

O CE é obtido através da relação entre o número de séries eficientes com relação ao total de séries simuladas, conforme Equação 16 e Equação 17,

$$
\begin{array}{ll}
\text { SÉRIE EFICIENTE }=P_{\text {ótimo_médio }}-P_{\text {ótimo_série }}>0 & \text { Equação } 16 \\
C E=\frac{N^{\mathrm{o}} \text { séries eficientes }}{N^{\mathrm{o}} \text { séries total }} 100 \% & \text { Equação } 17
\end{array}
$$

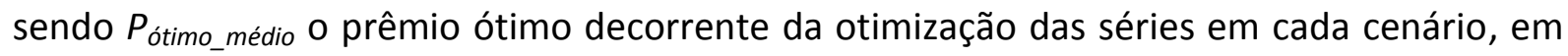
unidades monetárias; $P_{\text {ótimo_série }}$ o prêmio ótimo decorrente da otimização de cada série, em unidades monetárias.

Quanto maiores os valores de CE, melhores os resultados obtidos do ponto de vista da eficiência dos cenários.

\section{Índice de Sinistralidade (IS)}

O índice de sinistralidade (IS) avalia o percentual de comprometimento dos prêmios arrecadados frente à ocorrência dos sinistros (MACEDO; SILVA; SANTOS, 2006), conforme Equação 18,

$$
I S=\frac{\text { Prej }_{\text {médio }}}{P_{\text {ótimo_médio }}} 100 \%
$$


sendo Prej $_{\text {médio }}$ o prejuízo médio das séries simuladas para determinada faixa de cobertura, em unidades monetárias; $P_{\text {ótimo_médio }}$ o prêmio ótimo decorrente da otimização das séries em cada cenário, em unidades monetárias.

Para este índice, quanto menores os valores obtidos, melhor.

\subsection{RESULTADOS E DISCUSSÃO}

Os resultados obtidos para a análise de risco através do modelo AQUA-Risco, em subbacias da bacia hidrográfica do rio Piracicaba, são descritos a seguir. Também é demonstrada a aplicação do MTRH-SHS nessas bacias.

\subsubsection{Curvas de dano}

Conforme mencionado, as CDNs foram obtidas através da aplicação do modelo AQUA-Risco, desenvolvido no decorrer deste trabalho. Tais curvas permitem a associação entre as vazões $Q_{7 \min }$ ocorridas a cada ano a um determinado prejuízo econômico devido à ocorrência das mesmas.

Foram comparados o comportamento das curvas dos cenários Cli, CIUso, CIDis e CIUsDi ao cenário sem mudança (SMud). As curvas referentes às sub-bacias dos rios Camanducaia, Jaguari, Atibaia, Corumbataí e Piracicaba são demonstradas a seguir, para os cinco cenários elaborados. Na Figura 79 tem-se a exibição das curvas referentes à sub-bacia do rio Camanducaia. 


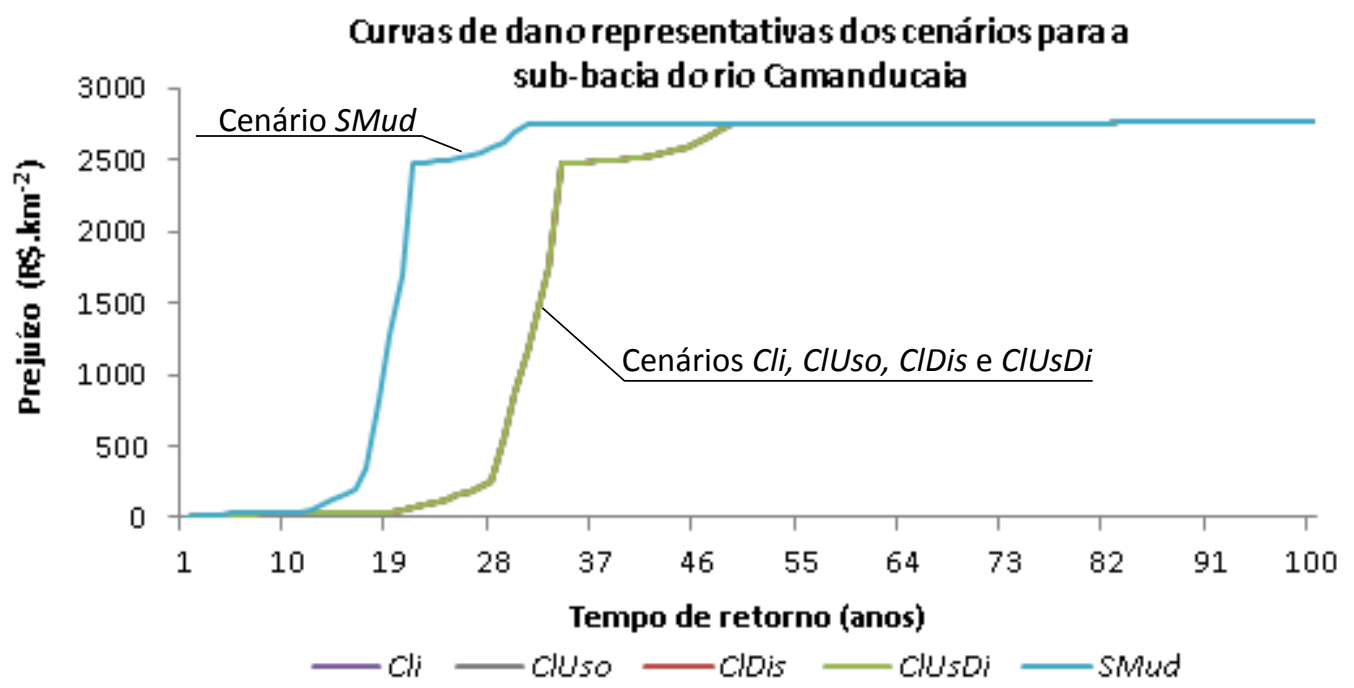

Figura 79. Curvas de dano para os cenários propostos, em função do período de retorno, para a subbacia do rio Camanducaia (Fonte: Elaborado pelo autor).

Na sub-bacia do rio Camanducaia, observa-se comportamento similar entre todos os cenários de mudança propostos (Cli, ClUso, ClDis e ClUsDi), em relação ao cenário SMud, pois não há interferência do Sistema Cantareira na bacia. Assim, os impactos na disponibilidade hídrica propostos não ocorrem, restando apenas os impactos climáticos e do uso da terra. Além disso, o comportamento da CDN é mantido para os cenários de mudanças, porém somente tem-se o deslocamento da curva na direção da redução dos prejuízos com o aumento do TR.

A Figura 80 representa as CDNs aplicadas na sub-bacia do rio Jaguari.

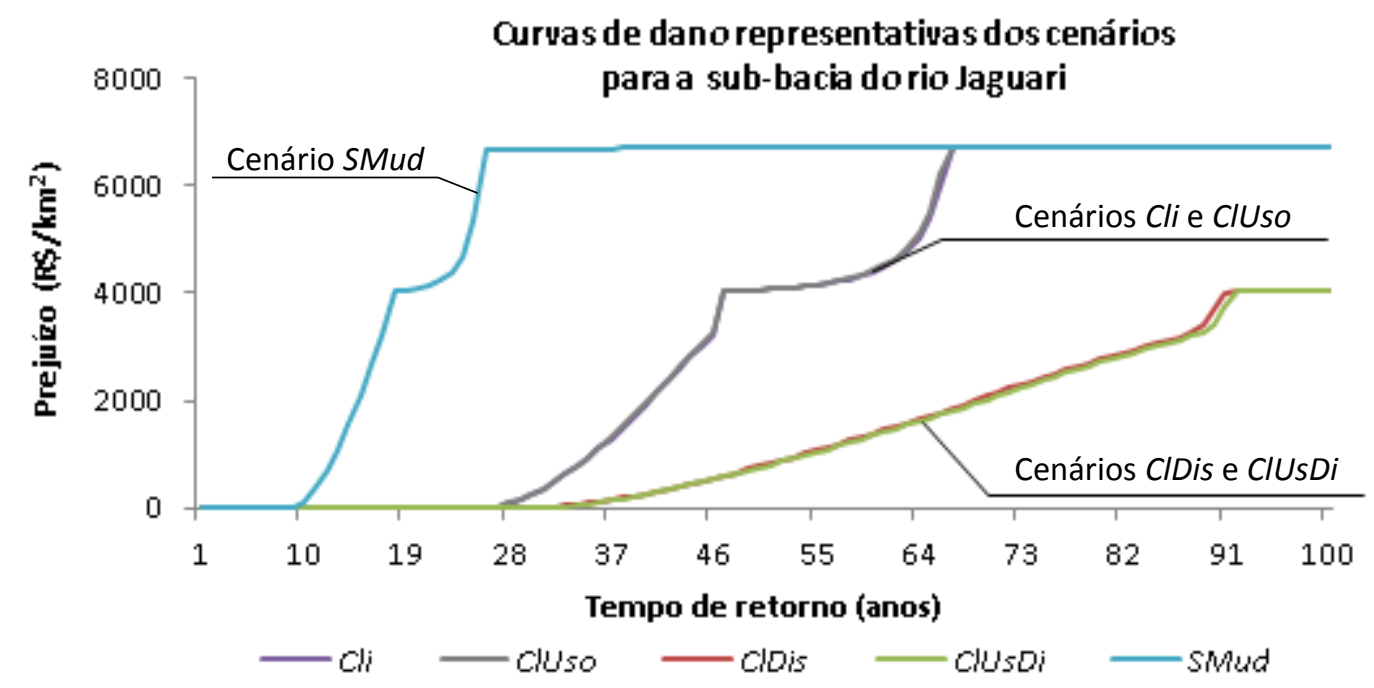

Figura 80. Curvas de dano para os cenários propostos, em função do período de retorno, para a subbacia do rio Jaguari (Fonte: Elaborado pelo autor). 
Nesta sub-bacia, já foi possível se perceber os impactos decorrentes de todos os fatores de mudança. Conforme mencionado no Capítulo 4, projetou-se o aumento da $Q_{7 \text { mín }}$ sob condições de variabilidade climática. Somado a isto, a operação constante do Sistema Cantareira aumenta a $\mathrm{Q}_{7 \text { mín }}$ na sub-bacia (cenários CIDis e CIUsDi), o que resulta a redução das perdas econômicas nos cenários que consideram esta premissa.

Com relação às mudanças climáticas e no uso da terra, sem a consideração do Sistema Cantareira, tem-se comportamento similar à curva observada na sub-bacia do rio Camanducaia. Com isso, observa-se o deslocamento da curva no sentido de redução dos prejuízos para TR menores. Já para TR maiores, o prejuízo se mantém igual.

Na Figura 81 tem-se a ilustração das curvas de dano para a sub-bacia do rio Atibaia.

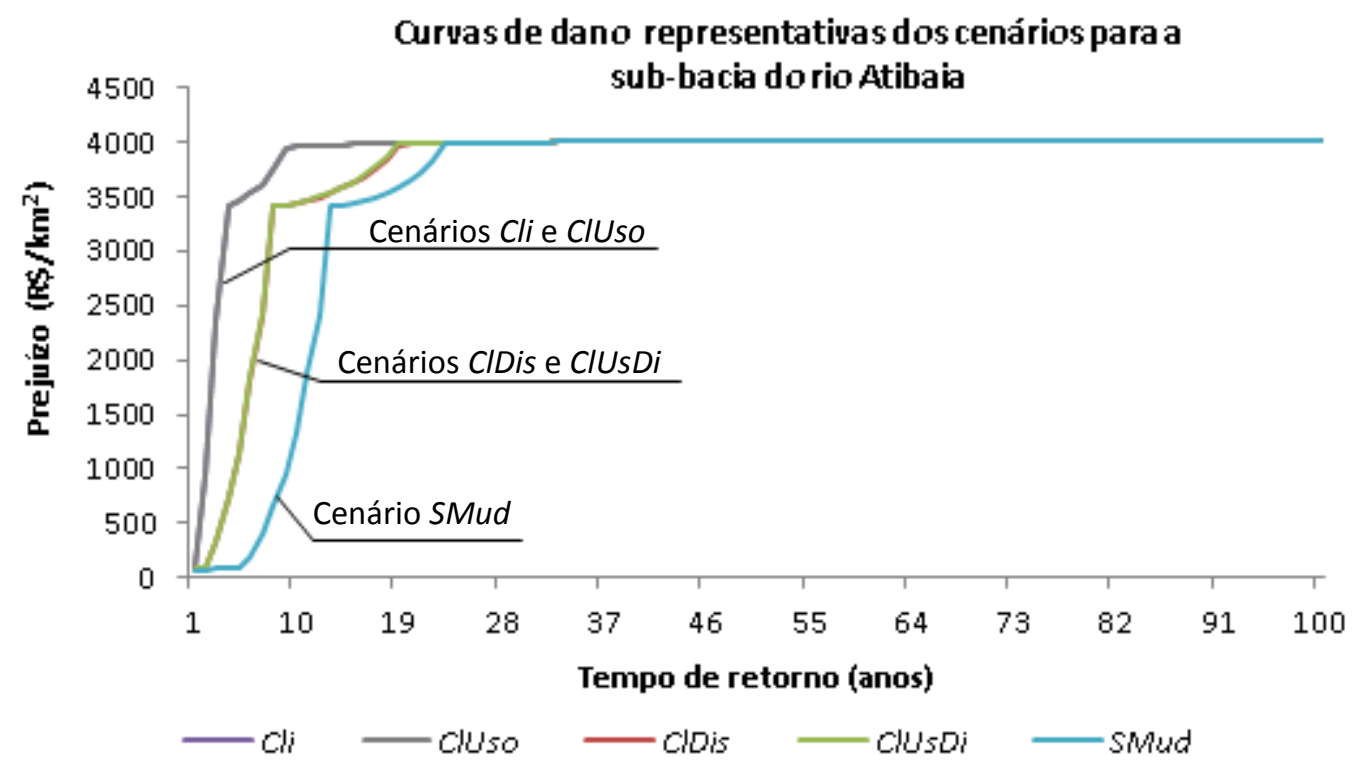

Figura 81. Curvas de dano para os cenários propostos, em função do período de retorno, para a subbacia do rio Atibaia (Fonte: Elaborado pelo autor).

Nesta sub-bacia observa-se pequena variação entre as CDNs referentes aos cenários de mudanças. Isto se deve ao fato de se tratar de uma sub-bacia com forte pressão sobre os recursos hídricos, onde durante situações de estiagem e escassez, a demanda se aproxima do limite oferecido pela bacia (ou até mesmo ultrapassa). Além disso, nesta bacia ocorre a transposição de $1,0 \mathrm{~m}^{3} \cdot \mathrm{s}^{-1}$ para a bacia do rio Jundiaí.

Nesta sub-bacia, condições de variabilidade climática e do uso da terra (cenários Cli e ClUso), sem considerar a operação do Sistema Cantareira, contemplam os maiores prejuízos. Conforme já foi mencionado, a operação dos reservatórios na bacia resulta no aumento da 
$Q_{7 m i n}$. Sem os reservatórios, o resultado é a redução das vazões mínimas e a antecipação dos prejuízos segundo TRs menores. Ainda que se considere a operação dos reservatórios, conforme os cenários CIDis e ClUsDi, observa-se a antecipação dos prejuízos, quando comparados ao cenário sem mudança (SMud).

Esta última situação pode ser explicada pelo critério de operação do Sistema Cantareira aqui considerado. Como o objetivo deste trabalho era a avaliação de situações extremas, a operação dos reservatórios foi definida com bases históricas, onde se considerou o menor valor diário observado a ser replicado continuamente no futuro, sucessivamente para cada dia do ano.

Com isso, a operação dos reservatórios têm papel fundamental na hidrologia dos trechos a jusante dos mesmos e, consequentemente, os danos associados à magnitude das situações de escassez hídrica. Cabe mencionar que condições de mudanças climáticas, cuja tendência seja de aumento da precipitação, podem alterar a operação dos reservatórios e, assim, viabilizar o aumento das vazões liberadas.

Os prejuízos referentes à sub-bacia do rio Corumbataí são demonstrados na Figura 82.

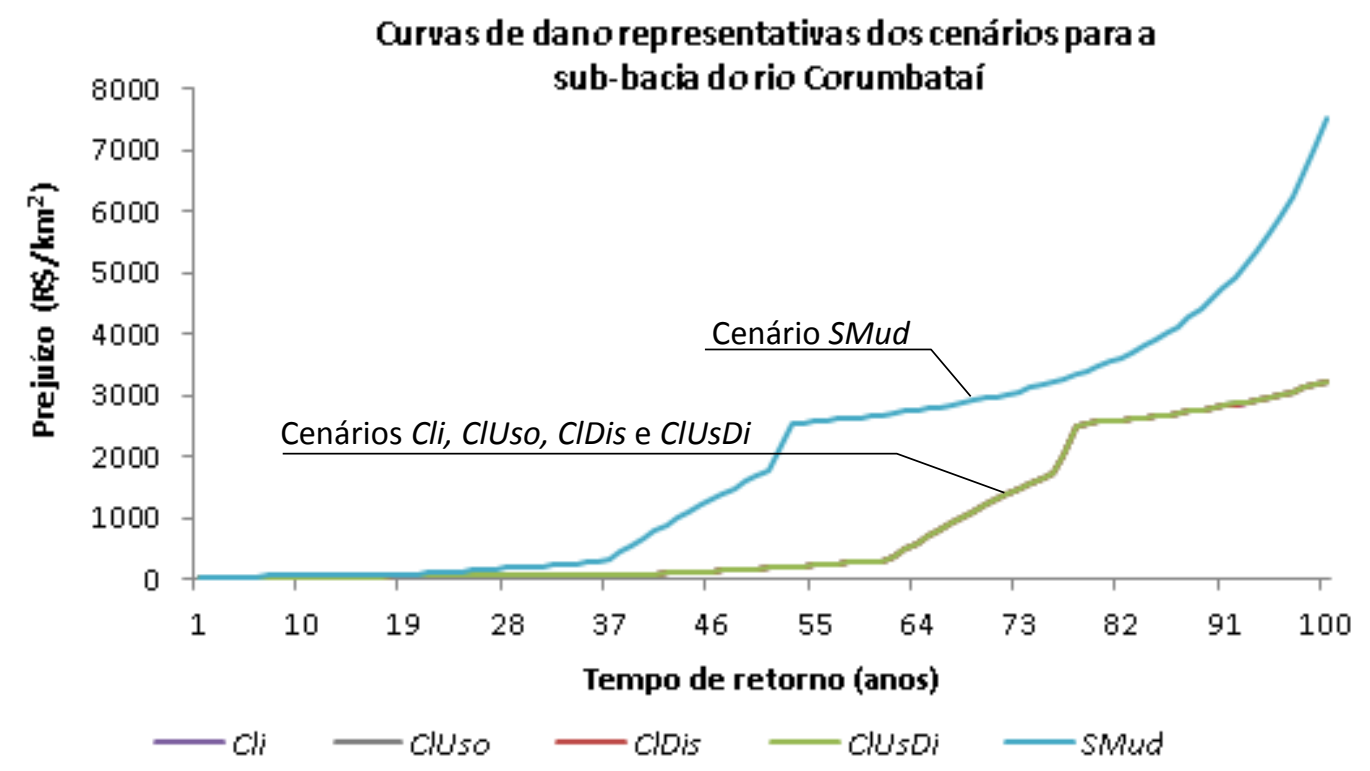

Figura 82. Curvas de dano para os cenários propostos, em função do período de retorno, para a subbacia do rio Corumbataí (Fonte: Elaborado pelo autor).

O comportamento das CDNs na sub-bacia do rio Corumbataí se fez semelhante à situação diagnosticada na sub-bacia do rio Camanducaia. Neste caso, ambas as sub-bacias 
são livres da influência do Sistema Cantareira. O regime de vazões, portanto, é natural e, sob condições de variações nas condições climáticas e no uso da terra, ocorre o incremento das vazões mínimas anuais $\left(Q_{7 m i n}\right)$. Assim, o impacto das mudanças nesta bacia resulta na suavização das CDNs e na redução dos prejuízos conforme há o aumento do TR.

Por fim, a Figura 83 caracteriza a CDN de cada cenário proposto para a sub-bacia hidrográfica do rio Piracicaba.

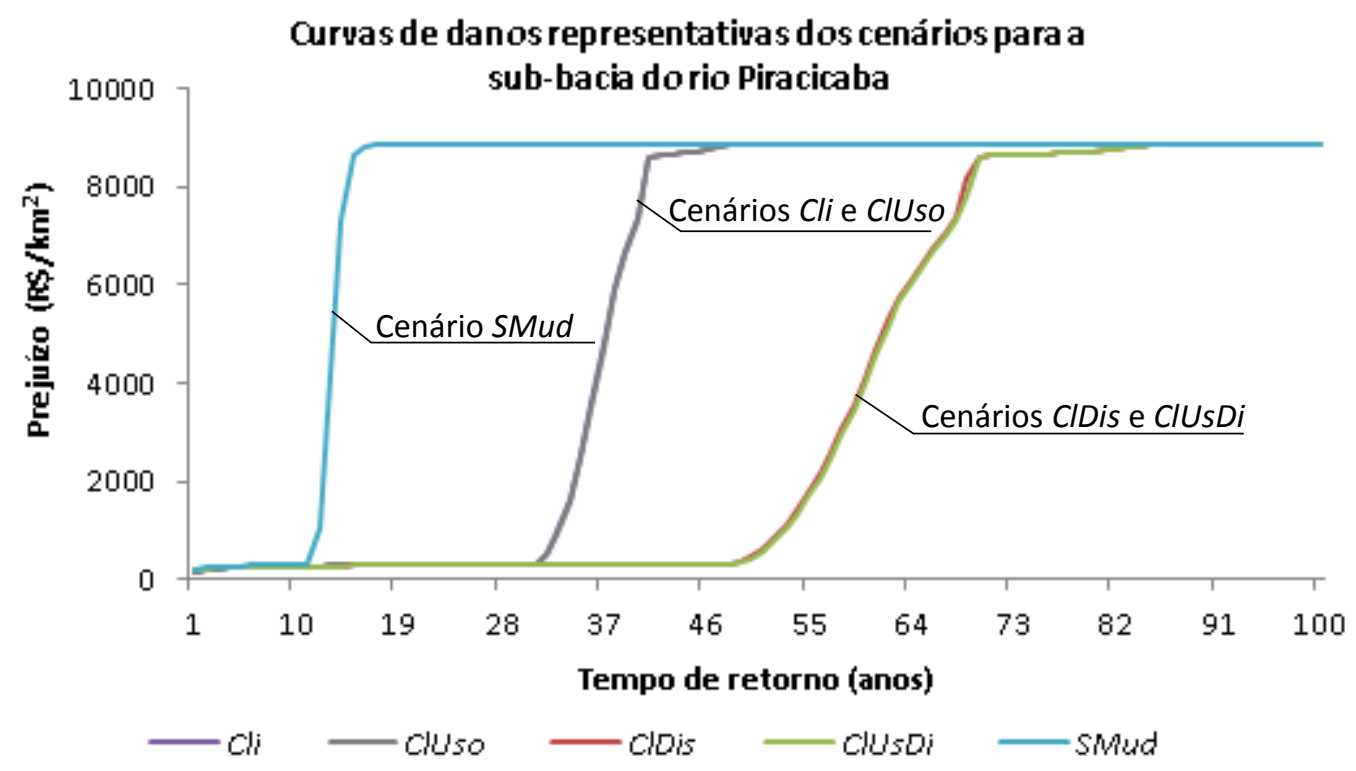

Figura 83. Curvas de dano para os cenários propostos, em função do período de retorno, para a subbacia do rio Piracicaba (Fonte: Elaborado pelo autor).

Nesta sub-bacia, sob condições atuais, observa-se o rápido crescimento dos prejuízos em função do aumento do TR. As mudanças globais propostas nos cenários Cli, ClUso, CIDis e CIUsDi resultam no deslocamento das CDN na direção da redução dos danos. Com isso, temse a redução dos prejuízos para TR menores.

As melhores condições são observadas no cenário de CIDis e CIUsDi, que consideram a operação dos reservatórios na bacia, quando comparados com o cenário SMud. Apesar deste trecho da bacia sofrer menor influência dos reservatórios divido à sua distância, a operação dos mesmos promove a regularização das vazões mínimas. Assim, situações de escassez hídrica extremas são suavizadas através da liberação constante de vazões prédefinidas a montante. Isso resulta no aumento da $Q_{7 \min }$, conforme observações no Capítulo 4. 


\subsubsection{Simulação do MTRH-SHS}

A simulação do MTRH-SHS considerou a associação entre as vazões mínimas anuais, de cada uma das 30 SEQs, aos prejuízos determinados pelas CDN. Assim, obteve-se a sequência de ocorrência dos sinistros anuais, a partir da qual foi calculado o prêmio ótimo para ressarcir os prejuízos em cada série. A Figura 84 ilustra a operação do fundo de seguros segundo uma série equiprovável, conforme prêmio otimizado e restrições consideradas.

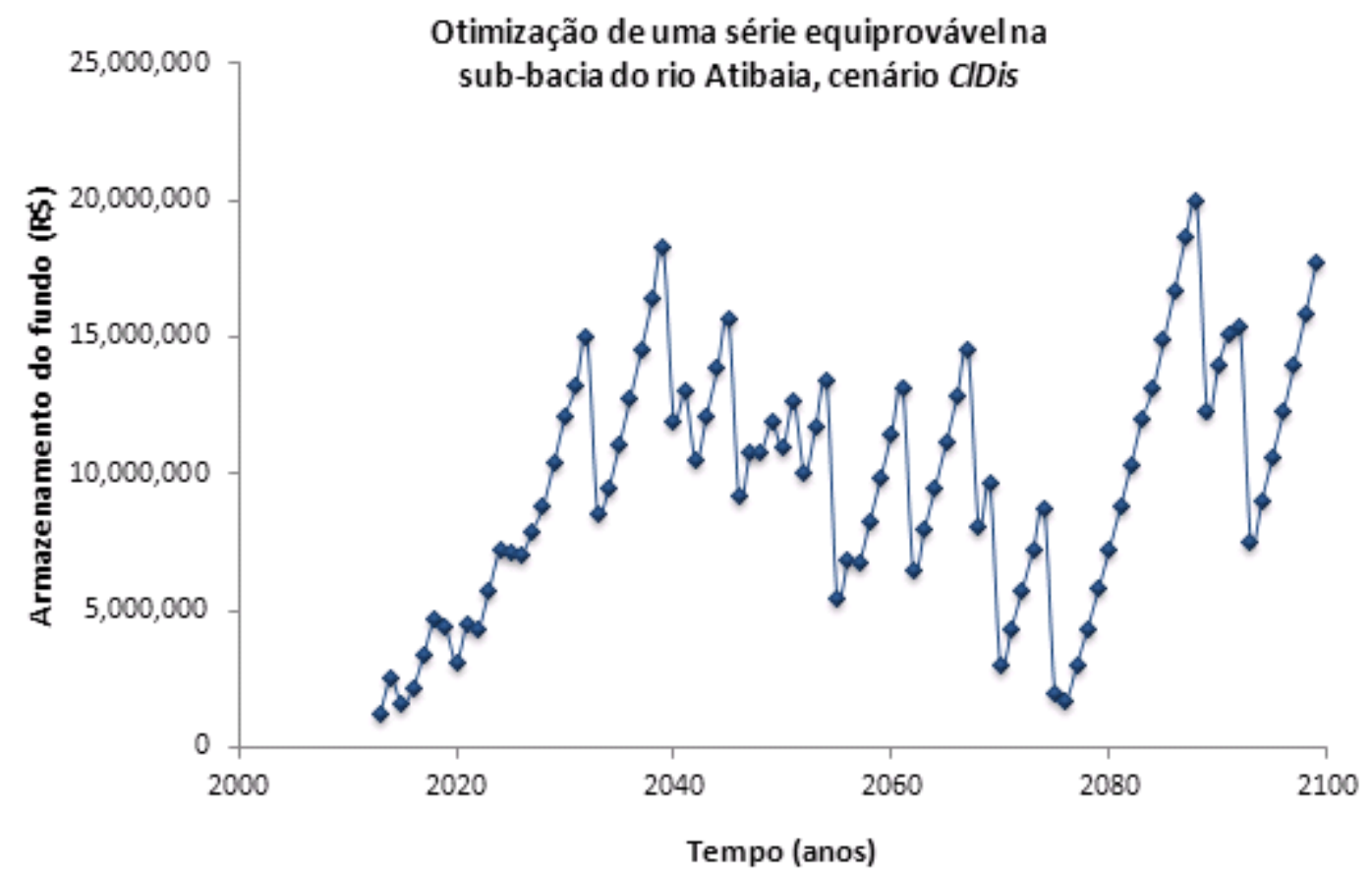

Figura 84. Exemplo de otimização do prêmio em uma série equiprovável limitada pelas restrições da operação do fundo de seguros (Fonte: Elaborado pelo autor).

Este procedimento foi reproduzido para cada uma das séries equiprováveis consideradas, em cada sub-bacia e sob as condições definidas em cada cenário. A Figura 85 ilustra operação do fundo de seguros, através do armazenamento financeiro decorrente das situações de sinistros, consideradas todas as SEQs. 


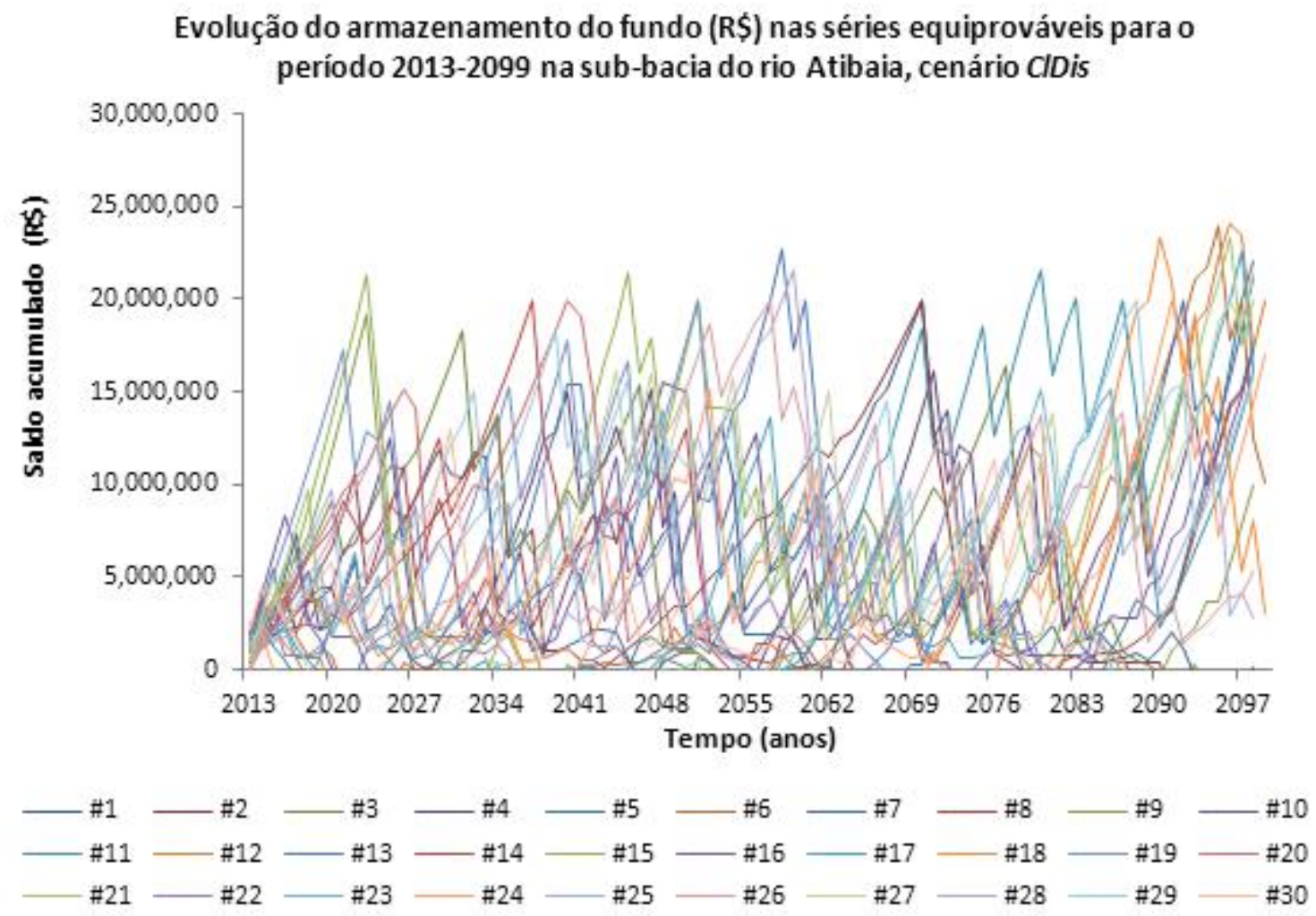

Figura 85. Simulação do MTRH-SHS através da otimização das séries equiprováveis (Fonte: Elaborado pelo autor).

A simulação de cada SEQ resultou em um prêmio ótimo e num prejuízo médios, determinados para cada sub-bacia e cenário de mudanças. Através destes valores foram obtidas as médias gerais para o prejuízo e para o prêmio, conforme ilustrado na Figura 86. 


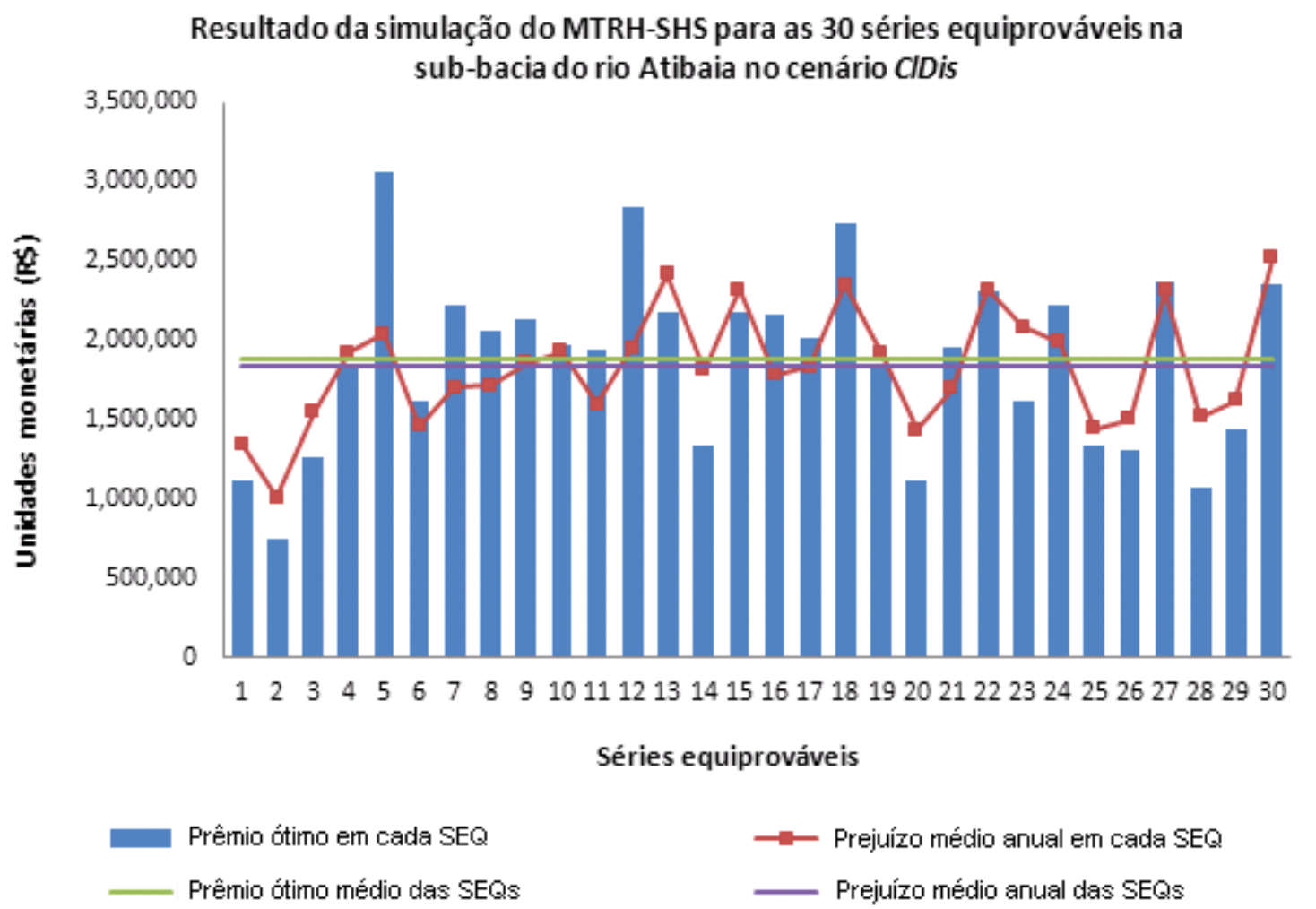

Figura 86. Exemplo de prêmio ótimo médio obtido resultado da otimização das séries em cada cenário de mudanças (Fonte: Elaborado pelo autor).

Os resultados obtidos para diferentes faixas de cobertura e cenários de mudança, nas sub-bacias dos rios Camanducaia (Tabela 20), Jaguari (Tabela 21), Atibaia (Tabela 22), Corumbataí (Tabela 23) e Piracicaba (Tabela 24) são demonstrados a seguir.

Tabela 20. Valores de prejuízo e do prêmio ótimo nos cenários, em $\mathrm{R} \$ \mathrm{~km}^{-2}$, na sub-bacia do Rio Camanducaia, para TR 10, 25, 50 e 100 anos.

\begin{tabular}{|c|c|c|c|c|c|c|c|c|c|c|}
\hline \multirow{2}{*}{$\begin{array}{l}\text { TR cobertura } \\
\text { (anos) }\end{array}$} & \multicolumn{5}{|c|}{ Prejuízo médio (R\$.km²-2) } & \multicolumn{5}{|c|}{ Prêmio ótimo médio $\left(\mathrm{R} \$ . \mathrm{km}^{-2}\right)$} \\
\hline & Cli & ClUso & ClDis & ClUsDi & SMud & Cli & ClUso & CIDis & ClusDi & SMud \\
\hline 10 & 9,5 & . & 9,5 & $\begin{array}{l}9,3 \\
\end{array}$ & 15,2 & 9,9 & 9,9 & 9,9 & 9,9 & 15,8 \\
\hline 25 & 14,3 & 14,3 & 14,3 & 14,3 & 131,9 & 15,4 & 15,4 & 15,4 & 15,4 & 144,7 \\
\hline 50 & 66,2 & 66,2 & 66,2 & 66,2 & 137,8 & 75,3 & 75,3 & 75,3 & 75,3 & 151,4 \\
\hline 100 & 66,2 & 66,2 & 66,2 & 66,2 & 137,8 & 75,3 & 75,3 & 75,3 & 75,3 & 151,4 \\
\hline Média & 39,1 & 39,0 & 39,1 & 39,0 & 105,7 & 44,0 & 44,0 & 44,0 & 44,0 & 115,8 \\
\hline
\end{tabular}

Fonte: Elaborado pelo autor. 
Tabela 21. Valores de prejuízo e do prêmio ótimo, em $\mathrm{R} \$ \mathrm{~km}^{-2}$, na sub-bacia do Rio Jaguari, para TR $10,25,50$ e 100 anos.

\begin{tabular}{|c|c|c|c|c|c|c|c|c|c|c|}
\hline \multirow{2}{*}{$\begin{array}{l}\text { TR cobertura } \\
\text { (anos) }\end{array}$} & \multicolumn{5}{|c|}{ Prejuízo médio (R\$.km $\left.{ }^{-2}\right)$} & \multicolumn{5}{|c|}{ Prêmio ótimo médio (R\$.km $\left.{ }^{-2}\right)$} \\
\hline & Cli & ClUso & CIDis & ClUsDi & SMud & Cli & ClUso & CIDis & ClUsDi & SMud \\
\hline 10 & 0,0 & 0,0 & 0,0 & 0,0 & 9,7 & 0,0 & 0,0 & 0,0 & 0,0 & 8,8 \\
\hline 25 & 0,1 & 0,1 & 0,0 & 0,0 & 289,0 & 0,1 & 0,1 & 0,0 & 0,0 & 276,9 \\
\hline 50 & 75,3 & 75,7 & 28,5 & 12,6 & 330,6 & 90,4 & 92,5 & 37,0 & 15,7 & 322,2 \\
\hline 100 & 95,8 & 96,5 & 28,5 & 27,7 & 330,8 & 117,7 & 121,3 & 37,0 & 36,2 & 322,5 \\
\hline 0 & 42,8 & 43,1 & 14,3 & 10,1 & 240,0 & 52,0 & 53,5 & 18,5 & 13,0 & 232,6 \\
\hline
\end{tabular}

Fonte: Elaborado pelo autor.

Tabela 22. Valores de prejuízo e do prêmio ótimo, em $\mathrm{R} \$ \mathrm{~km}^{-2}$, na sub-bacia do Rio Atibaia, para TR $10,25,50$ e 100 anos.

\begin{tabular}{|c|c|c|c|c|c|c|c|c|c|c|}
\hline \multirow{2}{*}{$\begin{array}{l}\text { TR cobertura } \\
\text { (anos) }\end{array}$} & \multicolumn{5}{|c|}{ Prejuízo médio (R\$.km ${ }^{-2}$ ) } & \multicolumn{5}{|c|}{ Prêmio ótimo médio (R\$. $\left.\mathrm{km}^{-2}\right)$} \\
\hline & Cli & ClUso & ClDis & ClUsDi & SMud & Cli & ClUso & ClDis & ClUsDi & SMud \\
\hline 10 & $1.431,0$ & & 7 & 2 & 6 & $1.457,8$ & & 5,7 & 0 & 237,0 \\
\hline 25 & $1.433,4$ & + & 3 & $L$ & 424,2 & 3 & 5 & 6 & 4 & 7 \\
\hline 5 & $1.433,6$ & 432,7 & 735,5 & 736,3 & 424,4 & $1.459,9$ & $1.478,9$ & 753,7 & 754,7 & 457,9 \\
\hline 100 & $1.433,7$ & $1.432,7$ & 735,6 & 736,3 & 424,4 & $1.459,8$ & $1.479,5$ & 753,7 & 754,8 & 458,0 \\
\hline & a & J2 & t. & 728,0 & 374,9 & $1.459,4$ & 2 & 144,2 & 745,0 & \\
\hline
\end{tabular}

Fonte: Elaborado pelo autor.

Tabela 23. Valores de prejuízo e do prêmio ótimo nos cenários, em $\mathrm{R} \$ \mathrm{~km}^{-2}$, na sub-bacia do Rio Corumbataí, para TR 10, 25, 50 e 100 anos.

\begin{tabular}{ccccccccccc}
\hline $\begin{array}{c}\text { TR cobertura } \\
\text { (anos) }\end{array}$ & \multicolumn{4}{c}{ Prejuízo médio $\left(\mathbf{R} \$ \mathbf{k m} \mathbf{k m}^{-2}\right)$} & \multicolumn{4}{c}{ Prêmio ótimo médio (R\$...m $\left.{ }^{-2}\right)$} \\
\hline $\mathbf{1 0}$ & 31,1 & 31,0 & 31,1 & 31,0 & 44,6 & 32,0 & 32,0 & 32,0 & 32,0 & 45,9 \\
$\mathbf{2 5}$ & 31,5 & 31,5 & 31,5 & 31,5 & 48,2 & 32,5 & 32,5 & 32,5 & 32,5 & 49,3 \\
$\mathbf{5 0}$ & 33,4 & 33,3 & 33,4 & 33,3 & 73,8 & 34,7 & 34,7 & 34,7 & 34,7 & 82,4 \\
$\mathbf{1 0 0}$ & 42,1 & 42,1 & 42,1 & 42,1 & 88,8 & 49,1 & 49,1 & 49,1 & 49,1 & 111,0 \\
\hline Média & 34,5 & 34,5 & 34,5 & 34,5 & 63,8 & 37,1 & 37,1 & 37,1 & 37,1 & 72,1 \\
\hline
\end{tabular}

Fonte: Elaborado pelo autor. 
Tabela 24. Valores de prejuízo e do prêmio ótimo, em R\$̣. $\mathrm{km}^{-2}$, na sub-bacia do Rio Piracicaba, para TR 10, 25, 50 e 100 anos.

\begin{tabular}{|c|c|c|c|c|c|c|c|c|c|c|}
\hline \multirow{2}{*}{$\begin{array}{l}\text { TR cobertura } \\
\text { (anos) }\end{array}$} & \multicolumn{5}{|c|}{ Prejuízo médio (R\$.km² } & \multicolumn{5}{|c|}{ Prêmio ótimo médio (R\$. $\left.\mathrm{km}^{-2}\right)$} \\
\hline & Cli & ClUso & CIDis & ClUsDi & SMud & Cli & ClUso & ClDis & ClUsDi & SMud \\
\hline 10 & 198,1 & 1 & 2 & 9 & 221,4 & 202,3 & .4 & 19,0 & 18,8 & 26,0 \\
\hline 25 & 200,1 & 200,0 & 21 & 215,3 & 797,5 & 204,0 & 1 & 220,2 & 1,0 & 745,8 \\
\hline 50 & 366,4 & 365,9 & 217,5 & 217,0 & 797,6 & 371,0 & 370,1 & 222,2 & 221,7 & 745,9 \\
\hline 100 & 366,4 & 365,9 & 279,7 & 278,9 & 797,7 & 371,0 & 368,6 & 303,3 & 302,7 & 745,9 \\
\hline & 282,7 & 282,5 & 231,7 & 231,3 & 653,6 & 287,1 & 286,3 & 241,2 & 240,8 & 615,9 \\
\hline
\end{tabular}

Fonte: Elaborado pelo autor.

Quando consideradas as diferentes faixas de cobertura utilizadas (TR 10, 25, 50 e 100 anos), a variação dos prejuízos é da ordem de 9,5 a 1.433,7 R\$. $\mathrm{km}^{-2}$. Por sua vez, os prêmios otimizados médios variaram entre 9,9 e 1.479,5 R\$. $\mathrm{km}^{-2}$.

Foram observados os menores prejuízos médios, entre as diferentes faixas de cobertura, nas sub-bacias Corumbataí (entre 34,5 e 63,8 R\$. $\mathrm{km}^{-2}$ ) e Camanducaia (entre 39,0 e 105,7 R\$. $\mathrm{km}^{-2}$ ). A sub-bacia do Rio Atibaia apresentou os maiores prejuízos médios específicos, com variação entre 374,9 e $1.432,9$ R\$. $\mathrm{km}^{-2}$ entre os cenários.

A análise dos impactos dos tipos de mudanças considerados, considerando-se de maneira isolada cada um dos fatores (clima, uso da terra e disponibilidade hídrica), permitiu que se observasse maior sensibilidade da bacia às mudanças de origem climática. Notou-se uma variação desde a redução em $-82,2 \%$ nos prejuízos (rio Jaguari) até o aumento em $+282,2 \%$ nos sinistros (sub-bacia Atibaia). Como consequência, a variação nos valores dos prêmios se deu entre $-77,6 \%$ até $+262,5 \%$ para este fator de mudança.

A mudança no uso das terras, representada pelo aumento da urbanização na bacia, isoladamente, foi identificada como responsável pela menor variação dos valores dos prejuízos e, consequentemente, dos prêmios. Esta variação foi entre -0,1\% (sub-bacia Piracicaba) até $+0,6 \%$ (sub-bacia Jaguari) para os prejuízos, e entre $-0,3 \%$ e $+2,8 \%$ para os prêmios.

Como fator de mudança intermediário, em termos de potencial de variação dos prejuízos, identificou-se a operação do Sistema Cantareira. Em média, em todas as subbacias influenciadas pelos reservatórios, este fator por si só foi responsável pela diminuição dos danos em -18,5\% (sub-bacia Piracicaba) até -66,7\% (sub-bacia Jaguari). Os prêmios para 
ressarcir os prejuízos, por sua vez, também foram reduzidos entre $-16,0 \%$ e $-64,4 \%$ nessas sub-bacias.

Do ponto de vista do prêmio, os valores obtidos situaram-se bem próximos aos valores dos sinistros. Isto pois, conforme já mencionado, a simulação do fundo buscou minimamente, desde que possível, ressarcir os prejuízos decorrentes dos eventos extremos.

\subsubsection{Avaliação dos indicadores de operação do fundo de seguros}

Conforme descrito no item referente à metodologia utilizada, a operação do fundo de seguros foi avaliada através dos indicadores $C S, C E$ e $I S$. Foi obtido um valor médio para cada indicador, em função das simulações para diferentes TR de cobertura.

\subsubsection{Solvência}

A solvência foi avaliada em todos os cenários, com base na média resultante das simulações para diferentes faixas de cobertura (TR). Os valores deste indicador variaram entre $-4,3 \%$ e $+20,9 \%$. Na Tabela 25 são demonstrados os valores de CS médio obtidos para cada sub-bacia em cada cenário.

Tabela 25. Valores do Coeficiente de Solvência (CS) para cada sub-bacia nos cenários de mudanças considerados.

\begin{tabular}{crrrrr}
\hline Sub-bacias & \multicolumn{5}{c}{ Cenários } \\
& \multicolumn{1}{c}{ Cli } & ClUso & ClDis & ClUsDi & SMud \\
\hline Camanducaia & $9,8 \%$ & $9,8 \%$ & $9,8 \%$ & $9,8 \%$ & $8,3 \%$ \\
Jaguari & $14,7 \%$ & $17,0 \%$ & $20,9 \%$ & $19,1 \%$ & $-3,1 \%$ \\
Atibaia & $1,8 \%$ & $3,2 \%$ & $2,3 \%$ & $2,3 \%$ & $7,1 \%$ \\
Corumbataí & $6,8 \%$ & $6,8 \%$ & $6,8 \%$ & $6,8 \%$ & $10,5 \%$ \\
Piracicaba & $1,6 \%$ & $1,5 \%$ & $3,8 \%$ & $3,8 \%$ & $-4,3 \%$ \\
\hline Média & $\mathbf{7 , 0 \%}$ & $\mathbf{7 , 7 \%}$ & $\mathbf{8 , 7 \%}$ & $\mathbf{8 , 4 \%}$ & $\mathbf{3 , 7 \%}$ \\
\hline
\end{tabular}

Fonte: Elaborado pelo autor. 
Os melhores valores foram obtidos para em cenários com a operação dos reservatórios (CIDis e ClUsDi), onde a vazão mínima foi regulada pelos mesmos, com a solvência média entre as bacias superior a $+8,0 \%$. Nos cenários sem a operação do Sistema Cantareira, porém considerando as demais mudanças (Cli e ClUso), a solvência média foi superior a $+7,0 \%$, ainda assim superior ao CS do cenário SMud, equivalente a $+3,7 \%$.

A Figura 87 representa a espacialização do indicador CS na bacia do Rio Piracicaba, conforme sua ocorrência em cada sub-bacia.
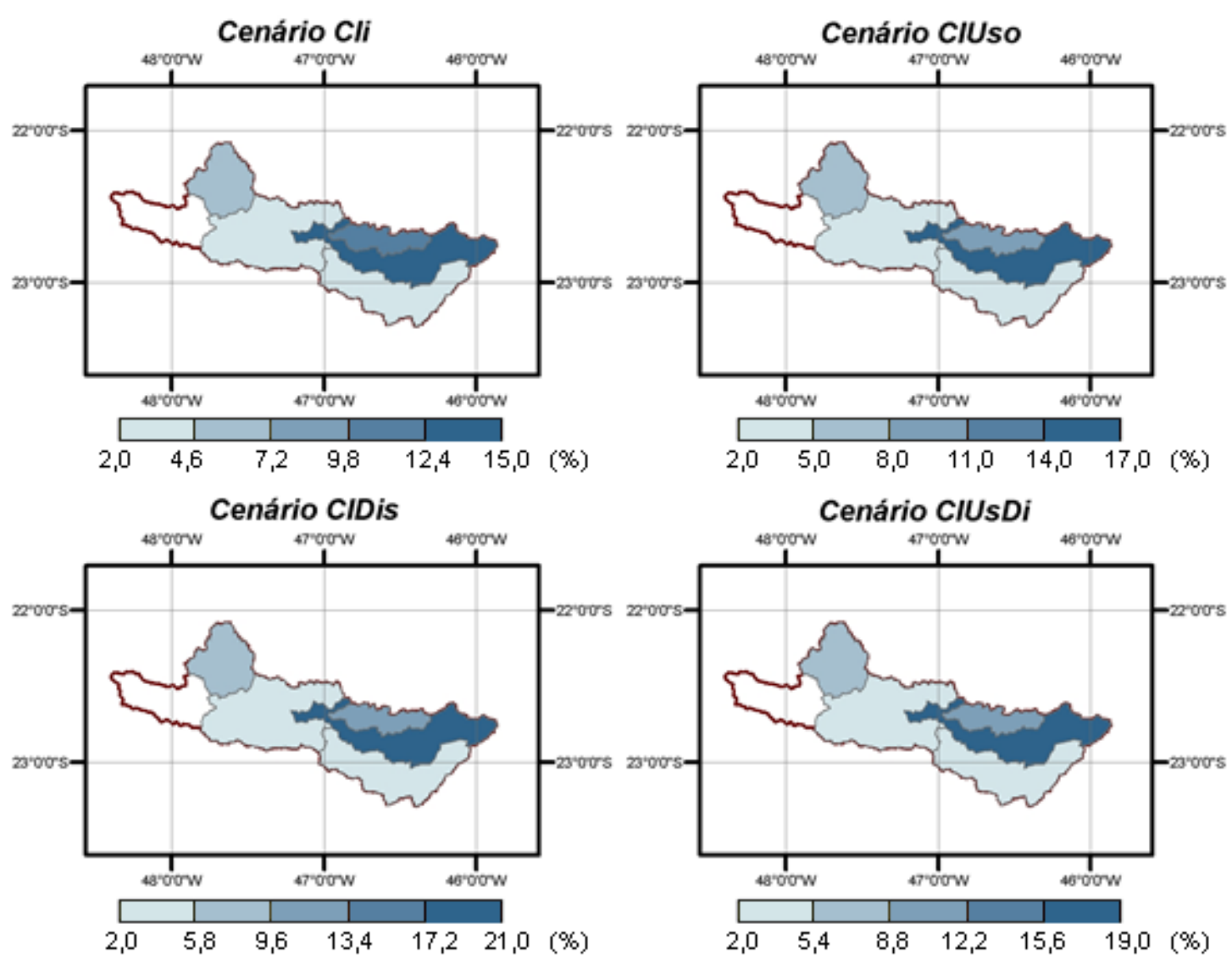

Cenário SMud

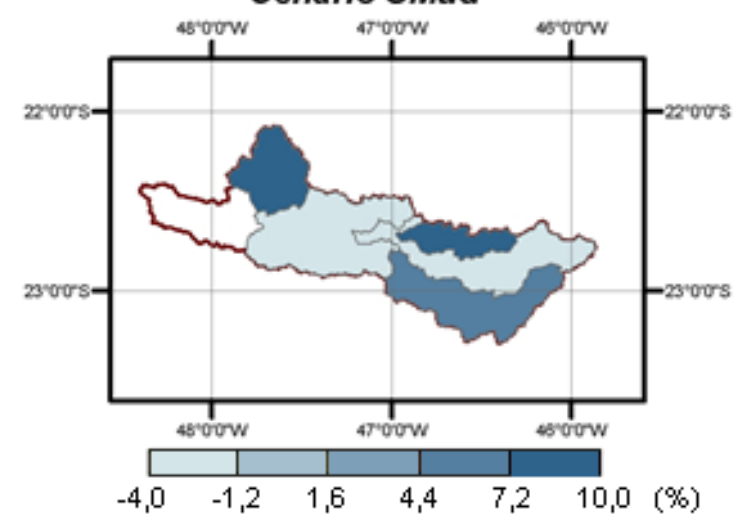

Figura 87. Coeficiente de Solvência (CS) determinado para as sub-bacias do Rio Piracicaba, nos cinco cenários de mudanças globais propostos (Fonte: Elaborado pelo autor). 


\subsubsection{Eficiência}

A avaliação da eficiência (CE) média dos cenários foi determinada de maneira semelhante à análise realizada no item anterior. Assim, obteve-se um indicador CE médio para os para os cinco cenários simulados, com variação entre observada entre $39,2 \%$ e 100,0\%. Na Tabela 26 são detalhados os valores de CE para as diferentes situações consideradas.

Tabela 26. Valores do Coeficiente de Eficiência (CE) para cada sub-bacia nos cenários de mudanças considerados.

\begin{tabular}{cccccc}
\hline Sub-bacias & \multicolumn{5}{c}{ Cenários } \\
& Cli & ClUso & ClDis & ClUsDi & \multicolumn{1}{c}{ SMud } \\
\hline Camanducaia & $93.3 \%$ & $93.3 \%$ & $93.3 \%$ & $93.3 \%$ & $86.7 \%$ \\
Jaguari & $94.4 \%$ & $94.4 \%$ & $85.6 \%$ & $92.2 \%$ & $84.4 \%$ \\
Atibaia & $39.2 \%$ & $42.5 \%$ & $57.5 \%$ & $44.2 \%$ & $86.7 \%$ \\
Corumbataí & $98.3 \%$ & $54.2 \%$ & $98.3 \%$ & $54.2 \%$ & $100.0 \%$ \\
Piracicaba & $60.8 \%$ & $62.5 \%$ & $62.5 \%$ & $62.5 \%$ & $55.0 \%$ \\
\hline Média & $\mathbf{7 7 . 2 \%}$ & $\mathbf{6 9 . 4 \%}$ & $\mathbf{7 9 . 4 \%}$ & $\mathbf{6 9 . 3 \%}$ & $\mathbf{8 2 . 6 \%}$ \\
\hline
\end{tabular}

Fonte: Elaborado pelo autor.

Foi observada a tendência de redução do valor médio de $C E$ em todos os cenários simulados, quando comparados aos resultados do cenário SMud. A redução deste indicador indica que, no futuro, sob condições de mudanças, a probabilidade de uma série desfavorável ocorrer é maior do que se considerada a manutenção dos padrões das séries observadas (cenário SMud).

As bacias que se mostraram mais sensíveis a este indicador foram as dos rios Atibaia e Corumbataí. A justificativa encontrada para este comportamento na primeira sub-bacia, Atibaia, é o fato desta sub-bacia ser fortemente influenciada pela operação dos reservatórios do Sistema Cantareira. Além disso, trata-se de uma região com grande desenvolvimento industrial e urbano, com elevada concentração populacional e, consequentemente, maior demanda hídrica. Efeito similar também foi observado na subbacia do Rio Corumbataí, 
Através da Figura 88 buscou-se a representação espacial do comportamento desde indicador na bacia.
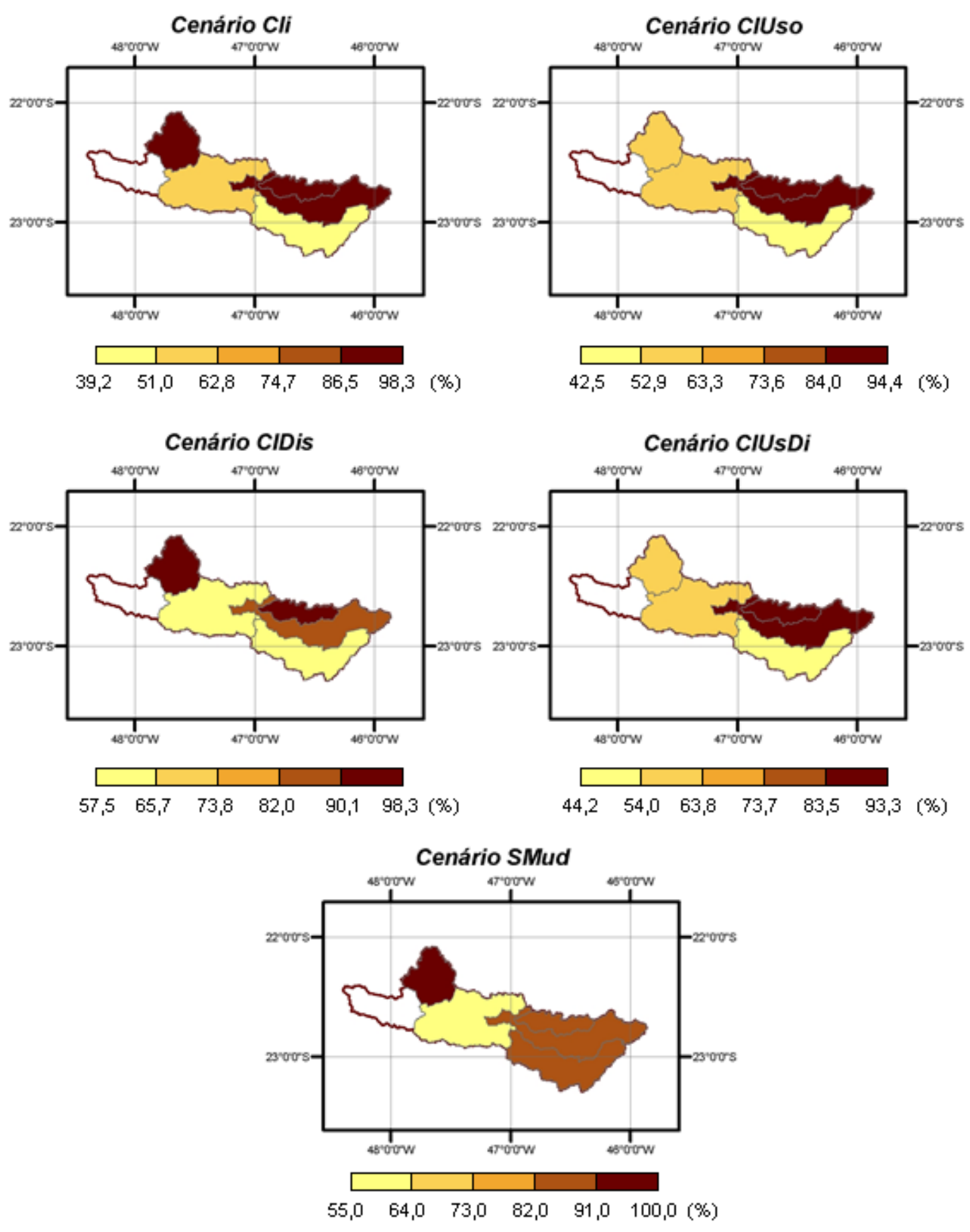

Figura 88. Coeficiente de Eficiência (CE) determinado para as sub-bacias do Rio Piracicaba, nos cinco cenários de mudanças globais propostos (Fonte: Elaborado pelo autor). 


\subsubsection{Sinistralidade}

O indicador IS permitiu que fosse avaliado o percentual dos prêmios arrecadados que está comprometido com o pagamento dos sinistros simulados. Este indicador é importante para demonstrar a sustentabilidade da operação do fundo de seguros, bem como, de maneira simplificada, avaliar a rentabilidade do mesmo. Os valores deste indicador variaram entre $83,7 \%$ e 104,7\%, conforme pode-se observar na Tabela 27.

Tabela 27. Valores do Índice de Sinistralidade (IS) para cada sub-bacia nos cenários de mudanças considerados.

\begin{tabular}{cccccr}
\hline Sub-bacias & \multicolumn{5}{c}{ Cenários } \\
& Cli & ClUso & CIDis & ClUsDi & \multicolumn{1}{c}{ SMud } \\
\hline Camanducaia & $91,2 \%$ & $91,2 \%$ & $91,2 \%$ & $91,2 \%$ & $92,4 \%$ \\
Jaguari & $87,8 \%$ & $86,1 \%$ & $83,7 \%$ & $84,9 \%$ & $103,2 \%$ \\
Atibaia & $98,2 \%$ & $96,9 \%$ & $97,7 \%$ & $97,7 \%$ & $93,4 \%$ \\
Corumbataí & $93,9 \%$ & $93,9 \%$ & $93,9 \%$ & $93,9 \%$ & $91,1 \%$ \\
Piracicaba & $98,4 \%$ & $98,5 \%$ & $96,4 \%$ & $96,4 \%$ & $104,7 \%$ \\
\hline Média & $\mathbf{9 3 , 9 \%}$ & $\mathbf{9 3 , 3 \%}$ & $\mathbf{9 2 , 6 \%}$ & $\mathbf{9 2 , 8 \%}$ & $\mathbf{9 7 , 0 \%}$ \\
\hline
\end{tabular}

Fonte: Elaborado pelo autor.

Observou-se que os fundos simulados foram operados bem próximos ao seu limite de pagamento, uma vez que um valor de IS de igual ou superior a $100 \%$ indica o comprometimento dos valores dos prêmios pagos. Situações críticas foram identificadas nas sub-bacias Jaguari e Piracicaba, com valores de IS respectivamente de 103,2\% e $104,7 \%$. Isto indica que, neste cenário, os valores dos prêmios pagos não foram suficientes para ressarcir os prejuízos decorrentes dos sinistros projetados. Esta situação é resolvida com o aumento do valor de SAmáx, o que permite que o fundo acumule mais capital.

Em condições de mudança, foi tendência em todas as bacias a melhoria (redução) do valor de IS. Resultados mais significativos foram observados na sub-bacia do Rio Jaguari, onde este indicador atingiu resultados inferiores a $90 \%$.

A espacialização das informações referentes a este indicador, em todos os cenários, são demonstradas na Figura 89. 

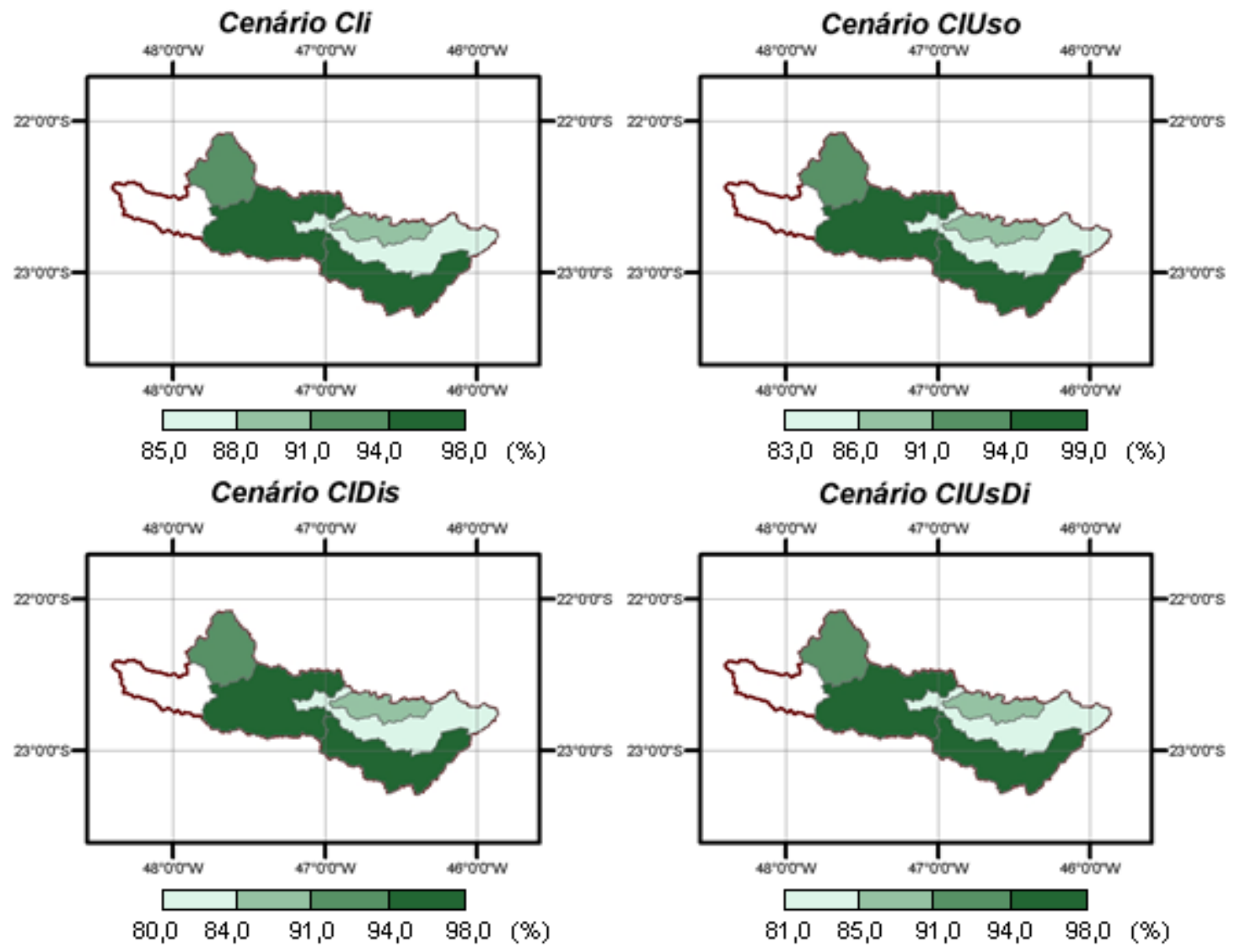

Cenário SMud

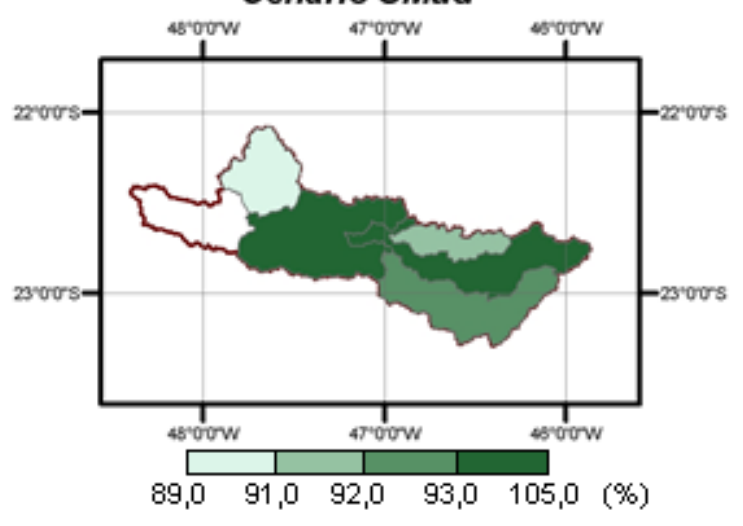

Figura 89. Índice de Sinistralidade (IS) determinado para as sub-bacias do Rio Piracicaba, nos cinco cenários de mudanças globais propostos (Fonte: Elaborado pelo autor).

\subsection{CONSIDERAÇÕES FINAIS}

A simulação do MTRH-SHS foi realizada para a bacia hidrográfica do Rio Piracicaba, mediante análise concentrada dos riscos de ocorrência de $Q_{7 \text { mín }}$ anuais em cinco sub-bacias contribuintes do Rio Piracicaba. A acoplagem do modelo AQUA-Risco ao MTRH-SHS permitiu 
que fossem analisadas todas as componentes do risco envolvidas: perigo, exposição, vulnerabilidade e resiliência.

Identificou-se que, para uma boa calibração do modelo, deve-se considerar principalmente os parâmetros SAmáx (armazenamento máximo do fundo) e o limite de cobertura do fundo. A definição destes parâmetros deve estar amparada nos objetivos do fundo de seguros, sejam eles o simples ressarcimento dos sinistros (seguros operados por entidades públicas) ou, além disso, acumular capital a investidores (fundos privados). Resultados mais significativos são obtidos se o modelo AQUA-Risco for abastecido com informações confiáveis e que representem a situação da bacia.

Os valores de dano obtidos variaram entre as sub-bacias e conforme a faixa de cobertura pré-estabelecida, estando contidos na faixa de 9,5 a 1.433,7 R\$. $\mathrm{km}^{-2}$. Por sua vez, os prêmios otimizados médios variaram entre 9,9 e $1.479,5 \mathrm{R} \$ \mathrm{~km}^{-2}$, referentes aos sinistros quantificados. Entre os indicadores, a variação de CS se deu entre $-4,3 \%$ e $+20,9 \%$. 0 indicador CE variou entre $39,2 \%$ e $100,0 \%$. Os valores de IS giraram em torno de $90 \%$, com mínimo de $83,7 \%$ e máximo de $104,7 \%$. 


\section{CAPÍTULO 6}

\section{CONCLUSÕES}

Neste item são discutidas as principais conclusões obtidas no decorrer da pesquisa. Em seguida, são definidas algumas recomendações e possíveis desdobramentos deste trabalho.

As conclusões são apresentadas com base nos objetivos específicos propostos no Capítulo 1 (item 1.2), relacionadas aos resultados alcançados. Por fim, é descrito o progresso na direção do objetivo geral desta dissertação.

\section{Objetivo 1: Calibrar e validar o modelo hidrológico MGB-IPH na bacia hidrográfica do Rio} Piracicaba e em sub-bacias afluentes, no período 1971-1990:

A calibração e a validação do modelo MGB-IPH na bacia hidrográfica do Rio Piracicaba obtiveram bons resultados. Foram utilizadas dez sub-bacias correspondentes a postos fluviométricos espacialmente distribuídos na bacia, com variação da área entre 927,1 $\mathrm{km}^{2}$ e $10.929,9 \mathrm{~m}^{2}$.

Buscou-se o ajuste entre os hidrogramas observado e calculado, onde foi priorizada a representação das vazões de alta permanência na bacia. Como estratégia, para melhora na simulação das vazões mínimas na bacia, foi adicionada a análise de $\Delta Q 90$ ao grupo de FO avaliadas. As demais FO consideradas foram o NSE, NSE $E_{\text {log }}$ e $\Delta V$.

Os valores de NSE 0,54 e 0,90 durante a calibração e 0,49 a 0,95 na validação. 0 $\mathrm{NSE}_{\text {log }}$ variou entre 0,68 e 0,90 no primeiro período e 0,80 e 0,94 no segundo período. 0 erro de volume médio foi de $+0,77 \%$, variando nos postos entre $-11,63 \%$ e $+7,69 \%$ durante a calibração e $-10,25 \%$ e $+11,76 \%$ na validação. O erro da Q90 variou entre $-17,98 \%$ e $+6,23 \%$ na validação e $-10,64 \%$ e +5,71\% na etapa de calibração.

Têm-se, a seguir, as principais conclusões: 
i. De acordo com revisão de resultados encontrados na literatura, consideraram-se aceitáveis os valores das FO nos postos;

ii. Os resultados demonstraram que o modelo pode ser considerado apto a representar as vazões médias e a Q90 e, portanto;

iii. O modelo MGB-IPH foi calibrado com sucesso.

Objetivo 2: Realizar projeções de vazões mínimas anuais, segundo modelagem hidrológica, com base em cenários de mudanças no clima e no uso das terras na bacia, para o período 2013-2099;

Este objetivo considerou a projeção de vazões mínimas anuais de longo prazo, através de modelagem hidrológica. Foi adotada a $Q_{7 \operatorname{mín}}$ como vazão a ser simulada, conforme condições de mudanças no clima, no uso da terra e na disponibilidade hídrica propostas em quatro cenários. O quinto cenário considerou a manutenção de padrões estatísticos de dados observados no período 1971-1990.

A análise dos cenários de mudanças permitiu concluir que é projetado o aumento da precipitação na bacia. Como consequência, há o aumento das vazões nos corpos d'água. Um aumento médio de $+24,8 \%$ na $Q_{7 m i ́ n}$ anual é esperado para o período futuro, segundo condições de variabilidade climática, quando comparado à média atual. A operação do Sistema Cantareira tende a reduzir em $-14,6 \%$ as vazões mínimas que ocorreriam em situações naturais na bacia. A expansão da mancha urbana, considerando níveis de crescimento atuais, pouco interfere no aumento da $Q_{7 \min }(+0,2 \%)$.

A partir dessas informações, conclui-se que:

i. As mudanças globais possuem impactos significativos nos recursos hídricos e nas vazões mínimas na escala de bacias hidrográficas, sejam eles positivos ou negativos;

ii. Produtos de acoplagem de modelagem climática, principalmente a precipitação, ainda são inferiores quando comparados a dados monitorados em campo. Todavia, a acoplagem de modelos climáticos a modelos hidrológicos se mostrou uma estratégia viável, principalmente sob condições de incertezas sobre o comportamento de parâmetros estatísticos de variáveis climáticas e hidrológicas no futuro; 
iii. O aumento da precipitação na bacia do Rio Piracicaba, conforme projeções do modelo Eta-CPTEC, reflete no aumento da $Q_{7 m i ́ n}$ anual na bacia. Porém, em condições de manutenção (ou aumento) das demandas hídricas atuais, tem-se o aumento da vulnerabilidade à escassez hídrica, conforme análise decorrente da operação do Sistema Cantareira;

Objetivo 3: Simular e avaliar o desempenho de indicadores econômicos na operação de fundos de seguros em sub-bacias da bacia do Rio Piracicaba, de maneira concentrada, como estratégia de adaptação frente à ocorrência de sinistros relativos às vazões mínimas simuladas no período 2013-2099;

A simulação do MTRH-SHS nas sub-bacias do Rio Piracicaba foi realizada e permitiu observar que bacia encontra-se vulnerável do ponto de vista da escassez hídrica. Conforme análise de riscos elaborada, quando ocorreram, os prejuízos médios variaram entre $\mathrm{R} \$ 9,5 \mathrm{e}$ $\mathrm{R} \$ 1.433,7$ por $\mathrm{km}^{2}$ de área de drenagem, conforme variação por sub-bacia, cenários e faixa de cobertura do fundo. Por sua vez, os prêmios otimizados variaram entre $R \$ 9,9$ e $R \$ 1.479,5$ por $\mathrm{km}^{2}$.

Devido à faixa de operação do fundo definida, conforme valores de SAmín e SAmáx, os prêmios otimizados obtidos foram bastante próximos aos prejuízos. Isto porque optou-se pela operação do fundo para minimamente atender às demandas dos danos, sem levar em conta acumulação de capital para geração de lucro.

A análise dos indicadores da operação do fundo demonstrou a solvência variando entre $-4,3 \%$ e $+20,9 \%$ entre as simulações. Melhores resultados foram obtidos nas subbacias dos rios Jaguari e Corumbataí. A sinistralidade, que relaciona a proporção entre os prejuízos e prêmio médios, variou entre $83,7 \%$ e $104,7 \%$. Na sub-bacia do Rio Jaguari também foram atingidas as melhores médias deste valor. A eficiência das séries simuladas variou entre $39,2 \%$ e $100 \%$.

Em duas sub-bacias, para o cenário SMud, respectivamente Jaguari e Piracicaba, a otimização do prêmio não foi suficiente para ressarcir os prejuízos decorrentes das vazões mínimas. O principal motivo para que isto tenha ocorrido é a definição de SAmáx, que limita o armazenamento do fundo.

A alteração deste parâmetro deve ocorrer segundo os objetivos e fundamentos do fundo a ser implantado. Fundos cujo objetivo seja minimamente honrar os compromissos 
decorrentes da ocorrência dos prejuízos, devem considerar operar com SAmáx próximo aos valores dos sinistros. Este é o caso de fundos operados por entidades públicas.

Fundos privados, cujo objetivo seja acumular capital e gerar lucro a seus investidores, devem operar sem limite do SAmáx, ou com um limite bem superior aos danos ocorridos. Porém, a desvantagem de se operar desta maneira é que será obtido um prêmio ótimo elevado, o que pode tornar o fundo menos interessante para os prováveis contratantes do serviço. Deve-se buscar, portanto, o equilíbrio entre o valor do prêmio e o lucro desejado.

Portanto, conclui-se que:

i. A ocorrência da $Q_{7 m i ́ n}$ anual possui impactos econômicos no desenvolvimento da bacia.

ii. Nas sub-bacias sob influência do Sistema Cantareira, projeta-se uma redução nos prejuízos em todos os cenários de mudanças, principalmente devido à variabilidade climática e aumento da precipitação. Em sub-bacias diretamente influenciadas pela operação dos reservatórios, como já esperado, observou-se a diminuição dos sinistros, devido ao aumento das vazões mínimas extremas.

iii. Na sub-bacia do Rio Piracicaba, mais a jusante da bacia, os efeitos da operação dos reservatórios são pouco percebidos e a disponibilidade hídrica é afetada devido à demanda dos usuários dos recursos hídricos. Nos cenários definidos pela operação do Sistema Cantareira, nesta bacia, os prejuízos obtidos são maiores entre todos os cenários.

iv. O valor de SAmáx deve ser determinado com critério, para que os prêmios possam ser ao menos capazes de ressarcir os prejuízos da bacia a longo prazo. A análise dos indicadores utilizados neste trabalho pode subsidiar a comparação dos resultados de diferentes faixas de operação do fundo de seguros

Objetivo Geral: Acoplar modelos de circulação regional a modelos hidrológicos distribuídos do tipo chuva-vazão e ao Modelo de Transferência de Riscos Hidrológicos, ou Modelo de Seguros Hidrológicos, como estratégia de adaptação à escassez hídrica em bacias hidrográficas brasileiras.

A sequência das etapas metodológicas contidas nos capítulos deste trabalho buscou a análise da viabilidade acoplagem entre diferentes modelos como uma estratégia de 
adaptação a situações de escassez hídrica. De modo geral, houve sucesso na acoplagem, sendo que o delineamento proposto na pesquisa foi cumprido e foram obtidos resultados satisfatórios.

Estratégias voltadas à adaptação se fazem importantes, pois, em muitas bacias, o risco da escassez hídrica passa despercebido e somente são destacados os eventos extremos de grande impacto. Como estratégia de adaptação e prevenção, devem-se considerar também os eventos de menor impacto, com menores períodos de retorno. Neste trabalho, através de um fundo de seguros, foi implantando um mecanismo que fortalece a resiliência dos usuários de recursos hídricos na bacia. Assim, a comunidade local encontra-se mais preparada para enfrentar eventos de escassez hídricas que possam acarretar perdas econômicas aos envolvidos.

\section{Recomendações}

Como desdobramento desta pesquisa, espera-se contribuir para a gestão de recursos hídricos no Estado de São Paulo. Em especial, buscou-se embasar o sistema FEHIDRO (Fundo Estadual de Recursos Hídricos) na melhoria de instrumentos de plano de bacia, monitoramento, enquadramento e cobrança pelo uso de recursos hídricos em bacias críticas em termos de escassez hídrica.

Como recomendação geral, sugere-se que sejam aprimoradas as redes de monitoramento hidrológico em todo o país, para que as atividades de modelagem possam obter cada vez melhores resultados. Trata-se, ainda, de uma realidade distante em muitas bacias brasileiras, que sofrem com extremos hidrológicos e ao mesmo tempo não possuem um banco de dados de monitoramento confiável.

Com este trabalho, espera-se contribuir e motivar o desenvolvimento de novas pesquisas na área de análise da vulnerabilidade, quantificação de impactos e implantação de estratégias de adaptação. Por sua vez, como desdobramento do método e resultados aqui alcançados, novos questionamentos surgiram.

Questiona-se se esta estratégia é replicável em outras bacias brasileiras, considerando-se a mesma finalidade aqui analisada. Para ser efetiva, uma estratégia deve ser abrangente. Com isso, recomenda-se que seja testada a metodologia aqui utilizada em bacias hidrográficas, sob variadas condições climáticas e com diferentes características 
hidrológicas e usos antrópicos. Outras áreas do projeto FAPESP no qual este trabalho se inclui são potencialmente aptas para se replicar esta estratégia, entre elas Região Metropolitana das cidades de São Paulo e Campinas, bem como as bacias UGRHIs da Baixada Santista e Vale do Ribeira.

Outra indagação se dá com relação aos valores considerados como limiar para análise dos sinistros. Neste trabalho, considerou-se somente o mínimo valor anual da $Q_{7 m i ́ n}$. Todavia, nada impede que seja considerada uma faixa limite de valores de vazões mínimas que, quando superados, gerem os sinistros.

Também se deve avaliar o impacto das incertezas climáticas e hidrológicas na quantificação dos riscos e na otimização do MTRH-SHS. Com isto, recomenda-se testar o desempenho do MTRH-SHS acoplado a diferentes modelos hidrológicos e climáticos, em diferentes escalas, bem conforme variados cenários de emissões de gases de efeito estufa. Assim, espera-se que possam ser percorridos os limites das incertezas, na tentativa de melhorar os resultados e atingir um melhor cenário de adaptação às mudanças globais.

O potencial de gestão associado ao MTRH-SHS faz deste modelo uma importante ferramenta a ser utilizada e considerada durante a tomada de decisão no gerenciamento de recursos hídricos. Assim, deve-se avaliar a viabilidade da acoplagem de modelos climáticos, hidrológicos e de transferências de riscos, associados a sistemas de suporte à decisão, no âmbito dos comitês de bacias. Esta pesquisa espera subsidiar este tipo de estratégia, por exemplo, como apoio ao projeto pesquisa de doutorado FAPESP "Sistema web-mapping integrado de suporte à decisão de riscos hidrológicos em bacias hidrográficas urbanas (2011/10929-1)". 


\section{REFERÊNCIAS}

ADGER, W. N.; AGRAWALA, S.; MIRZA, M. M. Q.; CONDE, C.; O’BRIEN, K.; PULHIN, J.; PULWARTY, R.; SMIT, B.; TAKAHASHI, K. Assessment of adaptation practices, options, constraints and capacity. In: PARRY, M.; CANZIANI, O.; PALUTIKOF, J.; VAN DER LINDEN, P.; HANSON, C. (Orgs). Climate Change 2007: Impacts, Adaptation and Vulnerability. IPCC Fourth Assessment Report.Cambridge: Cambridge University Press, 2007. Chapter 17, p. 717-743.

ALCÁNTARA-AYALA, I. Geomorphology, natural hazards, vulnerability and prevention of natural disasters in developing countries.Geomorphology, Amsterdam, v. 47, n. 2, p. 107-124, 2002.

ALLASIA, D. G.; SILVA, B. C.; COLLISCHONN, W.; TUCCI, C. Large basin simulation experience in South America. Predictions in Ungauged Basins: Promise and Progress (Proceedings of symposium $\mathrm{S7}$ held during the Seventh IAHS Scientific Assembly at Foz do Iguaçu, Brazil, April 2005). IAHS Publ. 303, 2006.

ARNELL, N. W. Uncertainty in the relationship between climate forcing and hydrological response in UK catchments. Hydrology and Earth System Sciences, Goettingen, v. 15, n. 3, p. 897-912, 2011.

AZCUE, P.; MULER, N. Optimal investment strategy to minimize the ruin probability of an insurance company under borrowing constraints. Insurance: Mathematics and Economics, Amsterdam, v. 44, n. 1, p. 26-34, 2009.

BAHAT, Y.; GRODEK, T.; LEKACH, J.; MORIN, E. Rainfall-runoff modeling in a small hyper-arid catchment. Journal of Hydrology, Amsterdam, v. 373, n. 1, p. 204-217, 2009.

BAUWENS, A.; SOHIER, C.; DEGRÉ, A. Hydrological response to climate change in the Lesse and the Vesdre catchments: contribution of a physically based model (Wallonia, Belgium). Hydrology and Earth System Sciences, Goettingen, v. 15, n. 6, p. 1745-1756, 2011.

BELDRING, S. Multi-criteria validation of a precipitation-run off model. Journal of Hydrology, Amsterdam, v. 257, n. 1, p.189-211, 2002.

BENSON, C.; CLAY, E. J. Disasters, Vulnerability, and the Global Economy. In: KREIMER, A.; ARNOLD, M.; CARLIN, A. (Eds). Building Safer Cities: The Future of Disaster Risk.Disaster Risk Management Series n. 3. Washington DC: World Bank, 2003. Chapter 1, p. 3-31.

BERGSTRÖM, S.; CARLSSON, B.; GARDELIN, M.; LINDSTRÖM, G.; PETTERSSON, A.; RUMMUKAINEN, $M$. Climate change impacts on runoff in Sweden - assessments by global climate models, dynamical downscaling and hydrological modeling. Climate Research, Oldendorf, v. 16, p. 101-112, 2001. 
BERNHARDSEN, T. Geographic Information Systems: An introduction. Arendal: Viak IT, 1992.

BEVEN, K. Causal models as multiple working hypotheses about environmental processes. Comptes Rendus Geoscience, Issy les Moulineaux, v. 344, n. 2, p. 77-88, 2012.

BEVEN, K. How far can we go in distributed hydrological modelling?. Hydrology and Earth System Sciences, Goettingen, v. 5, n. 1, p. 1-12, 2001.

BEVEN, K.; O'CONNELL, P. On the role of physically based distributed modelling in hydrology. Wallingford: Institute of Hydrology, 1982. Report n. 81.40 p.

BOUGHTON, W.; CHIEW, F. Estimating runoff in ungauged catchments from rainfall, PET and the AWBM model. Environmental Modelling \& Software, Kidlington, v. 22, n. 4, p. 476-487, 2007.

BOUWER, L.; AERTS, J. Financing climate change adaptation. Disasters, Oxford, v.30, n. 1, p. 49-63, 2006.

BRASIL. Resolução CNSP № 8, de 21 de julho de 1989.

BROZOVIC, N.; SUNDING, D.; ZILBERMAN, D. Estimating business and residential water supply interruption losses from catastrophic events. Water Resources Research, Washington, v. 43, 2007.

BUYTAERT, W.; VUILLE, M.; DEWULF, A.; URRUTIA, R.; KARMALKAR, A.; CÉLLERI, R. Uncertainties in climate change projections and regional downscaling in the tropical Andes: implications for water resources management. Hydrology and Earth System Sciences, Goettingen, v. 14, p. 1247-1258, 2010.

CALLOW, J. N.; VAN NIEL, K. P.; BOGGS, G. S. How does modifying a DEM to reflect known hydrology affect subsequent terrain analysis? Journal of Hydrology, Amsterdam, v. 332, n.2-1, p. 30- 39, 2007.

CÂMARA, G.; QUEIROZ, G. Arquitetura de Sistemas de Informação Geográfica. In: CÂMARA, G.; DAVIS, C.; MONTEIRO, A. (Org.). Introdução à Ciência da Geoinformação. São José dos Campos: INPE, 2001.

CARAM, R. O. Mudanças no uso e cobertura do solo e resposta hidrológica da bacia do rio Piracicaba. 2010. $141 \mathrm{f}$. Tese (Doutorado em Ciências) - Escola Superior de Agricultura "Luiz de Queiroz", Universidade de São Paulo, Piracicaba, 2010.

CARRIQUIRY, M.; OSGOOD, D. Index insurance, probabilistic climate forecasts, and production. The Journal of Risk and Insurance, Hoboken, v. 79, n. 1, p. 287-299, 2012.

CASTIGLIONI, S.; LOMBARDI, L.; TOTH, E.; CASTELLARIN, A.; MONTANARI, A. Calibration of rainfallrunoff models in ungauged basins: A regional maximum likelihood approach. Advances in Water Resources, Kidlington, v. 33, n. 10, p. 1235-1242, 2010.

CASTRO, C.; PIELKE, R.; LEONCINI, G. Dynamical downscaling: Assessment of value retained and added using the Regional Atmospheric Modeling System (RAMS). Journal of Geophysical Research, Washington, v. 110, D05108, 2005.

CAVALCANTI, I. Large scale and synoptic features associated with extreme precipitation over South America: A review and case studies for the first decade of the 21st century. Atmospheric Research, Amsterdam, v. 118, p. 27-40, 2012. 
CHEN, J.; BRISSETTE, F.; LECONTE, R. Uncertainty of downscaling method in quantifying the impact of climate change on hydrology. Journal of Hydrology, Amsterdam, v. 401, n. 3-4, p. 190-202, 2011.

CHIEW, F. Estimation of rainfall elasticity of streamflow in Australia, Hydrological Sciences Journal, Abingdon, v. 51, n. 4, p. 613-625, 2006.

CHIEW, F.; TENG, J.; VAZE, J.; KIRONO, D. Influence of global climate model selection on runoff impact assessment. Journal of Hydrology, Amsterdam, v. 379, n.1-2, p. 172-180, 2009.

CHOU, S.; MARENGO, J.; LYRA, A.; SUEIRO, G.; PESQUERO, J.; ALVES, L.; KAY, G.; BETTS, R.; CHAGAS, D.; GOMES, J.; BUSTAMANTE, J.; TAVARES, P. Downscaling of South America present climate driven by 4-member HadCM3 runs. Climate Dynamics, Heidelberg, v. 38, n. 3-4, p. 635-653, 2011.

COLLINS, M.; TETT, S.; COOPER, C. The internal climate variability of a HadCM3, a version of the Hadley centre coupled model without flux adjustments. Climate Dynamics, Heidelberg, v. 17, n. 1, p. 61-81, 2001.

COLLISCHONN, B.; COLLISCHONN, W.; TUCCI, C. Daily hydrological modeling in the Amazon basin using TRMM rainfall estimates. Journal of Hydrology, Amsterdam, v. 360, n. 1-4, p. 207-216, 2008.

COLLISCHONN, W. Simulação hidrológica de grandes bacias. 2001. 270 f. Tese (Doutorado em Engenharia) - Instituto de Pesquisas Hidráulicas, Universidade Federal do Rio Grande do Sul, Porto Alegre, 2001.

COLLISCHONN, W.; ALLASIA, D.; SILVA, B.; TUCCI, C. The MGB-IPH model for large-scale rainfallrunoff modeling. Hydrological Sciences-Journal-des Sciences Hydrologiques, v. 52, n. 5, p. 878-895, 2007.

COLLISCHONN, W.; FAN, F. M. Coupling the MGB-IPH hydrological model with MapWindow GIS platform. In: Open Source GIS conference, 2012, Velp, Holanda. Open Source GIS conference, 2012.

COLLISCHONN, W.; TUCCI, C. Ajuste multiobjetivo dos parâmetros de um modelo hidrológico. RBRH. Revista Brasileira de Recursos Hídricos, Porto Alegre, v. 8, n.3, p. 27-39, 2003.

COLLISCHONN, W.; TUCCI, C. Simulação Hidrológica de Grandes Bacias. Revista Brasileira de Recursos Hídricos, Porto Alegre, v. 6, n. 1, p. 95-118, 2001.

CONSÓRCIO PCJ \& COBRAPE (PCJ/COBRAPE). Plano das Bacias Hidrográficas dos Rios Piracicaba, Capivari e Jundiaí 2010-2020, com Propostas de Atualização do Enquadramento dos Corpos d'água e de Programa para Efetivação do Enquadramento dos Corpos d'água até o ano de 2035. Relatório Final. Piracicaba: COMITÊ PCJ/COBRAPE, 2010. 815p.

CRÓSTA, A. Processamento Digital de Imagens de Sensoriamento Remoto. Campinas, SP: Instituto de Geociências/UNICAMP, 1992.

CUO, L.; GIAMBELLUCA, T.; ZIEGLER, A.; NULLET, M. Use of the distributed hydrology soil vegetation model to study road effects on hydrological processes in Pang Khum Experimental Watershed, northern Thailand. Forest Ecology and Management, v. 224, n. 1-2, p. 81-94, 2006.

DAWSON, R.; BALL, T.; WERRITTY, J.; WERRITTY, A.; HALL, J.; ROCHE, N. Assessing the effectiveness of non-structural flood management measures in the Thames Estuary under conditions of socioeconomic and environmental change. Global Environmental Change, Oxford, v. 21, p. 628-646, 2011. 
DI LUCA, A.; ELÍA, R.; LAPRISE, R. Potential for added value in precipitation simulated by highresolution nested Regional Climate Models and observations. Climate Dynamics, Heidelberg, v. 38, n. 5-6, p. 1229-1247, 2012.

DIXIT, A.; MCGRAY, H. Paying the Premium: Insurance as a risk management tool for climate change. WRI Working Paper. Washington DC: World Resources Institute, 2009. 15 p.

DUFEK, A.; AMBRIZZI, T. Precipitation variability in São Paulo State, Brazil. Theoretical and Applied Climatology, v. 93, n. 3-4, p. 167-178, 2008.

DUNN, S. M.; MACKAY, R. Spatial variation in evapotranspiration and the influence of land use on catchment hydrology. Journal of Hydrology, Amsterdam, v. 171, n. 1, p. 49-73, 1995.

ECKHARDT, K.; ARNOLD, J. Automatic calibration of a distributed catchment model. Journal of Hydrology, Amsterdam, v. 251, n. 1-2, p. 103-109, 2001.

FAN, F.; COLLISCHONN, W.; BUARQUE, D.; PAIVA, R.; KAYSER, R. Manual de definição de unidades de resposta hidrológica (blocos) do modelo MGB-IPH. Versão 2.0. Agosto de 2010.

FLORENZANO, T. Imagens de satélite para estudos ambientais. São Paulo: Oficina de Textos, 2002.

FLÜGEL, W. Delineating Hydrological Response Units by Geographical Information System analyses for regional hydrological modelling using PRMS/MMS in the drainage basin of the River Brol, Germany . Hydrological Processes, Bognor Regis, v. 9, n. 3-4, p 423-436, 1995.

FOHRER, N.; HAVERKAMP, S.; ECKHARDT, K.; FREDE, H. G. Hydrologic Response to Land Use Changes on the Catchment Scale. Physics and Chemistry of the Earth (B), v. 26, n. 7-8, p. 577-582, 2001.

FOLKE, C. Resilience: The emergence of a perspective for social-ecological systems analyses. Global Environmental Change, Oxford, v. 16, p. 253-267, 2006.

FOWLER, H.; BLENKINSOP, S.; TEBALDI, C. Linking climate change modelling to impacts studies: recent advances in downscaling techniques for hydrological modeling. International Journal of Climatology, v. 27, n.12, p. 1547-1578, 2007.

FRANCHINI, M.; PACCIANI, M. Comparative analysis of several conceptual rainfall-runoff models. Journal of Hydrology, Amsterdam, v. 122, n. 1, p. 161-219, 1991.

FRANCZYK, J; CHANG, $\mathrm{H}$. The effects of climate change and urbanization on the runoff of the Rock Creek basin in the Portland metropolitan area, Oregon, USA. Hydrological Processes, Bognor Regis, v. 23, n. 6, p. 805-815, 2009.

FUNDAÇÃO INSTITUTO DE PESQUISAS ECONÔMICAS (FIPE). Estimação da Elasticidade-Preço da Demanda dos Clientes Comerciais e Industriais da SABESP. São Paulo: FIPE, 2009. 117 p.

GALLO, Z. O Processo de Industrialização e Urbanização na Bacia do Rio Piracicaba (1970/2000). Revista de Ciência \& Tecnologia, v. 8, n. 17, p. 9-17, 2001.

GETIRANA, A. Integrating spatial altimetry data into the automatic calibration of hydrological models. Journal of Hydrology, Amsterdam, v. 387, n. 3-4, p. 244-255, 2010. 
GETIRANA, A.; BONNET, M.; CALMANT, S.; ROUX, E.; ROTUNNO FILHO, O.; MANSUR, W. Hydrological monitoring of poorly gauged basins based on rainfall-runoff modeling and spatial altimetry. Journal of Hydrology, Amsterdam, v. 379, n. 3-4, p. 205-219, 2009.

GLEICK, P. Basic Water Requirements for Human Activities: Meeting Basic Needs. Water International, Philadelphia, v. 21, p. 83-92, 1996.

GORDON, C.; COOPER, C.; SENIOR, C.; BANKS, H.; GREGORY, J.; JOHNS, T.; MITCHELL, J.; WOOD, R. The simulation of SST, sea ice extents and ocean heat transport in a version of the Hadley centre coupled model without flux adjustments. Climate Dynamics, Heidelberg, v. 16, n. 2-3, p. 147-168, 2000.

GOSLING, S.; TAYLOR, R.; ARNELL, N.; TODD, M. A comparative analysis of projected impacts of climate change on river runoff from global and catchment-scale hydrological models. Hydrology and Earth System Sciences, Goettingen, v. 15, n. 1, p. 279-294, 2011.

GRACIOSA, M. P. Modelo de seguro para riscos hidrológicos com base em simulação hidráulicohidrológica como ferramenta de gestão do risco de inundações. 2010. $191 \mathrm{f}$. Tese (DoutoradoPrograma de Pós-Graduação e Área de Concentração em Engenharia Hidráulica e Saneamento) Escola de Engenharia de São Carlos, Universidade de São Paulo, São Carlos, 2010.

GRACIOSA, M.; MENDIONDO, E. Seguro-enchente como mecanismo de gestão do risco de inundações em bacias hidrográficas urbanas. Água em um mundo em transformação (Anais do XIX Simpósio Brasileiro de Recursos Hídricos) Maceió: ABRH, 2011.

GROPPO, J.; MILDE, L. C. E.; GUAMERO, M. E.; MORAES, J. M.; MARTINELLI, L. A. Análise de Séries Temporais de Vazão e de Precipitação na Bacia do Rio Piracicaba. Revista de Ciência \& Tecnologia, Piracicaba, v. 8, n 18, p. 109-117, 2001.

GROPPO, J.; STENICO, A.; SALEMI, L.; BEDUSCHI, C.; TREVISAN, R.; MORAES, J. Análise do Efeito da Operação das Barragens do Sistema Cantareira no Regime Hidrológico do Rio Piracicaba. RBRH. Revista Brasileira de Recursos Hídricos, Porto Alegre, v. 14, n.1, p. 41-51, 2009.

GUPTA, A.; LI, L. Integrating long-term care insurance purchase decisions with saving and investment for retirement". Insurance: Mathematics and Economics, Amsterdam, v. 41, n. 3, p. 362-381, 2007.

GUPTA, H.; SOROOSHIAN, S.; YAPO, P. Status of automatic calibration for hydrologic models: Comparison with multilevel expert calibration. Journal of Hydrologic Engineering, Reston, v. 4, n. 2, p. 135-143, 1999.

GUPTA, H.; WAGENER, T.; LIU, Y. Reconciling theory with observations: elements of a diagnostic approach to model evaluation. Hydrological Processes, Bognor Regis, v. 22, n. 18, p. 3802-3813, 2008.

HAGEMANN, S.; CHEN, C.; HAERTER, J. O.; HEINKE, J.; GERTEN, D.; PIANI, C. Impact of a Statistical Bias Correction on the Projected Hydrological Changes Obtained from Three GCMs and Two Hydrology Models. Journal of Hydrometeorology, Boston, v. 12, n. 4, p. 556-578, 2011.

HALLEGATTE, S. Strategies to adapt to an uncertain climate change. Global Environmental Change, Oxford, v. 19, p. 240-247, 2009. 
HANCOCK, G.; MARTINEZ, C.; EVANS, K.; MOLIERE, D. A comparison of SRTM and high-resolution digital elevation models and their use in catchment geomorphology and hydrology: Australian examples. Earth Surface Processes and Landforms, Bognor Regis, v. 31, n. 11, p. 1394-1412, 2006.

HAYLOCK, M. R.; CAWLEY, G. C.; HARPHAM, C.; WILBY, R. L.; GOODESS, C. M. Downscaling Heavy Precipitation Over The United Kingdom: A Comparison Of Dynamical And Statistical Methods And Their Future Scenarios. International Journal of Climatology, Bognor Regis, v. 26, n. 10, p. 13971415, 2006.

HURKMANS, R.; TERINK, W.; UIJLENHOET,R.; TORFS, P.; JACOB, D.; TROCH, P. Changes in Streamflow Dynamics in the Rhine Basin under Three High-Resolution Regional Climate Scenarios. Journal of Climate, Boston, v. 23, n. 3, p. 679-699, 2010.

INSTITUTO BRASILEIRO DE GEOGRAFICA E eSTATístICA (IBGE). Produção da Pecuária Municipal. $2010 . \quad$ Disponível em: <http://www.ibge.gov.br/home/estatistica/economia/ppm/2010/default.shtm>. Acesso em: 17 Ago. 2011.

INTERGOVERNMENTAL PANEL ON CLIMATE CHANGE (IPCC). Managing the Risks of Extreme Events and Disasters to Advance Climate Change Adaptation. New York: IPCC, 2012. A Special Report of Working Groups I and II of the Intergovernmental Panel on Climate Change. 582 p.

INTERGOVERNMENTAL PANEL ON CLIMATE CHANGE (IPCC). Special Report Emission Scenarios. Summary for Policymakers. A Special Report of IPCC Working Group III. Geneva: IPCC, 2000. 27p.

INTERGOVERNMENTAL PANEL ON CLIMATE CHANGE (IPCC).Climate Change 2007: Synthesis Report. Geneva: IPCC, 2007. Contribution of Working Groups I, II and III to the Fourth Assessment Report of the Intergovernmental Panel on Climate Change. 104 p.

INTERNATIONAL INSTITUTE FOR AEROSPACE SURVEY AND EARTH Sciences (ITC). ILWIS 3.0 Academic: User's Guide. Enschede, The Netherlands. May 2001. ITC-ILWIS, 2001.

JARVIS, A.; REUTER, H.; NELSON, A.; GUEVARA, E. Hole-filled seamless SRTM data.Version 4. International Centre for Tropical Agriculture (CIAT). 2008. Disponível em: <http://srtm.csi.cgiar.org>. Acesso em: 29 Set. 2010.

JORDAN, C. Derivation of Leaf-Area Index from Quality of Light on the Forest Floor. Ecology, Ithaca, v. 50, n. 4, p. 663-666, 1969.

KELMAN, J. Gerenciamento de Recursos Hídricos: Outorga e Cobrança. Anais do $12^{\circ}$ Simpósio Brasileiro de Recursos Hídricos, Vitória-ES, 1997.

KINGSTON, D.; TAYLOR, R. Sources of uncertainty in climate change impacts on river discharge and groundwater in a headwater catchment of the Upper Nile Basin, Uganda. Hydrology and Earth System Sciences, Goettingen, v. 14, n. 7, p. 1297-1308, 2010.

KLEIN, R. J. T.; HUQ, S. Inter-relationships between adaptation and mitigation.In: PARRY, M. L.; CANZIANI, O. F.; PALUTIKOF, J. P.; VAN DER LINDEN, P. J.; HANSON, C. E. (Eds). Climate Change 2007: Impacts, Adaptation and Vulnerability. IPCC Fourth Assessment Report.Cambridge: Cambridge University Press, 2007. Chapter 18, p. 745-777. 
KOUWEN, N.; SOULIS, E.; PIETRONIROFL, A.; DONALD, J.; HARRINGTON, R. Grouped Response Units for distributed hydrologic modeling. Journal of Water Resources Planning and Management, Reston, v. 119, n. 3, p. 289-305, 1993.

KRAUSE, P.; BOYLE, D. P.; F. BÄSE. Comparison of different efficiency criteria for hydrological model assessment. Advances in Geosciences, Goettingen, v. 5, p. 89-97, 2005.

KUNDZEWICZ, Z.; MATA, L. J.; ARNELL, N. W.; DÖLL, P.; KABAT, P.; JIMÉNEZ, B.; MILLER, K. A.; OKI, T.; SEN, Z.; SHIKLOMANOV, I.A. 2007: Freshwater resources and their management. Climate Change 2007: Impacts, Adaptation and Vulnerability. Contribution of Working Group II to the Fourth Assessment Report of the Intergovernmental Panel on Climate Change, M.L. Parry, O.F. Canziani, J.P. Palutikof, P.J. van der Linden and C.E. Hanson, Eds., Cambridge University Press, Cambridge, UK, p. 173-210.

LAPRISE, R. Regional climate modeling. Journal of Computational Physics, Maryland Heights, v. 227, n. 7, p. 3641-3666, 2008.

LEANDER, R; BUISHAND, T. Resampling of regional climate model output for the simulation of extreme river flows. Journal of Hydrology, Amsterdam, v. 332, n. 3-4, p. 487-496, 2007.

LI, H.; SHEFFIELD, J.; WOOD, E. Bias correction of monthly precipitation and temperature fields from Intergovernmental Panel on Climate Change AR4 models using equidistant quantile matching. Journal of Geophysical Research, Washington, v. 115, D10101, 2010.

LI, Z.; LIU, W.; ZHANG, X.; ZHENG, F. Impacts of land use change and climate variability on hydrology in an agricultural catchment on the Loess Plateau of China. Journal of Hydrology, Amsterdam, v. 377, n. 1-2, p. 35-42, 2009.

LIANG, X.; LETTENMAIER, D.; WOOD, E.; BURGES, S. A simple hydrologically based model of land surface water and energy fluxes for general circulation models. Journal of Geophysical Research, Washington, v. 99, n. 7, p. 14415-14428, 1994.

LIEBMANN, B.; VeRA, C. S.; CARVALHO, L. M. V.; CAMILLONI, I. A.; HOERLING, M. P.; ALLURED, D.; BARROS, V. R.; BÁEZ, J.; BIDEGAIN, M. An Observed Trend in Central South American Precipitation. Journal of Climate, Boston, v. 17, n. 22, p. 4357-4367, 2004.

LIN, H. Earth's Critical Zone and hydropedology: concepts, characteristics, and advances. Hydrology and Earth System Sciences, Goettingen, v. 14, n. 1, p. 25-45, 2010.

LONGLEY, P.; GOODCHILD, M.; MAGUIRE, D.; RHIND, D. Geographic Information Systems and Science. 2nd edition. New York: Wiley, 1999. 512 p.

LOOPER, J. P.; VIEUX, B. E.; MORENO, M. A. Assessing the impacts of precipitation bias on distributed hydrologic model calibration and prediction accuracy. Journal of Hydrology, Amsterdam, v. 418-419, p. 110-122, 2012.

LOPES, A.; FREITAS, M. A alocação de água como instrumento de gestão de recursos hídricos: experiências brasileiras. Revista de Gestão de Água da América Latina (Rega), Porto Alegre, v. 4, n. 1, 2007.

LUDWIG, K.; BREMICKER, M. (Ed.). The water balance model LARSIM-design, content and applications. Freiburger Schriften zur Hydrologie, v. 22. Institut für Hydrologie Universität Freiburg, Germany, 2006. 130 p. 
LUZIO, M.; SRINIVASAN, R.; ARNOLD, J. A GIS-Coupled Hydrological Model System for the Watershed Assessment of Agricultural Nonpoint and Point Sources of Pollution. Transactions in GIS, Oxford, v. 8, n. 1, p. 113-136, 2004.

LYBBERT, T.; SUMNER, D. Agricultural technologies for climate change in developing countries: Policy options for innovation and technology diffusion. Food Policy, Oxford, v. 37, p. 114-123, 2012).

MACEDO, M.; SILVA, F.; SANTOS, R. Análise do mercado de seguros no Brasil: Uma visão do desempenho organizacional das seguradoras no ano de 2003. Revista Contabilidade \& Finanças, São Paulo, Especial Autuária, p. 88-100, 2006.

MADSEN, H. Parameter estimation in distributed hydrological catchment modelling using automatic calibration with multiple objectives. Advances in Water Resources, Kidlington, v. 26, n. 2, p. 205216, 2003.

MAIDMENT, D. R. (Ed.). Arc Hydro: GIS for Water Resources, ESRI Press, Redlands, Ca. 2002. 203 p.

MAKUNGO, R; ODYIO, J.; NDIRITU, J.; MWAKA, B. Rainfall-runoff modelling approach for ungauged catchments: A case study of Nzhelele River sub-quaternary catchment. Physics and Chemistry of the Earth, v. 35, n. 13, p. 596-607, 10th WaterNet/WARFSA/GWP-SA Symposium: IWRM - Environmental Sustainability, Climate Change and Livelihoods, 2010.

MANGO, L.; MELESSE, A.; MCCLAIN, M.; GANN, D.; SETEGN, S. Land use and climate change impacts on the hydrology of the upper Mara River Basin, Kenya: results of a modeling study to support better resource management. Hydrology and Earth System Sciences, Goettingen, v. 15, n. 7, p. 2245-2258, 2011.

MANTELLI, L.; BARBOSA, J.; BITENCOURT, M. Assessing ecological risk through automated drainage extraction and watershed delineation. Ecological Informatics, Amsterdam, v. 6, n. 5, p. 325-331, 2011.

MANWELL, J.; MCGOWAN, J.; ROGERS, A. Wind energy explained. New York: Wiley, 2002. 569 p.

MARENGO, J.; CHOU, S.; KAY, G.; ALVES, L.; PESQUERO, J.; SOARES, W.; SANTOS, D.; LYRA, A.; SUEIRO, G.; BETTS, R.; CHAGAS, D.; GOMES, J.; BUSTAMANTE, J.; TAVARES, P. Development of regional future climate change scenarios in South America using the Eta CPTEC/HadCM3 climate change projections: climatology and regional analyses for the Amazon, São Francisco and the Paraná River basins. Climate Dynamics, Heidelberg, v. 38, p. 1829-1848, 2012.

MARENGO, J.; RUSTICUCCI, M.; PENALBA, O.; RENOM, M. An intercomparison of observed and simulated extreme rainfall and temperature events during the last half of the twentieth century: part 2: historical trends. Climatic Change, Dordrecht, v. 98, p. 509-529, 2010.

MARENGO, J.; VALVERDE, M.C. Caracterização do clima no Século XX e Cenário de Mudanças de clima para o Brasil no Século XXI usando os modelos do IPCC-AR4. Revista Multiciência, Campinas, v. 8, p. 5-28, 2007.

MARKE, T.; MAUSER, W.; PFEIFFER, A.; ZÄNGL, G. A pragmatic approach for the downscaling and bias correction of regional climate simulations - evaluation in hydrological modeling. Geoscientific Model Development Discussions, Goettingen, v. 4, n. 1, p. 45-63, 2011. 
MECHLER, R. Natural Disaster Risk and Cost-Benefit Analysis. In: KREIMER, A.; ARNOLD, M.; CARLIN, A. (Eds). Building Safer Cities: The Future of Disaster Risk. Disaster Risk Management Series n. 3. Washington DC: World Bank, 2003. Chapter 3. p. 45-55.

MELLO, C.; CURI, N. Hydropedology. Ciência e Agrotecnologia, Lavras, v. 36, n. 2, p. 137 -146, 2012.

MENDES, D.; MARENGO, J. A.Temporal downscaling: a comparison between artificial neural network and autocorrelation techniques over the Amazon Basin in present and future climate change scenarios. Theoretical and Applied Climatology, Vienna, v. 100, n. 3, p. 413-421, 2010.

MENDIONDO, E. M. An overview on urban flood risk management. Revista Minerva Pesquisa e Tecnologia, São Carlos, v. 2, n. 2, p. 131-143, 2005.

MENDIONDO, E. M. Reducing vulnerability to water-related disasters in urban areas of the humid tropics. In: PARKINSON, J.; GOLDENFUM, J.; TUCCI, C. (Orgs). Integrated Urban Water Management. Paris: UNESCO-IHP, 2010. Chapter 6, p. 109-127.

MENDIONDO, E. M.; VALDÉS, J. B. Strategies for Sustainable Development of Water Resources Systems. Eco-compatible Solutions for Aquatic Environments (Proceedings of the International Conference on New Trends in Water and Environmental Engineering Safety and Life), Capri, p. 1-20, 2002.

MENDIONDO, E.; TUCCI, C. Escalas Hidrológicas. I: Conceitos. Revista Brasileira de Recursos Hídricos, Porto Alegre, v. 2, n. 2, p. 21-44, 1997.

MISRA, V.; DIRMEYER, P. A.; KIRTMAN, B. P. Dynamic Downscaling of Seasonal Simulations over South America. Journal of Climate, Boston, v. 16, n. 1, p. 103-117, 2003.

MOORE, I.; GRAYSON, R.; LADSON, A. Digital terrain modeling: A review of hydrological, geomorphological, and biological applications. Hydrological Processes, Bognor Regis, v. 5, n. 1, p. 330, 1991.

MORIASI, D.; ARNOLD, J.; VAN LIEW, M.; BINGNER, R.; HARMEL, R.; VEITH, T. Model evaluation guidelines for systematic quantification of accuracy in watershed simulations. Transactions of the ASABE, v. 50, n. 3, p. 885-900, 2007.

MOSS, R.; EDMONDS, J.; HIBBARD, K.; MANNING, M.; ROSE, S.; VAN VUUREN, D.; CARTER, T.; EMORI, S.; KAINUMA, M.; KRAM, T.; MEEHL, G.; MITCHELL, J.; NAKICENOVIC, N.; RIAHI, K.; SMITH, S.; STROUFFER, R.; THOMSOM, A.; WEYANT, J.; WILLBANKS, T. The next generation of scenarios for climate change research and assessment. Nature, London, v. 463, n. 7282, p. 747-756, 2010.

MOULTON, T.; SOUZA, M. Conservação com base em bacias hidrográficas. In: ROCHA, C. F. D.; BERGALLO, H. G.; VAN SLUYS, M.; ALVES, M. A. S. (Orgs.). Biologia da conservação. São Carlos: Rima Editora, 2006. p. 157-182.

MUNICH RE. Topics Geo 2005: Natural catastrophes in 2005: Review - Outlook. Munich: Munich Re Group, 2006. 56 p.

MUNICH RE. Topics Geo 2010: Natural catastrophes analyses, assessments, positions. Munich: Munich Re Group, 2011. 58 p.

NAGHETTINI, M.; PINTO, E. Hidrologia estatística. Editora da CPRM - Serviço Geológico do Brasil, Belo Horizonte, 2007. 552 p. 
NIJSSEM, B; LETTENMAIER, D.; LIANG, X.; WETZEL, S.; WOOD, E. Streamflow simulation for continental-scale river basins. Water Resources Research, Washington, v. 33, n. 4, p. 711-724, 1997.

NOBRE, A.; CUARTAS, L.; HODNETT, M.; RENNÓ, C.; RODRIGUES, G.; SILVEIRA, A.; WATERLOO, M.; SALESKA, S. Height Above the Nearest Drainage - a hydrologically relevant new terrain model. Journal of Hydrology, Amsterdam, v. 404, n. 1-2, p. 13-29, 2011.

NOBRE, C.; SAMPAIO, G.; SALAZAR, L. Cenários de mudança climática para a América do Sul para o final do século 21. Parcerias Estratégicas, Brasília, n. 27, p. 19-42, 2008.

NÓBREGA, M. T.; COLLISCHONN, W.; TUCCI, C. E. M.; PAZ, A. R. Uncertainty in climate change impacts on water resources in the Rio Grande Basin, Brazil. Hydrology and Earth System Sciences, Goettingen, v. 15, n. 2, p. 585-595, 2011.

NÓBREGA, M.; COLLISCHONN, W.; TUCCI, C.; PAZ, A. Uncertainty in climate change impacts on water resources in the Rio Grande Basin, Brazil. Hydrology and Earth System Sciences, Goettingen, v. 15, n. 2, p. 585-595, 2011.

NYERGES, T. GIS for Environmental Modellers: An Overview. First International Conference/Workshop on Integrating GIS and Environmental Modeling, NCGIA, Boulder. 1991.

O'BRIEN, G.; O'KEEFE, P.; ROSE, J.; WISNER, B. Climate change and disaster management. Disasters, Oxford, v.30, n. 1, p. 64-80, 2006.

ODUM, E. Fundamentals of ecology. 3rd edition. Philadelphia: W. B. Saunders, 1971. 474 p.

OLIVEIRA, J.; CAMARGO, M.; ROSSI, M.; CALDERANO FILHO, B. Mapa pedológico do Estado de São Paulo. Instituto Agronômico/EMBRAPA Solos. Campinas, 1999.

PAIVA, R.; COLLISCHONN, W.; TUCCI, C. Large scale hydrologic and hydrodynamic modeling using limited data and a GIS based approach. Journal of Hydrology, Amsterdam, v. 406, n. 3-4, p. 170-181, 2011.

PALHARES, J. Estimando o consumo de água de suínos, aves e bovinos em uma propriedade. Concórdia: Embrapa Suínos e Aves, 2005. 2p.

PAZ, A.; COLLISCHONN, W. River reach length and slope estimates for large-scale hydrological models based on a relatively high-resolution digital elevation model. Journal of Hydrology, Amsterdam, v. 343, n. 3-4, p. 127-139, 2007.

PAZ, A.; COLLISCHONN, W.; RISSO, A.; MENDES, C. Errors in river lengths derived from raster digital elevation models. Computers \& Geosciences, Kidlington, v. 34, n. 11, p. 1584-1596, 2008.

PESQUERO, J. F.; CHOU, S. C.; NOBRE, C. A.; MARENGO, J. A. Climate downscaling over South America for 1961 - 1970 using the Eta Model. Theoretical and Applied Climatology, Vienna, v. 99, n. 1-2, p. 75-93, 2009.

PIANI, C.; HAERTER, J.; COPPOLA, E. Statistical bias correction for daily precipitation in regional climate models over Europe. Theoretical and Applied Climatology, Vienna, v. 99, n. 1-2, p. 187-192, 2010. 
PIANI, C.; WEEDON, G.; BEST, M.; GOMES, S.; VITERBO, P.; HAGEMANN, S.; HAERTER, J. Statistical bias correction of global simulated daily precipitation and temperature for the application of hydrological models. Journal of Hydrology, Amsterdam, v. 395, n. 3-4, p. 199-215, 2010.

PILAR, J. V.; MENDIONDO, E. M.; LANNA, E. Um modelo de seguro agrícola para a gestão de riscos na agricultura em sequeiro. Revista Brasileira de Recursos Hídricos, Porto Alegre, v. 6, n. 1, p. 85-93, 2001.

PILOTTO, I.; CHOU, S.; NOBRE, P. Seasonal climate hindcasts with Eta model nested in CPTEC coupled ocean - atmosphere general circulation model. Theoretical and Applied Climatology, Vienna, 2012. In press. Disponível em: $<$ https://springerlink3.metapress.com/content/61h7118271788130/resourcesecured/?target=fulltext.pdf\&sid=zriueOrqlgniru3rsg0nnhiv\&sh=www.springerlink.com>. Acesso em:13 Mai. 2012.

POFF, N. L.; BLEDSOE, B. P.; CUHACIYAN, C. O. Hydrologic variation with land use across the contiguous United States: Geomorphic and ecological consequences for stream ecosystems. Geomorphology, Amsterdam, v. 79, n. 3-4, p. 264-285, 2006.

POSTEL, S.; THOMPSON, B. Watershed protection: Capturing the benefits of nature's water supply services. Natural Resources Forum, Oxford, v. 29, n. 2, p. 98-108, 2005.

PRICE, K. Effects of watershed topography, soils, land use, and climate on baseflow hydrology in humid regions: A review. Progress in Physical Geography, London, v. 35, n. 4, p. 465-492, 2011.

PRUDHOMME, C.; DAVIES, H. Assessing uncertainties in climate change impact analyses on the river flow regimes in the UK. Part 1: baseline climate. Climatic Change, Dordrecht, v. 93, n. 1-2, p. 177195, 2009.

PULLAR, D.; SPRINGER, D. Towards integrating GIS and catchment models. Environmental Modelling \& Software, Kidlington, v. 15, n. 5, p. 451-459, 2000.

REIS, L. V. S. Cobertura florestal e custo do tratamento de águas em bacias hidrográficas de abastecimento público: Caso do manancial do município de Piracicaba. 2004. 215 f. Tese (Doutorado-Conservação de Ecossistemas Florestais) - Escola Superior de Agricultura Luiz de Queiroz, Universidade de São Paulo, Piracicaba, 2004.

RENNÓ, C.; NOBRE, A.; CUARTAS, L.; SOARES, J.; HODNETT, M.; TOMASELLA, J.; WATERLOO, M. HAND, a new terrain descriptor using SRTM-DEM: Mapping terra-firme rainforest environments in Amazonia. Remote Sensing of the Environment, New York, v. 112, n. 9, p. 3469-3481, 2008.

RIBEIRO NETO, A.; SILVA, R.; COLLISCHONN, W.; TUCCI, C. Simulação na Bacia Amazônica com Dados Limitados: Rio Madeira. Revista Brasileira de Recursos Hídricos, Porto Alegre, v. 13, n. 3, p. 47-58, 2008.

RIBEIRO, C.; GALLERANI, M. 2004. Industrialização, urbanização e recursos hídricos nas bacias dos rios Piracicaba, Capivari e Jundiaí, de 1970 a 2001. Pós. Revista do Programa de Pós-Graduação em Arquitetura e Urbanismo da FAUUSP, São Paulo, n. 16, 2004. Disponível em: $<$ http://www.revistasusp.sibi.usp.br/scielo.php?script=sci_arttext\&pid=S151895542004000200007\&lng=pt\&nrm=iso>. Acesso em: 9 dez. 2010.

RICHARDS, J. A.; JIA, X. Remote sensing digital image analysis: an introduction (4th edition), Germany: Springer, 2006. 439p. 
RIGHETTO, J; MENDIONDO, E.; RIGHETTO, A. Modelo de Seguro para Riscos Hidrológicos. Revista Brasileira de Recursos Hídricos, Porto Alegre, v. 12, n. 2, p. 107-113, 2007.

SÃO PAULO. Lei Estadual no 9.034, de 27 de dezembro de 1994. Dispõe sobre o Plano Estadual de Recursos Hídricos.

SARTORI, A.; NETO, F.; GENOVEZ, A. Classificação Hidrológica de Solos Brasileiros para a Estimativa da Chuva Excedente com o Método do Serviço de Conservação do Solo dos Estados Unidos Parte 1: Classificação. Revista Brasileira de Recursos Hídricos, Porto Alegra, v. 10, n. 4, p. 05-18, 2005.

SCHNEIDER, S. H.; SEMENOV, S. PATWARDHAN, A. Assessing key vulnerabilities and the risk from climate change. In: PARRY, M. L.; CANZIANI, O. F.; PALUTIKOF, J. P.; VAN DER LINDEN, P. J.; HANSON, C. E. (Eds). Climate Change 2007: Impacts, Adaptation and Vulnerability. IPCC Fourth Assessment Report. Cambridge: Cambridge University Press, 2007. Chapter 19, p. 779-810.

SECRETARIA DO MEIO AMBIENTE/COORDENADORIA DE RECURSOS HÍDRICOS (SMA/CRH). Situação dos Recursos Hídricos no Estado de São Paulo: Ano base 2007. São Paulo: SMA, 2009. 147 p.

SHS CONSULTORIA E PROJETOS DE ENGENHARIA S/S LTDA (SHS). Plano de bacias hidrográficas 20042007 dos rios Piracicaba, Capivari e Jundiaí: síntese do relatório final. São Carlos: Suprema Gráfica e Editora, 2006. 48p.

SHUTTLEWORTH, W. Evaporation. In: Handbook of Hydrology (ed. by D. Maidment), 4.1-4.53 McGraw-Hill, New York, USA. 1993.

SILVA DIAS, M. A. F.; DIAS, J.; CARVALHO, L. M. V.; FREITAS, E. D.; SILVA DIAS, P. L.. Changes in extreme daily rainfall for São Paulo, Brazil. Climatic Change, Dordrecht, 2012.

SINGH, R.; WAGENER, T.; VAN WERKHOVEN, K.; MANN, M. E.; CRANE, R. A trading-space-for-time approach to probabilistic continuous streamflow predictions in a changing climate - accounting for changing watershed behavior. Hydrology and Earth System Sciences, Goettingen, v. 15, n. 11, p. 3591-3603, 2011.

SINGH, V.; WOOLHISER, D. Mathematical Modeling of Watershed Hydrology. Journal of Hydrologic Engineering, Reston, v. 7, n. 4, p. 270-292, 2002.

SIRIWARDENA, L.; FINLAYSON, B.; MCMAHON, T. The impact of land use change on catchment hydrology in large catchments: The Comet River, Central Queensland, Australia. Journal of Hydrology, Amsterdam, v. 326, n. 1-4, p. 199-214, 2006.

SIVAPALAN, M.; TAKEUCHI, K.; FRANKS, S. W.; GUPTA, V. K.; KARAMBIRI, H.; LAKSHMI, V.; LIANG, X.; MCDONNELL, J. J.; MENDIONDO, E. M.; O'CONNELL, P. E.; T. OKI, T.; POMEROY, J. W.; SCHERTZER, D.; UHLENBROOK, S.; ZEHE, E. IAHS Decade on Predictions in Ungauged Basins (PUB), 2003-2012: Shaping an exciting future for the hydrological sciences. Hydrological Sciences Journal, Abingdon, v. 48, n. 6, 2003.

SIVAPALAN, M.; TAKEUCHI, K.; FRANKS, S. W.; GUPTA, V.; KARAMBIRI, H.; LAKSHMI, V.; LIANG, X.; MCDONNELL, J.; MENDIONDO, E.; O'CONNELL, P.; OKI, T.; POMEROY, J.; SCHERTZER, D.; UHLENBROOK, S.; ZEHE, E. IAHS Decade on Predictions in Ungauged Basins (PUB), 2003-2012: Shaping an exciting future for the hydrological sciences. Hydrological Sciences Journal, Abingdon, $v$. 48, n. 6, p. 857-880, 2003. 
SMEDT, F.; YONGBO, L; GEBREMESKEL, S. Hydrologic modelling on a catchment scale using GIS and remote sensed land use information. In: C. A. Brebbia (ed.), Risk Analysis II, WIT press, Southampton, Boston, 2000. p. 295-304.

SMIT, B.; PILIFOSOVA, O.; BURTON, I.; CHALLENGER, B.; HUQ, S.; KLEIN, R. J. T.; YOHE, G. Adaptation to Climate Change in the Context of Sustainable Development and Equity. In: MCCARTHY, J.; CANZIANI, O.; LEARY, N.; DOKKEN, D.; WHITE, K. (Orgs). Climate Change 2001: Impacts, Adaptation and Vulnerability. IPCC Third Assessment Report. Cambridge: Cambridge University Press, 2001. Chapter 18, p. 877-912.

SMIT, B.; WANDEL, J. Adaptation, adaptive capacity and vulnerability. Global Environmental Change, Oxford, v. 16, p. 282-292, 2006.

SUNYER, M. A.; MADSEN, H.; ANG, P.H. A comparison of different regional climate models and statistical downscaling methods for extreme rainfall estimation under climate change. Atmospheric Research, Amsterdam, v. 103, p. 119-128, 2012.

TAPIADOR, J.; ANGELIS, C.; VILTARD, N.; CUARTERO, F.; CASTRO, M. On the suitability of regional climate models for reconstructing climatologies. Atmospheric Research, Amsterdam, v. 101, n. 3, p. 739-751, 2011.

TAYLOR, G.; BUCHANAN, R. The Management of Solvency. In: CUMMINS, J.; DERRIG, R. (Orgs). Classical Insurance Solvency Theory. Boston: Kluwer Academic Publishers, 1988. 192 p.

TE LINDE, A.; AERTS, J.; BAKKER, A.; KWADIJK, J. Simulating low - probability peak discharges for the Rhine basin using resampled climate modeling data. Water Resources Research, Washington, v. 46, 2010.

TERINK, W.; HURKMANS, R.; TORFS, P.; UIJLENHOET, R. Evaluation of a bias correction method applied to downscaled precipitation and temperature reanalysis data for the Rhine basin. Hydrology and Earth System Sciences, Goettingen, v. 14, n. 1, p. 687-703, 2010.

TOMER, M.; SCHILLING, K. A simple approach to distinguish land-use and climate-change effects on watershed hydrology. Journal of Hydrology, Amsterdam, v. 376, n. 1-2, p. 24-33, 2009.

TOMPKINS, E.; ADGER, N.; BOYD, E.; NICHOLSON-COLE, S.; WEATHERHEAD, K.; ARNELL, N. Observed adaptation to climate change: UK evidence of transition to a well-adapting society. Global Environmental Change, Oxford, v. 20, p. 627-635, 2010.

TONG, S. T.Y.; SUN, Y.; RANATUNGA, T.; HE, J.; YANG, Y. J. Predicting plausible impacts of sets of climate and land use change scenarios on water resources. Applied Geography, Kidlington, v. 32, n. 2, p. 477-489, 2011.

TRAVIS, W. Going to extremes: propositions on the social response to severe climate change. Climatic Change, Dordrecht, v. 98, p. 1-19, 2010.

TUCCI, C. Modelos Hidrológicos. 2a edição. Porto Alegre: Editora da UFRGS, 2005. 678 p.

TUNDISI, J. Água no século XXI: Enfrentando a escassez. São Carlos: RiMa, IIE, 2003. 248p.

UNITED NATIONS ENVIRONMENTAL PROGRAMME FINANCE INITIATIVE (UNEP FI). Advancing adaptation through climate information services. Genebra: UNEP FI e SBI, 2011, 28 p. 
UNITED NATIONS DEVELPMENT PROGRAMME (UNDP). Reducing Disaster Risk: A Challenge for Development. New York: UNDP, 2004. $161 \mathrm{p}$.

UNITED NATIONS ENVIRONMENTAL PROGRAMME FINANCE INITIATIVE (UNEP FI). Insuring for Sustainability: Why and How the Leaders are doing it. Paris: UNEP FI, 2007. 64 p.

UNITED NATIONS INTERNATIONAL STRATEGY FOR DISASTER REDUCTION (UNISDR). Living with Risk: A global review of disaster reduction initiatives. Genebra: UNISDR, 2004. 429 p.

UNITED NATIONS INTERNATIONAL STRATEGY FOR DISASTER REDUCTION (UNISDR). Global Assessment Report on Disaster Risk Reduction. Genebra: UNISDR, 2009. 207 p.

UNITED NATIONS INTERNATIONAL STRATEGY FOR DISASTER REDUCTION (UNISDR). Global Assessment Report on Disaster Risk Reduction: Summary and Main Findings. Genebra: UNISDR, 2011. 24 p.

VALERIANO, M.; KUPLICH, T.; STORINO, M.; AMARAL, B.; MENDES JR, J.; LIMA, D. Modeling small watersheds in Brazilian Amazonia with shuttle radar topographic mission-90 m data. Computers \& Geosciences, Kidlington, v. 32, n. 8, p. 1169-1181, 2006.

VAN PELT, S.; KABAT, P.; TER MAAT, H.; VAN DEN HURK, B.; WEERTS, A. Discharge simulations performed with a hydrological model using bias corrected regional climate model input. Hydrology and Earth System Sciences, Goettingen, v. 13, n. 12, p. 2387-2397, 2009.

VÖRÖSMARTY, C.; MCINTYRE, P.; GESSNER, M.; DUDGEON, D.; PRUSEVICH, A.; GREEN, P.; GLIDDEN, S.; BUNN, S.; SULLIVAN, C.; LIERMANN, C.; DAVIES, P. Global threats to human water security and river biodiversity. Nature, London, v. 467, p. 555-561, 2010.

VRUGT, J. A.; GUPTA, H. V.; BASTIDAS, L. A.; BOUTEN, W.; SOROOSHIAN, S. Effective and efficient algorithm for multiobjective optimization of hydrologic models. Water Resources Research, Washington, v. 39, n. 8, 1214, 2003

WADA, Y.; VAN BEEK, L. P. H.; BIERKENS, M. F. P. Modelling global water stress of the recent past: on the relative importance of trends in water demand and climate variability. Hydrology and Earth System Sciences, Goettingen, v. 15, n. 12, p. 3785-3808, 2011.

WAGENER, T. Evaluation of catchment models. Hydrological Processes, Bognor Regis, v. 17, n. 16, p. 3375-3378, 2003.

WAGENER, T.; BOYLE, D.; LEES, M.; WHEATER, H.; GUPTA, H.; SOROOSHIAN, S. A framework for development and application of hydrological models. Hydrology and Earth System Sciences, Goettingen, v. 5, n. 1, p. 13-26, 2001.

WAGENER, T.; GUPTA, H. V. Model identification for hydrological forecasting under uncertainty. Stochastic Environmental Research and Risk Assessment, Heidelberg, v. 19, n. 6, p. 378-387, 2005.

WAGENER, T.; MONTANARI, A. Convergence of approaches toward reducing uncertainty in predictions in ungauged basins. Water Resources Research, Washington, v. 47, W06301, 2011.

WAGENER, T.; SIVAPALAN, M.; TROCH, P. A.; MCGLYNN, B. L.; HARMAN, C. J.; GUPTA, H. V.; KUMAR, P.; RAO, P. S. C.; BASU, N. B.; WILSON, J. S. The future of hydrology: An evolving science for a changing world. Water Resources Research, Washington, v. 46, W05301, 2010. 
WHATELY, M.; CUNHA, P. Cantareira 2006: um olhar sobre o maior manancial de água da Região Metropolitana de São Paulo. São Paulo: Instituto Socioambiental, 2007. 67 p.

WHITAKER, A.; ALILA, Y.; BECKERS, J.; TOEWS, D. Application of the Distributed Hydrology Soil Vegetation Model to Redfish Creek, British Columbia: model evaluation using internal catchment data. Hydrological Processes, Bognor Regis, v. 17, n. 2, p. 199-224, 2003.

WIGMOSTA, M.; VAIL, L.; LETTENMAIER, D. A distributed hydrology-vegetation model for complex terrain. Water Resources Research, Washington, v. 30, n. 6, p. 1665-1679, 1994.

WILBANKS, T. J.; KATES, R. W. GLOBAL Change in Local Places: How Scale Matters. Climatic Change, Dordrecht, v. 43, n. 3, p. 601-628, 1999.

WILBY, R.; CHARLES, S.; ZORITA, E.; TIMBAL, B.; WHETTON, P.; MEARNS, L. Guidelines for use of climate scenarios developed from statistical downscaling methods. 2004.

WILBY, R.; ORR, A.; WATTS, G.; BATTARBEE, R.; BERRY, P.; CHADD, R.; DUGDALE, S.; DUNBAR, M.; ELLIOTT, J.; EXTENCE, C.; HANNAH, D.; HOLMES, N.; JOHNSON, A.; KNIGHTS, B.; MILNER, N.; ORMEROD, S.; SOLOMON, D.; TIMLETT, R.; WHITEHEAD, P.; WOOD, P. Evidence needed to manage freshwater ecosystems in a changing climate: Turning adaptation principles into practice. Science of the Total Environment, Amsterdam, v. 408, p. 4150-4164, 2010.

WILLEMS, P.; VRAC, M. Statistical precipitation downscaling for small-scale hydrological impact investigations of climate change. Journal of Hydrology, Amsterdam, v. 402, n. 3-4, p193-205, 2011.

WORLD METEOROLOGICAL ORGANIZATION (WMO). Climate Knowledge for Action: A Global Framework for Climate Services. Genebra: WMO, 2011. 248 p.

XAVIER, A.; VETTORAZZI, C. Leaf Area Index of ground covers in a subtropical watershed. Scientia Agricola, Piracicaba, v. 60, n. 3, p. 425-431, 2003.

YAPO, P.; GUPTA, H.; SOROOSHIAN, S. Automatic calibration of conceptual rainfall-runoff models: sensitivity to calibration data. Journal of Hydrology, Amsterdam, v. 181, n. 1-4, p. 23-48, 1996.

YAPO, P.; GUPTA, H.; SOROOSHIAN, S. Multi-objective global optimization for hydrologic models. Journal of Hydrology, Amsterdam, v. 204, n. 1-4, p. 83-97, 1998.

YOUNG, A. Stream flow simulation within UK ungauged catchments using a daily rainfall-runoff model. Journal of Hydrology, Amsterdam, v. 320, n. 1, p. 155-172, 2006.

YU, P.; YANG, T.; CHEN, S. Comparison of uncertainty analysis methods for a distributed rainfallrunoff model. Journal of Hydrology, Amsterdam, v. 244, n. 1, p. 43-59, 2001.

YU, P; YANG, T. Fuzzy multi-objective function for rainfall-runoff model calibration. Journal of Hydrology, Amsterdam, v. 238, n. 1, p. 1-14, 2000.

ZHANG, L.; DAWES, W.; WALKER, G. Response of mean annual evapotranspiration to vegetation changes at catchment scale. Water Resources Research, Washington, v. 37, n. 3, p. 701-708, 2001. 


\section{APÊNDICE A}

\section{DADOS METEOROLÓGICOS E PLUVIOMÉTRICOS}

Neste item são listadas as estações meteorológicas utilizadas como fonte de dados climáticos (Tabela 28) e as estações pluviométricas (Tabela 29).

Tabela 28. Dados das estações meteorológicas utilizadas como entrada no modelo MGB-IPH.

\begin{tabular}{|c|c|c|c|}
\hline CÓDIGO & NOME & LATITUDE & LONGITUDE \\
\hline 02147048 & MOCOCA (IAC) & $-21^{0} 28^{\prime}$ & $-47^{\circ} 01^{\prime}$ \\
\hline 02147050 & SANTA RITA PASSA QUATRO & $-21043^{\prime}$ & $-47028^{\prime}$ \\
\hline 02147052 & PIRASSUNUNGA & $-21^{\circ} 59^{\prime}$ & $-47020^{\prime}$ \\
\hline 02149046 & LINS & $-21040^{\prime}$ & $-49049^{\prime}$ \\
\hline 02150044 & ARAÇATUBA & $-21^{\circ} 12^{\prime}$ & $-50^{\circ} 26^{\prime}$ \\
\hline 02244095 & PASSA QUATRO & $-22023^{\prime}$ & $-44058^{\prime}$ \\
\hline 02246042 & MONTE ALEGRE DO SUL & $-22042^{\prime}$ & $-46^{\circ} 40^{\prime}$ \\
\hline 02246048 & OURO FINO & $-22017^{\prime}$ & $-46^{\circ} 22^{\prime}$ \\
\hline 02247060 & SÃO CARLOS & $-22 \circ 01^{\prime}$ & $-47054^{\prime}$ \\
\hline 02247062 & LIMEIRA - IA & $-22037^{\prime}$ & $-47032^{\prime}$ \\
\hline 02247069 & NOVA ODESSA & $-22042^{\prime}$ & $-47018^{\prime}$ \\
\hline 02247070 & TUPI - IA & $-22043^{\prime}$ & $-47033^{\prime}$ \\
\hline 02247072 & CAMPINAS - IA & $-22054^{\prime}$ & $-47^{\circ} 05^{\prime}$ \\
\hline 02247089 & LIMEIRA (DFPV) & $-22034^{\prime}$ & $-47024^{\prime}$ \\
\hline 02247196 & CRHEA-BROA & $-22{ }^{\circ} 10^{\prime}$ & $-47053^{\prime}$ \\
\hline 02248036 & JAÚ - IA & $-22017^{\prime}$ & $-48^{\circ} 34^{\prime}$ \\
\hline 02248040 & BOTUCATU & $-22052^{\prime}$ & $-48^{\circ} 27^{\prime}$ \\
\hline 02249039 & BAURU (AEROPORTO) & $-22019^{\prime}$ & $-49 \circ 04^{\prime}$ \\
\hline 02345144 & SÃO JOSÉ DOS CAMPOS & $-23^{\circ} 13^{\prime}$ & $-45^{\circ} 51^{\prime}$ \\
\hline 02346114 & SÃO PAULO (HORTO CANTAR.) & $-23^{\circ} 27^{\prime}$ & $-46^{\circ} 39^{\prime}$ \\
\hline 02346117 & SÃO PAULO (MIRANTE SANTANA) & $-23030^{\prime}$ & $-46^{\circ} 37^{\prime}$ \\
\hline 02347065 & FAZENDA IPANEMA (CNEA) & $-23025^{\prime}$ & $-47035^{\prime}$ \\
\hline 02347068 & TIETÊ - IA & $-23^{\circ} 03^{\prime}$ & $-47043^{\prime}$ \\
\hline
\end{tabular}

Fonte: HidroWeb/ANA. 
Tabela 29. Estações pluviométricas utilizadas como fonte da precipitação observada considerada no modelo MGB-IPH.

\begin{tabular}{|c|c|c|c|}
\hline CÓDIGO & NOME & LATITUDE & LONGITUDE \\
\hline 02245050 & SÃO FRANCISCO XAVIER & $-22^{\circ} 55^{\prime}$ & $-45^{\circ} 58^{\prime}$ \\
\hline 02245104 & SAPUCAÍ-MIRIM & $-22^{\circ} 44^{\prime}$ & $-45^{\circ} 44^{\prime}$ \\
\hline 02246012 & HORTO FLORESTAL & $-22^{\circ} 27^{\prime}$ & $-46 \div 57^{\prime}$ \\
\hline 02246013 & ITAPIRA & $-22^{\circ} 27^{\prime}$ & $-46 \div 49^{\prime}$ \\
\hline 02246015 & MARTIM FRANCISCO & $-22^{\circ} 31^{\prime}$ & $-46^{\circ} 57^{\prime}$ \\
\hline 02246017 & SOCORRO & $-22^{\circ} 36^{\prime}$ & $-46^{\circ} 32^{\prime}$ \\
\hline 02246019 & SERRA NEGRA & $-22^{\circ} 36^{\prime}$ & $-46 \div 42^{\prime}$ \\
\hline 02246020 & FAZENDA CHAPADÃO & $-22^{\circ} 37^{\prime}$ & $-46 \div 51^{\prime}$ \\
\hline 02246022 & MONTE ALEGRE DO SUL & $-22^{\circ} 42^{\prime}$ & $-46^{\circ} 40^{\prime}$ \\
\hline 02246023 & AMPARO & $-22^{\circ} 42^{\prime}$ & $-46 \div 46^{\prime}$ \\
\hline 02246025 & PINHALZINHO & $-22^{\circ} 47^{\prime}$ & $-46 \div 36^{\prime}$ \\
\hline 02246028 & PEDREIRA & $-22^{\circ} 45^{\prime}$ & $-46 \div 56^{\prime}$ \\
\hline 02246029 & TUIUTI & $-22^{\circ} 49^{\prime}$ & $-46^{\circ} 41^{\prime}$ \\
\hline 02246032 & MÃE DOS HOMENS & $-22^{\circ} 53^{\prime}$ & $-46 \div 37^{\prime}$ \\
\hline 02246033 & RIO ABAIXO (FAZ. CACHOEIRA) & $-22^{\circ} 52^{\prime}$ & $-46^{\circ} 37^{\prime}$ \\
\hline 02246034 & MORUNGABA & $-22^{\circ} 53^{\prime}$ & $-46 \div 47^{\prime}$ \\
\hline 02246035 & VARGEM (US. FLORES - CPFL) & $-22^{\circ} 54^{\prime}$ & $-46 \div 25^{\prime}$ \\
\hline 02246036 & BRAGANÇA PAULISTA & $-22^{\circ} 56^{\prime}$ & $-46^{\circ} 32^{\prime}$ \\
\hline 02246037 & USINA SALTO GRANDE (CPFL) & $-22^{\circ} 56^{\prime}$ & $-46 \div 54^{\prime}$ \\
\hline 02246038 & ITATIBA & $-22^{\circ} 59^{\prime}$ & $-46^{\circ} 49^{\prime}$ \\
\hline 02246042 & MONTE ALEGRE DO SUL & $-22^{\circ} 42^{\prime}$ & $-46 \div 40^{\prime}$ \\
\hline 02246050 & CAMBUÍ (CSME) & $-22^{\circ} 36^{\prime}$ & $-46^{\circ} 02^{\prime}$ \\
\hline 02246057 & CAMANDUCAIA & $-22^{\circ} 45^{\prime}$ & $-46 \div 08$ \\
\hline 02246086 & GUIRRA & $-22^{\circ} 59^{\prime}$ & $-46^{\circ} 02^{\prime}$ \\
\hline 02246087 & BARREIRO & $-22^{\circ} 57^{\prime}$ & $-46 \div 42^{\prime}$ \\
\hline 02246088 & FORMIGA & $-22^{\circ} 44^{\prime}$ & $-46^{\circ} 25^{\prime}$ \\
\hline 02246090 & JOANÓPOLIS & $-22^{\circ} 56^{\prime}$ & $-46^{\circ} 16^{\prime}$ \\
\hline 02246095 & PEDRA BELA & $-22^{\circ} 48^{\prime}$ & $-46^{\circ} 27^{\prime}$ \\
\hline 02246099 & FAZENDA BONFIM & $-22^{\circ} 58^{\prime}$ & $-46^{\circ} 06^{\prime}$ \\
\hline 02246104 & MOJI-MIRIM & $-22^{\circ} 26^{\prime}$ & $-46^{\circ} 58^{\prime}$ \\
\hline 02246133 & BRAGANÇA PAULISTA - FUMEST & $-22^{\circ} 57^{\prime}$ & $-46 \div 32$ \\
\hline 02247003 & SÍTIO SÃO GERALDO & $-22^{\circ} 07^{\prime}$ & $-47^{\circ}-25^{\prime}$ \\
\hline
\end{tabular}


Tabela 29. Estações pluviométricas utilizadas como fonte da precipitação observada considerada no modelo MGB-IPH (continuação).

\begin{tabular}{|c|c|c|c|}
\hline 02247004 & ANALÂNDIA & $-22^{\circ} 08^{\prime}$ & $-47^{\circ}-40^{\prime}$ \\
\hline 02247010 & CORUMBATAI & $-22^{\circ} 13^{\prime}$ & $-47^{\circ} 37^{\prime}$ \\
\hline 02247011 & FAZENDA SANTANA (FAZ. SÃO BENTO) & $-22^{\circ} 15^{\prime}$ & $-47^{\circ} 23^{\prime}$ \\
\hline 02247012 & ITIRAPINA & $-22^{\circ} 14^{\prime}$ & $-47^{\circ} 48^{\prime}$ \\
\hline 02247015 & GRAUNA & $-22^{\circ} 18^{\prime}$ & $-47^{\circ}-45^{\prime}$ \\
\hline 02247017 & FAZENDA BELMONTE & $-22^{\circ} 18^{\prime}$ & $-47^{\circ} 27^{\prime}$ \\
\hline 02247018 & FAZENDA SÃO JOSÉ & $-22^{\circ} 20^{\prime}$ & $-47^{\circ} 29^{\prime}$ \\
\hline 02247019 & CAMPO REDONDO & $-22^{\circ} 22^{\prime}$ & $-47^{\circ} 59^{\prime}$ \\
\hline 02247020 & RIO CLARO & $-22^{\circ} 25^{\prime}$ & $-47^{\circ} 33^{\prime}$ \\
\hline 02247022 & SANTA GERTRUDES & $-22^{\circ} 29^{\prime}$ & $-47^{\circ} 31^{\prime}$ \\
\hline 02247024 & CHARQUEADA & $-22^{\circ} 31^{\prime}$ & $-47^{\circ} 47^{\prime}$ \\
\hline 02247025 & SÃO PEDRO & $-22^{\circ}-32^{\prime}$ & $-47^{\circ} 55^{\prime}$ \\
\hline 02247027 & LIMEIRA & $-22^{\circ} 34^{\prime}$ & $-47^{\circ} 22^{\prime}$ \\
\hline 02247030 & FAZENDA SUCATA & $-22^{\circ} 39^{\prime}$ & $-47^{\circ} 47^{\prime}$ \\
\hline 02247031 & USINA ESTER & $-22^{\circ} 40^{\prime}$ & $-47^{\circ} 13^{\prime}$ \\
\hline 02247032 & ARTEMIS & $-22^{\circ} 41^{\prime}$ & $-47^{\circ} 46^{\prime}$ \\
\hline 02247039 & FAZENDA SÃO PEDRO & $-22^{\circ} 45^{\prime}$ & $-47^{\circ} 27^{\prime}$ \\
\hline 02247040 & IBITIRUNA & $-22^{\circ} 47^{\prime}$ & $-47^{\circ} 58^{\prime}$ \\
\hline 02247041 & FAZENDA MONTE D'ESTE & $-22^{\circ} 47^{\prime}$ & $-47^{\circ} 02^{\prime}$ \\
\hline 02247042 & BARÃO GERALDO & $-22^{\circ} 50^{\prime}$ & $-47^{\circ} 04^{\prime}$ \\
\hline 02247043 & FAZENDA BOM RETIRO (US. S. BARB) & $-22^{\circ} 49^{\prime}$ & $-47^{\circ} 28^{\prime}$ \\
\hline 02247044 & RIO DAS PEDRAS & $-22^{\circ} 52^{\prime}$ & $-47^{\circ} 37^{\prime}$ \\
\hline 02247046 & CAMPINAS - IA & $-22^{\circ} 53^{\prime}$ & $-47^{\circ} 05^{\prime}$ \\
\hline 02247050 & BAIRRO PAVIOLI & $-22^{\circ} 56^{\prime}$ & $-47^{\circ} 15^{\prime}$ \\
\hline 02247051 & MONTE MOR (ETA) & $-22^{\circ} 57^{\prime}$ & $-47^{\circ} 19^{\prime}$ \\
\hline 02247052 & USINA BOM RETIRO & $-22^{\circ} 53^{\prime}$ & $-47^{\circ} 27^{\prime}$ \\
\hline 02247075 & UHE AMÉRICANA (CPFL) & $-22^{\circ} 42^{\prime}$ & $-47^{\circ} 17^{\prime}$ \\
\hline 02247094 & PIRACICABA (SEMAE) & $-22^{\circ} 43^{\prime}$ & $-47^{\circ} 39^{\prime}$ \\
\hline 02247097 & TANQUINHO & $-22^{\circ} 34^{\prime}$ & $-47^{\circ} 36^{\prime}$ \\
\hline 02247098 & TUPI & $-22^{\circ} 45^{\prime}$ & $-47^{\circ} 31^{\prime}$ \\
\hline 02247100 & ARTUR NOGUEIRA & $-22^{\circ} 34^{\prime}$ & $-47^{\circ} 10^{\prime}$ \\
\hline 02247113 & SANTA TEREZINHA & $-22^{\circ} 41^{\prime}$ & $-47^{\circ} 42^{\prime}$ \\
\hline 02247130 & FAZENDA SETE QUEDAS & $-22^{\circ} 58^{\prime}$ & $-47^{\circ} 05^{\prime}$ \\
\hline
\end{tabular}


Tabela 29. Estações pluviométricas utilizadas como fonte da precipitação observada considerada no modelo MGB-IPH (continuação).

\begin{tabular}{|c|c|c|c|}
\hline 02247180 & ITIRAPINA & $-22^{\circ} 14$ & $-47^{\circ} 49^{\prime}$ \\
\hline 02247181 & FAZENDA JANGADA & $-22^{\circ} 20^{\prime}$ & $-47^{\circ} 50^{\prime}$ \\
\hline 02247183 & SIRIEMA & $-22^{\circ} 16^{\prime}$ & $-47^{\circ} 54^{\prime}$ \\
\hline 02247184 & ITAQUERI DA SERRA & $-22^{\circ} 20^{\prime}$ & $-47^{\circ} 55^{\prime}$ \\
\hline 02247194 & BELA VISTA & $-22^{\circ} 04^{\prime}$ & $-47^{\circ}-43^{\prime}$ \\
\hline 02247198 & FAZENDA PEQUENA HOLANDA & $-22^{\circ} 10^{\prime}$ & $-47^{\circ}-46^{\prime}$ \\
\hline 02247207 & ENGENHEIRO COELHO & $-22^{\circ} 29^{\prime}$ & $-47^{\circ} 13^{\prime}$ \\
\hline 02247208 & RECREIO & $-22^{\circ} 35^{\prime}$ & $-47^{\circ} 41^{\prime}$ \\
\hline 02247209 & ANALÂNDIA - FUMEST & $-22^{\circ} 07^{\prime}$ & $-47^{\circ}-40^{\prime}$ \\
\hline 02247210 & FACULDADE ENGENHARIA - UNICAMP & $-22^{\circ} 33^{\prime}$ & $-47^{\circ} 26^{\prime}$ \\
\hline 02247214 & SUMARÉ & $-22^{\circ} 51^{\prime}$ & $-47^{\circ} 15^{\prime}$ \\
\hline 02248016 & DOIS CÓRREGOS & $-22^{\circ} 22^{\prime}$ & $-48^{\circ} 23^{\prime}$ \\
\hline 02248023 & SANTA MARIA DA SERRA & $-22^{\circ} 34^{\prime}$ & $-48^{\circ} 09^{\prime}$ \\
\hline 02248025 & FAZENDA DO BARREIRO RICO & $-22^{\circ} 41^{\prime}$ & $-48^{\circ} 07^{\prime}$ \\
\hline 02248028 & ANHEMBI & $-22^{\circ} 47^{\prime}$ & $-48^{\circ} 08^{\prime}$ \\
\hline 02248045 & PCH TRÊS SALTOS & $-22^{\circ} 23^{\prime}$ & $-48^{\circ} 10^{\prime}$ \\
\hline 02248050 & FAZENDA SERRETA & $-22^{\circ} 32^{\prime}$ & $-48^{\circ} 14^{\prime}$ \\
\hline 02248079 & MINEIROS DO TIETÊ (CPEF) & $-22^{\circ} 25^{\prime}$ & $-48^{\circ} 27^{\prime}$ \\
\hline 02248086 & RIO BONITO & $-22^{\circ} 41^{\prime}$ & $-48^{\circ} 20^{\prime}$ \\
\hline 02248115 & FAZENDA BOA VISTA & $-22^{\circ} 38^{\prime}$ & $-48^{\circ} 12^{\prime}$ \\
\hline 02346001 & ITATIBA & $-23^{\circ} 01^{\prime}$ & $-46^{\circ} 50^{\prime}$ \\
\hline 02346003 & VINHEDO & $-23^{\circ} 02^{\prime}$ & $-46^{\circ} 58^{\prime}$ \\
\hline 02346004 & PIRACAIA & $-23^{\circ} 03^{\prime}$ & $-46^{\circ} 21^{\prime}$ \\
\hline 02346005 & BATATUBA & $-23^{\circ} 05^{\prime}$ & $-46^{\circ} 24^{\prime}$ \\
\hline 02346006 & REPRESA (MONTE CLARO) & $-23^{\circ} 06^{\prime}$ & $-46^{\circ} 02^{\prime}$ \\
\hline 02346007 & ATIBAIA & $-23^{\circ} 09^{\prime}$ & $-46^{\circ} 33^{\prime}$ \\
\hline 02346010 & NAZARÉ PAULISTA & $-23^{\circ} 11^{\prime}$ & $-46^{\circ} 24^{\prime}$ \\
\hline 02346015 & RIO ACIMA & $-23^{\circ} 13^{\prime}$ & $-46^{\circ} 40^{\prime}$ \\
\hline 02346017 & MORRO GRANDE & $-23^{\circ} 16^{\prime}$ & $-46^{\circ} 25^{\prime}$ \\
\hline 02346019 & SANTA ISABEL & $-23^{\circ} 20^{\prime}$ & $-46^{\circ} 14^{\prime}$ \\
\hline 02346020 & MAIRIPORÃ & $-23^{\circ} 19^{\prime}$ & $-46^{\circ} 35^{\prime}$ \\
\hline 02346094 & PIRACAIA & $-23^{\circ} 03^{\prime}$ & $-46^{\circ} 21^{\prime}$ \\
\hline
\end{tabular}


Tabela 29. Estações pluviométricas utilizadas como fonte da precipitação observada considerada no modelo MGB-IPH (continuação).

\begin{tabular}{llll}
\hline 02346095 & ATIBAIA & $-23^{\circ} 06^{\prime}$ & $-46^{\circ} 33^{\prime}$ \\
02346097 & JUNDIAÍ & $-23^{\circ} 11^{\prime}$ & $-46^{\circ} 52^{\prime}$ \\
02346155 & MAIRIPORÃ & $-23^{\circ} 30^{\prime}$ & $-46^{\circ} 43^{\prime}$ \\
02346329 & FAZENDA PRIMAVERA & $-23^{\circ} 00^{\prime}$ & $-46^{\circ} 43^{\prime}$ \\
02346334 & CRIOULOS & $-23^{\circ} 04^{\prime}$ & $-46^{\circ} 18^{\prime}$ \\
02346349 & RIBEIRÃO & $-23^{\circ} 03^{\prime}$ & $-46^{\circ} 39^{\prime}$ \\
02346352 & RIBEIRÃO ACIMA & $-23^{\circ} 11^{\prime}$ & $-46^{\circ} 20^{\prime}$ \\
\hline
\end{tabular}

Fonte: HidroWeb/ANA. 


\section{APÊNDICE B}

\section{PARÂMETROS DE CALIBRAÇÃO DO MODELO}

A calibração do modelo contemplou os parâmetros fixos e calibráveis. Os valores de cada parâmetro, para cada bloco de uso das terras, são descritos nas tabelas a seguir.

\section{B.1 Parâmetros fixos}

Tabela 30. Valores de albedo definidos para cada bloco de uso da terra.

\begin{tabular}{lllllllllllll}
\hline \multicolumn{1}{c}{ Bloco } & Jan & Fev & Mar & Abr & Mai & Jun & Jul & Ago & Set & Out & Nov & Dez \\
\hline agr_prof & 0,15 & 0,15 & 0,15 & 0,20 & 0,20 & 0,20 & 0,20 & 0,20 & 0,20 & 0,15 & 0,15 & 0,15 \\
agr_mod & 0,15 & 0,15 & 0,15 & 0,20 & 0,20 & 0,20 & 0,20 & 0,20 & 0,20 & 0,15 & 0,15 & 0,15 \\
agr_med & 0,15 & 0,15 & 0,15 & 0,20 & 0,20 & 0,20 & 0,20 & 0,20 & 0,20 & 0,15 & 0,15 & 0,15 \\
agr_ras & 0,15 & 0,15 & 0,15 & 0,20 & 0,20 & 0,20 & 0,20 & 0,20 & 0,20 & 0,15 & 0,15 & 0,15 \\
veg_prof & 0,11 & 0,11 & 0,11 & 0,16 & 0,16 & 0,16 & 0,16 & 0,16 & 0,16 & 0,11 & 0,11 & 0,11 \\
veg_mod & 0,11 & 0,11 & 0,11 & 0,16 & 0,16 & 0,16 & 0,16 & 0,16 & 0,16 & 0,11 & 0,11 & 0,11 \\
veg_med & 0,11 & 0,11 & 0,11 & 0,16 & 0,16 & 0,16 & 0,16 & 0,16 & 0,16 & 0,11 & 0,11 & 0,11 \\
veg_ras & 0,11 & 0,11 & 0,11 & 0,16 & 0,16 & 0,16 & 0,16 & 0,16 & 0,16 & 0,11 & 0,11 & 0,11 \\
Urb & 0,35 & 0,35 & 0,35 & 0,10 & 0,10 & 0,10 & 0,10 & 0,10 & 0,10 & 0,35 & 0,35 & 0,35 \\
Agua & 0,05 & 0,05 & 0,05 & 0,05 & 0,05 & 0,05 & 0,05 & 0,05 & 0,05 & 0,05 & 0,05 & 0,05 \\
\hline
\end{tabular}

Fonte: Elaborado pelo autor.

Tabela 31. Valores do índice de área foliar (IAF) definidos para cada bloco de uso da terra.

\begin{tabular}{lllllllllllll}
\hline \multicolumn{1}{c}{ Bloco } & Jan & Fev & Mar & Abr & Mai & Jun & Jul & Ago & Set & Out & Nov & Dez \\
\hline agr_prof & 1,41 & 2,36 & 1,59 & 1,61 & 1,92 & 1,93 & 1,48 & 1,07 & 1,12 & 1,11 & 1,09 & 1,27 \\
agr_mod & 1,41 & 2,36 & 1,59 & 1,61 & 1,92 & 1,93 & 1,48 & 1,07 & 1,12 & 1,11 & 1,09 & 1,27 \\
agr_med & 1,41 & 2,36 & 1,59 & 1,61 & 1,92 & 1,93 & 1,48 & 1,07 & 1,12 & 1,11 & 1,09 & 1,27 \\
agr_ras & 1,41 & 2,36 & 1,59 & 1,61 & 1,92 & 1,93 & 1,48 & 1,07 & 1,12 & 1,11 & 1,09 & 1,27 \\
veg_prof & 3,85 & 4,08 & 3,40 & 3,04 & 2,81 & 2,51 & 2,99 & 2,28 & 2,44 & 2,81 & 3,72 & 3,87 \\
veg_mod & 3,85 & 4,08 & 3,40 & 3,04 & 2,81 & 2,51 & 2,99 & 2,28 & 2,44 & 2,81 & 3,72 & 3,87 \\
veg_med & 3,85 & 4,08 & 3,40 & 3,04 & 2,81 & 2,51 & 2,99 & 2,28 & 2,44 & 2,81 & 3,72 & 3,87 \\
veg_ras & 3,85 & 4,08 & 3,40 & 3,04 & 2,81 & 2,51 & 2,99 & 2,28 & 2,44 & 2,81 & 3,72 & 3,87 \\
Urb & 1,00 & 1,00 & 1,00 & 1,00 & 1,00 & 1,00 & 1,00 & 1,00 & 1,00 & 1,00 & 1,00 & 1,00 \\
Agua & 0,00 & 0,00 & 0,00 & 0,00 & 0,00 & 0,00 & 0,00 & 0,00 & 0,00 & 0,00 & 0,00 & 0,00 \\
\hline
\end{tabular}

Fonte: Elaborado pelo autor. 
Tabela 32. Valores de altura da vegetação definidos para cada bloco de uso da terra.

\begin{tabular}{lrrrrrrrrrrrr}
\hline \multicolumn{1}{c}{ Bloco } & \multicolumn{1}{c}{ Jan } & \multicolumn{1}{c}{ Fev } & Mar & Abr & Mai & Jun & Jul & Ago & Set & Out & Nov & Dez \\
\hline agr_prof & 1,5 & 1,5 & 1,5 & 1,5 & 1,5 & 1,5 & 1,5 & 1,5 & 1,5 & 1,5 & 1,5 & 1,5 \\
agr_mod & 1,5 & 1,5 & 1,5 & 1,5 & 1,5 & 1,5 & 1,5 & 1,5 & 1,5 & 1,5 & 1,5 & 1,5 \\
agr_med & 1,5 & 1,5 & 1,5 & 1,5 & 1,5 & 1,5 & 1,5 & 1,5 & 1,5 & 1,5 & 1,5 & 1,5 \\
agr_ras & 1,5 & 1,5 & 1,5 & 1,5 & 1,5 & 1,5 & 1,5 & 1,5 & 1,5 & 1,5 & 1,5 & 1,5 \\
veg_prof & 15,0 & 15,0 & 15,0 & 15,0 & 15,0 & 15,0 & 15,0 & 15,0 & 15,0 & 15,0 & 15,0 & 15,0 \\
veg_mod & 15,0 & 15,0 & 15,0 & 15,0 & 15,0 & 15,0 & 15,0 & 15,0 & 15,0 & 15,0 & 15,0 & 15,0 \\
veg_med & 15,0 & 15,0 & 15,0 & 15,0 & 15,0 & 15,0 & 15,0 & 15,0 & 15,0 & 15,0 & 15,0 & 15,0 \\
veg_ras & 15,0 & 15,0 & 15,0 & 15,0 & 15,0 & 15,0 & 15,0 & 15,0 & 15,0 & 15,0 & 15,0 & 15,0 \\
Urb & 1,5 & 1,5 & 1,5 & 1,5 & 1,5 & 1,5 & 1,5 & 1,5 & 1,5 & 1,5 & 1,5 & 1,5 \\
Agua & 0,1 & 0,1 & 0,1 & 0,1 & 0,1 & 0,1 & 0,1 & 0,1 & 0,1 & 0,1 & 0,1 & 0,1 \\
\hline
\end{tabular}

Fonte: Elaborado pelo autor.

Tabela 33. Valores de resistência superficial definidos para cada bloco de uso da terra.

\begin{tabular}{lcccccccccccc}
\hline \multicolumn{1}{c}{ Bloco } & Jan & Fev & Mar & Abr & Mai & Jun & Jul & Ago & Set & Out & Nov & Dez \\
\hline agr_prof & 70.0 & 70.0 & 70.0 & 75.0 & 75.0 & 75.0 & 75.0 & 75.0 & 75.0 & 70.0 & 70.0 & 70.0 \\
agr_mod & 70.0 & 70.0 & 70.0 & 75.0 & 75.0 & 75.0 & 75.0 & 75.0 & 75.0 & 70.0 & 70.0 & 70.0 \\
agr_med & 70.0 & 70.0 & 70.0 & 75.0 & 75.0 & 75.0 & 75.0 & 75.0 & 75.0 & 70.0 & 70.0 & 70.0 \\
agr_ras & 70.0 & 70.0 & 70.0 & 75.0 & 75.0 & 75.0 & 75.0 & 75.0 & 75.0 & 70.0 & 70.0 & 70.0 \\
veg_prof & 90.0 & 90.0 & 90.0 & 85.0 & 85.0 & 85.0 & 85.0 & 85.0 & 85.0 & 90.0 & 90.0 & 90.0 \\
veg_mod & 90.0 & 90.0 & 90.0 & 85.0 & 85.0 & 85.0 & 85.0 & 85.0 & 85.0 & 90.0 & 90.0 & 90.0 \\
veg_med & 90.0 & 90.0 & 90.0 & 85.0 & 85.0 & 85.0 & 85.0 & 85.0 & 85.0 & 90.0 & 90.0 & 90.0 \\
veg_ras & 90.0 & 90.0 & 90.0 & 85.0 & 85.0 & 85.0 & 85.0 & 85.0 & 85.0 & 90.0 & 90.0 & 90.0 \\
Urb & 99.9 & 99.9 & 99.9 & 99.9 & 99.9 & 99.9 & 99.9 & 99.9 & 99.9 & 99.9 & 99.9 & 99.9 \\
Agua & 0.0 & 0.0 & 0.0 & 0.0 & 0.0 & 0.0 & 0.0 & 0.0 & 0.0 & 0.0 & 0.0 & 0.0 \\
\hline
\end{tabular}

Fonte: Elaborado pelo autor.

\section{B.2. Parâmetros calibráveis}

Tabela 34. Parâmetros calibráveis ajustados para a sub-bacia no 01 (Posto Pires).

\begin{tabular}{|c|c|c|c|c|c|c|c|c|c|c|c|}
\hline Uso & Wm & B & Kbas & Kint & $X \mathbf{X}$ & CAP & Wc & CS & $\mathrm{Cl}$ & CB & QB \\
\hline agr_prof & 250.00 & 0.20 & 4.94 & 10.95 & 0.67 & 0.00 & 0.10 & \multirow{10}{*}{15.50} & \multirow{10}{*}{50.15} & \multirow{10}{*}{2644.00} & \multirow{10}{*}{0.01} \\
\hline agr_mod & 200.00 & 0.20 & 4.94 & 10.95 & 0.67 & 0.00 & 0.10 & & & & \\
\hline agr_med & 200.00 & 0.20 & 4.94 & 10.95 & 0.67 & 0.00 & 0.10 & & & & \\
\hline agr_ras & 150.00 & 0.20 & 4.94 & 10.95 & 0.67 & 0.00 & 0.10 & & & & \\
\hline veg_prof & 400.00 & 0.20 & 4.94 & 10.95 & 0.67 & 0.00 & 0.10 & & & & \\
\hline veg_mod & 350.00 & 0.20 & 4.94 & 10.95 & 0.67 & 0.00 & 0.10 & & & & \\
\hline veg_med & 350.00 & 0.20 & 4.94 & 10.95 & 0.67 & 0.00 & 0.10 & & & & \\
\hline veg_ras & 300.00 & 0.20 & 4.94 & 10.95 & 0.67 & 0.00 & 0.10 & & & & \\
\hline urb & 50.00 & 0.20 & 4.94 & 10.95 & 0.67 & 0.00 & 0.10 & & & & \\
\hline agua & 0.00 & 0.00 & 0.00 & 0.00 & 0.00 & 0.00 & 0.00 & & & & \\
\hline
\end{tabular}

Fonte: Elaborado pelo autor. 
Tabela 35. Parâmetros calibráveis ajustados para a sub-bacia no 02 (Posto Buenópolis).

\begin{tabular}{lrllllllllll}
\hline \multicolumn{1}{c}{ Uso } & \multicolumn{1}{c}{ Wm } & B & Kbas & Kint & XL & CAP & Wc & CS & Cl & CB & QB \\
\hline agr_prof & 250.00 & 0.20 & 4.94 & 10.95 & 0.67 & 0.00 & 0.10 & & & & \\
agr_mod & 200.00 & 0.20 & 4.94 & 10.95 & 0.67 & 0.00 & 0.10 & & & & \\
agr_med & 200.00 & 0.20 & 4.94 & 10.95 & 0.67 & 0.00 & 0.10 & & & & \\
agr_ras & 150.00 & 0.20 & 4.94 & 10.95 & 0.67 & 0.00 & 0.10 & & & & \\
veg_prof & 400.00 & 0.20 & 4.94 & 10.95 & 0.67 & 0.00 & 0.10 & & & & \\
veg_mod & 350.00 & 0.20 & 4.94 & 10.95 & 0.67 & 0.00 & 0.10 & 15.50 & 50.15 & 2997.25 & 0.01 \\
veg_med & 350.00 & 0.20 & 4.94 & 10.95 & 0.67 & 0.00 & 0.10 & & & & \\
veg_ras & 300.00 & 0.20 & 4.94 & 10.95 & 0.67 & 0.00 & 0.10 & & & & \\
Urb & 50.00 & 0.20 & 4.94 & 10.95 & 0.67 & 0.00 & 0.10 & & & & \\
Agua & 0.00 & 0.00 & 0.00 & 0.00 & 0.00 & 0.00 & 0.00 & & & & \\
\hline
\end{tabular}

Fonte: Elaborado pelo autor.

Tabela 36. Parâmetros calibráveis ajustados para a sub-bacia no 03 (Posto Jaguariúna).

\begin{tabular}{|c|c|c|c|c|c|c|c|c|c|c|c|}
\hline Uso & Wm & B & Kbas & Kint & $X L$ & CAP & Wc & CS & $\mathrm{Cl}$ & CB & QB \\
\hline agr_prof & 250.00 & 0.08 & 0.60 & 17.29 & 0.67 & 0.00 & 0.10 & \multirow{10}{*}{5.80} & \multirow{10}{*}{29.00} & \multirow{10}{*}{3024.33} & \multirow{10}{*}{0.01} \\
\hline agr_mod & 200.00 & 0.08 & 0.60 & 17.29 & 0.67 & 0.00 & 0.10 & & & & \\
\hline agr_med & 200.00 & 0.08 & 0.60 & 17.29 & 0.67 & 0.00 & 0.10 & & & & \\
\hline agr_ras & 150.00 & 0.08 & 0.60 & 17.29 & 0.67 & 0.00 & 0.10 & & & & \\
\hline veg_prof & 400.00 & 0.08 & 0.60 & 17.29 & 0.67 & 0.00 & 0.10 & & & & \\
\hline veg_mod & 350.00 & 0.08 & 0.60 & 17.29 & 0.67 & 0.00 & 0.10 & & & & \\
\hline veg_med & 350.00 & 0.08 & 0.60 & 17.29 & 0.67 & 0.00 & 0.10 & & & & \\
\hline veg_ras & 300.00 & 0.08 & 0.60 & 17.29 & 0.67 & 0.00 & 0.10 & & & & \\
\hline Urb & 50.00 & 0.08 & 0.60 & 17.29 & 0.67 & 0.00 & 0.10 & & & & \\
\hline Agua & 0.00 & 0.00 & 0.00 & 0.00 & 0.00 & 0.00 & 0.00 & & & & \\
\hline
\end{tabular}

Fonte: Elaborado pelo autor.

Tabela 37. Parâmetros calibráveis ajustados para a sub-bacia no 04 (Posto Monte Alegre do Sul).

\begin{tabular}{lccccccccccc}
\hline \multicolumn{1}{c}{ Uso } & Wm & B & Kbas & Kint & XL & CAP & Wc & CS & CI & CB & QB \\
\hline agr_prof & 250.00 & 0.22 & 5.32 & 9.30 & 0.67 & 0.00 & 0.10 & & & & \\
agr_mod & 200.00 & 0.22 & 5.32 & 9.30 & 0.67 & 0.00 & 0.10 & & & & \\
agr_med & 200.00 & 0.22 & 5.32 & 9.30 & 0.67 & 0.00 & 0.10 & & & & \\
agr_ras & 150.00 & 0.22 & 5.32 & 9.30 & 0.67 & 0.00 & 0.10 & & & & \\
veg_prof & 400.00 & 0.22 & 5.32 & 9.30 & 0.67 & 0.00 & 0.10 & 23.28 & 33.28 & 2357.80 & 0.01 \\
veg_mod & 350.00 & 0.22 & 5.32 & 9.30 & 0.67 & 0.00 & 0.10 & & & & \\
veg_med & 350.00 & 0.22 & 5.32 & 9.30 & 0.67 & 0.00 & 0.10 & & & & \\
veg_ras & 300.00 & 0.22 & 5.32 & 9.30 & 0.67 & 0.00 & 0.10 & & & & \\
Urb & 50.00 & 0.22 & 5.32 & 9.30 & 0.67 & 0.00 & 0.10 & & & & \\
Agua & 0.00 & 0.00 & 0.00 & 0.00 & 0.00 & 0.00 & 0.00 & & & & \\
\hline
\end{tabular}

Fonte: Elaborado pelo autor. 
Tabela 38. Parâmetros calibráveis ajustados para a sub-bacia no 05 (Posto Fazenda Barra).

\begin{tabular}{|c|c|c|c|c|c|c|c|c|c|c|c|}
\hline Uso & $W m$ & B & Kbas & Kint & $X L$ & CAP & Wc & CS & $\mathrm{Cl}$ & CB & QB \\
\hline agr_prof & 300.00 & 0.20 & 1.55 & 4.59 & 0.67 & 0.00 & 0.10 & \multirow{10}{*}{9.57} & \multirow{10}{*}{62.55} & \multirow{10}{*}{2619.60} & \multirow{10}{*}{0.01} \\
\hline agr_mod & 250.00 & 0.20 & 1.55 & 4.59 & 0.67 & 0.00 & 0.10 & & & & \\
\hline agr_med & 250.00 & 0.20 & 1.55 & 4.59 & 0.67 & 0.00 & 0.10 & & & & \\
\hline agr_ras & 150.00 & 0.20 & 1.55 & 4.59 & 0.67 & 0.00 & 0.10 & & & & \\
\hline veg_prof & 500.00 & 0.20 & 1.55 & 4.59 & 0.67 & 0.00 & 0.10 & & & & \\
\hline veg_mod & 450.00 & 0.20 & 1.55 & 4.59 & 0.67 & 0.00 & 0.10 & & & & \\
\hline veg_med & 450.00 & 0.20 & 1.55 & 4.59 & 0.67 & 0.00 & 0.10 & & & & \\
\hline veg_ras & 350.00 & 0.20 & 1.55 & 4.59 & 0.67 & 0.00 & 0.10 & & & & \\
\hline Urb & 50.00 & 0.20 & 1.55 & 4.59 & 0.67 & 0.00 & 0.10 & & & & \\
\hline Agua & 0.00 & 0.00 & 0.00 & 0.00 & 0.00 & 0.00 & 0.00 & & & & \\
\hline
\end{tabular}

Fonte: Elaborado pelo autor.

Tabela 39. Parâmetros calibráveis ajustados para a sub-bacia no 06 (Posto Usina Ester).

\begin{tabular}{|c|c|c|c|c|c|c|c|c|c|c|c|}
\hline Uso & Wm & B & Kbas & Kint & $\mathrm{XL}$ & CAP & Wc & CS & $\mathrm{Cl}$ & CB & QB \\
\hline agr_prof & 250.00 & 0.04 & 3.57 & 4.52 & 0.67 & 0.00 & 0.10 & \multirow{10}{*}{17.73} & \multirow{10}{*}{88.65} & \multirow{10}{*}{3063.75} & \multirow{10}{*}{0.01} \\
\hline agr_mod & 200.00 & 0.04 & 3.57 & 4.52 & 0.67 & 0.00 & 0.10 & & & & \\
\hline agr_med & 200.00 & 0.04 & 3.57 & 4.52 & 0.67 & 0.00 & 0.10 & & & & \\
\hline agr_ras & 150.00 & 0.04 & 3.57 & 4.52 & 0.67 & 0.00 & 0.10 & & & & \\
\hline veg_prof & 400.00 & 0.04 & 3.57 & 4.52 & 0.67 & 0.00 & 0.10 & & & & \\
\hline veg_mod & 350.00 & 0.04 & 3.57 & 4.52 & 0.67 & 0.00 & 0.10 & & & & \\
\hline veg_med & 350.00 & 0.04 & 3.57 & 4.52 & 0.67 & 0.00 & 0.10 & & & & \\
\hline veg_ras & 300.00 & 0.04 & 3.57 & 4.52 & 0.67 & 0.00 & 0.10 & & & & \\
\hline Urb & 50.00 & 0.04 & 3.57 & 4.52 & 0.67 & 0.00 & 0.10 & & & & \\
\hline Agua & 0.00 & 0.00 & 0.00 & 0.00 & 0.00 & 0.00 & 0.00 & & & & \\
\hline
\end{tabular}

Fonte: Elaborado pelo autor.

Tabela 40. Parâmetros calibráveis ajustados para a sub-bacia no 07 (Posto Bairro da Ponte).

\begin{tabular}{|c|c|c|c|c|c|c|c|c|c|c|c|}
\hline Uso & $\mathrm{Wm}$ & B & Kbas & Kint & $X L$ & CAP & Wc & CS & $\mathrm{Cl}$ & CB & QB \\
\hline agr_prof & 250.00 & 0.18 & 0.46 & 6.09 & 0.67 & 0.00 & 0.10 & \multirow{10}{*}{19.47} & \multirow{10}{*}{175.23} & \multirow{10}{*}{2177.75} & \multirow{10}{*}{0.01} \\
\hline agr_mod & 200.00 & 0.18 & 0.46 & 6.09 & 0.67 & 0.00 & 0.10 & & & & \\
\hline agr_med & 200.00 & 0.18 & 0.46 & 6.09 & 0.67 & 0.00 & 0.10 & & & & \\
\hline agr_ras & 150.00 & 0.18 & 0.46 & 6.09 & 0.67 & 0.00 & 0.10 & & & & \\
\hline veg_prof & 400.00 & 0.18 & 0.46 & 6.09 & 0.67 & 0.00 & 0.10 & & & & \\
\hline veg_mod & 350.00 & 0.18 & 0.46 & 6.09 & 0.67 & 0.00 & 0.10 & & & & \\
\hline veg_med & 350.00 & 0.18 & 0.46 & 6.09 & 0.67 & 0.00 & 0.10 & & & & \\
\hline veg_ras & 300.00 & 0.18 & 0.46 & 6.09 & 0.67 & 0.00 & 0.10 & & & & \\
\hline Urb & 50.00 & 0.18 & 0.46 & 6.09 & 0.67 & 0.00 & 0.10 & & & & \\
\hline Agua & 0.00 & 0.00 & 0.00 & 0.00 & 0.00 & 0.00 & 0.00 & & & & \\
\hline
\end{tabular}

Fonte: Elaborado pelo autor. 
Tabela 41. Parâmetros calibráveis ajustados para a sub-bacia № 08 (Posto Desembargador Furtado).

\begin{tabular}{lccccccccccc}
\hline \multicolumn{1}{c}{ Uso } & Wm & B & Kbas & Kint & XL & CAP & Wc & CS & Cl & CB & QB \\
\hline agr_prof & 250.00 & 0.05 & 1.80 & 3.20 & 0.67 & 0.00 & 0.10 & & & & \\
agr_mod & 200.00 & 0.05 & 1.80 & 3.20 & 0.67 & 0.00 & 0.10 & & & & \\
agr_med & 200.00 & 0.05 & 1.80 & 3.20 & 0.67 & 0.00 & 0.10 & & & & \\
agr_ras & 150.00 & 0.05 & 1.80 & 3.20 & 0.67 & 0.00 & 0.10 & & & & \\
veg_prof & 400.00 & 0.05 & 1.80 & 3.20 & 0.67 & 0.00 & 0.10 & 16.37 & 81.85 & 1224.00 & 0.01 \\
veg_mod & 350.00 & 0.05 & 1.80 & 3.20 & 0.67 & 0.00 & 0.10 & & & & \\
veg_med & 350.00 & 0.05 & 1.80 & 3.20 & 0.67 & 0.00 & 0.10 & & & & \\
veg_ras & 300.00 & 0.05 & 1.80 & 3.20 & 0.67 & 0.00 & 0.10 & & & & \\
Urb & 50.00 & 0.05 & 1.80 & 3.20 & 0.67 & 0.00 & 0.10 & & & & \\
Agua & 0.00 & 0.00 & 0.00 & 0.00 & 0.00 & 0.00 & 0.00 & & & & \\
\hline Fonte: Elabonncy
\end{tabular}

Fonte: Elaborado pelo autor.

Tabela 42. Parâmetros calibráveis ajustados para a sub-bacia no 09 (Posto Recreio).

\begin{tabular}{|c|c|c|c|c|c|c|c|c|c|c|c|}
\hline Uso & Wm & B & Kbas & Kint & $X L$ & CAP & Wc & CS & $\mathrm{Cl}$ & CB & QB \\
\hline agr_prof & 250.00 & 0.35 & 2.66 & 10.91 & 0.67 & 0.00 & 0.10 & \multirow{10}{*}{7.50} & \multirow{10}{*}{50.75} & \multirow{10}{*}{3075.17} & \multirow{10}{*}{0.01} \\
\hline agr_mod & 200.00 & 0.35 & 2.66 & 10.91 & 0.67 & 0.00 & 0.10 & & & & \\
\hline agr_med & 200.00 & 0.35 & 2.66 & 10.91 & 0.67 & 0.00 & 0.10 & & & & \\
\hline agr_ras & 150.00 & 0.35 & 2.66 & 10.91 & 0.67 & 0.00 & 0.10 & & & & \\
\hline veg_prof & 400.00 & 0.35 & 2.66 & 10.91 & 0.67 & 0.00 & 0.10 & & & & \\
\hline veg_mod & 350.00 & 0.35 & 2.66 & 10.91 & 0.67 & 0.00 & 0.10 & & & & \\
\hline veg_med & 350.00 & 0.35 & 2.66 & 10.91 & 0.67 & 0.00 & 0.10 & & & & \\
\hline veg_ras & 300.00 & 0.35 & 2.66 & 10.91 & 0.67 & 0.00 & 0.10 & & & & \\
\hline Urb & 50.00 & 0.35 & 2.66 & 10.91 & 0.67 & 0.00 & 0.10 & & & & \\
\hline Agua & 0.00 & 0.00 & 0.00 & 0.00 & 0.00 & 0.00 & 0.00 & & & & \\
\hline
\end{tabular}

Fonte: Elaborado pelo autor.

Tabela 43. Parâmetros calibráveis ajustados para a sub-bacia № 10 (Posto Artemis).

\begin{tabular}{|c|c|c|c|c|c|c|c|c|c|c|c|}
\hline Uso & Wm & B & Kbas & Kint & $\mathrm{XL}$ & CAP & Wc & CS & $\mathrm{Cl}$ & CB & QB \\
\hline agr_prof & 250.00 & 0.19 & 2.19 & 13.06 & 0.67 & 0.00 & 0.10 & \multirow{10}{*}{5.11} & \multirow{10}{*}{45.99} & \multirow{10}{*}{1956.17} & \multirow{10}{*}{0.01} \\
\hline agr_mod & 200.00 & 0.19 & 2.19 & 13.06 & 0.67 & 0.00 & 0.10 & & & & \\
\hline agr_med & 200.00 & 0.19 & 2.19 & 13.06 & 0.67 & 0.00 & 0.10 & & & & \\
\hline agr_ras & 150.00 & 0.19 & 2.19 & 13.06 & 0.67 & 0.00 & 0.10 & & & & \\
\hline veg_prof & 400.00 & 0.19 & 2.19 & 13.06 & 0.67 & 0.00 & 0.10 & & & & \\
\hline veg_mod & 350.00 & 0.19 & 2.19 & 13.06 & 0.67 & 0.00 & 0.10 & & & & \\
\hline veg_med & 350.00 & 0.19 & 2.19 & 13.06 & 0.67 & 0.00 & 0.10 & & & & \\
\hline veg_ras & 300.00 & 0.19 & 2.19 & 13.06 & 0.67 & 0.00 & 0.10 & & & & \\
\hline Urb & 50.00 & 0.19 & 2.19 & 13.06 & 0.67 & 0.00 & 0.10 & & & & \\
\hline Agua & 0.00 & 0.00 & 0.00 & 0.00 & 0.00 & 0.00 & 0.00 & & & & \\
\hline
\end{tabular}

Fonte: Elaborado pelo autor. 


\section{APÊNDICE C}

\section{CONVERSÃO DAS SAÍDAS DO MODELO ETA-CPTEC PARA ENTRADA NO MGB-IPH}

Nesta seção são descritos os procedimentos e equações considerados na conversão dos dados climáticos gerados pelo modelo climático Eta-CPTEC para o formato e unidades necessários para entrada no modelo hidrológico MGB-IPH.

\section{C.1 Temperatura}

Os dados de temperatura gerados pelo modelo Eta-CPTEC encontravam-se na unidade Kelvin. Entretanto, o MGB-IPH demanda que os mesmos estejam em graus Celsius. Assim, realizou-se a conversão das unidades, conforme Equação 19,

$$
\mathrm{T}_{\mathrm{C}}=\mathrm{T}_{\mathrm{K}}-273
$$

sendo $T_{C}$ a temperatura média diária corrigida, em ${ }^{\circ} \mathrm{C} ; T_{K}$ a temperatura média diária calculada pelo modelo Eta-CPTEC, em $\mathrm{K}$.

\section{C.2 Insolação}

A informação referente à insolação foi obtida através da variável radiação solar incidente na superfície, em W.m ${ }^{-2}$, calculada pelo modelo Eta-CPTEC.

Primeiramente, foi necessário o cálculo da radiação solar no topo da atmosfera, em MJ.m ${ }^{-2} \cdot$ dia $^{-1}$. Para isso, calculou-se a declinação solar ( $\delta$, Equação 20), o ângulo horário do nascer do sol (hn, Equação 21), a máxima duração da insolação (HIM, Equação 22) e o fator diário (DF, Equação 23), 
$\delta=0,4093 \operatorname{SEN}\left[\left(\frac{2 \pi}{365}\right) \mathrm{RDIA}-1,405\right]$

Equação 20

$\mathrm{hn}=\operatorname{ACOS}[-\mathrm{TAN}(\Phi) \mathrm{TAN}(\delta)]$

Equação 21

$\mathrm{HIM}=24 \frac{\mathrm{hn}}{\pi}$

Equação 22

$D F=1+0,033 \operatorname{COS}\left(\frac{2 \pi R D I A}{365}\right)$

Equação 23

sendo $\delta$ a declinação solar, em radianos; RDIA o dia juliano; $h n$ o ângulo horário do nascer do sol, em radianos; $\Phi$ a latitude, em graus; HIM é a máxima duração da insolação, em horas; DF o fator diário, adimensional.

Assim, pôde-se determinar o valor da radiação solar no topo da atmosfera, em mm.dia-1 (Equação 24) e em MJ.m ${ }^{-2} \cdot$ dia $^{-1}$ (Equação 25),

$S T O=15,392 D F[h n * \operatorname{SEN}(\Phi) * \operatorname{SEN}(\delta)+\operatorname{COS}(\Phi) \operatorname{COS}(\delta) \operatorname{SEN}(h n)] \quad$ Equação 24

$S T O_{J}=0,75\left(\frac{S T O}{1000}\right) \rho \lambda$

Equação 25

sendo STO a radiação solar no topo da atmosfera, em mm.dia ${ }^{-1}$; DF o fator diário, adimensional; $\Phi$ a latitude, em graus; $\delta$ a declinação solar, em radianos; STO, a radiação solar no topo da atmosfera, em $\mathrm{MJ} \cdot \mathrm{m}^{-2} \cdot \mathrm{dia}^{-1} ; \rho$ a massa específica da água, em $\mathrm{kg} \cdot \mathrm{m}^{-3} ; \lambda$ o calor latente de vaporização da água, em MJ.kg ${ }^{-1}$.

O calor latente de vaporização $(\lambda)$, foi determinado conforme a temperatura calculada pelo modelo Eta-CPTEC, segundo Equação 26,

$\lambda=2,501-0,002361 T_{C}$

Equação 26 
sendo $\lambda$ o calor latente de vaporização da água, em MJ. $\mathrm{kg}^{-1} ; T_{C}$ a temperatura média diária, em 으.

Por fim, o cálculo da insolação, em horas de sol diárias, se deu conforme Equação 27,

$S O L=\left[\left(\frac{0,0216 R A D}{S T O_{J}}\right)-0,25\right]\left[\frac{H I M}{0,5}\right]$

Equação 27

sendo $S O L$ a insolação diária, em horas; $R A D$ é a radiação solar que chega à superfície, em MJ.m ${ }^{-2}$.dia ${ }^{-1}$; STO, a radiação solar no topo da atmosfera, em MJ.m ${ }^{-2} \cdot$ dia $^{-1}$; HIM é a máxima duração da insolação, em horas. 0 fator 0,0216 foi utilizado para converter a radiação calculada pelo modelo Eta-CPTEC de W. $\mathrm{m}^{-2}$ para MJ.m ${ }^{-2} \cdot d i a^{-1}$.

\section{C.3 Precipitação}

A precipitação calculada pelo modelo Eta-CPTEC, com acumulação diária, encontrava-se em metros. Foi necessária, portanto, sua conversão para milímetros, conforme Equação 28,

$$
P_{\text {cor }}=1000 P_{E t a}
$$

Equação 28

sendo $P_{\text {cor }}$ a precipitação diária corrigida, em $\mathrm{mm} ; P_{E t a}$ a precipitação acumulada pelo modelo Eta-CPTEC, em $\mathrm{m}$.

\section{C.4 Pressão atmosférica}

Com relação aos dados de pressão atmosférica, procedeu-se à conversão de hecto Pascal (hPa) para quilo Pascal (kPa) (Equação 29),

$$
\text { Pres }_{\mathrm{cor}}=\frac{\text { Pres }_{\mathrm{Eta}}}{10}
$$


sendo Pres $_{c o r}$ a pressão atmosférica média diária corrigida, em kPa; Pres Eta $_{\text {a }}$ pressão atmosférica média calculada pelo modelo Eta-CPTEC, em hPa.

\section{C.5 Umidade relativa}

Para o cálculo da umidade relativa, foram utilizados dados de temperatura da superfície $\left(T_{C}\right)$ e do ponto de orvalho $\left(T_{O}\right)$ do modelo Eta-CPTEC, para a obtenção dos valores de pressão de saturação de vapor $\left(e_{s}\right)$ e da pressão atual de vapor $\left(e_{a}\right)$. Assim, aplicou-se a Equação 30 e a Equação 31,

$$
\begin{aligned}
& e_{s}=0,6108 \cdot \exp ^{\frac{17,3 T_{C}}{237,3+T_{C}}} \\
& e_{a}=0,6108 \cdot \exp ^{\frac{17,3 T_{o}}{237,3+T_{o}}}
\end{aligned}
$$

sendo $e_{s}$ a pressão de saturação de vapor, em $\mathrm{kPa} ; T_{C}$ a temperatura, em ${ }^{\circ} \mathrm{C} ; e_{a}$ a pressão atual de vapor, em $\mathrm{kPa} ; T_{o}$ a temperatura do ponto de orvalho, em ${ }^{\circ} \mathrm{C}$.

A umidade relativa $(U R)$, por sua vez, foi determinada a partir da relação percentual entre a pressão atual de vapor $\left(e_{a}\right)$ e a pressão de saturação de vapor $\left(e_{s}\right)$, na Equação 32.

$$
U R=\frac{e_{a}}{e_{s}} 100
$$

\section{C.6 Velocidade do vento}

Neste item, utilizou-se uma equação para converter altura de medição da velocidade do vento de dez metros, saída do modelo Eta-CPTEC, para dois metros, segundo Equação 33,

$$
u_{2}=u_{10} \cdot\left(\frac{\ln \left(\frac{2}{z_{0}}\right)}{\ln \left(\frac{10}{z_{0}}\right)}\right)
$$


sendo $u_{2}$ é a velocidade do vento a dois metros de altura, em $\mathrm{m} . \mathrm{s}^{-1} ; u_{10}$ é a velocidade do vento a dez metros de altura, em m.s ${ }^{-1} ; z_{0}$ é a rugosidade da superfície, em metros.

Essa conversão foi realizada para adequar os dados de velocidade do vento à realidade de monitoramento climatológico no Brasil, o qual normalmente se dá à altura de dois metros da superfície.

Manwell, McGowan e Rogers (2002) definiram valores de rugosidade superficial $\left(z_{0}\right)$, em milímetros, para variados tipos de terreno. Calculou-se, então, um valor de rugosidade superficial médio para a bacia, a partir das porcentagens de ocupação e dos tipos de uso da terra obtidas no Capítulo 2. O valor de $z_{0}$ calculado foi de 0,27 metros. 


\section{EQUAÇÕES DO MODELO AQUA-Risco PARA DETERMINAÇÃO DOS PREJUÍZOS DECORRENTES DA ESCASSEZ HÍDRICA PARA CADA SETOR USUÁRIO}

Conforme já descrito no Capítulo 5, o modelo AQUA-Risco considera a quatificação dos riscos econômicos diretos e tangíveis, decorrentes da escassez hídrica, em bacias hidrográficas. São considerados diferentes usos, calculados individualmente, sendo eles abastecimento público urbano, dessedentação animal, produção agrícola, produção industrial e diluição da poluição.

Os danos são quantificados para a bacia hidrográfica do Rio Piracicaba como um todo. A quantificação dos danos por sub-bacia se deu a partir da demanda hídrica e dos lançamentos de efluentes em cada sub-bacia, mediante relação de proporcionalidade aos danos totais da bacia. Nos itens em seguida é descrito o método e as equações consideradas na quantificação dos riscos por setor.

\section{D.1 Abastecimento público urbano}

Segundo Brozović, Sunding e Zilberman (2007), existe grande dificuldade para se determinar a resiliência econômica frente a interrupções no fornecimento de água para abastecimento público. Isso porque, em áreas residenciais, não ocorre a produção de bens com valor facilmente mensurável. Todavia, é fato que a falta de água causa prejuízos aos moradores das residências. Com isso, os autores propuseram uma metodologia para mensuração do prejuízo conforme a disponibilidade a pagar para evitar que o abastecimento seja interrompido, conforme Equação 34, 


$$
W_{x}\left(z_{x, y}\right)=\frac{\eta}{1+\eta} P_{l b} Q_{l b}\left[1-\left(\frac{Q_{r}\left(z_{x, y}\right)}{Q_{l b}}\right)^{\frac{1+\eta}{\eta}}\right]
$$

sendo $W_{x}\left(z_{x, y}\right)$ a perda diária de bem-estar per capita, em $\mathrm{R} \$$ hab $^{-1}$.dia ${ }^{-1} ; P_{l b}$ (linha de base) o preço da água em condições normais de abastecimento, em $R \$$; $Q_{1 b}$ (linha de base) a vazão média consumida em condições normais de abastecimento; $Q_{r}$ a disponibilidade de água; $\eta$ a elasticidade do preço para demanda de água, definido em $-0,352$ (FIPE, 2009); $z_{i t}$ a severidade da escassez, entre 0 e 1 , onde $z=0$ corresponde a total escassez e $z=1$ corresponde ao abastecimento normal.

Ao se utilizar a equação anterior, assume-se que o governo se responsabilize pelo suprimento de água em situações onde a disponibilidade hídrica seja nula, que atendam ao menos as necessidades básicas da população. Gleick (1996) sugere o valor de 50 I.hab ${ }^{-1}$.dia ${ }^{-1}$ como referência, valor esse também considerado nos cálculos aqui realizados. O cálculo da disponibilidade de água conforme Equação 35,

$Q_{r}\left(z_{x, y}\right)=R M A+\left[1-\alpha_{x}\left(1-z_{x, y}\right)\right]\left(Q_{l b}-R M A\right)$

sendo $Q_{r}$ a disponibilidade de água; $z_{x, y}=0$ corresponde a total escassez e $z_{x, y}=1$ corresponde a abastecimento normal; RMA o requerimento mínimo de água de 50 I.hab ${ }^{-1} \cdot \mathrm{dia}^{-1}$ (GLEICK, 1996); $\alpha$ a proporção entre abastecimento superficial e subterrâneo; $Q_{1 b}$ a vazão média consumida em condições normais de abastecimento (linha de base).

Na Tabela 44 são demonstrados os valores obtidos para $\alpha$ e $Q_{l b}$, a partir das informações contidas no relatório síntese do Plano de Bacias 2004-2007 do Comitê PCJ (SHS, 2006). 
Tabela 44. Valores calculados para a determinação da disponibilidade de água $\left(Q_{r}\right)$ em cada sub-bacia estudada.

\begin{tabular}{|c|c|c|c|c|c|}
\hline \multirow{2}{*}{ Bacia } & \multirow{2}{*}{$\begin{array}{l}\text { Área } \\
\mathbf{k m}^{2}\end{array}$} & \multirow{2}{*}{ A } & \multirow{2}{*}{$\begin{array}{l}\text { POP. ESTIMADA } \\
\text { Hab }\end{array}$} & \multicolumn{2}{|c|}{$Q_{\mathrm{lb}}$} \\
\hline & & & & $\mathrm{m}^{3} \cdot \mathrm{s}^{-1}$ & I.hab ${ }^{-1} \cdot$ dia $^{-1}$ \\
\hline Camanducaia & 927,1 & 0,93 & 106.527 & 0,3 & 213,90 \\
\hline Jaguari & $3.397,5$ & 0,93 & 423.457 & 2,7 & 548,24 \\
\hline Atibaia & $2.487,7$ & 0,93 & 1.117 .643 & 2,2 & 170,37 \\
\hline Corumbataí & $1.577,5$ & 0,93 & 318.240 & 5,2 & $1.405,87$ \\
\hline Piracicaba & $2.540,1$ & 0,95 & 1.346 .252 & 1,9 & 118,67 \\
\hline
\end{tabular}

Fonte: Elaborado pelo autor a partir de dados de SHS (2006).

Assim, o prejuízo total da bacia para o setor de abastecimento público em decorrência do risco de escassez é determinado através da Equação 36,

$$
D_{x, y}^{u}\left(r_{u}\right)=N_{x, y} W_{x, y}\left(1-\frac{1}{T R}\right)
$$

sendo $D_{x, y}{ }^{u}$ o prejuízo ao abastecimento público urbano, em $\mathrm{R} \$$, em função do risco $r_{u}$; $N_{x, y}$ a população da bacia $x$ no ano $y ; W_{x, y}$ a perda diária de bem-estar per capita, em $\mathrm{R} \$ \mathrm{hab}^{-1} \cdot \mathrm{dia}^{-1}$; TR o tempo de retorno associado ao evento considerado, em anos, obtido através do ajuste à distribuição Gumbel.

\section{D.2 Dessedentação animal}

Para a determinação do prejuízo na bacia referente à dessedentação animal, utilizou-se uma aproximação quantitativa, mediante consulta a bases de dados estatísticos de produção e rentabilidade da pecuária. Foram seguidas as etapas descritas a seguir, referentes à (i) determinação do rebanho na bacia, (ii) cálculo das demandas para dessedentação animal e, por fim, (iii) estimativa do prejuízo.

\section{D.2.1 Determinação do rebanho na bacia}

O rebanho na bacia hidrográfica do Rio Piracicaba foi determinado mediante consulta à Pesquisa Pecuária Municipal (IBGE, 2010). Foram considerados três grupos de animais, sendo pequeno $\left(R B_{\text {peq }}\right)$, médio $\left(R B_{\text {méd }}\right)$ e grande porte $\left(R B_{\text {gde }}\right)$, obtidos a 
partir da soma das informações dos municípios contidos na bacia, conforme equações Equação 37, Equação 38 e Equação 39,

$$
\begin{aligned}
R B_{\text {peq }} & =\sum_{x=1}^{n} R B M P P_{x} \\
R B_{\text {méd }} & =\sum_{x=1}^{n} R B M M P_{x} \\
R B_{\text {gde }} & =\sum_{x=1}^{n} R B M G P_{x}
\end{aligned}
$$

sendo $R B_{\text {peq }}$ o rebanho de pequeno porte na bacia; $R B M P P_{x}$ o rebanho de pequeno porte no município $x ; R B_{\text {méd }}$ o rebanho de médio porte na bacia; $R B M M P_{x}$ o rebanho de médio porte no município $x ; R B_{g d e}$ o rebanho de grande porte na bacia; $R B M G P_{x} \mathrm{O}$ rebanho de grande porte no município $x$. Para efeito de simplificação, considerou-se de pequeno porte o grupo frangos, médio porte o grupo suínos e grande porte o grupo bovinos.

\section{D.2.2 Cálculo das demandas hídricas consumidas pelos rebanhos}

Assim como a estimativa da população, a demanda hídrica também foi considerada conforme os três grupos de animais mencionados anteriormente. Para tal, utilizaram-se coeficientes de consumo per capita encontrados na literatura, conforme Palhares (2005). A demanda hídrica dos rebanhos resultou da multiplicação desses coeficientes à população de animais em cada situação, conforme equações Equação 40, Equação 41 e Equação 42,

$$
\begin{gathered}
D E M_{\text {peq }}=R B_{\text {peq }} c_{p e q} \\
D E M_{\text {méd }}=R B_{\text {méd }} c_{m e ́ d} \\
D E M_{g d e}=R B_{g d e} c_{g d e}
\end{gathered}
$$$$
\text { Equação } 40
$$$$
\text { Equação } 41
$$ 
sendo $D E M_{\text {peq }}$ a demanda hídrica de animais de pequeno porte, em $\mathrm{m}^{3} ; R B_{\text {peq }} \mathrm{o}$ rebanho de pequeno porte na bacia; $c_{p e q}$ o consumo per capita de água para animais de pequeno porte, em $\mathrm{m}^{3}$.animal ${ }^{-1} \cdot$ dia $^{-1} ; D E M_{\text {méd }}$ a demanda hídrica de animais de médio porte, em $\mathrm{m}^{3}$; $R B_{\text {méd }} \mathrm{O}$ rebanho de médio porte na bacia; $c_{\text {méd }} \mathrm{O}$ consumo per capita de água para animais de médio porte, $\mathrm{m}^{3}$.animal ${ }^{-1} \cdot \mathrm{dia}^{-1} ; D E M_{\text {gde }}$ a demanda hídrica de animais de grande porte, em $\mathrm{m}^{3} ; R B_{g d e}$ o rebanho de grande porte na bacia; $c_{\text {gde }}$ o consumo per capita de água para animais de grande porte, $\mathrm{m}^{3}$.animal ${ }^{-1} \cdot \mathrm{dia}^{-1}$.

A demanda total de água na bacia, para a dessedentação animal, foi calculada mediante a soma das demandas dos três grupos de animais considerados, conforme a Equação 43.

$$
D E M_{\text {total }}=D E M_{\text {peq }}+D E M_{\text {méd }}+D E M_{g d e}
$$

\section{D.2.2 Estimativa do prejuízo}

O prejuízo decorrente do não-atendimento da demanda hídrica para dessedentação animal, em função do risco de escassez hídrica, foi calculado conforme Equação 44,

$$
D_{x, y}^{a n}\left(r_{a n}\right)=d\left[\left(\frac{R B_{\text {peq }}}{D E M_{\text {total }}} k_{\text {peq }}\right)+\left(\frac{R B_{\text {méd }}}{D E M_{\text {total }}} k_{\text {méd }}\right)+\left(\frac{R B_{\text {gde }}}{D E M_{\text {total }}} k_{\text {gde }}\right)\right]
$$

sendo $D_{x, y}^{a n}$ o prejuízo a atividades de pecuária, em R\$̦, em função do risco de escassez hídrica $r_{a n} ; d$ o percentual de dano ao rebanho, onde para $d=0$ não ocorre dano e $d=10$ dano é máximo; $R B_{\text {peq }}$ o rebanho de pequeno porte na bacia; $D E M_{\text {total }}$ a demanda hídrica total para dessedentação animal, em $\mathrm{m}^{3} ; k_{\text {peq }}$ o custo de produção de animais de pequeno porte, em $\mathrm{R} \$$.cabeça ${ }^{-1} ; R B_{\text {méd }} \mathrm{O}$ rebanho de médio porte na bacia; $k_{\text {méd }} \mathrm{O}$ custo de produção de animais de médio porte, em $R \$$.cabeça ${ }^{-1}$; $R B_{\text {gde }}$ o rebanho de grande porte na bacia; $k_{\text {gde }}$ o custo de produção de animais de grande porte, em $\mathrm{R}$.cabeça ${ }^{-1}$. 


\section{D.3 Produção agrícola}

Para a determinação da demanda de água para atividades agrícolas na bacia, bem como do prejuízo decorrente da escassez hídrica para o setor, considerou-se a produção específica $\left(P R_{e s p}\right)$, resultante da divisão do valor total da produção proporcional à área da bacia pela área agrícola na mesma. O valor da produção agrícola foi obtido através de consulta ao banco de dados SIDRA/IBGE, sobre os municípios inseridos na bacia. A partir do valor total da produção, realizou-se a divisão pela área total cultivada na bacia, conforme Equação 45,

$$
P R_{e s p}=\frac{V T}{A c}
$$

sendo $P R_{\text {esp }}$ a produção específica na bacia, em $\mathrm{R} \$ \mathrm{~km}^{-2}$; VT o valor total arrecadado com a produção na bacia, em R\$; e $A c$ a área total cultivada na bacia, em km².

Em seguida, determinou-se a demanda hídrica. A quantidade estimada de captação nas sub-bacias, para fins rurais, foi obtida conforme dados de SHS (2006). Por sua vez, a demanda agrícola foi calculada através da subtração da demanda para dessedentação animal, anteriormente determinada, da demanda rural total, segundo Equação 46,

$$
D E M_{\text {agr }}=D E M_{\text {rural }}-D E M_{\text {pec }}
$$

Equação 46

sendo $D E M_{a g r}$ a demanda hídrica para atividades agrícolas, em $\mathrm{m}^{3} ; D E M_{\text {rural }}$ a demanda para fins rurais na bacia, em $\mathrm{m}^{3}$; e DEMpec a demanda hídrica total para dessedentação animal.

Com isso, o prejuízo deste setor foi calculado através da Equação 47,

$$
D_{x, y}^{a g}\left(r_{a g}\right)=d\left(\frac{P R_{e s p}}{D E M_{a g r}}\right)
$$


sendo $D_{x, y}{ }^{a g}$ o prejuízo a atividades agrícolas, em $\mathrm{R} \$$, em função do risco de escassez hídrica $r_{a g} ; d$ o percentual de dano ao rebanho, onde para $d=0$ não ocorre dano e $d=1$ o dano é máximo; $P R_{\text {esp }}$ a produção específica na bacia, em $R \$ \$ ; ~ D E M_{a g r}$ a demanda hídrica para atividades agrícolas, em $\mathrm{m}^{3}$.

\section{D.4 Produção industrial}

O cálculo do dano causado ao setor industrial foi calculado pelo método descrito em Brozović, Sunding e Zilberman (2007). Nesta abordagem, estima-se quando seria produzido em condições normais, na ausência da escassez hídrica, e assim determina-se o prejuízo. A Equação 48 demonstra este cálculo,

$$
\lambda_{x, y}\left(z_{x, y}\right)=\frac{1-r_{x, y}}{0,95}\left[\alpha_{x}\left(1-z_{x, y}\right)-0,05\right]
$$

sendo $\lambda_{x, y}$ o dano proporcional diário, em R\$; $z_{x, y}$ a severidade da escassez, entre 0 e 1 , onde $z=0$ corresponde a total escassez e $z=1$ corresponde ao abastecimento normal, em função do período de retorno; $r_{x, y}$ a resiliência do setor, adimensional, aqui definida por $r=0,5$; e $\alpha_{x}$ a proporção entre abastecimento superficial e subterrâneo (consideradas iguais ao item $D .1$ para cada sub-bacia). Se $\alpha_{x}\left(1-z_{x, y}\right) \leq$ 0,05 , então considerou-se zero o prejuízo na bacia, conforme recomendação dos autores.

Assim, determinou-se o prejuízo em cada sub-bacia conforme Equação 49,

$D_{x, y}^{i}\left(r_{i}\right)=V_{x, y} \lambda_{x, y}$

Equação 49

sendo $D_{x, y}^{i}$ o prejuízo ao setor industrial na bacia, em $\mathrm{R} \$$, em função do risco de escassez hídrica $r_{i} ; V_{x, y}$ o valor diário de prejuízo, em se comparando a condições de produção normais; e $\lambda_{x, y}$ o dano proporcional diário, em $\mathrm{R} \$$.

O prejuízo diário foi determinado através de informações do banco de dados de Informações dos Municípios Paulistas - IMP, da Fundação SEADE. 


\section{D.5 Diluição da poluição}

A demanda para quantificação do volume de água necessário para diluição do esgoto lançado na bacia considerou o balanço de massa, conforme Equação 50 proposta por Kelman (1997),

$$
Q_{d i l}=Q_{e f} \cdot \frac{\left(C_{e f}-C_{p e r m}\right)}{\left(C_{p e r m}-C_{\text {nat }}\right)}
$$

sendo $Q_{\text {dil }}$ a vazão necessária para diluição do efluente; $Q_{e f}$ a vazão de efluente lançanda; $C_{e f}$ a concentração de poluentes no efluente; $C_{\text {perm }}$ a concentração remanescente permitida por lei ou regulamentação; $C_{\text {nat }}$ a concentração natural encontrada do corpo receptor.

A vazão e a concentração dos efluentes lançados na bacia foram determinados conforme SHS (2006). As concentrações naturais dos corpos d'água referentes a cada sub-bacia foram obtidos segundo dados da Companhia Ambiental do Estado de São Paulo - CETESB (CETESB, 2011).

Para a quantificação dos prejuízos, considerou-se estudo realizado por Reis (2004), que fez o levantamento dos custos de operação de ETEs na bacia do Rio Piracicaba. Os resultados divulgados pelo autor demonstraram um custo médio de $\mathrm{R} \$ 0,06 . \mathrm{m}^{-3}$ de água tratada. Tais custos não envolvem a construção de novas ETEs na bacia, apenas a operação da estrutura atual da bacia.

Assim, o prejuízo total deste item na bacia é calculado quando a vazão necessária para diluição $\left(Q_{\text {dil }}\right)$ não é atendida pelo corpo receptor devido à ocorrência do evento extremo, em função de TR. Na Equação 51 tem-se a descrição do cálculo do prejuízo,

$D_{x, y}^{d}\left(r_{d}\right)=Q_{\text {lanc }} V_{t}$ Equação 51 sendo $D_{x, y}^{d}$ o prejuízo ambiental da poluição dos corpos d'água, em R\$, em função do risco de não diluição $r_{d} ; Q_{l a n c}$ o volume de esgoto que não será diluído, em $\mathrm{m}^{3}$; e $V_{t}$ o custo de tratamento (REIS, 2004). 